Presented to the Faculty of Forestry

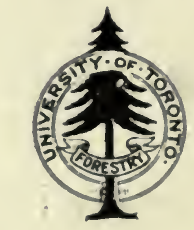

LIBRARY

By W. E. Steele A.D. 1972 
(2) 400

W. E. Steele.

East Pause

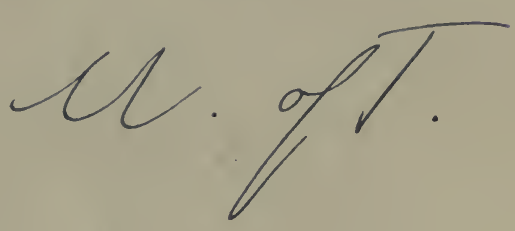

LIBRARY

FACULTY OF FORESTRY

UNIVERSITY OF TORONTO 
Digitized by the Internet Archive in 2007 with funding from Microsoft Corporation 




\title{
THE PRACTICE OF SILVICULTURE
}

WITH PARTICULAR REFERENCE TO ITS APPLICATION IN THE UNITED STATES

\author{
BY \\ RALPH C. HAWLEY \\ Professor of Forestry, Yale University
}

$164^{55^{4}}$

NEW YORK

JOHN WILEY \& SONS, INC.

LONDON: CHAPMAN \& HALL, LIMTTED

- I92I 
Copyright, I921,

BY

RALPH C. HAWLEY

TECHNICAL COMPOSITION CO.

CAMBrIdge, Mass.。 U. 8. A. 


\section{PREFACE}

The "Practice of Silviculture" has been prepared for use as a text book to cover a field at present unfilled. So far as is known there is no recent book applicable to the forests of this continent covering the field of silviculture. Graves' "Principles of Handling Woodlands," published in I9I I, and Schlich's "Manual of Forestry," Vols. I and II, revised in I 895 are practically the only works on the subject in the English language. Government and state publications contain, in more or less fragmentary form, a large store of knowledge concerning the practice of silviculture.

Forest Terminology in the Appendix is copied verbatim from the Journal of Forestry, Vol. XV, I9I 7, published by the Society of American Foresters.

The author does not claim originality for the greater part of the information. Available sources have been investigated and a selection and compilation made of such information as is deemed most useful to-day.

Presentation of the subject is from the standpoint of the teacher and the arrangement and discussion are shaped in a manner which it is believed will be clear to the student.

A possible criticism in connection with some parts of the book is that the treatment of the subject is too theoretical. In answer to this it may be said that the writer realizes, from fifteen years' experience in applying silviculture on forest properties and in teaching the subject, that, while, in the application of silviculture, methods as given in books often must be so modified and changed to fit local conditions as to iii 
be scarcely recognizable, yet, for best results in teaching students, definite theories and methods must be elaborated and set off distinctly one from the other.

No attempt has been made to cover in an absolutely complete way and with full detail all branches of applied silviculture. Such a work can well be postponed another decade until American silviculture progresses further through the formative period. On the contrary the purpose has been to keep the text brief with the idea of producing a work to fill an immediate need, containing such information as appears applicable to-day or likely to be applicable (at least in some parts of the country) in the near future.

The lists of references following each chapter are not exhaustive but are intended to afford additional reading supplementing the text. 


\section{CONTENTS}

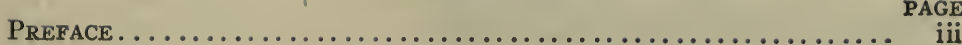

Chapter I. General Considerations.................... I

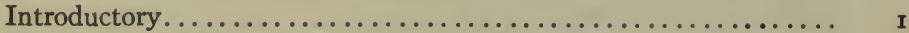

Production in Managed and Unmanaged Forests............. 3

The Purpose of Silviculture........................ 5

The Field of Silviculture........................ 5

The Cost of Silviculture.......................... 7

References.................................. ro

Chapter II. Reproduction Methods. Treatment of the Stand During the Period of Regeneration or EstablishMENT .............................. II

Definition ............................ II

Standard Reproduction Methods..................... II

Field Identification of Reproduction Methods.............. I2

Classification of Reproduction Methods................. 14

Importance of the Standard Reproduction Methods........... I5

Factors Influencing Natural Reproduction............... I7

Artificial Reproduction Compared with Natural Reproduction..... $\quad$ I8

Advantages of Artificial Reproduction............... I9

Advantages of Natural Reproduction................ 2I

Opportunities for Applying Artificial Reproduction........... 22

References................................. ${ }_{23}$

Chapter III. Clearcutting Method................... 25

Definition.................................. ${ }_{25}$

Form of Forest Produced......................... 25

Details of the Method........................... 25

Clearcutting with Artificial Reproduction............... 25

Clearcutting with Natural Reproduction ............... 26

Modifications of the Method......................... $3_{32}$

Clearcutting in Strips................................ $3^{2}$

$A$. Alternate Strips........................... $3^{2}$

B. Progressive Strips......................... $3_{32}$

Clearcutting in Patches........................ 37 
Advantages and Disadvantages of the Clearcutting Method....... 40

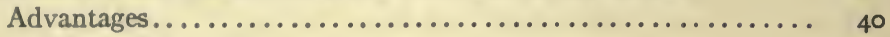

Disadvantages.................................. 40

Application of the Clearcutting Method............... 4 I

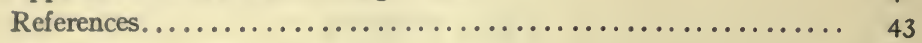

Chapter IV. The Seed Tree Method.................. 44

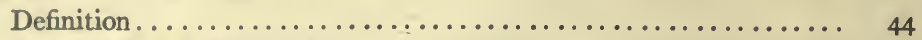

Form of Forest Produced....................... 45

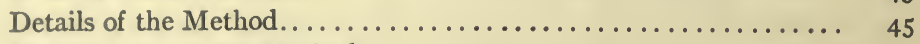

Modifications of the Method........................ 50

Group Seed Tree Method....................... 50

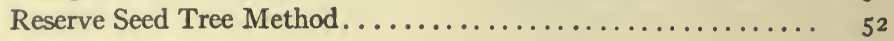

Fire Seed Trees.................................... 54

Advantages and Disadvantages of the Seed Tree Method........ 55

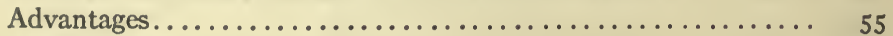

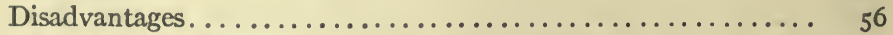

Application of the Method........................... 57

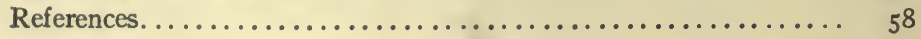

Chapter V: The Shelterwood Method................. 59

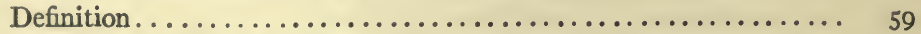

Form of Forest Produced.......................... 59

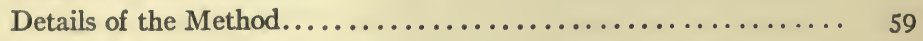

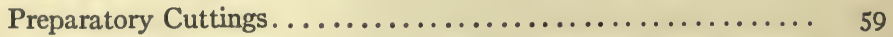

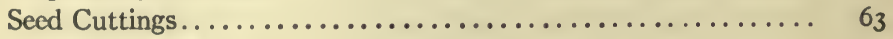

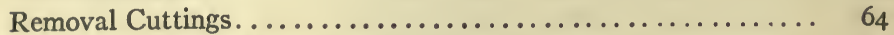

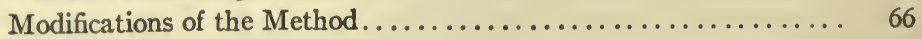

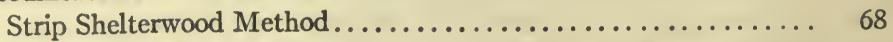

Wagner's "Border Cuttings" ..................... 7०

Group Shelterwood Method...................... 70

Extensive versus Intensive Application. ............... 72

Advantages and Disadvantages of the Method............. 77

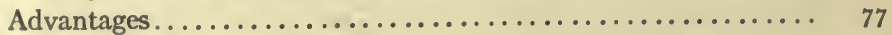

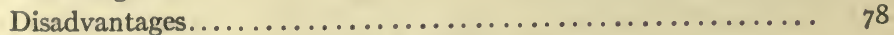

Application of the Shelterwood Method................. 79

References................................. $8 \mathbf{r}$

Chapter VI. The Selection Method................. 83

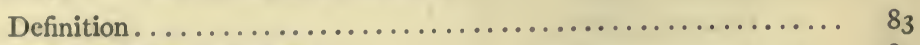

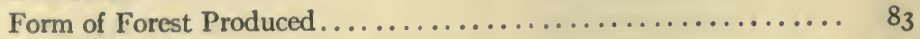

Details of the Method.............................. 84 
Modifications of the Selection Method.

Group Selection. . . . . . . . . . . . . . . . . . . . . . . . . . 96

Strip Selection........................... 98

Extensive versus Intensive Application of the Selection Method.. 98

Advantages and Disadvantages of the Selection Method........ I02

Advantages............................... I02

Disadvantages............................... I04

Application of the Selection Method................... I06

References................................. 109

Chapter Vit. The Coppice Method..................... im

Definition.................................... III

Form of Forest Produced.$\ldots \ldots \ldots \ldots \ldots \ldots \ldots \ldots \ldots \ldots$ III

Details of the Method............................ III

Modifications of the Method...................... II 7

The Polewood Coppice Method................... II

Pollarding.............................. II9

Advantages and Disadvantages of the Method............. I I I

Advantages................................. I2I

Disadvantages............................. 122

Application of the Method...................... I 23

References.............................. 125

Chapter Vili. The Coppice with Standards Method......... r 27

Definition................................. I27

Form of Forest Produced........................ I 27

Details of the Method.......................... I27

Modifications of the Method........................ $\quad$ I 36

Advantages and Disadvantages of the Method.............. ${ }_{136}$

Advantages................................. ${ }_{13} 6$

Disadvantages.............................. 137

Application of the Method......................... ${ }_{13} 8$

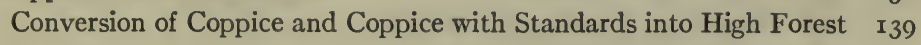

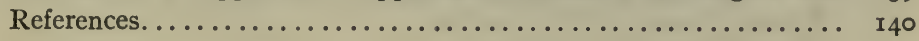

Chapter IX. Intermediate Cuttings................... I4I

Definition and General Considerations................. I4 I

Classification of Intermediate Cuttings................. $\mathbf{1 4 2}^{2}$

Application in Evenaged versus Unevenaged Stands........... 143

Cleanings................................... $\quad$ I44

Liberation Cuttings........................... 149

References................................... ${ }_{152}$ 
PAGE

Chapter X. $\_$Intermediate Cuttings (Contd.) - Thinnings....... I53

Natural Development of the Stand ................. I53

Classification into Crown Classes.................. I 54

Advantages of Thinnings.............................. ${ }_{5} 6$

Time to Start Thinnings........................ 159

Methods of Making Thinnings.................... I60

The German or Ordinary Method of Thinning........... I ${ }_{2}$

Interlucation or Accretion Cuttings............... I I

The French Method. ........................ I7

Borggreve's Method........................ I77

Special Methods of Thinning .................... I83

Application of Thinnings...................... I85

'References.............................. I89

Chapter XI. Intermediate Cuttings (Contd.)........... I92

Improvement Cuttings. ....................... I92

Salvage Cuttings........................... I94

Severance Cuttings............................ I96

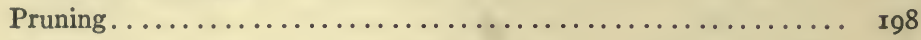

References................................ 203

Chapter XII. Methods of Controlling Cuttings............. 204

Control through Inspection......................... 204

Control through Marking of the Trees.................. 205

Marking Rules............................... 208

Control of Waste and Destruction in I.ogging . . . . . . $\ldots \ldots \ldots$ II

References............................... $\mathrm{Ir}_{3}$

Chapter XIII. Slash Disposal.................. 215

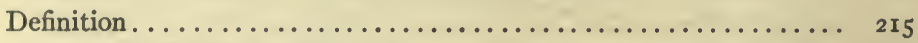

Silvicultural Effects of Slash.................... 2 I 5

Slash in Relation to the Soil. .................... 2 I6

Slash in Relation to Reproduction.................. 217

Slash in Relation to Forest Fires................... 2 I 7

Slash in Relation to Insects.................... 2 I9

Slash in Relation to Fungi...................... 2 I9

Slash in Relation to Forest Esthetics............... 2 I9

Methods of Slash Disposal. ....................... 220

Disposal of Slash by Piling...................... 220

Disposal of Slash by Piling and Burning.............. 221

Disposal of Slash by Burning as the Logging Proceeds........ 223

Disposal of Slash by Broadcast Burning............. 223 
PAGE

Disposal of Slash by Lopping.................... $\quad 225$

Disposal of Slash by Pulling the Tops................. 226

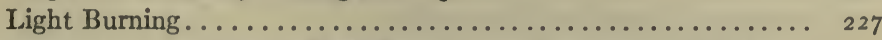

Application of Slash Disposal Methods Under Various Kinds of Cuttings.................................. 229

Reproduction Cuttings........................ 229

Cuttings Under the Clearcutting Method.............. 229

- Cuttings Under the Seed Tree Method................ 230

Cuttings Under the Shelterwood Method.............. 230

Cuttings Under the Selection Method................. 230

Cuttings Under the Coppice Methods............... $23 \mathrm{I}$

Intermediate Cuttings........................ 23 I

Selecting the Method of Slash Disposal................. 232

References................................. $\quad 235$

Chapter XIV. Forest Protection..................... 237

General Considerations.......................... 237

References................................. 240

Chapter XV. Protection Against Forest Fires............ 24 I

Effects of Forest Fires....................... 24I

Annual Fire Loss........................... $24 \mathrm{I}$

Classification of the Injuries Caused by Forest Fires.......... 243

Injury to Trees Containing Merchantable Material.......... 244

Injury to Young Growth Including Reproduction........... 246

Injury to the Soil.......................... 247

Injury to the Productive Power of the Forest............ 248

Injury to Forage............................ 249

Injury to Stream Flow and Industry................ 249

Injury to Other Property............................ 250

Injury to Human Life........................... 250

Character of Forest Fires........................ 250

Factors Influencing the Spread and Severity of Forest Fires..... 254

Inflammable Material.......................... 255

Topography................................ 257

Atmospheric Conditions......................... ${ }_{25} 8$

Methods of Forest Fire Protection.................... 259

References................................ 26r

Chapter XVI. Protection Against Insects................. 263

Extent of the Damage Caused by Insects............... 263

Character of the Injury.......................... ${ }_{2} 6_{3}$ 
Insects Responsible for the Damage ..........................

The Causes of Insect Attacks...................... 265

Methods of Control and Prevention.................. 267

Protection and Increase of the Natural Enemies of the Injurious

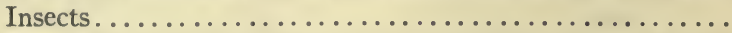

Disposal of Slash and Other Material in which Insects find Favorable Conditions for Breeding.................. 268

Special Silvicultural Measures to Prevent the Creation of Conditions Favorable to Injurious Insects.............. 270

References................................ $27 \mathbf{I}$

Chapter XVII. Protection Against Tree Diseases........... 274

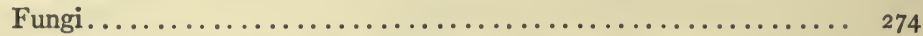

Extent and Character of the Injury................. 275

Methods of Control and Prevention.................. 277

Tree Diseases and Injuries Other than Those Produced by Fungi... $\quad 279$

References................................... 280

Chapter XVIII. Protection Against Domestic Animals; Grazing 284

Introductory............................... ${ }_{28} 84$

The Effects of Grazing.......................... 285

Effect Upon the Soil............................ ${ }_{285}$

Effect Upon Reproduction...................... $\quad 286$

Effect Upon Trees Past the Reproduction Stage........... ${ }_{287}$

Effect Upon the Control and Prevention of Forest Fires....... 287

Benefits versus Injuries from Grazing. ................ 287

Methods of Control and Prevention................... 288

Protection by Excluding Domestic Animals.............. 289

Protection by Close Regulation of the Grazing............ 289

References................................. 29I

Chapter XIX. Protection Against Animals - Other than Insects and Domestic Animals..................... 293

Deer......................................... 293

Beaver....................................... 293

Porcupines................................... ${ }_{293}$

Rabbits.................................... 294

Squirrels.................................... ${ }^{294}$

Mice...................................... 294

Birds.................................... ${ }^{294}$

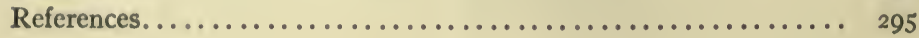


Chapter XX. Protection Against Avalanches, Landslides, Floods and Shifting SAnd...................... 296

Avalanches................................. ${ }_{296}$

Landslides.................................... 297

Floods...................................... 297

Shifting Sands................................ 298

References................................. 298

ApPendix. Forest Terminology....................... 299 



\section{THE}

\section{PRACTIGE OF SILVICULTURE}

\section{CHAPTER I \\ GENERAL CONSIDERATIONS}

Introductory. - B. E. Fernow ${ }^{1}$ the Dean of American forestry aptly says, "silviculture, the production of wood crops, is the pivot of the whole forestry business."

Silviculture is defined as "the art of producing and tending a forest; the application of the knowledge of silvics in the treatment of a forest." * This definition indicates the relation existing between silviculture and silvics. The latter deals with the underlying principles which control the life of individual forest trees and stands. It furnishes the scientific basis upon which silviculture rests. In a broader interpretation of the term silviculture includes the foundations of silviculture; namely, silvics, the science, and the practice of silviculture or the art.

An understanding of silvics is a pre-requisite for the study of silviculture or for its intelligent application. Such knowledge is taken for granted in those who read this book, which does not include the subject of silvics within its scope.

Relatively little is known concerning silviculture. This may be attributed to three causes:

* Forest Terminology. See Appendix. This is a compilation of Terms in Forestry arranged by a committee of the Society of American Foresters. The definitions which it contains will be used frequently and accepted as standard except as otherwise specified. 
First, silviculture as yet has been practiced to a limited extent and during a period of only a few years in North America, whereas it requires several decades to build up definite silvicultural practice.

Second, silvicultural practice is essentially a local consideration, varying in important details from forest to forest. Generalizations and the intelligent use of knowledge gained by others develop slowly under such a condition.

Third, application of knowledge to treatment of a forest is seriously hampered when such knowledge is fragmentary. Silvics, which in theory affords the scientific basis for silviculture, is still in its infancy so far as furnishing definite information for use of practitioners on numerous important problems is concerned.

Despite these difficulties and deficiencies a body of information has been built up as to methods and lines of procedure from which, as the starting point, the details of local silviculture must be worked out.

The need to-day for silviculture in practice is colossal and coextensive with the area of non-agricultural land. Business conditions control the practice of silviculture as in a similar way they do the practice of agricultural science on farm lands. Intensive silviculture, like intensive agriculture, pays only where markets for products are accessible and prices high. A crude application of silviculture is practicable to-day on a great majority of the forest lands.

Silviculture, like agriculture, requires expenditure or investment made in order to secure some crop or return of more value than would be obtained without such action. The return in agriculture comes within one year or at most within a few years after the expenditure is made, while in the practice of silviculture the return is delayed several decades. In either case the intensity of the work and the amount of 
the expenditure justified is in proportion to the return to be realized.

The long interval before the crop can be harvested is an undoubted drawback, but in spite of this, expenditures in silvicultural and agricultural practice to increase productivity have a common economic basis. Indeed, when once adequately organized, forest properties producing timber crops may frequently pay as well as or better than lands producing agricultural crops.

The unmanaged or mismanaged forests, like poorly cared for farm lands, do not produce forest products of the kind, in the amount, or of the value which might be grown. Silviculture, by properly tending the wild forest and establishing new forests on open areas, increases productivity.

Production in Managed and Unmanaged Forests. - The unmanaged or mismanaged forest shows lower production than it should, due to one or more of the following defects.

(a) Species of quality inferior to those which might be growing occupy part or all of the area. Such species are the weeds of the silviculturist. They flourish at the expense of better varieties. Inferior species are particularly apt to appear after disturbance in the forest cover, due to such agencies as lumbering and fires. Silviculture must eliminate and keep inferior species from reappearing. "Inferior," as here used, is a relative term, since a species may be, under one set of circumstances, the best tree to grow and elseiwhere a forest weed.

(b) The forest may be too sparsely or too densely stocked with trees for the best results. Either of these two extremes is detrimental, both having the final effect of reducing the value of the crop produced. Too sparse stocking results in part of the area being unproductive during a portion, at least, 
of the life cycle of the forest, while too dense stocking leads, as in the case of a thick bed of beets (to draw an illustration from the garden), to stagnation and a small final crop.

Silviculture must provide and maintain throughout life enough trees to properly stock the area and no more.

(c) Part of the area which should be forested is without forest. Fires, logging and clearing, for agricultural use, lands which are unsuited for that purpose are chiefly responsible.

The deforested condition may be only temporary - natural seeding stocking the open lands - or may be, for all intents and purposes, permanent, due to the extent of the deforested lands and lack of trees to reseed them. Silviculture must prevent the creation of further open areas and restock those now existing.

(d) Crooked, misshapen and defective trees (even though of valuable species) are apt to accumulate in the forest not under silvicultural treatment and retard the development of better individuals. These trees should be removed.

(e) Losses, due to agencies such as insects, animals, fungi, wind, etc., are sustained, often without salvage of the damaged material and without efforts to check the injury from being spread to adjacent parts of the forest. Silviculture must afford protection to the forest.

$(f)$ Due to mismanagement and lack of protection the forest may cease to properly protect the site on which it grows and lands adjacent to or indirectly related to the forest. The forest floor may be destroyed and the soil eroded or baked and cracked open to the detriment of the physical factors of the site. Lands depending upon the forest for protection may be eroded or covered with infertile soil and débris. Navigation on the lower reaches of streams rising in the forest may be interfered with, reservoirs be filled and irrigation works rendered useless. 
Silviculture must prevent injuries to the site and also to lands and industries dependent upon the forest for protection.

(g) As a result of the various defects already mentioned the production, quantitatively, qualitatively and financially, of forest products figured on an acreage and a time basis is less than it might be.

The Purpose of Silviculture. - The purpose of silviculture might then be summed up as the creation and maintenance of such a forest as will yield the highest returns in a given time. Such a statement should be qualified, because the object which the owner of a forest has in view will be the controlling factor in the silvicultural work. The statement should be modified to read: The purpose of silviculture is the production and maintenance of such a forest as shall best fulfill the objects of the owner. Where the forest must be handled with the object of furnishing protection to other property, silviculture not entirely in harmony with the owner's desires may have to be applied, but this is an exceptional case. The objects of the owner may be of diverse character. The essential thing is that the object for which silviculture is applied be known and the treatment be shaped to the accomplishment of the desired end.

The commonest object for which silviculture is practiced is the production of the highest returns, financially, in a given time. Protection of watersheds and lands adjacent to the forest and development of the best æsthetic effects are other objects which may be of primary importance with certain owners.

The Field of Silviculture. - The field of silviculture divides logically into three parts defined as:

I. Treatment of the stand during the period of regeneration or establishment: a consideration of reproduction methods.

When a bare area is restocked with trees, either brought in 
by artificial means or originating from natural reproduction, there ensues a term of several years during which the young plants are being established or adjusting themselves to the new environment. When this adjustment is successful and the reproduction completed the period of establishment or regeneration may be considered closed.

In every stand the time comes, sooner or later, when it is desired to harvest a portion or all of the timber and replace the trees removed by others of a new generation. Cuttings are made with the two purposes of removing the old trees and establishing reproduction. They are known as reproduction cuttings and the period over which they extend is known as the regeneration or reproduction period. Reproduction cuttings range from one to several in number and the regeneration period may extend from less than five to more than 50 years. In the case of the selection forest this period is identical with the rotation.

2. Treatment of the stand during that portion of the rotation not included in the period of regeneration: a consideration of intermediate cuttings.

After a new stand is established on open land or on wooded areas as a result of reproduction cuttings, a long period ensues during which the young stand grows and passes through various stages until mature and ready, in its turn, to be harvested and give place to a succeeding generation. The various cuttings made during its development from the reproduction stage to maturity are termed Intermediate cuttings. They have as their object the improvement of the existing stand without thought of reproduction. (See Fig. I.)

3. Protection of the stand against injuries of many kinds. The more important are fire, insects, fungi, animals and wind. This subject leads into various specialized fields, such as fire protection, entomology, pathology and zoölogy. 
All of these, while directly affecting the production of tree crops, usually are studied as units by themselves and will here be given only brief consideration.

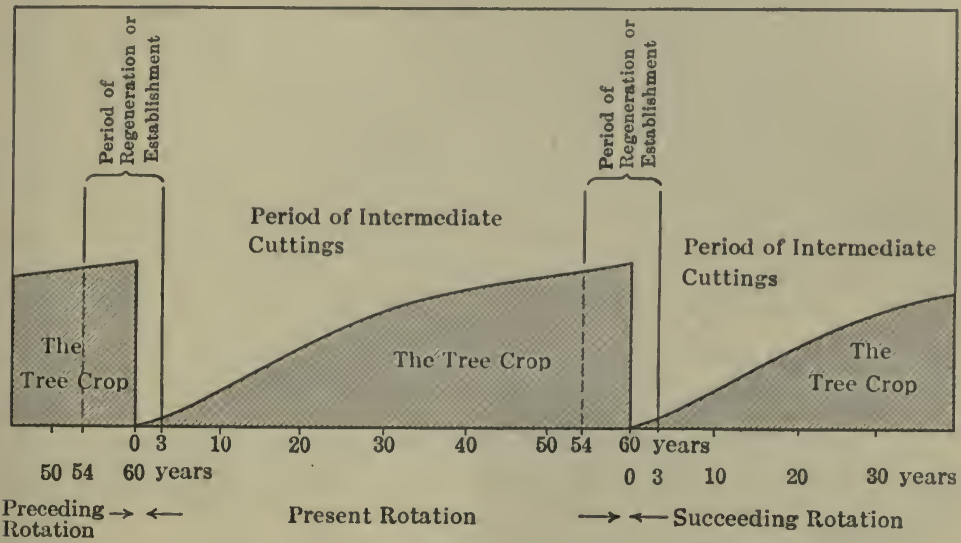

FIG. I.

An illustration based on eastern white pine managed on a 60 year rotation under shelterwood to show the relation between the period of regeneration and the period of intermediate cuttings.

The Cost of Silviculture. - The production of tree crops, in common with other commercial enterprises, involves the assumption of certain investments and expenditures. Compared with the business of harvesting standing forest products (i.e., logging), the costs will be greater for silviculture, since the former simply conducts the first stages of utilization or manufacture of any existing crop of trees and does not have as its function the growing of succeeding crops.

A common way of expressing the costs of silviculture is to compare them with the costs of the business of logging, thus indicating the extra expenditures and investments required.

The question of whether silviculture is "impracticable" (a term too often loosely employed in this connection) does 
not depend upon the relative costs of the two distinct businesses - viz., logging timber and growing timber - but, in reality, hinges upon whether a profit ultimately can be made in excess of the expenditures necessary in growing the tree crop.

It is true that the lack of capital to invest and of the financial strength to carry an investment for a period of years bar many owners of forest property from practicing silviculture.

Where the desire to enter the business of forestry exists in conjunction with the requisite amount of capital, silviculture will, in the majority of cases, prove to be a practical undertaking. Forest properties sufficiently well stocked with timber to return an immediate and continuous income offer more favorable opportunities for the practice of silviculture than those upon which the timber is so deficient as to necessitate a long period of waiting before returns on the investment are available.

The actual costs of silviculture and the degree to which they increase the cost of logging are subject to wide variation. Graves ${ }^{2}$ stated in I9II that the cost of silviculture, expressed in terms of the annual cut, is likely to fall between 50 cents and $\$ 1.00$ per thousand feet; board measure. In calculating the extra cost of logging timber on the National Forests, as contrasted with the unrestricted logging on private lands, for California forests in I9I8 Birch $^{3}$ concludes that expenditures are increased $\$ 0.855$ per thousand feet, board measure, and lowered \$o.78, making the net excess of cost \$o.075 per thousand feet, board measure. In favorable instances a crude application of silviculture may involve very slight increased charges. On the other hand intensive application may require large initial costs, although eventually returning better net profits than the crude application.

It is not purposed to attempt a statement of the actual costs, but rather to set forth the various classes of items 
which must be considered in determining the cost of silviculture in the case of an individual property. These items are arranged under the following five major headings.

I. Cost of Reproduction. The artificial regeneration of the area by seeding or planting may be required. Treatment of the soil, litter, ground cover or underbrush may be needed to establish proper seedbed conditions for natural reproduction. It may be necessary to retain a portion of the old stand, either for a part or for all of the next rotation, to provide seed or the right amount of shelter. The young seedlings, naturally or artificially started, may require cleanings to secure their final establishment.

2. Cost of Protection. Annual, periodic or special expenditures are likely to be necessary against one or more enemies. Examples are: the annual charges for the prevention of forest fires; the periodic eradication of ribes species in the eastern white pine regions; and special work on cutting areas to dispose of brush, trees affected with fungi or insects and snags, and for fighting fires or dangerous outbreaks by other enemies. The cost of insurance (where such can be economically secured), or the carrying and distribution of a certain fixed charge per acre to cover average losses from enemies, is a proper charge against silviculture.

3. Increased Expenses of Logging. Increased costs of logging come principally through the need of greater care in felling, bucking and skidding, to save young growth and seed trees left on the cutting area, and in the heightened costs per thousand feet, board measure, of construction work, due to a decreased cut when part of the merchantable stand is left. The leaving of the smaller trees may effect a saving in logging costs, because such trees are the most expensive to handle and produce the lowest quality of product. Disposal of the slash may so clear the area as to effect a reduction in skidding costs. 
4. Cost of Administration. The marking of the trees to be cut or left, extra inspection and supervision, to see that cutting and other work is carefully and properly executed, are likely to be necessary.

5. Costs Due to Making the Investment a Permanent One. The investment in the value of the land may become permanent instead of being terminated, through sale or devotion to other use, when the area is cut over.

A considerable investment in wood capital (the growing stock) is required where silviculture is systematically applied. Interest and taxes upon the investment in land and wood capital must be met.

\section{REFERENCES}

I. Fernow, B. E. Suggestions as to Possibilities of Silviculture in America. Proceedings of the Society of American Foresters, Vol. XI, rg16, pp. I7I-176.

2. Graves, H. S. Principles of Handling Woodlands. New York, IgII, p. 19.

3. BIRCH, D. C. Extra Costs of Logging National Forest Stumpage. Journal of Forestry, Vol. XVI, I9I8, pp. 909-9I4.

Churchill, H. L. The Approximate Cost of Private Forestry Measures in the Adirondacks. Journal of Forestry, Vol. XVIII, 1920, pp. 26-30.

Graves, H. S. Present Condition of American Silviculture. Proceedings of the Society of American Foresters, Vol. III, 1908, pp. 29-40.

Woolsey, T. S. JR. Studies in French Forestry. Wiley \& Sons, Inc., New York, 1920. (This excellent book, published Dec. 1920, arrived too late to be referred to in detail. The best that can be done is to list it here as a valuable reference book on various phases of Silviculture, - particularly Chapters $v$ and vi.) 


\section{CHAPTER II}

\section{REPRODUCTION METHODS}

Treatment of the Stand during the Period of Regeneration or Establishment

Definition. - A reproduction method may be defined as an orderly procedure or process by which a forest is renewed or established either naturally or artificially. This process is accomplished during the reproduction or regeneration period, which comes when the stand is harvested at the end of every rotation. It is accomplished through skillful cuttings of the mature timber supplemented where necessary by special treatment to create and maintain conditions favorable for the start and early life of reproduction. Where artificial methods of regeneration are employed, as may be the case in renewing established forests and must be used in reforesting open lands, the seeding or planting of the area is included as part of the process.

The term "silvicultural system" is used frequently as practically synonymous with reproduction method. As sometimes employed it is intended to include both the reproduction method and the intermediate cuttings applied in a given case.

Standard Reproduction Methods. - Many different reproduction methods have been developed, but they can be reduced on analysis to a few standard methods which are applicable in principle the world round. In practice the details of applying a standard reproduction method may vary for every species, forest region and owner. As time passes 
this leads to the origin of quite definite reproduction methods worked out in detail and based on local practice which may be advanced as original and advocated for general adoption. Under close examination such methods prove to be mere modifications of the few standard reproduction methods and not as applicable for general use as the standard methods.

Combinations of several reproduction methods within the same stand are common practice in treating the irregular unmanaged forests which are the rule to-day Eventually only one method will be applied within a single stand because-each method produces distinctive results and recognizable differences in the character of the forest, which make it advisable to have stand boundaries coincide with variations in reproduction methods.

Field Identification of Reproduction Methods. - Since local adaptations of reproduction methods are developed wherever silvicultural practice is applied, difficulty frequently is experienced in determining under what standard method a given series of reproduction cuttings should be classed.

Identification in the forest of the reproduction methods is particularly puzzling in a country where all forestry practice has taken place within the last twenty years and most of it within the last ten. A field inspection of the cuttings together with information about the matters listed below should make possible a correct decision as to the reproduction method. Information should be obtained as to:

(a) The form of forest which will be produced under the method of cutting in operation. Certain reproduction methods result in the maintenance of even-aged stands; others produce irregular or uneven-aged stands.

(b) Character of the present cutting. There are such obvious differences in character of the reproduction cuttings between many of the methods that a field inspection sheds 
much light on the method. On the other hand certain methods are quite alike in their first reproduction cutting.

(c) Length of time which will elapse before the next reproduction cutting and what the character of that cutting will be.

(d) The length of the rotation and length of the reproduction period. The length of the rotation determines the allowable range in age between individual trees if that particular stand is to be classed as even-aged. The longer the rotation the greater can be the difference in age between individual trees without loss of the even-aged form. For instance if the rotation is 50 years, a difference in age of ro years might be the maximum and have the stand still remain even-aged, while if the rotation were 200 years, differences of 40 to 50 years between individuals would be allowable.

(e) Origin of the reproduction, whether from sprout or seed, whether naturally or artificially obtained.

( $f$ ) The minimum size of area considered as a subdivision in the forest. In other words the minimum size of the individual stand or portion of the forest differing from adjacent portions in composition, character or age. Such minimum size will be determined principally by the intensity of the silvicultural operations which in turn is controlled by the economic situation. Where intensive work is possible, areas of less than one acre may be recognized as subdivisions. (See Fig. 2.) If work on an extensive scale alone is possible it may be that subdivisions of less than several hundred acres are impracticable. The minimum size of the single stand or subdivision is important in its effect on the form of the stand. Large areas of forest are much less uniform in composition, character or age than small areas which may be separated out from within a single large area. For example a forest of rooo acres located in the southern Appalachian mountains distant 
from markets may be handled as a single stand of irregular age. The same forest if located within five miles of a large city may be divided into twenty to one hundred different subdivisions or stands most of which are classed as even-aged.

The same cutting which in the first instance has to be classed as selection may in the second furnish examples of clearcutting and shelterwood methods.

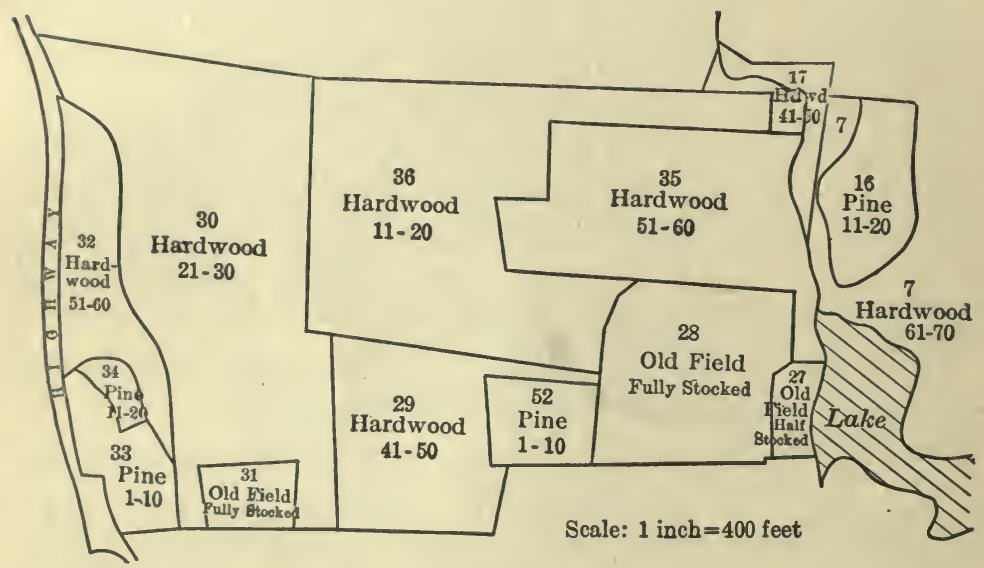

Fig. 2.

Map of portion of forest property showing the division into subcompartments (stands) based on type distinctions and (within the same type) upon ro year age class differences. The upper figures are the sub-compartment numbers, while those below the type name indicate the age class.

Due consideration of all these factors in their relations with one another should be given in analyzing a reproduction method in its application in the forest.

Classification of Reproduction Methods. - The classification of reproduction methods which will be used agrees in all but one particular with that given in Forest Terminology.*

* The difference comes in including under the clearcutting method, reproduction both artificially and naturally secured, which are listed as two separate methods under Forest Terminology, in Journal of Forestry, Vol. XV, p. 89. 


\section{Standard Reproduction Methods}

High Forest Mcthods: - Producing forests originating from seed.

Clearcutting method.

Seed tree method.

Shelterwood method.

Selection method.

Coppice Forest Methods:- Producing forests originating wholly or mainly from sprouts and suckers.

Coppice method.

Coppice with standards method.

Each of these methods is treated in a separate chapter to which reference should be made for definitions and discussion.

Importance of the Standard Reproduction Methods. There is a tendency in.some quarters to belittle the importance of recognizing standard reproduction methods. This may be attributed to several causes.

First, because of a tendency to undervalue methods of European origin. These standard methods arose in European practice and find there to-day their most elaborate development. It is what logically is to be expected since forestry was first practiced abroad. Despite the great difference in economic conditions between Europe and America the laws of growth of trees and stands are the same. The standard reproduction methods have a sound basis in silvics which will hold on both continents.

Second, because of failure to recognize that any one of these standard methods is to be applied only as a framework, allowing wide range in respect to details to fit the purely local needs of each forest.

Natural reproduction follows cuttings not as a direct result 
of the cuttings themselves, but due to favorable site conditions. Theoretically these conditions should be created by the cuttings. A reproduction method is successful in so far as it accomplishes this and the variation in detail of application is for the purpose of creating the proper site conditions.

As the standard reproduction methods are studied it becomes apparent that one method grades into another and that into still another and so on in a complete series embracing all the possible ways of removing a mature stand by cutting. In passing through this series every conceivable combination of open and dense stands, of young and old trees, with the consequent maximum range in desired effect upon basic site factors possible to produce by cuttings can be obtained.

Just as the sites in a given region range in a continuous series from the least to the most productive but are separated arbitrarily into a few broad classes for use, so with reproduction methods the gradations, from one method through various modifications to another, are almost unnoticed, when taken step by step, yet show extremes at the limits of the series and are for purposes of practical use classed into a few main divisions. Any possible combination of cuttings for harvesting a merchantable crop of timber and replacing it by a new stand can be placed under one of the six standard reproduction methods.

Third, because in the irregular overmature virgin forest now being cut in parts of this country, the style of cutting is rather rigidly circumscribed by the condition of the timber, logging possibilities and other economic conditions and consists in removing all or a very large proportion of the merchantable timber without thought of any particular reproduction method. ${ }^{1}$

Such reproduction as follows the cutting comes haphazard and uncontrolled, but will receive protection. Such forests 
are in the transition stage between the unmanaged forest of the past and the managed forest of the future. After the first cutting which utilizes the old overmature trees the possibilities and necessity of cutting systematically to secure reproduction will be seen.

Factors Influencing Natural Reproduction. - The method of cutting is only one among a number of factors which control the establishment of natural reproduction, such as climatic conditions (which is the dominating factor), occurrence of seed years, grazing and other injuries by animals, insects, fungi and fire. All these factors, outside of what direct mechanical influence some of them may exert in destroying established reproduction, affect the start and early development of reproduction through influence upon such fundamental factors as temperature, moisture and light which are of direct controlling importance. For successful natural reproduction there must be:

(I) Abundant seed supply in excess of that destroyed by rodents, insects and other agencies;

(2) Favorable conditions for germination of seed;

(3) Favorable conditions for the growth of seedlings.

Each species is likely to have different requirements and will vary more or less in its own requirements in different parts of its range. The silviculturist should be equipped with a definite knowledge of the basic requirements for natural reproduction of the species with which he deals, and should also know the effect in establishing and maintaining these requirements which methods of cutting, fire, grazing, etc., possess. Supplied with this knowledge he can utilize cuttings, fire and other means, so far as control of them may be in his power, to establish and maintain the conditions requisite for reproduction. 
A reproduction method then has for its object the establishment of reproduction and the removal of the old crop. Its first purpose may possibly, though rarely be achieved as a direct result of the cuttings. More probably the method of cutting is only one of a number of factors some within the control, some without the control of the silviculturist, but each exerting their effect on environmental conditions.

A reproduction method will include more than the making of cuttings. Other work to insure reproduction may have to be pursued. For example, the use of fire, protective methods against insects and animals, cultural operations to prepare the soil, conserve moisture and to lessen the competition with grass, herbs and shrubs, the use or exclusion of grazing, and disposal of slash as well as other matters may any one or all have a vital connection with the securing of a complete reproduction.

Unfortunately the science of silvics has not yet supplied either the accurate detailed knowledge of the silvical requirements of most commercial species nor has it determined with precision the exact effects of the various factors, cutting, fire, grazing, etc., upon the moisture, light and heat conditions of the site.

Meanwhile the silviculturist must advance as he can, often making mistakes, because he acts on information resting too largely on an empirical basis. It is the ignorance and backwardness of silvics the science which forces silviculture to grope in the dark as it carries on the art.

Artificial Reproduction Compared with Natural Reproduction. - Establishment or renewal of a forest may be obtained by (a) seed, (b) sprouts, from the stump, or from the roots (root suckers), (c) cuttings and $(d)$ layering. In the practice of silviculture, layering is not employed, cuttings are used infrequently and dependence is placed upon seed or sprouts to insure reproduction. 
Reproduction may be accomplished by either natural or artificial means. Natural reproduction accomplishes its purpose by self-sown seeds or by sprouts and, in instances so rare as to have no commercial importance, by layering. Artificial reproduction, defined as the renewal of a forest by direct seeding or planting, utilizes either seeds or young plants grown from seeds or cuttings.

Of these two methods natural reproduction is the more important because of the fact that it will be used on all but a small proportion of the forest area.

Artificial reproduction while logically a part of and included under reproduction methods is more conveniently treated as a unit by itself. This is due to the fact that two subjects, namely, the collection and treatment of tree seeds and the growing in nurseries of trees for planting must be developed to considerable length in connection with the establishment of forests by artificial means.

The comparative advantages of natural and artificial reproduction are outlined in the succeeding pages and later under each reproduction method is indicated the extent to which artificial reproduction may be employed.

For a detailed discussion of the various ways of securing reproduction by artificial means the reader is referred to special works on artificial reproduction, particularly to "Seeding and Planting in the Practice of Forestry," by J. W. Toumey. ${ }^{2}$

Both artificial and natural reproduction have special advantages of their own which are best considered in a comparative way. Among those in favor of artificial reproduction are the following:

Advantages of Artificial Reproduction. - I. The new stand can be established immediately without the loss of time which occurs when dependence is placed on natural reproduction. 
It may take from ten to thirty years after the cutting for an area to completely restock by natural means. Very rarely can natural reproduction be accomplished immediately after a cutting. On short rotations this advantage may be of great financial importance.

2. The species best adapted to fulfilling the purposes of the owner can be grown. Frequently the trees which reproduce naturally on a given area are of inferior value and rate of growth to other varieties which could be produced. Artificial reproduction makes it possible to introduce new and better species.

3. Complete reproduction is more certain under artificial methods than when naturally obtained. Not only is time liable to be wasted in securing natural reproduction but it may even happen that the latter is a partial or entire failure. In many instances natural reproduction may come in large enough quantities to stock the area but proves to be of the wrong species. Natural reproduction in mixed stands especially is difficult to predict in advance because of this factor.

4. The right spacing is secured to produce the desired results. Natural reproduction is apt to be either too sparse or too dense. The number of trees per acre established artificially is calculated so as to fulfill the objects of the owner.

5. Artificial reproduction permits the employment of a relatively simple reproduction method when more complicated and hence expensive methods may be required to secure reproduction naturally.

6. The yield per acre in quantity and value should average higher than in naturally reproduced stands due principally to the saving in time of establishment, the use of the best species and the right spacing. There undoubtedly are many naturally reproduced stands which have these three requisites that yield as much as or more than those artificially reproduced. 
7. In the case of over-mature stands of old growth timber, reproduction by artificial means may be the only available method, due to the valuable species in such stands having ceased the production of seed. This situation will be an exceptional case rather than one of every day occurrence.

Advantages of Natural Reproduction. - I. Natural reproduction is Nature's method and should renew the forest with species adapted to the site. It is apt to produce a mixed forest which is considered less susceptible to injuries and more productive than a pure forest, which is the usual kind produced by artificial means. ${ }^{4}$ While the above may be true in the forest undisturbed by other than natural factors it does not follow that it will hold in the forest after cuttings. Should the forest contain only valuable species and the cuttings not create conditions unfavorable for their reproduction then Nature's method may prove successful. On the other hand, it is quite possible that an inferior species in pure stands may be the result secured.

As a consequence of artificial reproduction injuries by insects and certain other agencies such as snow breakage, and windfall, are unquestionably more extensive than in the mixed naturally reproduced stand.

On the whole the argument that natural reproduction is Nature's method is not a particularly strong one when comparing with artificial reproduction.

2. Natural reproduction as compared with artificial reproduction is better suited to the less intensive methods of silviculture which must be employed for many years over the larger share of the forest area. To regenerate existing forests by artificial methods requires work of intensive character which the country is not ready for on a big scale.

3. Natural reproduction is cheaper on the whole than artificial reproduction. On many forest areas natural repro- 
duction can be secured for practically nothing or at a fraction of the expenditure required to reforest artificially. The reproduction so obtained and the stand finally produced may not compare with that possible under artificial methods, although the question is often an open one as to whether the poor naturally reproduced stand may not exceed in final net value the better artificial one.

There are many cases where natural reproduction does not cost more than artificial reproduction. Stumpage values of the trees left to establish reproduction may be a loss, and logging costs per thousand feet board measure due to the smaller amount cut per acre may be increased.

Even though the greater net returns of artificially reproduced stands may be quite clearly demonstrable, the actual amount of the initial cash expenditure may make the proposition impracticable for the owner.

4. Natural reproduction must be employed on many areas because of the physical limitations in the way of applying artificial reproduction.

Artificial reforestation on a large scale requires ${ }^{3}(a)$ collection and cleaning of large quantities of seed, (b) production of immense quantities of young trees, $(c)$ organization of big squads of laborers and usually the planting of extensive areas back from transportation lines and centers of population. The work must be accomplished in the short period of a few weeks in each year when climatic conditions permit of seeding or planting.

In theory this program may appear simple but in execution has never yet in North America, even by state or federal agencies, been conducted on a scale adequate to the needs.

Opportunities for Applying Artificial Reproduction. - In general the field for artificial reproduction to-day is in refor- 
esting burns and other areas which are at present non-forested, and which are either so far distant from seed trees or suffer such unfavorable site conditions as to preclude the possibility of natural restocking.

The vast extent of barren areas due to clearcuttings and fires, together with other open lands, will require many decades to reforest and will tax the capacity of all agencies to supply necessary seeds, plants, labor and funds. These lands are now unproductive. Artificial reproduction should be largely confined for the next half century at least to reforesting this type of land. Only in the regions where intensive management is possible, and in which the proportion of open unproductive land is small should artificial reproduction of existing forests be undertaken. Here the funds for relatively large initial outlay often are av ailable and the size of the projects are within the range of present physical limitations.

Artificial methods of reproduction are most commonly applied when using the clearcutting method or in reforesting open land. There is a field and a distinct need for artificial regeneration under other reproduction methods intensively applied to supplement natural reproduction by stocking the blanks.

\section{REFERENCES}

I. Clapp, E. H. Silvicultural Systems for Western Yellow Pine. Pruceedings of the Society of American Foresters, Vol. 7, I912, p. I69.

2. Toumey, J. W. Seeding and Planting in the Practice of Forestry. Wiley \& Sons, Inc., New York, I9r6.

3. Munger, T. T. Natural versus Artificial Regeneration in the Douglas Fir Region of the Pacific Coast. Proceedings of the Society of Americar, Foresters, Vol. VII, I912, pp. 187-196.

4. Nisbet, J. Studies in Forestry. Oxford, I894, pp. II $5^{-137}$

Reuss, Hermann. Die Forstliche Bestandesbegründing. Berlin, 1907, pp. $\mathrm{r}-38$. 
SECREST, E. The Rôle of Artificial Regeneration in the Re-enforcement of Hardwood Woodlots. Journal of Forestry, Vol. XVI, I9I8, pp. 329-334. Tillotson, C. R. Forest Planting in the Eastern United States. Bulletin I53, U. S. Department of Agriculture, Washington, r9r 5.

Troup, R. S. A note on some European Sylvicultural Systems, with Suggestions for Improvement in Indian Forest Management. Calcutta, rgr6. 


\section{CHAPTER III}

\section{THE CLEARCUTTING METHOD}

Definition. - In the clearcutting method the area is cut clear. Reproduction is secured after the cutting either artificially by seeding or planting, or naturally by seed distributed from trees standing outside the area cleared or from trees cut in the clearing operation. Depending on how reproduction is secured the method divides into (I) clearcutting with artificial reproduction and (2) clearcutting with natural reproduction.

Form of Forest Produced. - A clearcutting operation as a practical method can be used only in a stand where the trees are all of merchantable size. Such a stand may be either evenaged or contain several age classes the youngest of which contains trees as large as or larger than the minimum merchantable size. The new stand originating on a clear cut area is evenaged irrespective of whether the timber before the cutting was irregular or evenaged in character. In almost all stands of merchantable timber no matter how evenaged in form there will be occasional small unmerchantable trees which remain standing after a clearcutting. The majority of such trees are soon windthrown or die as a result of the changed conditions following the cutting.

Details of the Method. - The two different ways of securing reproduction each require separate consideration in discussing the details of the clearcutting method.

Clearcutting with Artificial Reproduction. - In this simple method the stand is cut clear and reproduced by seeding or 
planting.* Usually the artificial regeneration is accomplished soon after the clearcutting. The cleared area is likely to become stocked with grass, weeds, underbrush or undesirable trees which may prevent or render expensive the process of artificial reproduction. In exceptional cases it may be of advantage to defer seeding or planting for one or more years. For example, this may be advisable when it is desired to allow time for a thick humus to decompose, or when injuries to the new stand by insects breeding in stumps or tops can be avoided by delay.

Lumber, logs and cordwood should be removed from the area before it is regenerated in order to prevent damage to the young plants.

A clearcutting results in a large accumulation of tree tops and other logging débris. This may be so abundant as to interfere mechanically with the seeding or planting operations or constitute a serious fire hazard. If so this material should either be piled and burned or burned broadcast. See chapter relating to Slash Disposal.

Heavy underbrush may have to be disposed of in a similar manner.

As the young reproduction develops it will on many sites be overtopped by inferior trees and other vegetation. The proper treatment of the young stand under such circumstances is discussed in Chapter IX under Cleanings and Liberation Cuttings.

Clearcutting with Natural Reproduction. - The stand is cut clear and reproduction springs up naturally on the clear area. This reproduction to secure best results should start immediately but frequently requires several years. The seed from which the new stand originates comes from three sources:

"For discussion of the details of seeding and planting see "Seeding and Planting in the Practice of Forestry," by J. W. Toumey. 
(a) Trees standing outside (usually adjacent to) the area cleared. The seed is disseminated (by wind) over the cleared area most thickly close to the parent trees on the borders of the clearing and in decreasing amount toward the center. Reproduction arising from such seeding is apt to be too dense around the edges and too sparse or lacking altogether in the middle. (See Fig. 3.)

(b) Seed stored in the duff. With some species under certain climatic conditions quantities of seed may accumulate in the forest floor retaining vitality for many years and germi-

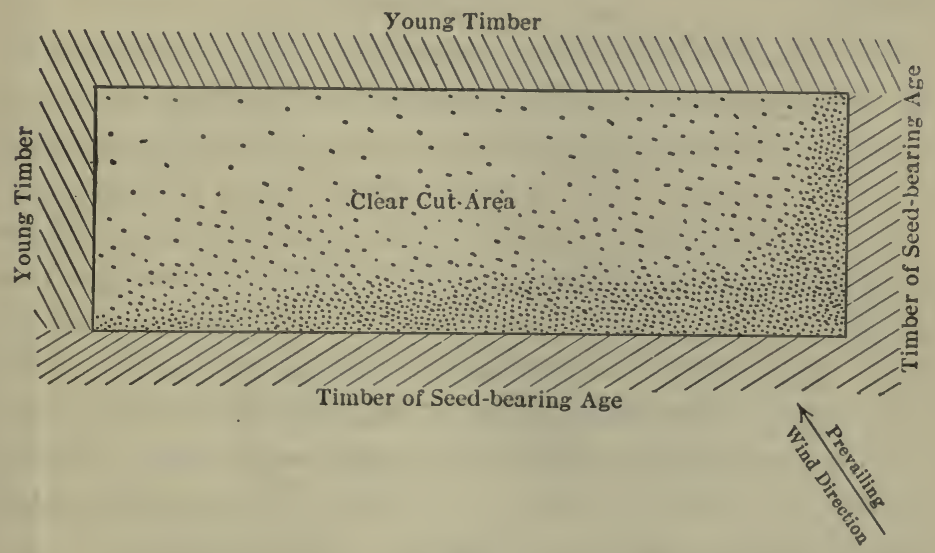

Fig. 3.

Clearcutting the whole stand, with reproduction secured by seed disseminated from seed trees located outside the stand cut. The density of the reproduction five years after the cutting is indicated by the dots.

nating when subjected to the changed conditions following a clearcutting. ${ }^{1}$ Reproduction secured in this way may be relatively uniform in its distribution over large areas.

(c) Seed stored on the trees removed in the clearcutting, or recently fallen from these trees. Certain species (lodgepole pine for example ${ }^{2}$ ) retain portions of several seed crops for 
a number of years. Following cutting (also after fires) such seed may be released and germinate. With most species the seed stored on the trees is the current seed crop. This may be still on the trees or recently fallen to the ground. A uniform and complete reproduction will frequently follow where this source of seed is available on the cleared area.

Successful natural reproduction following a clearcutting depends first on an abundant seed supply over the entire area and second upon the existence of conditions favorable to the germination of the seed and development of the young seedlings.

Since clearcutting differs more from Nature's system of regeneration than do other reproduction methods, it follows that the two requirements for success of the method must be met with precision before natural reproduction will appear.

In providing for an abundant seed supply the sources from which seed may be expected and the probable amount must be considered, as well as the natural enemies, especially rodents, which may destroy the seed. In artificial seeding it is often necessary to distribute poison systematically over the area to be reproduced in order to kill the rodents. Such methods applied just before a seed year in stands about to be reproduced naturally might be effective in increasing the seed supply available for germination. No instances are known where this has been done the expense being large and the uncertainty great as to whether this step would guarantee natural reproduction. Where seed from surrounding trees is the only source the clearing must be sufficiently small (usually long and narrow) to allow for adequate dissemination to all points. Direction of the wind at the time of seed dispersal should be known and the clearing so located that its long axis is at right angles to the wind direction.

Unless the cleared area can be made very narrow a heavy 
seeded species, depending principally upon gravity for dis- semination, will not furnish sufficient seed from trees outside the clearing. When seed in the duff or on the trees which are to be cut is available the weight of the seed becomes less important.

After providing for an adequate dispersal of seed over the clearing, favorable conditions for germination and early growth of seedlings of the desired species must be established and maintained for a few years. Establishment and maintenance of such conditions in many cases will require special work undertaken for this specific purpose.

The silvical habits of the species together with the condition of the site will indicate the character and amount of the work needed. In general such treatment falls under one of three heads:

(a) Disposal of the slash left by the lumbermen.

A variety of methods to accomplish this is available. (See Chapter XIII.) As already stated piling and burning or else broadcast burning are commonly used on clearings. The brush may be silviculturally of advantage in conserving moisture and protecting seedlings and in some cases may properly be left untouched.

(b) Removal of weeds, vines, shrubs and reproduction of undesired species which threaten to prevent germination or growth of seedlings. ${ }^{3.4} \mathrm{~A}$ fire running over the whole area in the latter part of the summer is the cheapest and most effective remedy for destroying the undesirable vegetation which may be present before reproduction starts.

Such burning may bring in a different kind of reproduction from that sought. If this is likely cutting or grubbing out of the objectionable vegetation may be necessary. This will be more expensive than the use of fire. Where the shrubs and reproduction of undesired species are too large to be cheaply 
cut and disposed of, girdling may be employed. From the standing trees the bark is removed in a ring around the trunk and if necessary to cause death, a groove is chopped in through the sapwood.

A cover may be of benefit to young seedlings in protecting them from frost, heat or wind. In such cases the cover should be preserved so long as it serves a useful purpose. Within a few years this cover ceases to be of benefit to the reproduction and becomes a hindrance to its proper development. Cleanings must then be made to uncover the reproduction and establish it in a dominant position.

(c) Treatment of the Soil. ' Frequently nothing need be done to improve soil conditions. The rate of decomposition increases on a cleared area and may sufficiently expose the soil and make available plant foods without any special treatment. Logging when there is no snow on the ground often results in mixing mineral soil and duff into an ideal seedbed.

Where further treatment is needed, burning over the area to remove the duff and lay bare the mineral soil is sometimes undertaken. Breaking up the soil in patches or furrows with a plow, log drag, ${ }^{5}$ spade or other implement will often be effective.

Moisture conditions on the clearing can be partially controlled by varying the width of the area cut clear. With a narrow strip, the adjacent timber affords protection against sun and wind. Proper regulation of moisture conditions may make the difference between success and failure of the reproduction.

In both forms of the clearcutting method (with artificial or with natural reproduction) so far considered the entire stand has been cut clear. One or more stands will make up the annual cut of the forest. The forest should contain enough stands to permit of one or more being cut each year. 
In order to avoid too large clearings for reasons already considered or to be explained under "Advantages and Disadvantages," these stands are kept relatively small, or at least narrow in one dimension. Stands cut in consecutive years should be scattered throughout the forest so arranged that timber of seedbearing age is adjacent on one or more sides and that recently cut over stands are not contiguous. (See Fig. 4.)

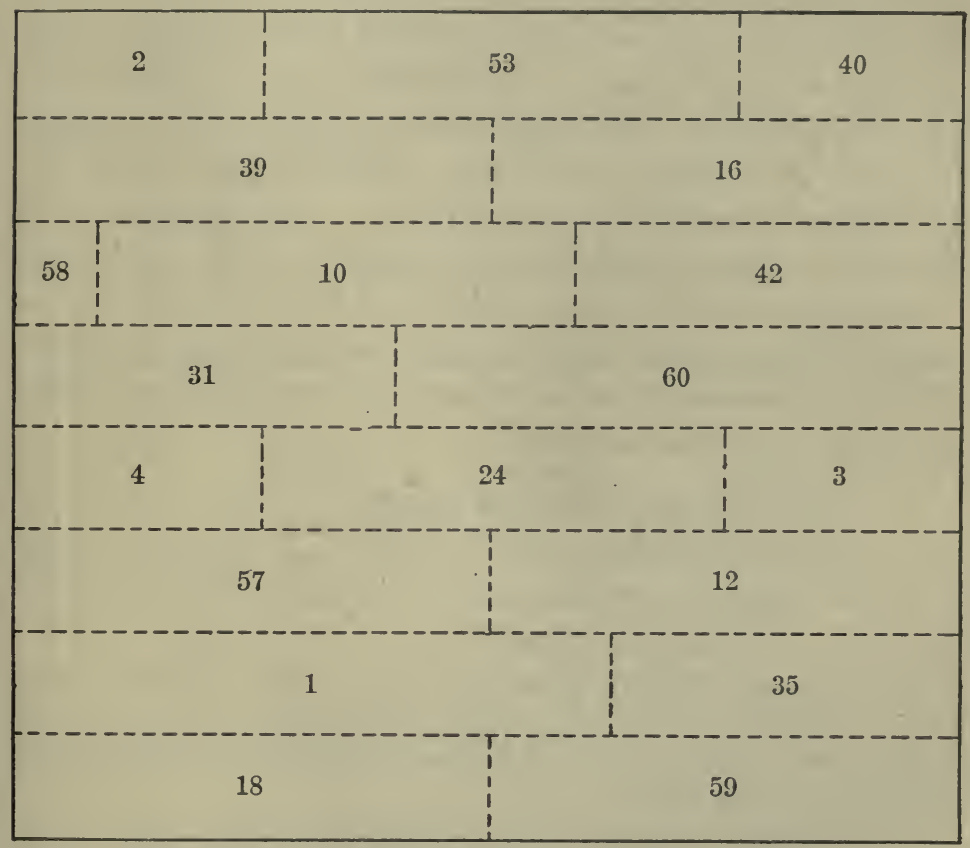

FIG. 4 .

Theoretical arrangement of a portion of the stands in a forest managed on a 60 year rotation and reproduced by clearcutting the whole stand. The numbers indicate the present age of each stand. For example the stand marked "I2" was cut over I 2 years ago and now is stocked with trees I 2 years of age. The one marked " 60 " will be cut clear during the present year. 
Modifications of the Method. - Modifications in application of the method, outside of changes in details which are expected to vary with each species and locality, affect principally the portion of the stand which is cut clear at one time. Under the ordinary meaning the term "clearcutting" implies the removal of the whole stand at one time. Where the individual stand is of large area it may take several years to complete the operation.

The reasons for extending a clearcutting operation through more than one year arises not entirely from logging considerations as to what can be covered in a year, although this may have weight. More important are the silvical requirements of the species, particularly available seed supply and conditions necessary for germination. These factors should determine whether the whole stand may be cut at one time.

Depending upon whether the timber is removed in one or more operations, and upon the relative size, shape and location of the portions cut in a single operation, the clearcutting methods may be classified as:

Clearcutting the whole stand

Clearcutting in strips

Alternate strips

Progressive strips

Clearcutting in patches.

The first method has already been discussed; it remains to consider the last two.

Clearcutting in Strips. - (A) Alternate Strips. Under this arrangement the stand is divided into a series of strips as shown in Fig. 5 and Fig. 6. The first strip is cut clear, the next left standing, the third cut, and so on throughout the stand. A few years later after reproduction is established, the timber on the uncut strips is removed. 
The two cuttings must occur close enough together in point of time so that the resultant stand is evenaged. From one to 20 years under ordinary circumstances represents the possible range of interval between the two cuttings. Three to ro years may be considered the average interval.

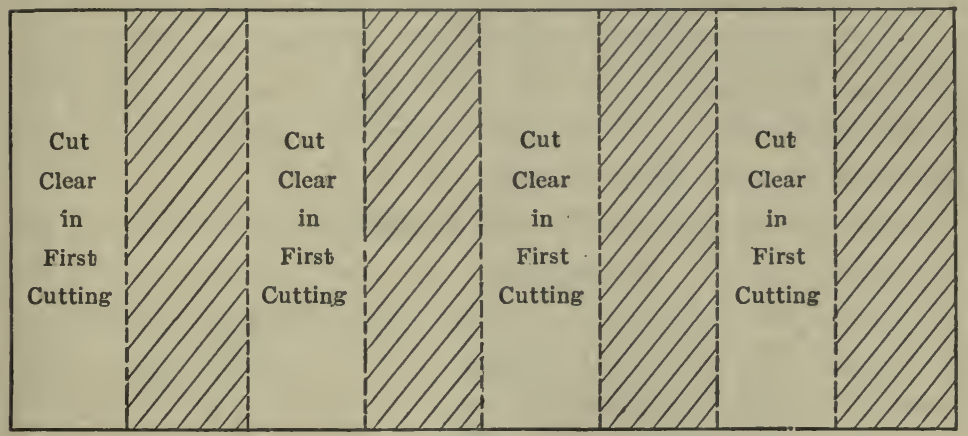

FIG. 5.

Illustrates the arrangement of the strips in a stand to be reproduced by clearcutting in alternate strips.

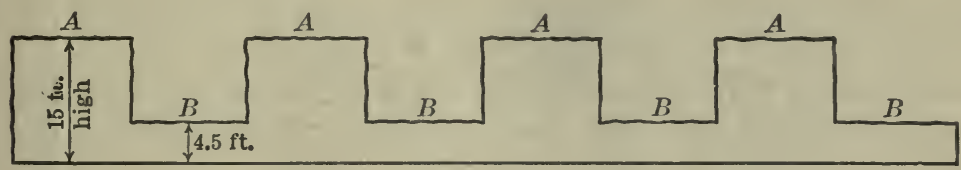

FIG. 6.

The same stand as shown in Fig. 5 ; but ten years after the clearcutting of the strips marked $A$ and five years after the clearcutting and reproduction by planting of the strips marked $B$. While there are now differences in height and age between the reproduction on the two sets of strips yet these differences are too small to cause the stand as a whole to lose its evenaged form. The difference in height will decrease as the stand grows older.

Reproduction may be secured either artificially or naturally. In general clearcutting the whole stand is used when artificial reproduction is to be employed. This is because the need for providing and distributing an adequate supply of 
seed and for creating ideal seedbed conditions becomes of importance only where dependence is placed upon natural reproduction.

The timber on the uncut strips furnishes a portion or all of the seed for stocking the uncut strips, to some extent favorably affects site conditions on uncut strips and affords protection to the seedlings which start. To perform these functions to best advantage the uncut strips must be relatively close together, and be located at right angles to the wind direction at seed dispersal time.

When the strips of timber left at the time of the first cut are removed, natural reproduction on these areas cannot be secured in the same way as on the strips first cut. There are no belts of timber left to furnish seed. The seed must come from the trees which are cut or else resort must be had to artificial reproduction. If a seed year can be selected as the time for making the second cutting successful reproduction may be secured. In many cases the cutting cannot be delayed until a good seed year. Under such circumstances in order to secure natural reproduction some other method than clearcutting may be used to reproduce the strips left standing at the first cutting. The seed tree or the shelterwood methods are commonly employed. Refer to Chapters IV and V. The use of either of these necessitates two or more cuttings to remove the timber, and hence lengthens the total period of regeneration. Reproduction may in some cases be hastened and made more certain by thinning the uncut strips at the time the first strips are clear cut.

The simplest and most satisfactory way of reproducing the strips left after the first cutting is to cut them clear and plant. This combines natural reproduction on the first strips with artificial regeneration upon the second.

In Fig. 5, 50 per cent of the area has been assigned to 
strips to be cut in the first operation and 50 per cent left for the second operation. This proportion is not a requirement of the strip method. (See Fig. 7.) From 30 to 70 per cent of the area might be cut in the first operation. Owing to the greater difficulties in securing natural reproduction on the strips cut in the second operation, 60 to 70 per cent (roughly two-thirds of the area) ordinarily should be cut over in the first operation. By making the uncut strips only half as wide as those cut this proportion is obtained. There is danger in making the uncut strips too narrow. They must be wide enough to offer protection to the cleared area, to be windfirm

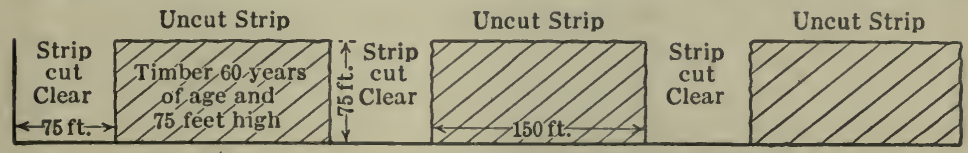

FIG. 7 .

Alternate strip method, where one-third of the area is cut clear in the first cutting. The cut strips are half the width of the uncut strips and equal in width to the height of the timber.

in storms and be large enough to make the second operation practicable as a logging proposition. In general the strips left should be at least as wide as the height of the timber.

Some windfall must be anticipated along the edges of the cleared area. This can be minimized by careful selection of the trees to be left on the borders of the strips. The strips cut for most species will range in width from two to four times the height of the stand.

(B) Progressive Strips. In this method three or more operations are required to remove the timber. Applied in its simplest form strip cuttings are made at short intervals starting at one side of the stand and advancing progressively across to the other side. (See Fig. 8.) 
The entire series of cuttings must be finished within a short enough period ( 10 to 20 years, depending on length of rotation), to make the new growth on the whole area evenaged if the method is to be classed as clearcutting. In large stands the entire area could not be cut over in a short enough time to produce evenaged timber and at the same time keep

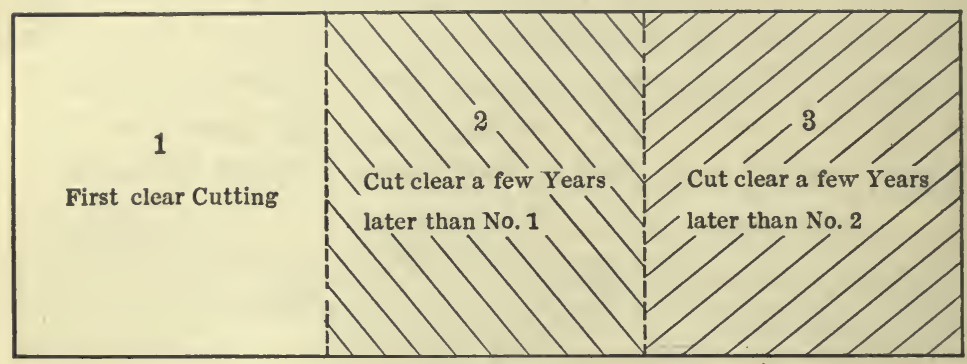

Fig. 8 .

A simple case of a small stand reproduced under the method of clearcutting in progressive strips.

the individual strip narrow enough to reproduce successfully unless more than one cutting series is initiated.

To overcome the difficulty several strips may be cut in one year, each in a separate cutting series as shown in Fig. 9 and Fig. 10. A large stand can be cut clear under this arrangement with as much protection to reproduction as may be secured in a small stand with a single cutting series. Reproduction may be secured either artificially or naturally. Where the latter method is used the uncut portions of each cutting series furnish seed and protection to seedlings. Each successive cutting should follow its predecessor as soon as reproduction is established on the last strip cut. This may vary from two to five years. If natural reproduction has not started in satisfactory amount at the end of five years, resort should be taken to artificial reproduction. 
When the time comes to cut the last strip of the cutting series artificial reproduction must be used or natural reproduction secured by some other method.

Clearcutting in Patches. - Where the topography is rugged and irregular in character, where soil conditions show wide

Cutting Series Cutting Series Cutting Series

Fig. 9.

Clearcutting in progressive strips, using three cutting series. The last strip (No. 3) in each series may be reproduced by a method other than clearcutting.

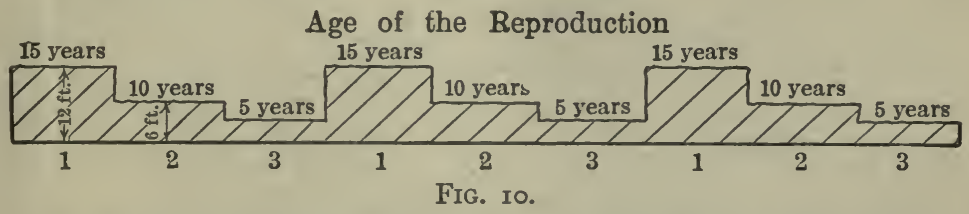

The same stand as shown in Fig. 9; but five years after the clearcutting and reproduction by planting of the strips marked 3. Despite the present difference in height and age the stand is evenaged.

range within relatively small areas and where the evenaged stand is lacking in uniformity, there the regular arrangement of cutting areas necessary under the strip method is impracticable.

The patch or group method, which is in reality merely an irregular strip method, can be employed instead. 
It requires two or more operations to remove the timber in a given stand. In the first cutting patches are selected which for some reason should be cut before the rest of the stand. A patch of injured trees or an opening in which seedlings are already springing up and which need more

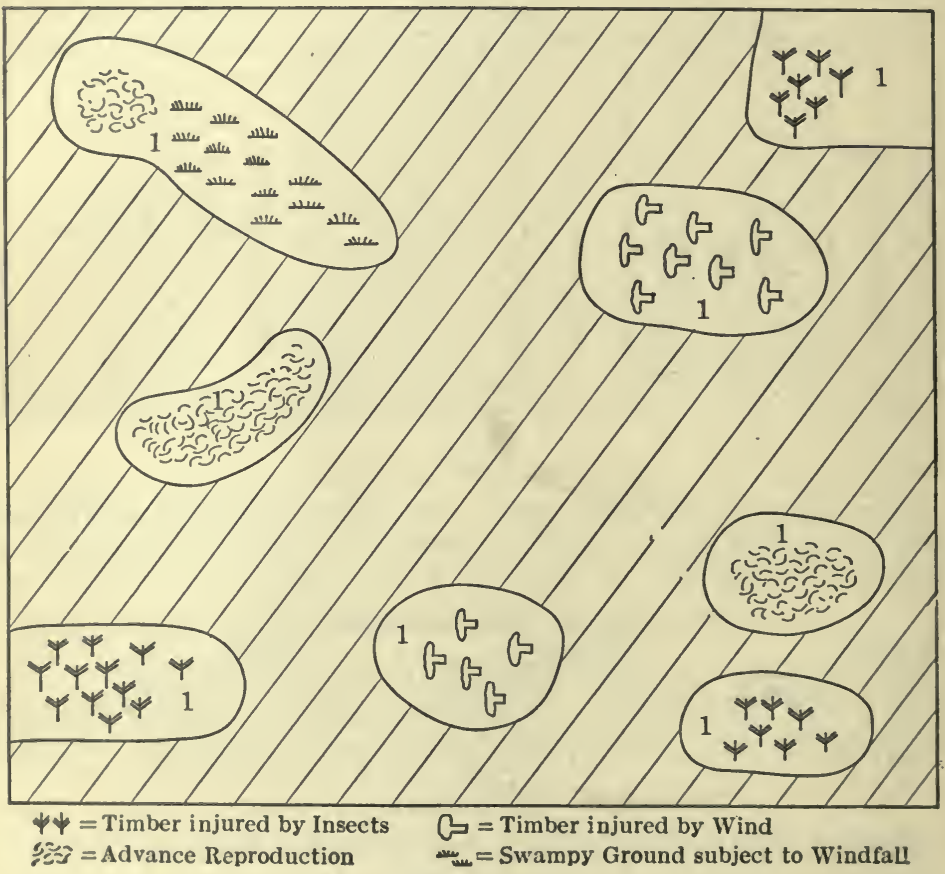

FIG. II.

Clearcutting in patches. Areas marked " 1 " are cut clear in the first operation. Their location is based on the condition of the timber as respects injury by wind or insects, presence of advance growth or location on swampy ground. In this illustration 26 per cent of the area is cleared in the first cutting.

light may determine the location of the first cutting. (See Fig. II.) Timber on swampy ground or on rocky knolls which if left exposed by adjacent cutting might be windthrown may 
be included in the patches cut in the first operation. Frequently the shape of the hills and direction of the slopes makes an irregular and patchy arrangement of the cutting areas advisable.

When the entire stand is removed in two operations the method resembles alternate strips in all details except the irregular shape of the cutting areas. When more than two

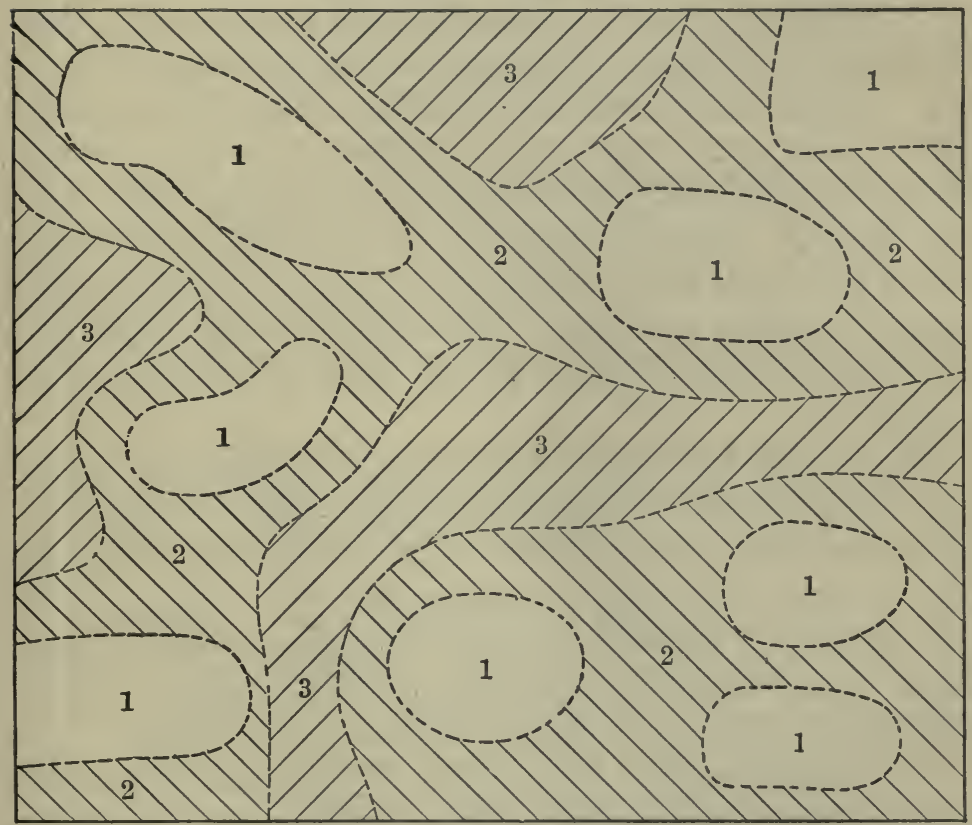

FIG. 12.

Same stand as in Fig. II showing the location of the three cutting operations used in removing the timber. The new stand will be evenaged in spite of minor differences in height and age. Areas marked " 1 " are cut in the first cutting; those marked " 2 " in the second and those marked " 3 " in the third.

operations are required to remove the timber it is similar to the progressive strip method except for the irregular shape of the cutting areas. (See Fig. I2.) 
Advantages and Disadvantages of the Clearcutting Method. - Advantages. - I. Best method for stands of overmature timber and for mature timber of large size. Silviculturally and financially such stands are ready for utilization. It is usually poor silviculture as well as impracticable from the logging side to cut large sized mature or over-mature timber otherwise than clear.

2. Logging is concentrated on relatively small areas. This tends to keep logging and transportation costs low.

3. Avoids loss of timber by windfall. Frequently on exposed slopes and ridges and on shallow soils and swamps where poor root development occurs, clearcutting is the only safe method. On soils which become saturated with moisture at seasons of the year when heavy winds prevail, clearcutting should be practiced. With shallow rooted species the necessity for clearcutting is greater than with deep rooted species.

Trees which have been grown under conditions of dense stocking show poor crown development and a correspondingly poor root system. With such timber clearcutting is often the only safe method of treatment.

4. When it is desired to change the species to one not now found in the stand, clearcutting is the best method. Artificial reproduction is a requisite in effecting this change.

5. Furnishes a bare exposed site for the start of natural reproduction. Where such condition is demanded by a given species for best reproduction clearcutting should be employed.

6. Clearcutting is simple and easy to practice.

7. The period of regeneration in each stand being confined to a small portion of the rotation permits use of the area for grazing during the remainder of the time.

Disadvantages. - I. The clearing of the area induces conditions which for most species are adverse to the growth of 
seedlings and render uncertain establishment of a satisfactory reproduction.

Such results may come from:

(a) Deterioration of the physical factors of the soil.

(b) Appearance of a grass, brush and weed growth which competes too successfully with reproduction.

(c) Exposure of reproduction to the drying influence of sun and wind, and to injury by frost.

(d) Greater activity of insects than is the case where reproduction is secured under the shelter of older trees.

2. Affords poor protection against erosion, landslides, snowslides and rapid run-off of water. In its protection value to the site and indirectly to other lands the clearcutting method ranks lowest and selection highest.

3. Esthetically is the least desirable of the four high forest methods.

These disadvantages are minimized as the size of the clearing is reduced, but correspondingly the advantage of concentrating logging and transportation on a small area is lost.

Application of the Clearcutting Method.-Clearcutting because of its simplicity and the high production of valuable timber possible in its evenaged stands has been extensively used in countries where forestry has been practiced longest, particularly with shallow rooted species like Norway spruce and where reproduction is secured artificially. In the United States clearcutting of extensive areas was and is the common practice of the lumbermen wherever the character of the timber enabled him to sell all the standing trees. Hundreds of thousands of acres have been left barren wastes through a careless or improper use of the method. As forestry practice develops there will be innumerable opportuni- 
ties for applying properly the different variations of clearcutting. Many conifers, such as Douglas fir and several of the southern pines, can be reproduced naturally following clearcutting. Cuttings in virgin timber, due to the large size of maturity of all individuals must in many instances, be of this type. Stands containing one or more inferior species frequently demand clearcutting and the establishment artificially of a valuable species to replace those now present. Work along this line is of intensive character and is being undertaken to-day principally on small tracts in the north Atlantic states.

Clearcutting with natural reproduction where seed comes from trees outside the area cut over is suitable only for relatively few light demanding and light seeded species capable of starting on exposed areas. Scrub pine in the region of its best development on the Piedmont Plateau might be successfully reproduced by this method.

With a species like Douglas fir where dependence can be placed on the seed supply stored in the forest floor clearcutting with natural reproduction should prove successful.

A good example of clearcutting with natural reproduction, the seed supply coming largely from cones stored on the trees removed in the cutting, is found in the case of certain evenaged overmature lodgepole pine stands. ${ }^{6}$

When the clearcutting can be made immediately following an abundant seed year, thus utilizing the current seed crop from the trees cut, the method can be extended in its application to a broader range of species.

Clearcutting the whole stand is especially suitable for areas to be reproduced artificially or where in organized forest naturally reproduced the area included in a single stand is small. The strip and patch modifications are useful in stands of large area or where detailed and intensive practice 
is possible. As yet they have been used to only a small extent in this country.

\section{REFERENCES}

I. Hofman, J. V. Natural Reproduction from Seed Stored in the Forest Floor. Journal of Agricultural Research, Vol. XI, Washington, I9I7, pp. 1-26.

2. Mason, D. T. Life History of Lodgepole Pine in Rocky Mountains. Bulletin I54, United States Department of Agriculture, Washington, I915, pp. 9-10.

3. Williamson, A. W. Cottonwood in the Mississippi Valley. Bulletin 24, United States Department of Agriculture, Washington, I913, pp. 33-37.

4. Sterrett, W. D. Forest Management of Loblolly Pine in Delaware, Maryland and Virginia. Bulletin II, United States Department of Agriculture, Washington, I914, p. 33.

5. Pearson, G. A. Management of Pine and Spruce in Sweden. Review of Skogsvardsföreningens Folksrifter, I-I2, No. I2, "Skogens Värd Ock Afverkning," by F. Aminoff. Proceedings of the Society of American Foresters, Vol. 9, I9I4, p. 452.

6. Mason, D. T. Utilization and Management of Lodgepole Pine in the Rocky Mountains. Bulletin 234, United States Department of Agriculture, Washington, I9I 5, pp. 25-26.

Bryant, R. C. Silviculture at Axton and in the Adirondacks Generally. Journal of Forestry, Vol. 15, I9I 7, pp. 891-893.

Fisher, R. T., and Terry, E. I. The Management of Second Growth White Pine in Central New England. Journal of Forestry, Vol. 18, 1920, pp. $358-363$.

Frothingham, E. H. White Pine under Forest Management. Bulletin I3, United States Department of Agriculture, Washington, I9I4, pp. 39-4I.

Hofman, J. V. The Importance of Seed Characteristics in the Natural Reproduction of Coniferous Forests. Studies in the Biological Sciences, Number 2. The University of Minnesota, Minneapolis, I9I8.

Matroon, W. R. Shortleaf Pine: Its Economic Importance and Forest Management. Bulletin 308, United States Department of Agriculture, Washington, I915, pp. 46-47.

Murphy, L. S. The Red Spruce: Its Growth and Management. Bulletin 544, United States Department of Agriculture, Washington, I9I7, pp. 48-5I.

ReckNagel, B. A. Some Aspects of European Forestry. Forestry Quarterly, Vol. XI, I9I3, pp. I35-I48. 


\section{CHAPTER IV}

\section{THE SEED TREE METHOD}

Definition. - The area is cut clear except for certain trees (called seed trees) left standing singly or in groups for the purpose of furnishing seed to restock naturally the cleared area. Only a small percentage of this total volume, ordi-

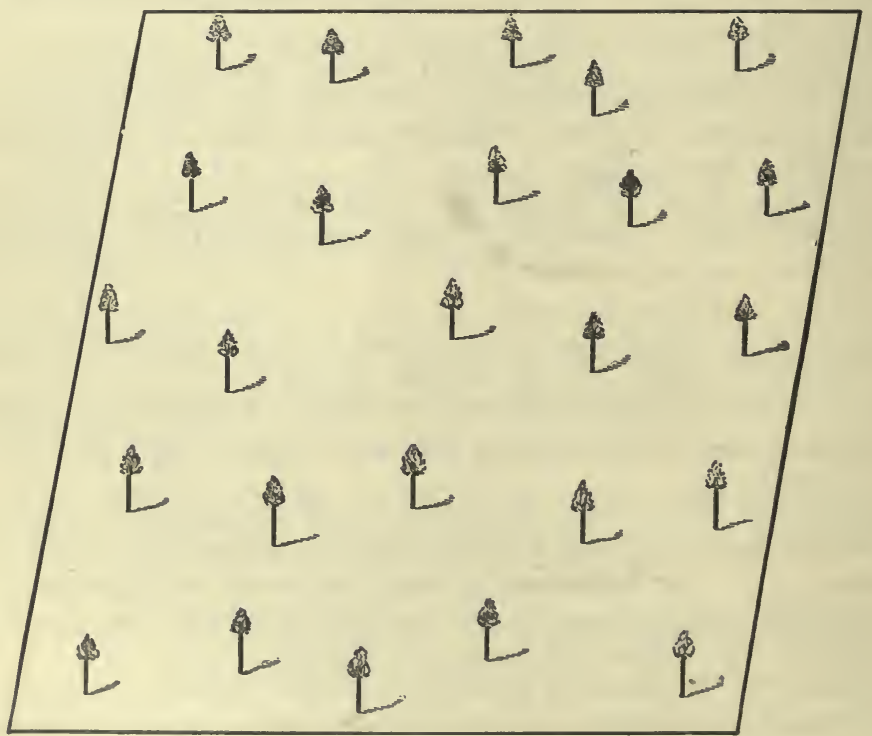

FIG. 13.

A stand reproduced by the scattered seed tree method, leaving approximately one seed tree per acre in fairly even distribution.

narily less than ro per cent, is left standing as seed trees. (See Fig. 13.) These seed trees after the new crop is estab- 
lished may be removed in a second cutting, or left indefinitely. In the latter case they usually are a total loss, rarely surviving in a sound condition until the end of the second rotation.

In some classifications the seed tree method has been included under clearcutting methods. The leaving of seed trees, together with the fact that the seed supply is furnished by these seed trees standing on the area cut instead of by trees, cut in the clearing operation or by trees standing outside the area cleared, warrants the separation into two methods.

Form of Forest Produced. - The seed tree method requires the same form of stand for its application as does clearcutting; namely, either evenaged or if containing more than one age class with all trees of merchantable size. As a result of the seed tree method an evenaged stand is produced. There may be a range of 10 to 20 years in age between the young seedlings which start on the cutover area, but not enough difference to prevent the stand being evenaged.

For a number of years immediately following the first cutting the stand presents a two-storied appearance, with the seed trees forming the upper story and the reproduction the understory.

In exceptional cases some or all of the seed trees may remain throughout the rotation. Where this occurs the stand may be termed either evenaged or two-storied depending on the number and per cent of the area occupied by the seed trees.

Details of the Method. - In the simplest form of the seed tree method the seed trees are left standing isolated as individuals after the removal of from 80 to over 90 per cent of the volume of the stand. Natural reproduction springs up under and around the seed trees in sufficient quantity to form a new stand. If conditions are favorable a single seed year may suffice to accomplish this. Frequently the seed trees produce several crops of seed before regeneration is completed. 
It is evident that since the seed trees are the source of the seed supply they must be selected with the greatest care. Windfirmness is a primary consideration so important that the scattered seed tree method cannot be used if the seed trees are easily thrown or broken by the wind. The isolated position of the trees makes them particularly susceptible to such injury. With shallow rooted species or on moist or shallow soils of poor holding capacity the scattered seed tree method is inapplicable. Even if the seed trees are not uprooted they may be broken off. This happens where the

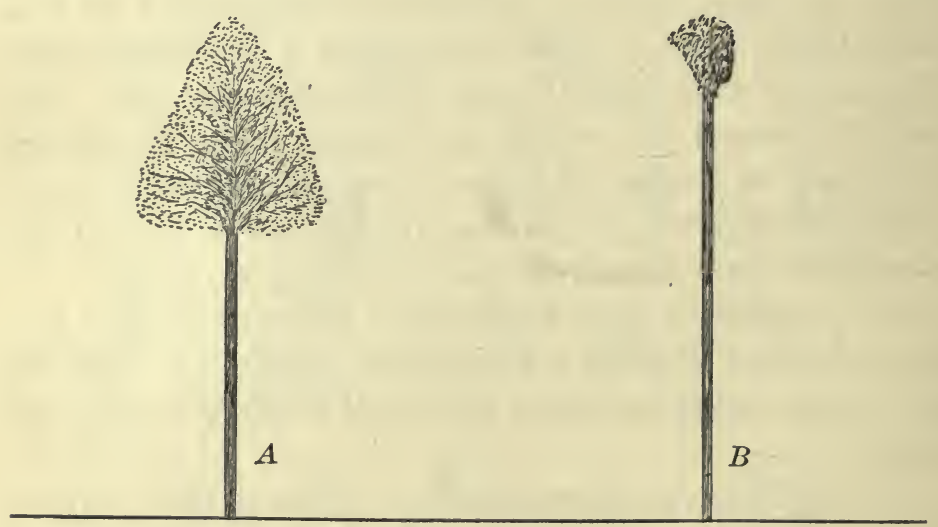

FIG. I4.

Good $(A)$ and poor $(B)$ types of seed trees. Tree $A$ with its wide and deep crown is wind resistant, capable of producing abundant seed and of making increased growth. Tree $B$ with its slim bole and tuft-like crown is weak and liable to be uprooted or broken by wind or scalded by sun and in addition is incapable of producing large seed crops.

stand was so dense before cutting as to produce tall slender trees. Some species appear more susceptible to breakage than others. Trees with open foliaged crowns are more likely to stand safely against wind than those with dense crowns. (See Fig. 14.) 
The seed trees must be old enough to produce abundant fertile seed. The age at which seed bearing begins in closed stands is the point which should be considered. Besides being old enough to bear seed the seed trees should be preferably of the dominant or at least of the co-dominant classes. Trees of the dominant class show the best crown development and may be expected to produce the largest amount of the best seed of any trees in the stand. The dominant trees are also among the stockiest and most strongly rooted trees.

Under "Definition" it was stated that the seed trees might either be removed after their function of establishing reproduction was performed or else left during the rotation in most cases to die before being harvested with the second crop. The selection of the seed trees will vary depending upon which of these two plans is to be followed.

If a second cutting can be made within a few years and the seed trees saved, then fine healthy dominant trees presumably the best seed producers and containing valuable timber may be selected. Where the seed trees are going to be left and must be considered as a total loss, then trees of a lower commercial value may have to be chosen. These may be the deformed or limby trees or trees attacked by fungi. As a general proposition it is unsafe and unwise to leave fungus infected trees if it can be avoided, because of the probable quality of the seed and seedlings produced, and the low vigor in resisting disease which trees from such stock may possibly inherit. Definite information as to the effect on future tree generations of different types of fungi is still fragmentary.

Investigations ${ }^{1}$ carried on at the Wind River Experiment Station, Carson, Washington, with Douglas fir indicate that conkiness caused mainly by Trametes pini reduces the yield of good seed per bushel of cones to 62 per cent of the normal and decreases the height growth of young seedlings in the 
nursery. But after five years growth in field plantations, seedlings from conky trees exceed those from sound trees in height growth. This particular fungus on Douglas fir, as it attacks only heartwood, may not affect the vitality of the tree.

Pearson's study of "the Influence of Age and Condition of the Tree upon Seed Production in Western Yellow Pine," 2 indicated that those affected with heart rot were apt to have a slightly higher germination per cent than sound trees, while mistletoe reduced the germination per cent. Seed from young trees (below I40 years) gave a higher germination per cent than that from older trees. Nothing is reported as to the quality of the seedlings produced by seed from these various classes of trees.

After fixing upon the kind of seed trees to be left the number per acre must be decided. The amount of seed produced per tree and the distance to which seed can be disseminated are among the principal determining factors. The very nature of the method requires that it be applied only with relatively light seeded species relying upon wind dissemination of the seed. Ample seed to restock all portions of the area must be provided. As a general rule with light seeded species satisfactory dissemination of seed can be counted on for a distance from the tree at least equal to the height of the tree. With large sized individuals of a decidedly light seeded species one tree per acre may be enough. The same species in small sized second growth timber may require ten per acre. A prolific seed producer, but with a heavy seed may need a similar number to insure uniform distribution. With site conditions favorable to germination and establishment of reproduction fewer seed trees will be needed than if the reverse is true. The necessity of securing reproduction either in one or during several seed years and whether the seed 
trees will be cut in a few years or remain also affect the number which can properly be left. From one to ten seed trees per acre may be regarded as the usual range.

If more than ten are left the crown spread of the seed trees occupies a considerable part of the area and the method begins to resemble shelterwood. At the other extreme a species is rarely found capable of disseminating the seed and thoroughly restocking an area if less than one seed tree per acre be retained.

When a species is diøecious, it will be necessary to provide for the leaving both of female and male trees. The cottonwood (populus deltoides) furnishes an example. In reproducing this species under the scattered seed tree method it is advised that one female tree be left to every acre and one male tree to every four acres. ${ }^{3}$

In order to secure adequate reproduction on all parts of the area uniform distribution of the seed trees should be attempted. It is more important to select the proper individuals to serve as seed trees than to attain an absolutely even spacing. Where the topography is uneven it will generally be best to leave a majority of the trees on the higher ground, from which vantage points they can scatter seed over the lower areas.

Destruction of the seed by rodents may be a serious factor. ${ }^{4}$ Where the supply is restricted to a few seed trees per acre the rodents may take the entire crop.

Just as in the case of the clearcutting method provision for an abundant seed supply is not sufficient; for in addition, favorable conditions for germination and early growth of seedlings must be established and maintained for a few years. Failure to apply the scattered seed tree method successfully may often be traced to neglect of this requirement. ${ }^{4}$

Disposal of the brush left by the lumbermen, removal of weeds, vines, shrubs and reproduction of undesired species 
and treatment of the soil are the measures by which the germination of seeds and development of young reproduction may be influenced. For details see page 29, under the Clearcutting Method.

The scattered seed trees assist in conserving surface moisture, and in protecting reproduction from injury by frost.

When enough seedlings to make a full stand have become established, the purpose for which the seed trees were left is accomplished. If it will pay financially the seed trees can now be removed leaving the new stand to develop unhampered. A portion of the reproduction will be destroyed in this cutting but not enough to seriously affect the new stand. Where a second cutting of this character is not feasible the seed trees are allowed to grow. Some few may live to be cut when the new crop is harvested and furnish material of exceptional size and quality. Most of them will succumb to the ravages of insects or fungi. Trees grown through life in a closed stand and then suddenly placed in an exposed position as seed trees suffer through changed site conditions and are apt to be weakened, suffer sun scald or become stagheaded and are susceptible to insect and fungi attacks.

The seedlings may start immediately after the first cutting or not for several years, depending on the occurrence of a seed year. If enough seedlings do not appear within five years it is unlikely that reproduction can be secured by natural means. Certainly not unless the expenditures for preparation of the site are repeated. The blanks should be filled by planting.

Modifications of the Method. - Group Seed Tree Method. One of the common variations is to leave the seed trees in groups instead of scattered singly over the area. The purpose of so doing is to minimize the danger of the seed trees being windthrown or broken. It is based on the theory that a group of trees standing together will stand unharmed against 
winds which would overturn or break the same trees if standing singly. This is probably the fact where all the trees available are relatively slender and small crowned. Such trees may have greater strength as a group than singly. In opposition to this field observations indicate that sometimes groups offer a greater resistance to winds, ${ }^{5}$ which are thus enabled to exert greater force against the group and often cause overturn or break all the trees in the group.*

The size of the seed group has of course great influence in determining its windfirmness. To be reasonably immune from windthrow a group should have length and breadth at least equal to its height. On exposed ridges or in moist ground groups of this size might be overthrown. Groups with breadth and width equal to their height are impracticable, requiring too great an investment for securing natural reproduction. Seed groups as ordinarily employed will contain from two to ten trees.

Except in reducing danger to the seed trees from wind the group seed method has nothing to recommend it in contrast to scattered seed trees. The distribution of seed to all parts of the area must be less even, unless a larger per cent of the total volume of the stand be reserved in the seed groups. If only the small volume percentage be retained as in the scattered seed tree method, then the distance between

* As an illustration the following is quoted from a circular letter, SI Protection-weather, Windfall Study, dated February 12, r9r5, sent from the Portland office to Supervisors of National Forests in District 6 of the U. S. Forest Service, speaking of windfall in yellow pine on a certain sale area.

"In groups of five or more trees there is considerably more windfall than where the trees are evenly distributed. Where there are sixteen or more trees in a group the loss is 13.4 per cent greater than where the groups are smaller. A good deal of the loss in groups comes from firm trees being knocked over or broken off by windthrown neighbors, or by their root anchorage being weakened by the uprooting of adjacent trees. This is on the principle that groups of trees do not give mutual support, but do give mutual resistance to the wind." 
groups will average longer than between single seed trees and are apt to become so great as to prevent dissemination of the seed over the entire area. This affects reproduction not only through a poorer distribution of the seed but also by reducing the slight amount of protection to soil and seedlings afforded by the scattered seed trees. (See Fig. I5.)

In a mixed stand a windfirm species sometimes can be included in a seed group for the purpose of furnishing support to a species easily windthrown which it is desired to reproduce. There is danger of course that the windfirm species may establish its own reproduction.

Reserve Seed Tree Method. - In certain cases the seed tree method may be applied not only with the idea of securing a new crop of natural reproduction but also with the purpose of reserving a portion of the mature stand for rapid increment during a second rotation. In this modification of the method the seed trees are selected not only for their capacity to furnish seed but also to grow rapidly, and remain thrifty during a second rotation. At the end of this second rotation the new crop is harvested together with the seed trees left at the beginning of the rotation. Some timber of exceptional size is produced.

The reserve seed tree method cannot be used with every stand. For its successful application the stand must be of moderate age when reproduced with the individual trees still thrifty and capable of withstanding the change in site conditions, due to the cutting, and of responding with increased growth. In stands past maturity this method cannot be successfully applied.

Dominant trees of as little present commercial value as possible are chosen: but they must be dominant, thrifty trees. As a rule healthier and better quality trees are left as seed trees than under the scattered seed tree method. The num- 
ber of reserve seed trees may vary depending upon whether emphasis is placed on the development of the stand or on the timber to be secured eventually from the seed trees. If the

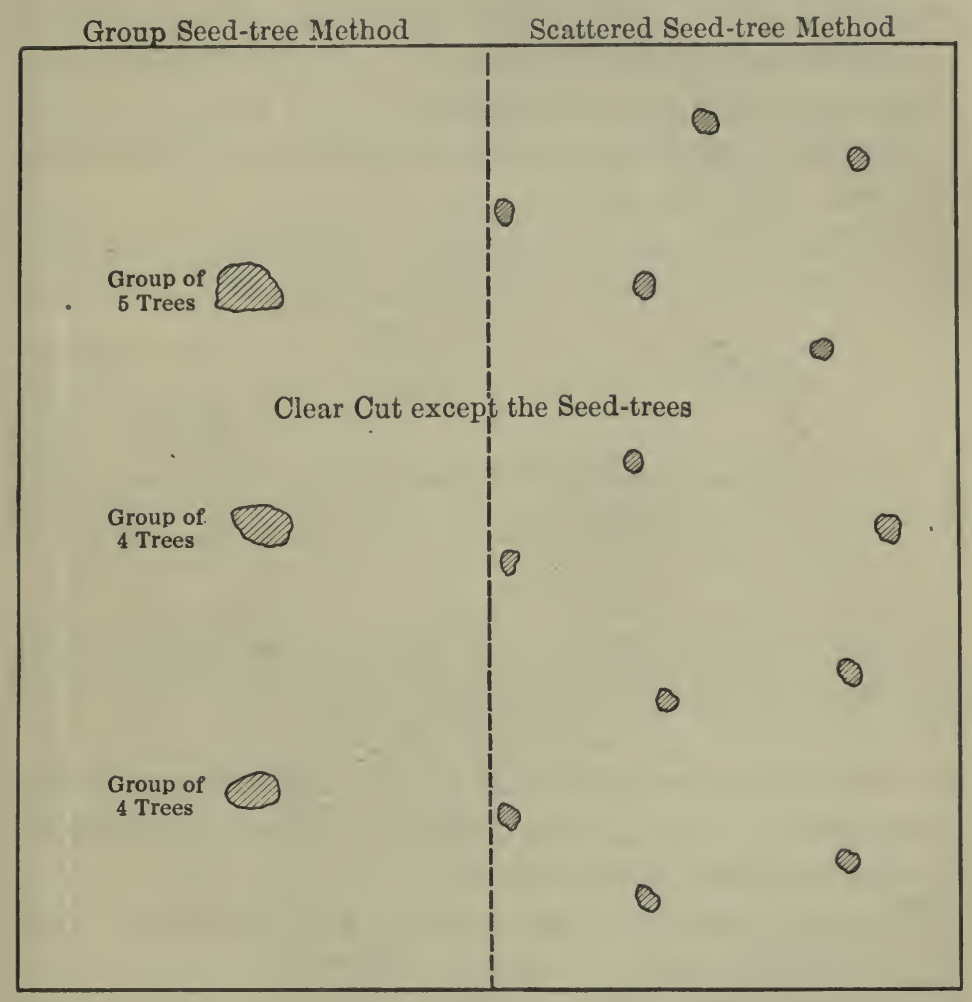

FIG. I5.

A comparison of the group and scattered seed tree methods where the same number of trees (and volume) are left in the stand under each of the methods. It is evident that dissemination of seed cannot be so uniform where the seed trees are arranged in groups as when distributed singly. The shaded areas indicate the portions of the tract occupied by the crowns of the seed trees.

new stand is to develop properly the reserve seed trees must be relatively few. If production of large timber is of primary 
importance the seed trees may be left as close together as rapid growth of the individuals will warrant. A distance of at least 30 to 40 feet should be left between the crowns of the reserve seed trees. This allows on the average for about 20 to 30 trees per acre as a maximum, or approximately twice as many as would be left under the scattered seed tree method.

The reserve seed tree method maintains a two storied form of forest. (See Fig. I6)

The advantages of the reserve as contrasted to the scattered seed tree method are that: better reproduction is

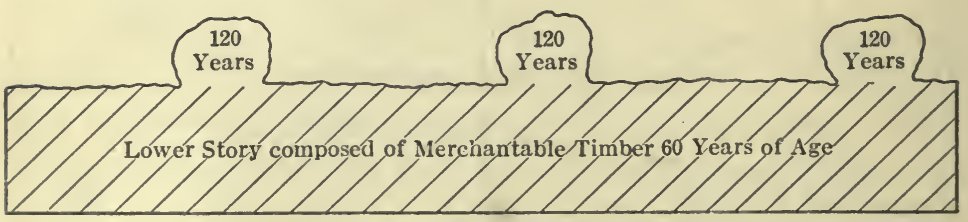

FIG. I6.

A stand ready to cut containing reserve seed trees. The form is two-storied. The large reserve seed trees will be removed and thrifty individuals selected from the lower story to remain during another rotation.

obtained due to the larger seed supply and increased protection furnished by the greater number of trees, and production of some large sized timber is secured.

The understory when harvested, is apt to be of low yield and poor quality due to interference from the upper story.

Fire Seed Trees. - It has been the practice of the United States Forest Service to retain on certain cutover areas, single scattered trees, which may be termed fire seed trees. These trees have been left after the final cuttings in various modifications of the clearcutting, seed tree and shelterwood methods. In most instances either reproduction already was established at the time the fire seed trees were left in their isolated position or other sources of seed supply were counted on to com- 
plete the reproduction. The purpose of the fire seed trees is then not primarily to establish the second crop. These trees are left as a measure of fire insurance. In case the reproduction is destroyed by fire the seed trees, due to their size and hardiness, are expected to escape and to provide the seed for restocking the burn. In some cases occasional large thickbarked Douglas fir which would escape fire have been left together with thrifty younger seed trees which would be killed by a severe fire. Species which are exceptionally fire resistant make ideal fire seed trees. Western larch is one of the best examples. This species has been left as fire seed trees in certain instances in the western white pine type in northern Idaho.

Fire resistant species cannot always be found to serve as fire seed trees. When less resistant species are used there is a question whether the fire which destroys the reproduction will not also kill the seed trees. It is also an open question as to whether the fire seed trees can successfully restock a bare burned area. If site conditions are unfavorable to natural reproduction it is unreasonable to expect restocking by scattered seed trees. If site conditions are favorable for natural reproduction it follows that artificial methods are possible. This being the case it is questionable whether the financial investment in leaving fire seed trees (unless of an exceptionally fire resistant species) is always justified. It may be cheaper to cut clear and to replace by artificial methods the occasional bodies of reproduction consumed by fire. Nevertheless when the fire danger is great and artificial regeneration on a large scale following fires might be needed over extensive areas the leaving of fire seed trees is fully justified.

Advantages and Disadvantages of the Seed Tree Method.Advantages. - I. Logging is concentrated on relatively small 
areas. This tends to keep logging and transportation costs low.

2. Furnishes a bare exposed site for the start of natural reproduction and hence may be a good method for those species which require such a germinating bed.

3. It stands next to clearcutting as a simple and easy method to practice.

4. The period of regeneration in each stand being confined to a small portion of the rotation permits use of the area for grazing during the remainder of the time.

5. As contrasted to clearcutting with natural reproduction it provides better control of the species in the reproduction on the cutover area since only individuals of species which it is desired to reproduce are left for seed trees.

6. As compared with shelterwood or clearcutting in two or more operations the seed tree method may be used, provided the trees are all of merchantable size, under more expensive logging conditions, since it does not absolutely require a second cutting.

Disadvantages. - $\mathrm{I}$. The virtual clearing of the area induces conditions which for most species are adverse to the growth of seedlings and render uncertain establishment of a satisfactory reproduction. (See under Clearcutting Method - Disadvantage No. I for further details.)

In the seed tree method exposure of the site takes place to a degree only slightly less than in clearcutting, with similar disadvantages.

2. Affords poor protection against erosion, landslides, snowslides and rapid runoff of water.

3. While æsthetically the seed tree method is to be preferred to clearcutting it does not commend itself from the standpoint of forest æsthetics as compared with shelterwood and selection. 
4. Due to the danger from wind in which isolated trees are placed, the seed tree method is applicable only with deep rooted species.

5. The method is restricted to species which have light wind disseminated seeds capable of germinating on clearings and developing thrifty seedlings under such circumstances.

6. The supply of seed is relatively scanty, compared with that available in the shelterwood and selection methods, coming as it does from a few seed trees.

7. As contrasted to clearcutting the seed tree method is not applicable in stands of overmature timber. Such stands may be past the age for producing abundant crops of fertile seed. The individual trees due to their large size and age are not well suited to be left as seed trees.

The disadvantages with the exception of numbers 4 and 7 are overcome to some extent when the reserve seed method is used.

Application of the Method. - The seed tree method so far has not been looked upon with favor in North America. This is due principally to the bad impression created by a few prominent examples ${ }^{6}$ of unsuccessful application. Ordinarily such failures have been caused by applying the method under conditions demanding some other method or by neglecting to properly attend to the details of application.

The scattered seed tree method was used in certain stands of white and Norway pine (Pinus resinosa) included in the Minnesota National Forest. This timber was evenaged old growth and as such not suited for reproduction by the seed tree method. Too few seed trees were left (due to legal restrictions) and those remaining were often poorly distributed. The preparation of the site for the establishment and development of reproduction was neglected. Is it surprising that the results so far as securing reproduction went were largely negative? 
Eventually the seed tree method should find frequent and successful use in forest regions where climate favors natural reproduction. In regions where natural reproduction is seriously handicapped by adverse climatic and site factors the seed tree method with its scanty seed supply and exposure of the site is out of place. Several of the southern pines, including loblolly, shortleaf and slash pines, should be easily reproduced by this method. Among the broadleaf trees, cottonwood, in some cases, can be managed by leaving seed trees.

Since the seed tree method can be applied with only one cutting which removes nearly all the timber it may find use where methods requiring more cuttings are too expensive.

\section{REFERENCES}

I. Willis, C. P., and Hofman, J. V. A Study of Douglas Fir Seed. Proceedings of the Society of American Foresters, Vol. X, I9I5, pp. I4I-I64; and Kraebel, C. J. Choosing the Best Tree Seeds. Journal of Heredity (Organ of the American Genetic Association), Vol. VIII, pp. 483-492.

2. Pearson; G. A. The Influence of Age and Condition of the Tree upon Seed Production in Western Yellow Pine. Circular 196, Forest Service, United States Department of Agriculture, Washington, I9I 2.

3. Williamson, A. W. Cottonwood in the Mississippi Valley. Bulletin 24, United States Department of Agriculture, Washington, I9I3, pp. 31-33.

4. Kenety, W. H. Report of Cloquet Forest Experiment Station. Bulletin 169 , The University of Minnesota, St. Paul, I917, pp. 59-60.

5. Munger, T. T. Western Yellow Pine in Oregon. Bulletin 4I8, United States Department of Agriculture, Washington, I9I7, p. I5.

6. Frothingham, E. H. White Pine under Forest Management, Bulletin I3, United States Department of Agriculture, Washington, I9I4, p. 46.

Howe, C. D. Address delivered before B. C. Forest Club. Proceedings of the British Columbia Forest Club, Vol. 2, Victoria, 1916, pp. 83-87.

Matroon, W. R. Shortleaf Pine: Its Economic Importance and Forest

Management. Bulletin 308, U. S. Department of Agriculture, Washington, I9I5, pp. 45-46.

Recknagel, A. B. Some Aspects of European Forestry. Forestry Quarterly, Vol. XI, I913, p. 475. 


\section{CHAPTER V}

\section{THE SHELTERWOOD METHOD}

Definition. - The principle of the shelterwood method involves the removal of the stand by a series of partial cuttings, resembling thinnings, that remove the entire stand within a period of years which is a small fraction of the rotation age. Natural reproduction starts under the protection of the older stand and is finally released from this shade and protection when able to endure the exposure. It is a logical further development of the seed tree method retaining large numbers of seed trees instead of a few.

The terms "stand" and "compartment" method have been used to describe the shelterwood method.

Form of Forest Produced. - The shelterwood method is best applied in evenaged stands, though it can be used in those of irregular form where merchantable age classes predominate. It produces an evenaged stand, thus resembling the clearcutting and seed tree methods. In some cases the reproduction cuttings may extend (when the rotation is long) over a period of forty to fifty years, which tends to create a wider range in the ages of the individual trees than occurs in the other two methods. Even with a long regeneration period the stand still remains essentially evenaged in character.

Details of the Method. - When using the shelterwood method, as its name implies, reproduction is secured under the shelter of a portion of the old stand. Besides furnishing the seed the old stand affords protection to the young seedlings. A time finally comes when this shelter instead of being 
a benefit is a hindrance to the growth of the seedlings. It becomes necessary to remove the remainder of the old stand, giving the new stand possession of the area and opportunity to develop in the evenaged form.

The whole process, including the securing of natural reproduction, its protection and final release from shelter, is accomplished within a relatively short period.

Several cuttings (at least two and sometimes six to ten) under intensive management, are required in applying the shelterwood method. They may be classed under three heads, as follows:

Preparatory cuttings which prepare for reproduction. Seed cuttings which accomplish the reproduction.

Removal cuttings which aid the development of the seedlings.

The detailed application of the method can best be presented by taking up each of these cuttings in turn.

Preparatory Cuttings. - If natural reproduction is to start under the old stand a supply of seed must be available and site conditions be favorable for germination of seed and establishment of seedlings.

With the entire stand available as a source of seed supply there should be an abundance of seed for restocking the area. In very dense stands where the best individual trees possess short narrow crowns and are poor seed producers, preparatory cuttings may be needed to encourage an enlargement of the crowns, to assist assimilation and as a consequence stimulate an increased production of seed. Ordinarily preparatory cuttings are not needed for this purpose. Their principal function is to create ideal site conditions for the germination of seed. In closed stands there is apt to be too thick and dry a forest floor for seedlings to get their roots down into.the soil. 
Decomposition of the litter can be hastened by admitting through cutting more light, heat and a free circulation of air. This is accomplished by the preparatory cutting. Too rapid and complete disintegration of the humus is possible and may allow a growth of grass and weeds to spring up. The right condition of seed bed for each species must be known and the severity of the preparatory cutting governed accordingly. (See Figs. 17 and 18. .)

When the mineral soil appears in spots here and there and small patches of grass and herbs start, then ordinarily the litter is sufficiently decomposed.

A minor object of the preparatory cutting may be in certain cases to develop windfirm trees which can safely be left isolated in the later cuttings. This is especially necessary in dense stands where the crown development of the individual - trees is poor.

It requires from three to ten years to accomplish the results for which the preparatory cuttings are made.

Preparatory cuttings range in number from one to several. In certain cases no preparatory cuttings at all are demanded. This is apt to be the case in stands which have been systematically thinned previous to the reproduction period. The number of cuttings depends on the length of time required to accomplish the purposes for which they are made and upon the necessity for making openings in a given stand only gradually.

The trees cut in preparatory cuttings may be selected from among five classes; namely:

Diseased and defective trees,

Overtopped trees,

Trees with over-developed and spreading crowns,

Slender small crowned trees liable to be windthrown, and Those of undesirable species. 


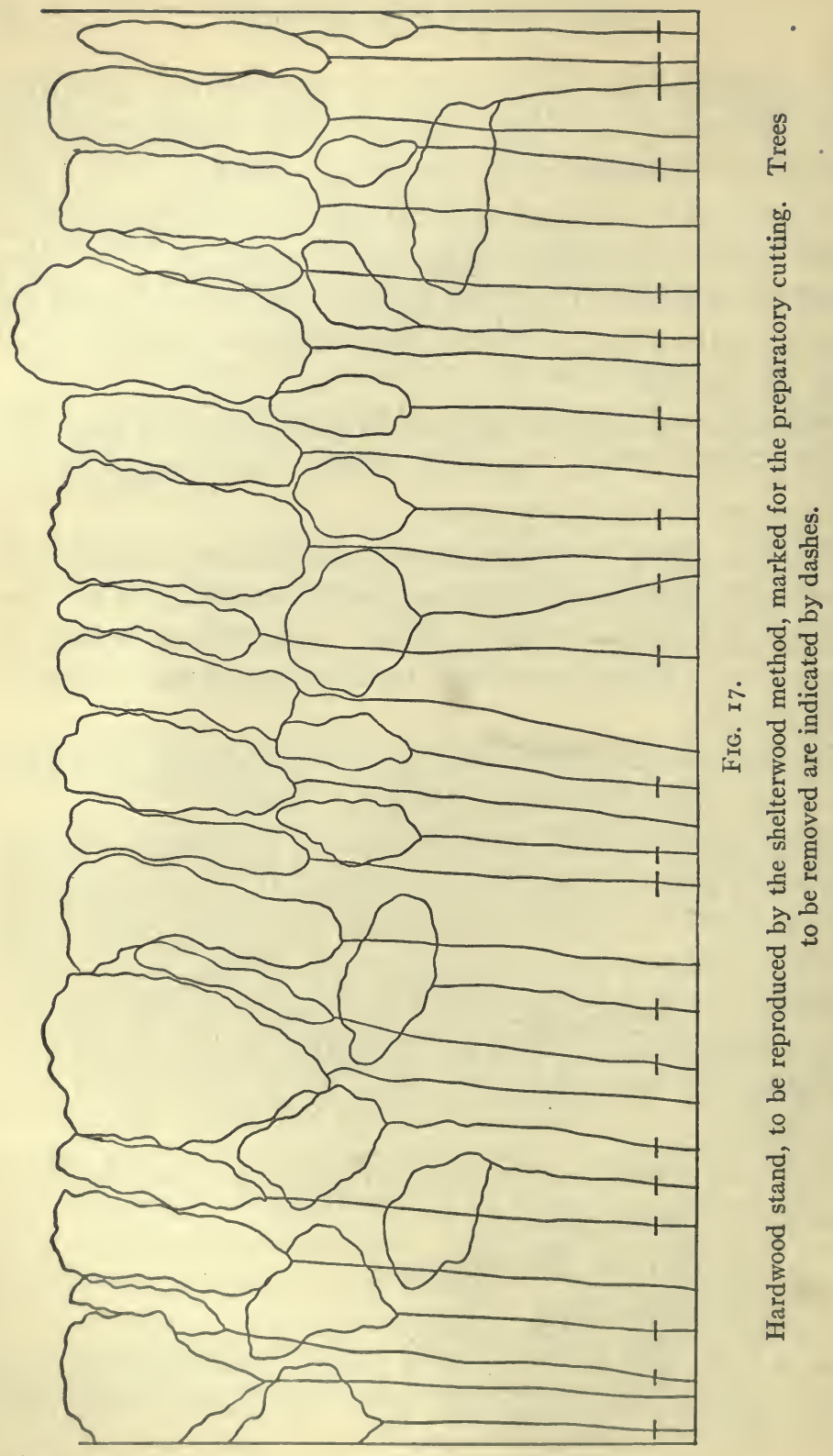


This leaves principally dominant and co-dominant trees. Ordinarily it is impossible to remove all the trees in these five classes without taking out a greater proportion of the stand than is warranted for accomplishing the purpose of the preparatory cuttings. Hence some of them must be left until later cuttings. The trees left should be so spaced as to provide an even crown cover over the area with spaces not more than three to five feet in width as a maximum between the edges of the crowns. In volume from 20 to 30 per cent of the stand should be cut in the preparatory cuttings.

Seed Cuttings. - The purpose of the seed cuttings (of which there should be only one) is to establish reproduction. The seedbed has been brought into excellent condition for the start of young seedlings. A seed year is awaited and when it arrives a cutting is made preferably just after the seed has matured. The logging serves to work the seed thoroughly into the thin humus and mineral soil. It finds here an ideal germinating bed with an abundance of light and heat made available as a consequence of the reduction in the forest cover.

If a perfect seedbed has been created and a plentiful supply of seed deposited upon it and mixed with the soil then a complete reproduction may be secured. Unfortunately such a combination is difficult of attainment. If it is apparent that the preparatory cuttings have failed to create the proper seedbed conditions they may be produced artificially. Such methods as preparing seed spots at close intervals, plowing furrows under the trees, or turning in hogs to work up the soil and humus may be employed. For further details in reference to treatment of the site see under Clearcutting, page 30.

Rarely is it necessary with the shelterwood system to resort to artificial restocking of failed places. Action of this sort would be taken only as a last resort when it was seen that natural seeding had proved a failure. 
The trees selected for removal in the seed cutting are of the same general classes as those taken in the preparatory cuttings. Should it be necessary to take out more trees than those kinds designated for removal in preparatory cuttings the poorer individuals in the co-dominant and dominant classes are cut.

The severity of the seed cutting is governed by the distance to which seed may be distributed and by the amount of shade which it is necessary to maintain in order to assist germination and to protect seedlings from drought, frost and rank growths of grass and herbs. In as much as the balance of the stand must be removed after reproduction is started and with considerable injury to the latter, it is advantageous to take off as much of the old stand as possible in the seed cutting. The amount removed should range from 25 to 50 per cent of the volume of the original stand before preparatory cuttings were begun.

It is not necessary that the distribution of the trees left be absolutely uniform, although reasonable uniformity is attempted. In fact an uneven distribution, provided the open areas among the old timber are kept small, may not be unfavorable to the seedlings in their competition with the older trees for soil moisture. In the seed cutting advantage is taken of all groups of advance growth, which may have started accidentally or as an unlooked for result of the preparatory cuttings. Over such groups the seed cutting is heavy and may even remove all the old timber. Usually three to five years elapse before the seed cutting is followed by a removal cutting.

Removal Cuttings. - Removal cuttings have as their object the gradual uncovering of the new crop which finally is given complete possession of the area. There may be one or (usually) several removal cuttings, the last of which is called the final cutting. The severity of the removal cuttings and 


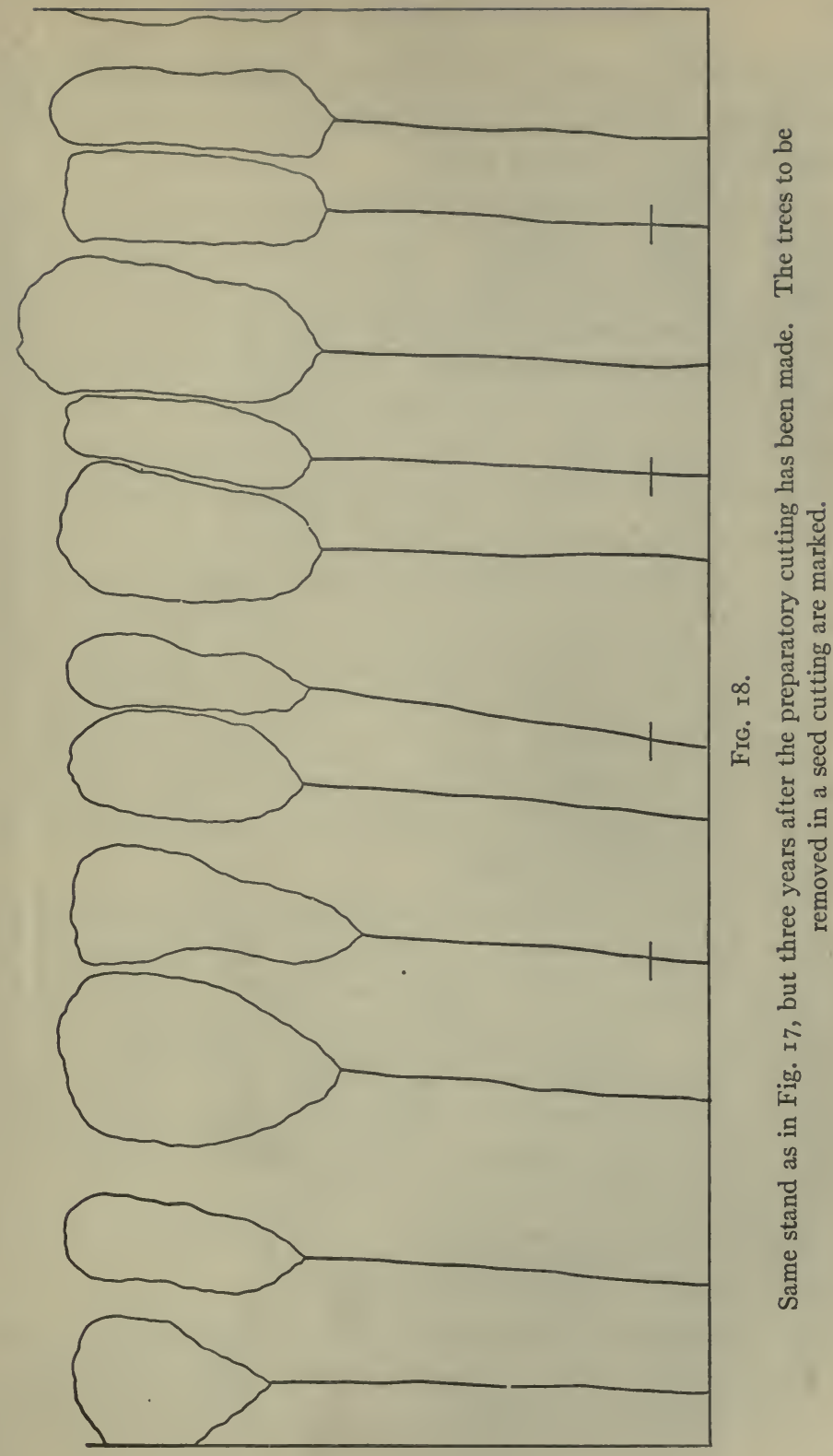


the intervals at which one follows the other are governed by the degree to which the young stand needs protection or is suffering from too much shelter.

After the reproduction is established it is watched for indications of poor condition. Such points especially as unhealthy color of the foliage, falling off of height growth and bending aside toward the light are taken as showing the need of less shade and competition. This condition of the reproduction is not likely to be found uniformly over the whole area, at any one time. On the contrary a patch here and a patch there will probably require treatment. Hence the removal cuttings are not made evenly over the whole area. A group may be cut clear here, a few trees thinned out in other places, while elsewhere there may be no cutting. A few years later other places need a similar cutting, and the process continues until at last all the old timber is harvested (see Fig. I9).

Removal cuttings are likely to be needed at intervals of two to five years and to cover a period of from two to 20 years. They utilize the remaining 25 to 50 per cent of the volume of the original stand.

Each removal cutting does some injury to the young stand. Where proper methods are enforced in felling trees and in hauling the $\operatorname{logs}$ to the roads this injury is not of serious consequence. Hauling out the logs with single horses makes narrow lanes through the reproduction and minimizes the damage from this source. While the trees in being felled will destroy many seedlings, yet this loss will rarely interfere with a full stocking of the area.

Modifications of the Method. - The shelterwood method may be applied in a given stand either:

(a) Uniformly over the entire stand. - the uniform method

(b) In strips, strip shelterwood

(c) In groups or patches, group shelterwood. 


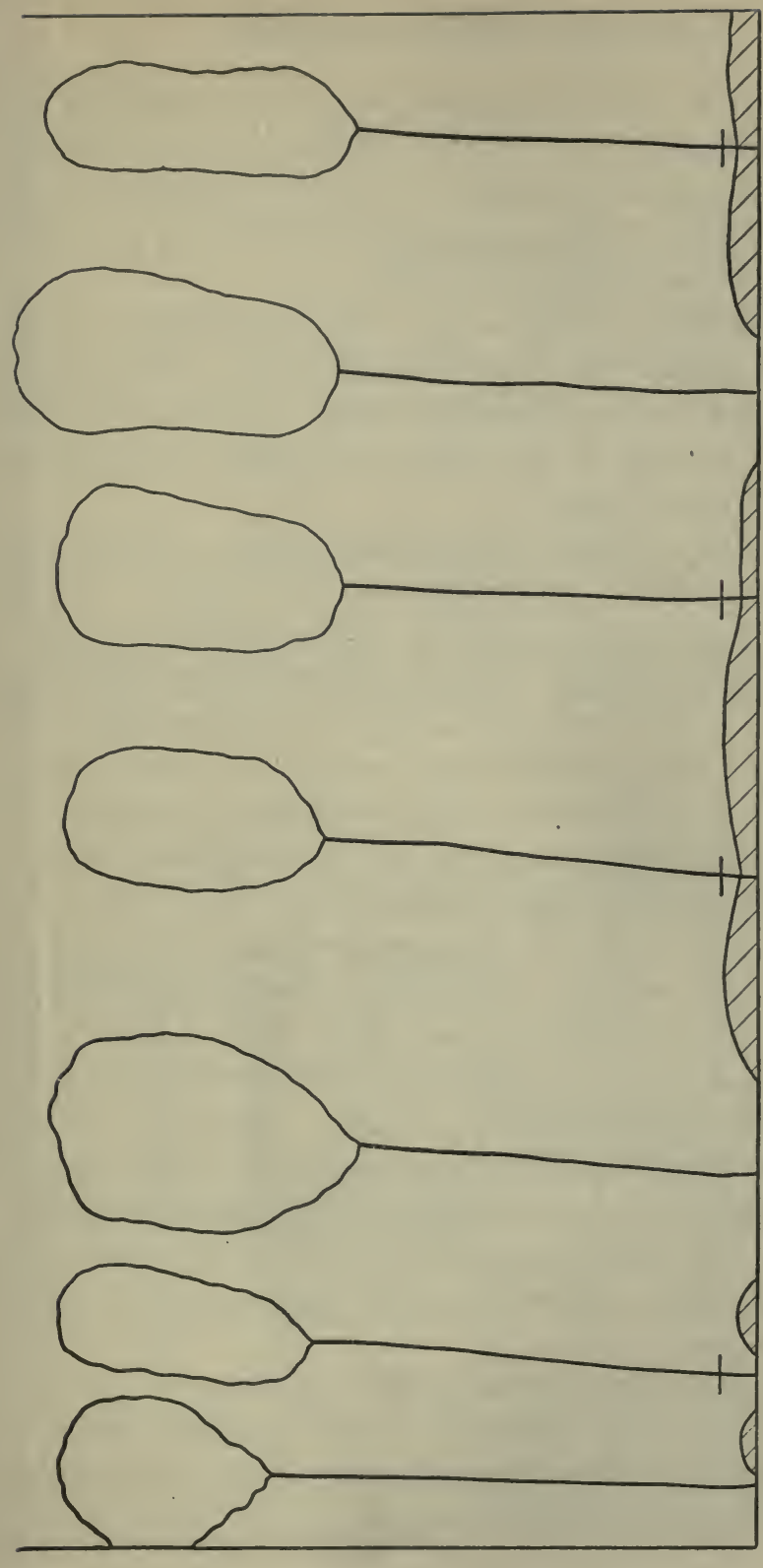

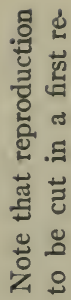

过

造

도ㅇㅠㅠ

.

㫕

ర్ల

o்

$\rightarrow$ 도

نำ 
The details as already described relate particularly to the uniform application of the method although in the strip and group modifications essentially the same procedure is followed except that a given cutting is extended over a portion only instead of over the entire stand.

Strip Shelterwood Method. - In this modification of the shelterwood method the stand is divided into strips laid out at right angles to the prevailing winds. Starting with the strip on the lee side of the stand the cuttings are made to progress against the wind.

The first strip receives a preparatory cutting. After a few years it may receive another preparatory cutting or a seed cutting, while at the same time the adjoining strip is given a first preparatory cutting. A few years later the first strip may receive a seed cutting or a first removal cutting, the second strip a second preparatory cutting or a seed cutting and a third strip be given a first preparatory cutting. In this manner (see Fig. 20 and Fig. 2I), the series of cuttings progress strip by strip across the stand.

There appear to be two advantages of the strip arrangement over the uniform application. Better protection is afforded against windfall since part of the stand is kept intact as a windbreak and no considerable areas on which the trees stand isolated are left at any one time. Better or quicker reproduction should be secured because of the extra amount of seed furnished by the trees on the adjoining strip which is less heavily cut, and because the side shade and protection against evaporation afforded by this strip should conserve the soil moisture.

Since complete reproduction can be counted on in less time the strip modification allows a decrease in the number of cuttings required to remove the whole stand and consequently those which are made may be heavier. 


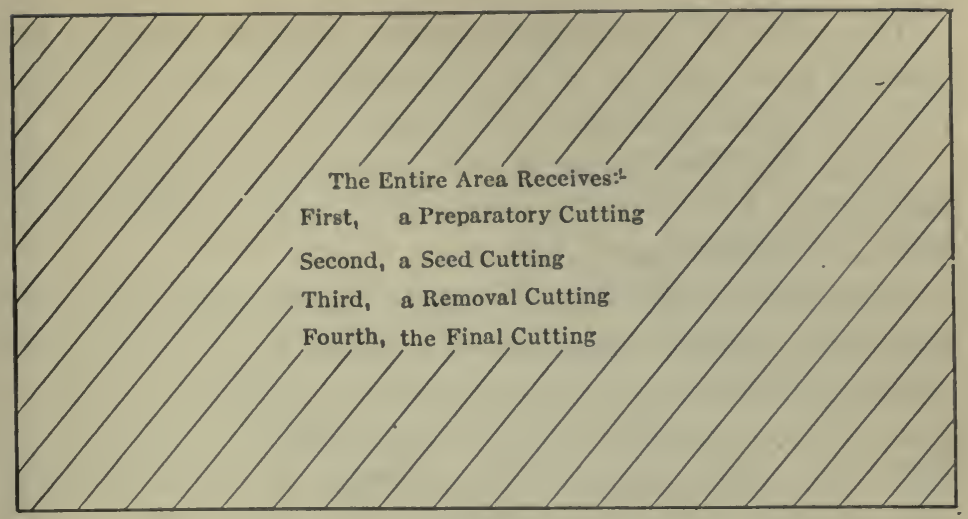

Fig. 20.

Diagram of a stand reproduced by the shelterwood method, each cutting being applied uniformly to the entire area. Compare with Figs. 21 to 24 .

Cutting Series No. 1

Cutting Series No. 2

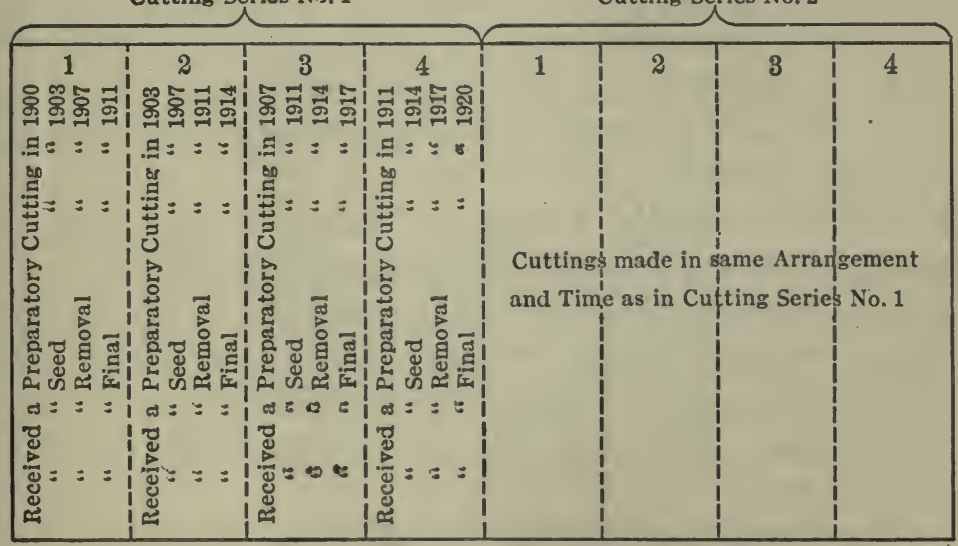

FIG. 2 I.

Diagram of a stand reproduced by the strip shelterwood method. Two cutting series are used. The period of regeneration is 20 years in length and the stand is kept in the evenaged form. 
The width of the strips depends upon the danger from windfall and upon the extent to which side shade and conservation of soil moisture are desirable.

Strips should rarely be less than Ioo feet in width, and if wider than 500 to 800 feet lose the inherent characteristics of a strip shelterwood cutting.

The length of the period of regeneration remains the same as under the uniform application of the method. If the strips must be made narrow and the stand is a large one, it may be necessary to establish several cutting series in order to complete the reproduction cuttings within the allotted period. For discussion of the use of several cutting series refer to clearcutting in strips on page 32 .

Strip shelterwood does, not necessarily cause any greater range of age between the individuals of the new stand than does application uniformly over the entire area, since the period of regeneration is the same in the two cases. The differences in age are not noticeable because the average ages of the trees on the strips first operated are greater than those on the strips in which cuttings start later. The total range of ages is so small as not to interfere with the evenaged character of the stand.

Wagner's "Border Cuttings." - Wagner ${ }^{1}$ developed in practice on a forest in Wurtemberg a modification of the strip shelterwood method which in this country has received the name "Border Cuttings." 2 Heralded as something quite new in silviculture it reduces in the last analysis to strip shelterwood with exceedingly narrow strips (less than Ioo feet in width).

Group Shelterwood Method. - Commonly in evenaged forests, particularly in those which have undergone thinning or had their regularity disturbed by natural agencies such as wind, insects or fungi, it happens that when the beginning of 
the period of regeneration is reached, groups of advance reproduction are already present. The groups may range from a few trees to considerable areas of young growth and from seedlings a few years old up to trees of sapling size.

Where this condition exists the reproduction cuttings are made, not uniformly over the area, but irregularly and entirely with reference to the special requirements of each group of advance reproduction. The first cutting made, which may be called a primary cutting, combines removal cuttings (including the final cutting), seed cuttings and preparatory cuttings all in the one operation. Where the advance reproduction is largest the cutting removes all of the old trees and is thus a final cutting. Where reproduction shows indications of too severe competition with the overwood, but is not yet capable of being left without some protection, a removal cutting, taking part of the old timber, is made. Where reproduction has not started as yet, but seedbed conditions are suitable for its establishment, a seed cutting is executed. Finally, in the denser portions of the stand if any cutting at all is made, it will be in the nature of a preparatory cutting. Ordinarily each group of advance reproduction serves as a center from which the cutting radiates. Over the higher reproduction at the center of the group a final cutting is made. In a belt surrounding this center, removal cuttings are made decreasing in severity as the younger reproduction toward the edges of the group is reached. In a belt encircling the group of reproduction a seed cutting takes place, while beyond this area a ring of forest receives a preparatory cutting. Beyond this ring the forest remains untouched.

After a few years when conditions indicate its desirability, another cutting called a secondary cutting is made of the same character as the primary cutting, uncovering additional areas of reproduction and extending the removal, seed 
and preparatory cuttings over additional territory. (See Fig. 22 and Fig. 23.)

At intervals additional successive cuttings are made steadily broadening the area cut over until finally the various groups which served as original starting points are expanded until they merge one with the other and the entire stand is reproduced. (See Fig. 24.)

The period allotted to reproduction cuttings under the group method may be of the same length as that used in uniform and strip shelterwood, but since advance reproduction (often 20 to 30 years old) is already present when reproduction cuttings commence, the range in age between individual trees of the new stand is apt to be wider than in the two latter methods. The stand can in most cases still be classed as evenaged.

Group shelterwood, when employed on a long rotation with a correspondingly long period of regeneration, approaches in form of forest that produced under the selection method, as will be better understood after consideration of the chapter on selection.

Extensive versus Intensive Application - The discussion of the shelterwood method has up to this point related particularly to its intensive application.

Shelterwood, requiring as it does several cuttings on the same area within a relatively short period, inherently is best adapted for employment under conditions allowing intensive management. Only in regions where the market allows sale of lower grade products, such as cordwood, and where a permanent road system exists, that permits easy access to all parts of the forest, can the shelterwood method be applied intensively.

The method meets so well the silvical requirements for reproduction of several important species that modifications to 


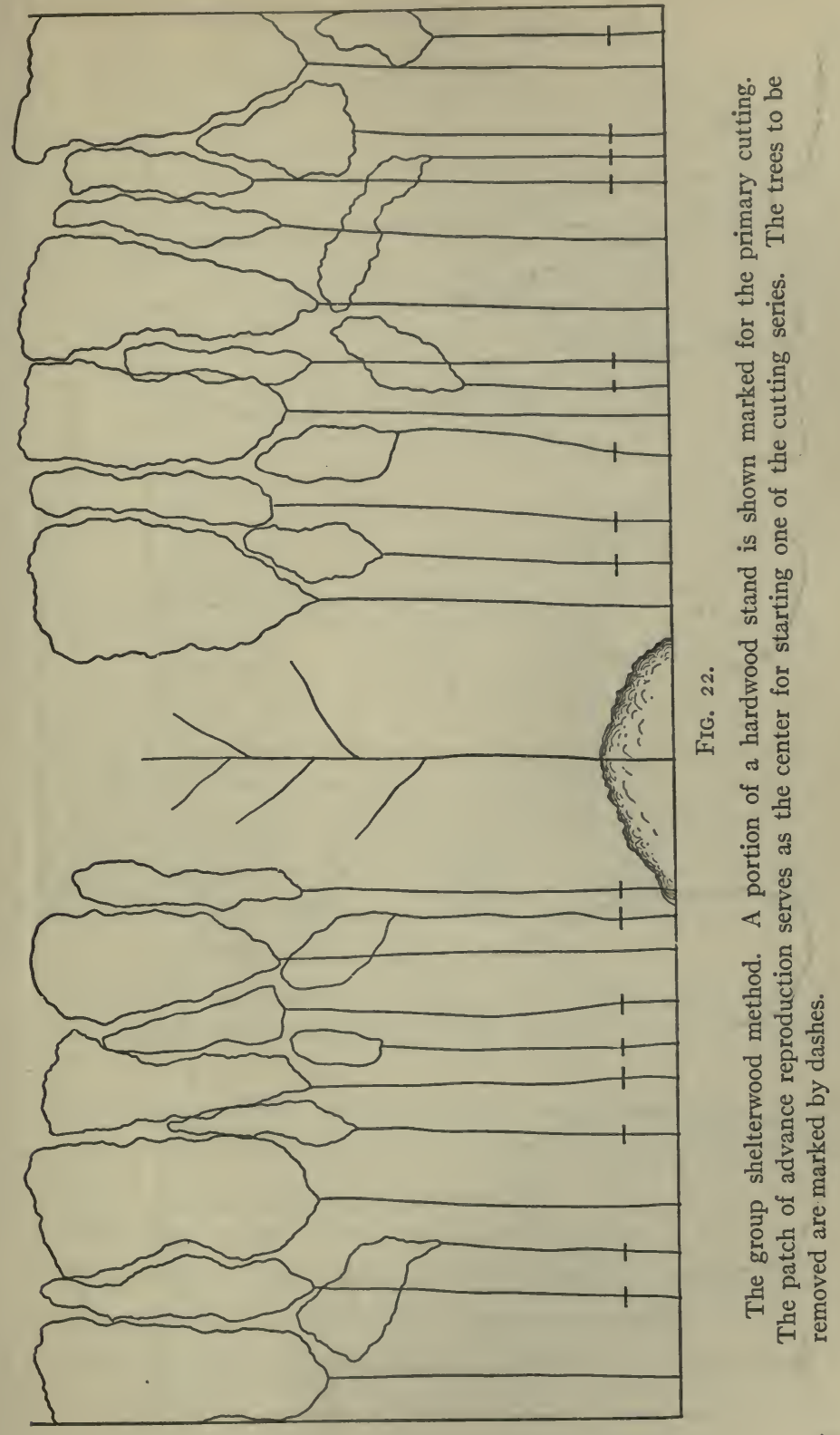




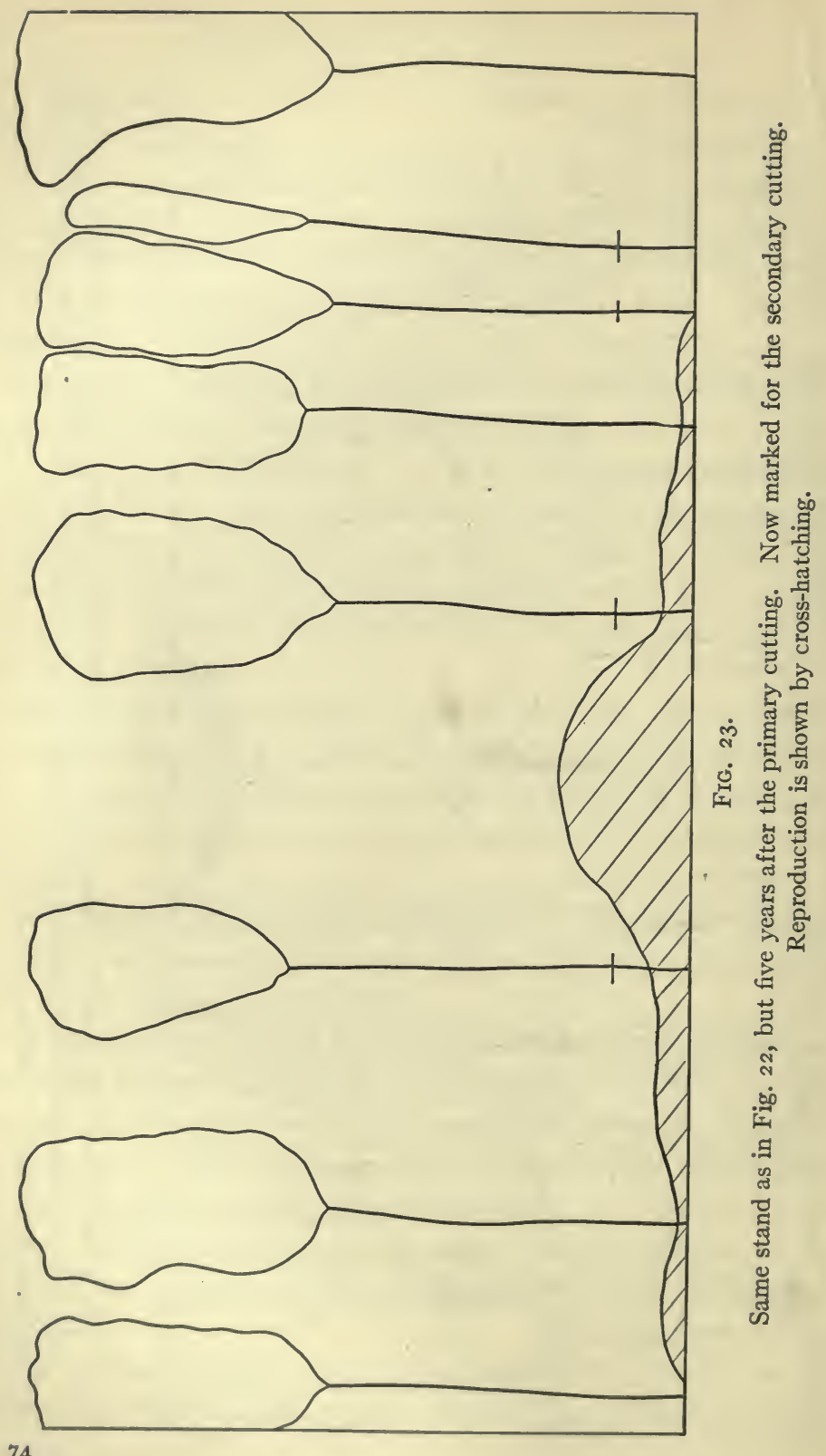




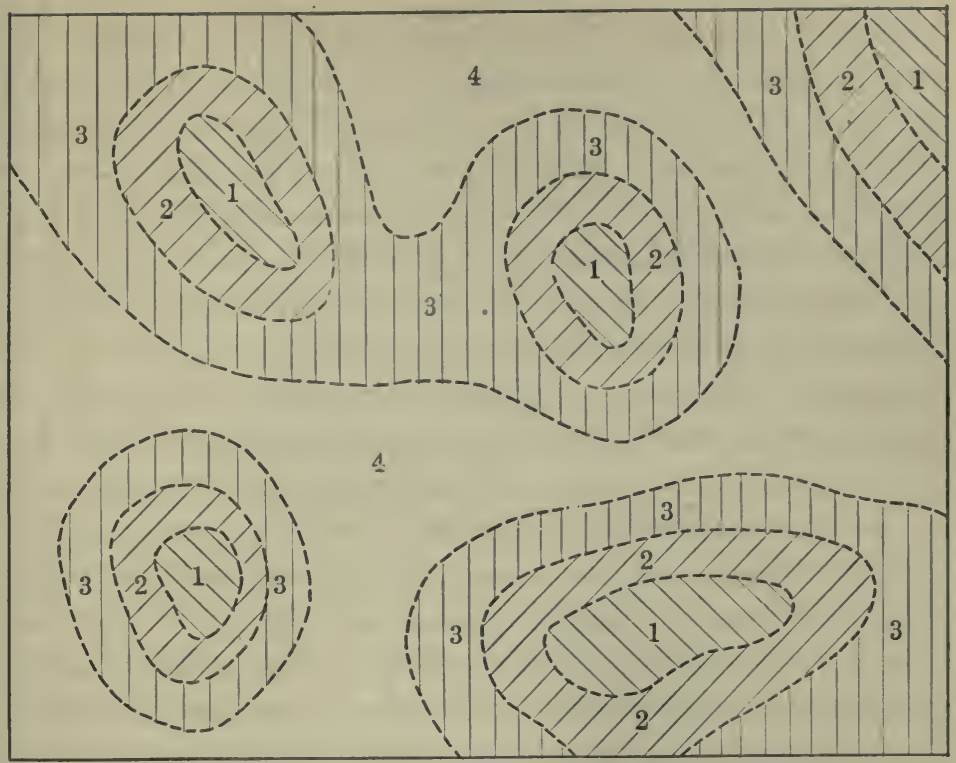

\begin{tabular}{|c|c|c|c|c|}
\hline \multirow{2}{*}{$\begin{array}{c}\text { Character } \\
\text { of Cutting }\end{array}$} & \multicolumn{4}{|c|}{ Areas Marked:- } \\
\cline { 2 - 5 } & 1 & 2 & 3 & 4 \\
\hline $\begin{array}{c}\text { Preparatory and Seed } \\
\text { Cutting combined }\end{array}$ & \multicolumn{4}{|c|}{ Received Cuttings in Years as follows:- } \\
\hline Removal Cutting & & 1900 & 1905 & 1910 \\
\hline Final Cutting & 1900 & 1905 & 1910 & 1915 \\
\hline
\end{tabular}

FIG. 24 .

Arrangement of the cuttings in a stand reproduced by the group shelterwood method. Advance reproduction was present on areas marked " 1 " before the cutting.

permit its application in an extensive way under poor market conditions and in the absence of permanent roads have been developed.

Summarized, these modifications consist in:

Reducing the total number of cuttings to two or three,

Lengthening the period of regeneration, and

Omitting all refinements for securing a complete restocking. 
Under extensive application no preparatory cuttings are made. Instead of such cuttings the natural opening up of the stand with old age or by accidental factors is relied upon to produce seedbed conditions favorable to the start of reproduction. In some instances cuttings are deferred until considerable reproduction is already established under the original over-mature stand, and in this.case no seed cutting is required.

Nature then frequently accomplishes the purpose of the preparatory and seed cuttings and enables the forester to commence his work with the removal cuttings. This fact furnishes one of the reasons why the shelterwood method may be so often successfully applied in an extensive manner. Opportunities for its use occur principally in stands of virgin timber which are opening up and deteriorating.

It is not necessary that reproduction be already on the ground when the first cutting is made or that the best conditions exist for the start of reproduction, although this latter is desirable.

The first cutting will have for its purpose the partial uncovering of reproduction already established and the establishment of reproduction on areas not yet stocked. While partaking of the character both of a seed cutting and a removal cutting it may be termed a seed cutting. Forty to 75 per cent of the volume is taken out. The trees cut are those of the same general character which would be selected for removal in the preparatory and seed cuttings of the method when applied intensively.

The virgin stands in which extensive application most frequently takes place usually contain a large percentage of defective trees. Frequently the problem in the first cutting is to find enough trees which can be profitably left until the next cutting. Good health, windfirmness, capacity for seed production and favorable location with respect to areas 
which require restocking or groups of reproduction which need shelter, together with the length of time before the second cut, govern the selection of the trees to be retained. Ten to 50 years after the seed cutting a second one called the final cutting is made, taking out all the remaining trees of the old stand, completing the reproduction cuttings and producing an evenaged stand. A 50 year interval between the two cuts is altogether too long for the best silvicultural results, even on a long rotation such as 200 years. Wherever market and logging conditions permit, the final cutting should follow the first within 20 years.

Advantages and Disadvantages of the Method. - Advantages. - I. Heavy seeded species whose seeds are distributed principally by gravity can be successfully reproduced as well as light seeded species. Shelterwood thus stands in contrast to the clearcutting and seed tree methods under which it is difficult if not impossible to secure adequate dissemination of heavy seeds.

2. Reproduction is more complete and certain than under the other methods of high forest which produce evenaged stands (clearcutting and seed tree methods). This is because of the greater number of seed trees which are present during the time reproduction is being established and the resulting larger crops of seed produced and available on all parts of the area.

3. Shelterwood is only exceeded by selection in its protective value. The ground is never bare of a forest cover. Even during the period of regeneration the old stand furnishes protection until reproduction is fully established against erosion, landslides, snowslides and rapid runoff of water. Excessive growths of grass and herbaceous cover are kept in check, while seedlings are sheltered from the drying influence of sun and wind and from injury by frost. Less injury from insects 
to young trees may be anticipated than where reproduction takes place on clearings.

4. While inferior to selection in the maintenance of æsthetic effects shelterwood is superior to all other high forest methods producing evenaged stands. This is particularly noticeable during the period of regeneration, when forests treated under the clearcutting and seed tree methods do not present an attractive appearance.

5. Since shelterwood is the only high forest method producing evenaged stands which furnishes shade and shelter to seedlings, it is the best method to use with species which can be reproduced naturally only under such conditions and for which evenaged stands are desired.

6. The period of regeneration in each stand being confined to a small portion of the rotation permits use of the area for grazing during the remainder of the rotation.

Disadvantages. - I. Shelterwood cannot be applied when there is great danger from windthiow or breakage since many trees stand isolated during the regeneration period. The danger may be minimized by several preparatory cuttings designed to develop windfirm individuals The inherent ability of the species to withstand windthrow and breakage as well as the relative exposure of the site to strong winds determine the importance of this disadvantage. With a species easily injured by wind or on much exposed sites some other method besides shelterwood should be employed. If the method can be applied intensively with numerous cuttings following one another at short intervals considerable windfall need not interfere with its successful application. The damaged trees are salvaged at each cutting. Should injury by wind affect a large portion of the old stand at any one time the results might be serious.

2. Shelterwood for intensive application demands economic 
conditions making profitable the removal of the stand in several cuttings. To justify such operations there must exist:

A market for small sized and low grade forest products (particularly cordwood).

An organization of the logging so arranged that the same area can be operated at short intervals for a period of years necessary to establish reproduction. This increases the expense of logging, requiring, as it does, an extension of the time within which a specific amount of timber is taken from a given area, and considerable care to preserve reproduction in felling and transporting trees from the felling area.

As explained under "Extensive versus Intensive Application," page 76, shelterwood, shorn of its refinements, can be used in a crude way under comparatively poor market conditions.

3. Greater technical skill is called for in applying shelterwood than is needed in the case of the clearcutting and seed tree methods. When selection is used with an equal degree of intensiveness it calls for more technical skill than does shelterwood.

4. Part of the reproduction is destroyed in the removal cuttings. Where the proper care is exercised the inevitable destruction of some young trees in the logging will not reduce the reproduction below the point of full density. Careful work to keep damage to reproduction at a minimum tends to increase the expense of logging as previously stated.

Application of the Shelterwood Method. - As yet the economic conditions permitting the intensive use of shelterwood are found in relatively few sections of the country. East of the Great Plains and north of Mason's and Dixon's line there are many districts where to-day cordwood is salable and 
logging can be so arranged as to permit shelterwood cuttings. Numerous instances of this use can be found on the small tracts typical of thickly settled districts.

Many of the heavy seeded hardwoods, particularly the oak family, are species which can be best managed under shelterwood.

Species such as red spruce, eastern balsam and eastern white pine, ${ }^{*}$ which under certain circumstances desire partial shade and protection for reproduction, frequently can be successfully handled by the shelterwood method.

For parks and estates where æsthetic effects are desired along with production of timber in evenaged stands shelterwood should be chosen.

Shelterwood extensively applied, i.e., with two cuttings, is suitable for all evenaged stands where the individual trees are mainly of merchantable size and condition but not overmature. Throughout the western United States, where in many places conservation of soil moisture and protection from sun and wind is essential for the success of natural reproduction, a crude form of shelterwood can often be applied. The pure forests of western yellow pine found in the Black Hills ${ }^{3}$ of South Dakota furnish a good illustration. Natural reproduction in this region starts so abundantly under a par-

* An illustration can be drawn from a permanent sample plot established in 1905 in a 53 year old white pine stand at Keene growing on a gravelly sand of second quality.

Two cuttings have been made, a light one (preparatory cutting) in I900 followed by a heavy one (seed cutting) in rgo4 which left the crowns of the remaining trees a few feet apart. Igo4 was a heavy seed year. At the time of establishment in I905 over II,000 white pine seedlings per acre were present nearly all from the 1904 seed crop. In 1909 seedlings up to 18 inches in height to the number of 4000 per acre still persisted under the shelter of the old stand. The overwood was cut clear in the winter of I912-13. In I9I5 there was an average stand of 1500 white pine seedlings per acre ranging up to four feet in height. The stand had been successfully reproduced by the shelterwood method. 
tial (or in some cases under a complete cover) as to make a two cutting shelterwood method successful.

Many western yellow pine stands elsewhere in the west will undoubtedly be treated in a similar manner. The principal difficulty under the economic conditions existing in the western yellow pine regions is to make the second and final cutting soon enough after the first cutting for the best silvicultural results to the young stand. A 30 to 60 year interval may have to elapse between cuttings.

As a general thing neither the economic situation nor the silvicultural condition of the stand justifies an intensive application of shelterwood in stands of old growth timber. In such stands reproduction is apt to be present in greater or less amount and the cuttings may be begun in the removal cutting stage.

Old growth timber is rarely found to-day located close to good markets and susceptible of intensive treatment.

Second growth stands younger, more regular and made up of trees of smaller size than the virgin timber, offer better opportunities for management under the shelterwood method.

\section{REFERENCES}

I. Wagner, C. Grundlagen der Raumlichen Ordnung im Walde. Second edition, Tubingen, I9II.

2. Recknagel, A. B. Border Cuttings - A Suggested Departure in American Silviculture. Proceedings of the Society of American Foresters, Vol. VII, I9I2, pp. I45-I 52.

3. Sмiтн, P. T. A Silvicultural System for Western Yellow Pine in the Black Hills. Proceedings of the Society of American Foresters, Vol. X, I9I5, pp. $294-300$.

Bericht uber den Waldbaukurz in Langenbrand im September, I9I3. Forstwissenschaftliches Centralblatt, Berlin, I9I4, pp. 87-97.

Fisher, R. T., and Terry, E. I. The Management of Second Growth White Pine in Central New England. Journal of Forestry, Vol. 18, 1920, pp. $35^{8}-363$. 
Frothingham, E. H. White Pine under Forest Management. Bulletin I3, United States Department of Agriculture, Washington, 1914, pp. 42-43.

Mrtchell, J. A. Incense Cedar. Bulletin 604, United States Department of Agriculture, Washington, I9I8, p. 34 .

Moore, B. The Sihlwald, an Example. American Forestry, Vol I7, I9I I, pp. $531-536$.

Recknagel, A. B. Some Aspects of European Forestry. 4. Natural Regeneration in the Black Forest. Forestry Quarterly, Vol. II, I9I3, pp. 330-339.

Sieber-Ernsee, Ph. Ueber Natürliche Verjüngung. Forstwissenschaftliches Centralblatt, I9I4, pp. I8I-r95.

Smythies, E. A. Sylvicultural Systems of Regeneration in Chir Pine Forests. The Indian Forester, Vol. 39, Dehra Dun, I9I3, pp. 513-525.

Sterretr, W. D. The Ashes: Their Characteristics and Management. Bulletin 299, United States Department of Agriculture, Washington, I9I 5 , pp. $42-43$.

Troup, R. S. Pinus Longifolia, Roxb. A Sylvicultural Study. The Indian Forest Memoirs, Vol. I, Part I, Silviculture Series, Calcutta, I9I6, pp. $8 \mathrm{I}-99$.

Woolsey, T. S., JR. Natural Regeneration of French Forests. American Forestry, Vol. 26, 1920, pp. 77-81.

Woolsey, T. S., JR. Cutting Western Yellow Pine in Arizona and New Mexico. Proceedings of the Society of American Foresters, Vol. 9, I9r4, pp. $479-5 \circ 3$. 


\section{CHAPTER VI}

\section{THE SELECTION METHOD}

Definition. - According to the principle of the selection method the oldest or largest trees in a stand are chosen for cutting, and the remainder are left. After one or more years another cutting of the same character is made. This process is repeated at intervals throughout the rotation. The trees taken in a single cutting may occur singly or in small groups. A stand is never completely cleared off, but instead small openings are made here and there. After each cutting reproduction should start in the openings just created. The necessary seed will be furnished by the trees standing around the openings.

Form of Forest Produced. - From what has been said it is evident that cuttings under the selection method must produce an unevenaged form of forest. Such form is not a necessary condition for starting the method. Evenaged stands ordinarily contain trees of considerable range in diameter. By selecting at each cutting the largest (if not the oldest) trees, an evenaged stand may be reproduced under the selection method ${ }^{*}$ and eventually converted into unevenaged form.

A stand ideally suited to a selection method of cutting should contain trees of every age class from one year seedlings to veterans of the rotation age. Such stands are not found in Nature, but are most nearly approximated in virgin forests.

* An exception to this statement occurs where the smaller trees in an evenaged stand lack the power of recovery from their suppressed condition, or are so small crowned and spindling as to be windthrown, injured by sun-scald, etc. 
But in virgin forests (ordinarily considered all-aged) certain of the younger or middle age classes are lacking, or not represented in the right proportion and the stand is apt to be composed either of mature trees of about the same height and differing comparatively little in age ${ }^{1}$ or else to be of the twostoried character, each story being of practically the same age. Since it is virtually impossible in Nature to find all age classes represented in a single stand, a forest is considered an all-aged or selection forest if a few broad age classes, each of 20 to 50 year range, are represented.

Details of the Method.-In theory the oldest age class is cut each year, the next oldest removed in the following year, and so on indefinitely. Reproduction springs up in the openings immediately after cutting. By the time all the age classes in an all-aged stand have been cut over once seedlings started on the area occupied by the age class which was cut first will have matured. Thus in a true selection stand an old age class ripe for cutting will be available each year. (See Fig., 25 and Fig. 26.) The volume of this age class will be equivalent to the annual growth of the stand. Each age class should occupy its proper per cent of the area. For example, if there are a hundred age classes, each class should have one hundredth of the crown space allotted to it; and then if one hundredth of the area, in this instance, is each year, actually cleared of trees or uncovered, only the trees belonging in the oldest age class will be removed. Since the trees making up the oldest age class are scattered it is necessary to work through the whole stand to find them and to conduct logging operations over the whole area each year.

In practice certain changes in this theory are demanded both from the logging and the silvicultural standpoints. The annual working of the whole area to secure a small cut per acre makes logging relatively expensive. Seed trees do not 


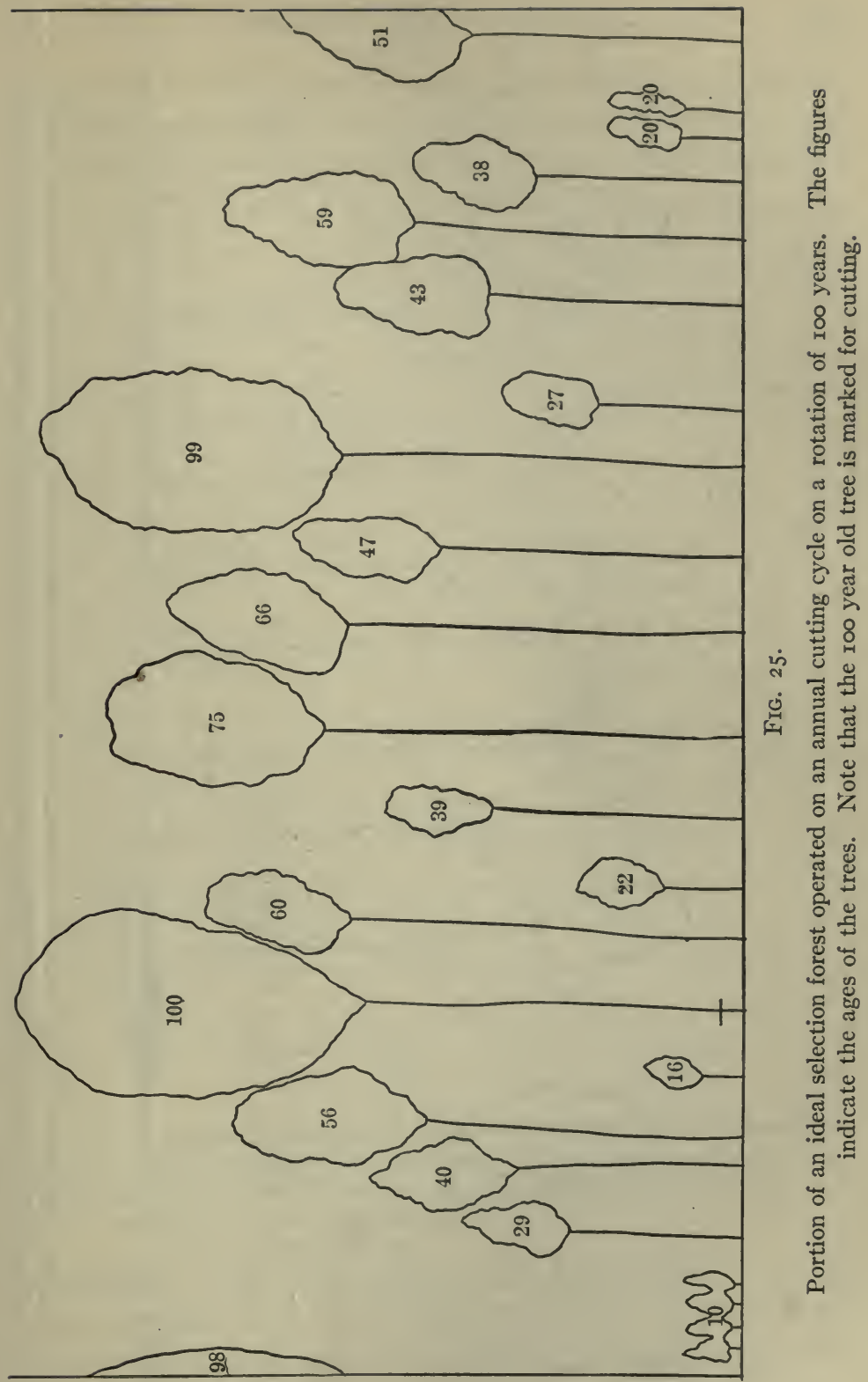




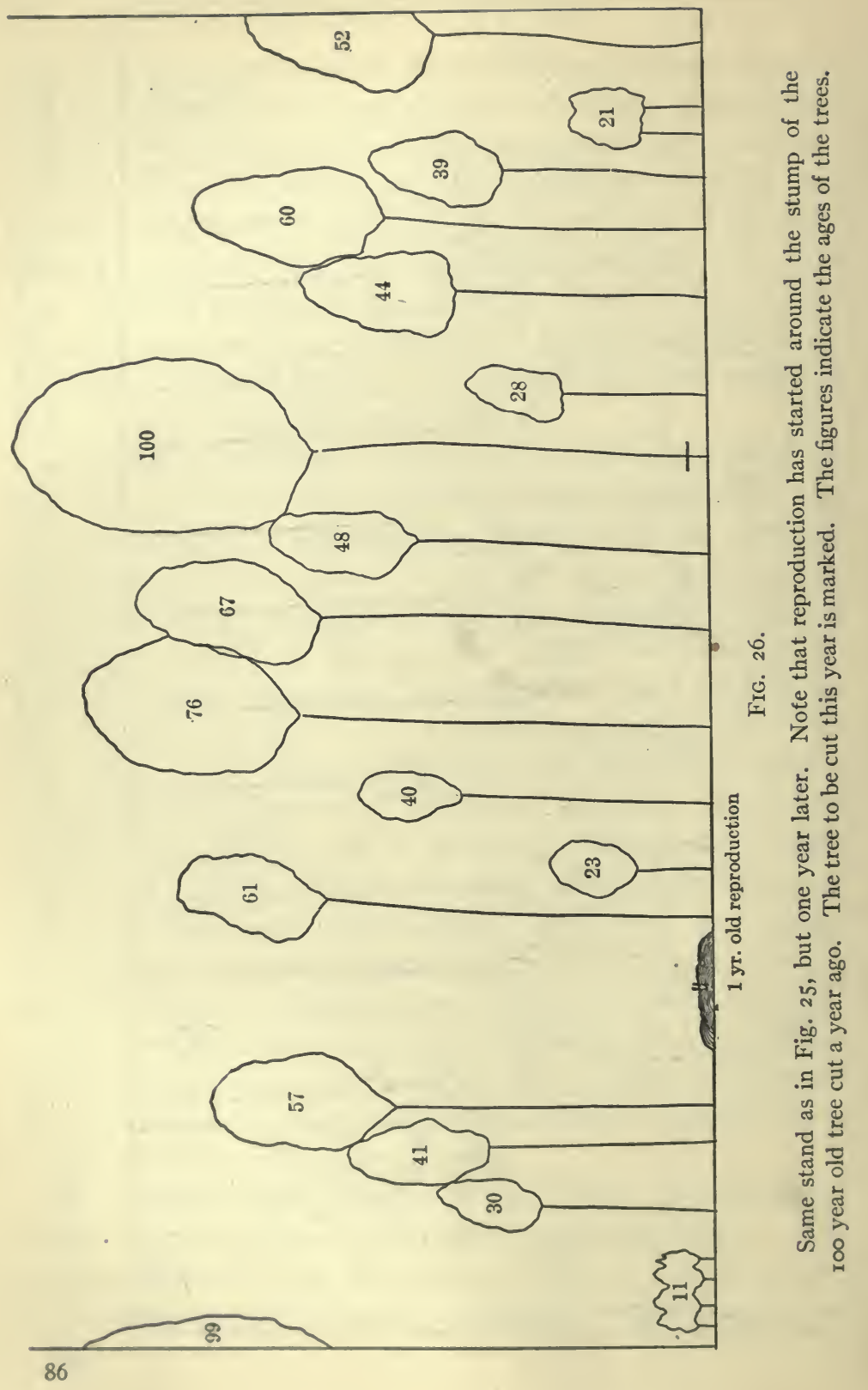


produce seed every year and seedlings have difficulty in becoming firmly established when the area is cut over each year. To avoid these difficulties what is known as a cutting cycle is

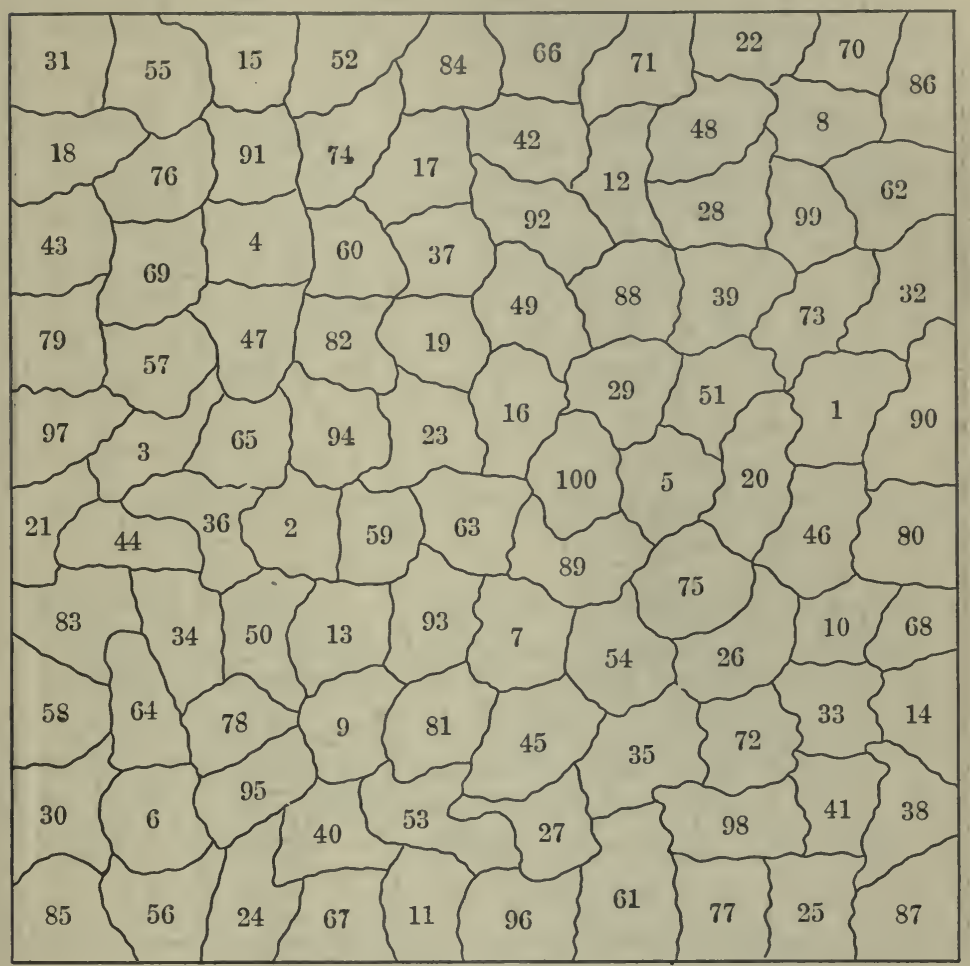

FIG. 27.

A portion (one acre) of an ideal single tree selection stand, managed on a rotation of 100 years, with a complete series of age classes on every acre, each occupying approximately the same area. The numbers indicate the ages of the trees occupying given portions of the acre.

established. Under this scheme the entire forest is not cut over each year; but it is divided into certain distinct stands. The cutting in a given year is restricted to one of these areas. 
Cuttings in successive years progress from one stand to another and finally return to the first. The interval between cuts on a given area determines the length of the cutting cycle.

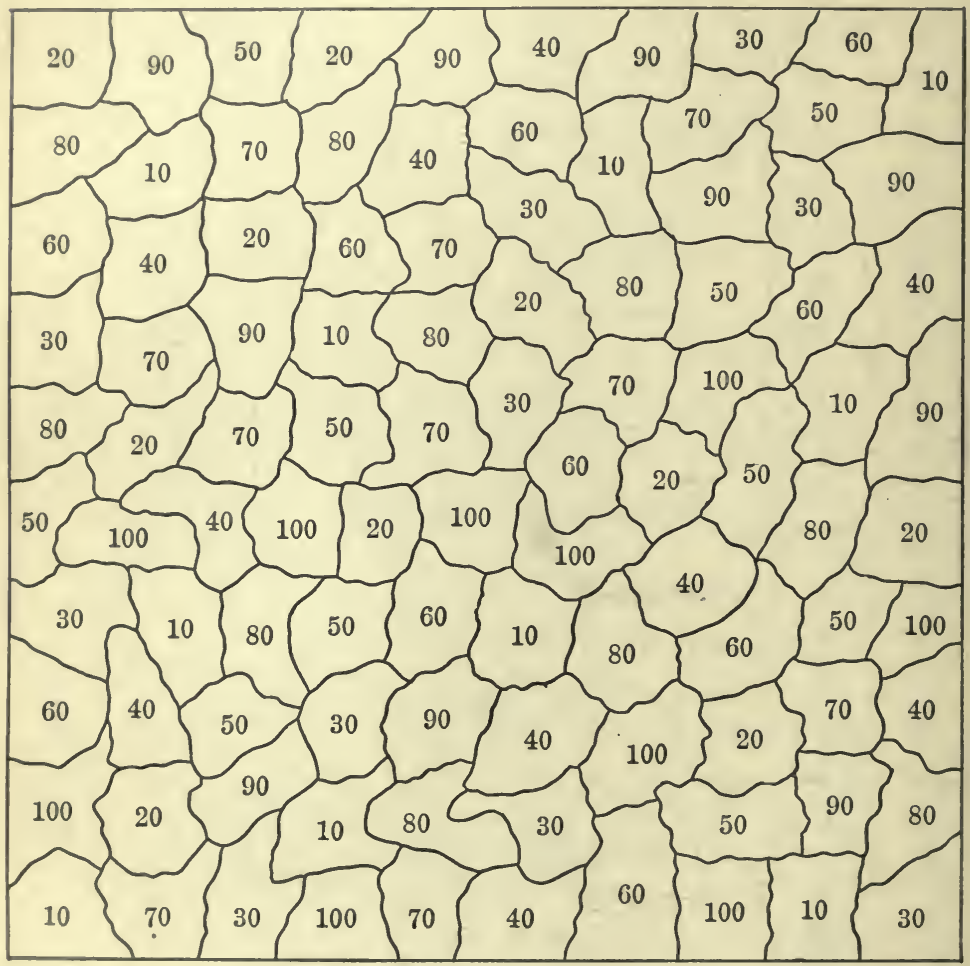

FIG. 28.

A portion (one acre) of an ideal single tree selection stand managed on a rotation of roo years under a 1o year cutting cycle. Ten age classes are represented each occupying approximately one-tenth of the area. The numbers indicate the age of the trees. Compare with Fig. 27, where a cutting cycle of one year is employed.

In Europe this is apt to be ro years or lower. In the United States the cutting cycle may be ro to 50 years in length. Where the cutting cycle is longer than one year every age 
will not be represented in the stand. There will be as many ages in the stand as there are cuttings during the rotation. To secure this number divide the rotation by the cutting cycle. (See Figs. 27, 28 and 29.)

\begin{tabular}{|c|c|c|c|c|}
\hline Stand 1 & Stand 2 & Stand 3 & Stand 4 & Stand 5 \\
\hline $\begin{array}{l}\text { Contains } \\
\text { age classes:- }\end{array}$ & $\begin{array}{l}\text { Contains } \\
\text { age classes:- }\end{array}$ & $\begin{array}{l}\text { Contains } \\
\text { age classes:- }\end{array}$ & $\begin{array}{l}\text { Contains } \\
\text { age classes:- }\end{array}$ & $\begin{array}{l}\text { Contains } \\
\text { age classes:- }\end{array}$ \\
\hline $\begin{array}{l}1,11,21, \\
31,41,51, \\
61,71,81, \\
\text { and } 91\end{array}$ & $\begin{array}{l}2,12,22, \\
32,42,52, \\
62,72,82, \\
\text { and } 92\end{array}$ & $\begin{array}{l}3,13,23, \\
33,43,53, \\
63,73,83, \\
\text { and } 93\end{array}$ & $\begin{array}{l}4,14,24, \\
34,44,54 \\
64,74,84, \\
\text { and } 94\end{array}$ & $\begin{array}{l}5,15,25, \\
35,45,55, \\
65,75,85, \\
\text { and } 95\end{array}$ \\
\hline Stand 6 & Stand 7 & Stand 8 & Stand 9 & Stand 10 \\
\hline $\begin{array}{l}\text { Contains } \\
\text { age classes:- }\end{array}$ & $\begin{array}{l}\text { Contains } \\
\text { age classes:- }\end{array}$ & $\begin{array}{l}\text { Contains } \\
\text { age classes:- }\end{array}$ & $\begin{array}{c}\text { Contains } \\
\text { age classes:- }\end{array}$ & $\begin{array}{l}\text { Contains } \\
\text { age classes:- }\end{array}$ \\
\hline $\begin{array}{l}6,16,26 \\
36,46,56, \\
66,76,86, \\
\text { and } 96\end{array}$ & $\begin{array}{l}7,17,27, \\
37,47,57, \\
67,77,87, \\
\text { and } 97\end{array}$ & $\begin{array}{l}8,18.28, \\
38,48,58, \\
68,78,88, \\
\text { and } 98\end{array}$ & $\begin{array}{l}9,19,29 \\
39,49,59 \\
69,79,89 \\
\text { and } 99\end{array}$ & $\begin{array}{l}10,20,30, \\
40,50,60, \\
70,80,90, \\
\text { and } 100\end{array}$ \\
\hline & & & & $\theta$ \\
\hline
\end{tabular}

FIG. 29.

Diagram of a selection forest managed on a rotation of 100 years with a cutting cycle of ro years. The forest contains ro stands, one of which is cut through each year, thus giving equal annual cuts. Each stand contains ro age classes and together the age classes in the ro stands form a continuous series of ages from I to roo years.

As the interval between cuts is lengthened the amount per acre removed in a single cutting is increased in direct 
proportion to the increased length of the cycle. For example, if 200 board feet per acre are removed when a given stand is cut through annually, then io $\times 200=2000$ board feet per acre should be removed at each cutting if the cutting cycle is changed to ro years. If the amount to be cut on an annual cutting cycle is known, then the cut for any other cycle can be quickly secured by multiplying the length of cycle by the annual cut per acre.

The actual percentage of the volume removed in a selection cutting is subject to great variation depending on the length of the cutting cycle and the unit in which the volume is expressed. When the board feet unit is employed roo per cent of the volume might be removed in a given cutting provided the old age class included all the trees of merchantable dimensions. More commonly on a cutting cycle of to to 20 years, 25 to 75 per cent of the board foot volume would be cut. Expressed in terms of cubic feet the percentage would usually range from 15 to $5 \circ$ per cent.

This leads to the question as to how the amount per acre which can be cut should be determined. If all age classes are represented each occupying the proper proportion of the area it is easy to limit the cut. Either the annual growth or the oldest age class could be removed each year, or the periodic growth be removed at the end of each cutting cycle, and sustained annual yield in an unevenaged stand be maintained indefinitely. The two (i.e., annual growth or oldest age class) are identical in volume provided the proper proportion exists between age classes. Unfortunately this ideal stand is non-existent which makes more complicated the problem of determining the amount to cut. The following procedure is suggested.*

* This question of limiting the cut or regulating the yield from a given area falls under regulation and outside the province of silviculture. Yet under the 
I. Decide on the length of rotation. This has influence on the possible growth and on the number of age classes which should be represented.

2. Determine the mean annual growth per acre.*

3. Ascertain the proportion of the area occupied by each age class.*

4. If each age class occupies its right proportion of the area the annual cut is equal to the mean annual growth.

5. If the age classes are not represented in the right proportion decide what relation the amount cut for the next few years or for the next cutting cycle shall bear to the mean annual growth.

6. The amount to be cut having been determined select enough trees to give this amount from the older age classes on the basis of their silvicultural condition, considering particularly such points as individual health, rate of growth and seed-bearing value. On the whole the oldest trees would be removed but opportunity is afforded for taking out poor individuals of younger age, and of leaving certain thrifty trees of older age.

The age of standing mature trees cannot be secured directly without cutting or boring into them. As this is impracticable diameter is taken as the best indication of age and the trees

selection method success in maintaining its typical form of forest is associated so much more intimately with proper regulation than in the case of methods producing evenaged stands, that brief mention is warranted. In fact regulation either on an annual or relatively short period basis is essential to silvicultural success under the selection method.

* It is recognized that determining for an unevenaged stand, either the mean annual growth per acre, or the proportion of the area occupied by individual age classes is a mensuration problem as yet without completely satisfactory solution. However, both problems can be answered within limits of accuracy which should furnish sufficient control for governing the cut. An attempt to elaborate methods of attacking these mensuration problems is considered out of place here. 
assigned to age classes on the basis of size. For this purpose tables showing the average age of trees of different diameters can be made by analysis of the growth of felled trees.

A diameter limit may then be established with the understanding that trees below this size are to be reserved and those above cut. This should not be made a rigid limit but should be applied discriminatingly, certain trees above the limit being reserved and some below the limit cut. In the parallel columns given below the chief reasons for cutting below or leaving trees above the limit are summarized.

Trees may be left above the diameter limit when:

r. Exceedingly thrifty and growing fast in volume and in value.

2. Standing in groups of smaller trees and liable if cut to cause windthrow or breakage among these trees. (See Fig. 3०.)

3. A large seed tree is needed in or on the edge of an opening. (See Fig. 3r.)

4. Needed for æsthetic reasons.

5. Required to protect soil conditions or seedlings.
Trees may be cut below the diameter limit when:

r. Unthrifty, slow growing and likely to decay or be killed before another cutting and those at present defective.

2. So exposed that if left they will be windthrown or broken in felling neighboring trees. This is apt to occur in case of tall, slender individuals growing in a group of larger trees.

3. By so doing the composition may be improved or the rate of growth of more promising neighbors increased. (See chapters on Intermediate Cuttings.)

The great temptation in cutting timber under the selection method is to take too much; in other words to cut trees too young or too small and thus deplete the younger and middle age classes.

This temptation exists because the young trees are intermingled with the old age classes instead of being segregated on separate areas as in the other high forest methods. Even though the merchantable trees below the diameter limit are 


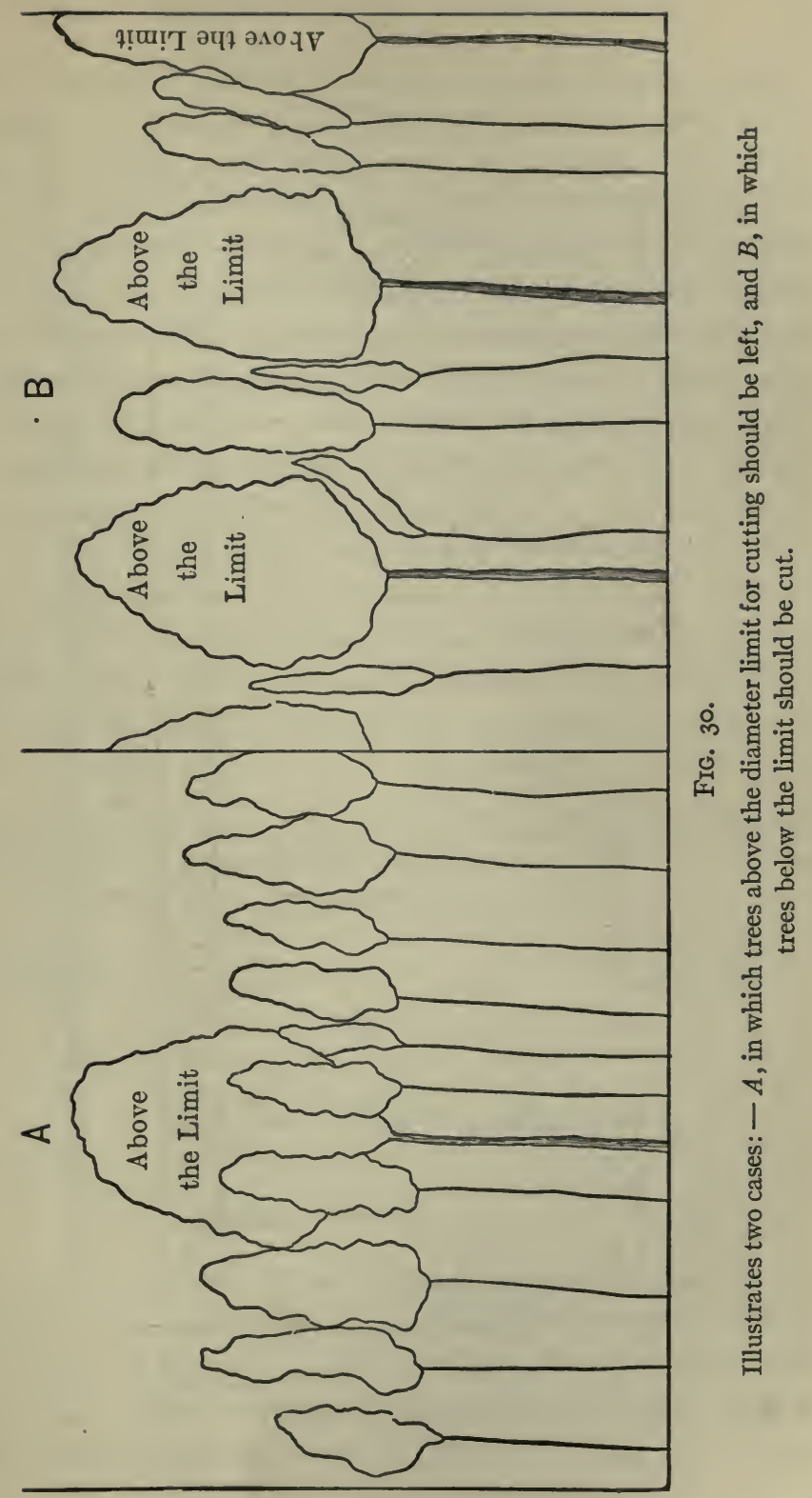




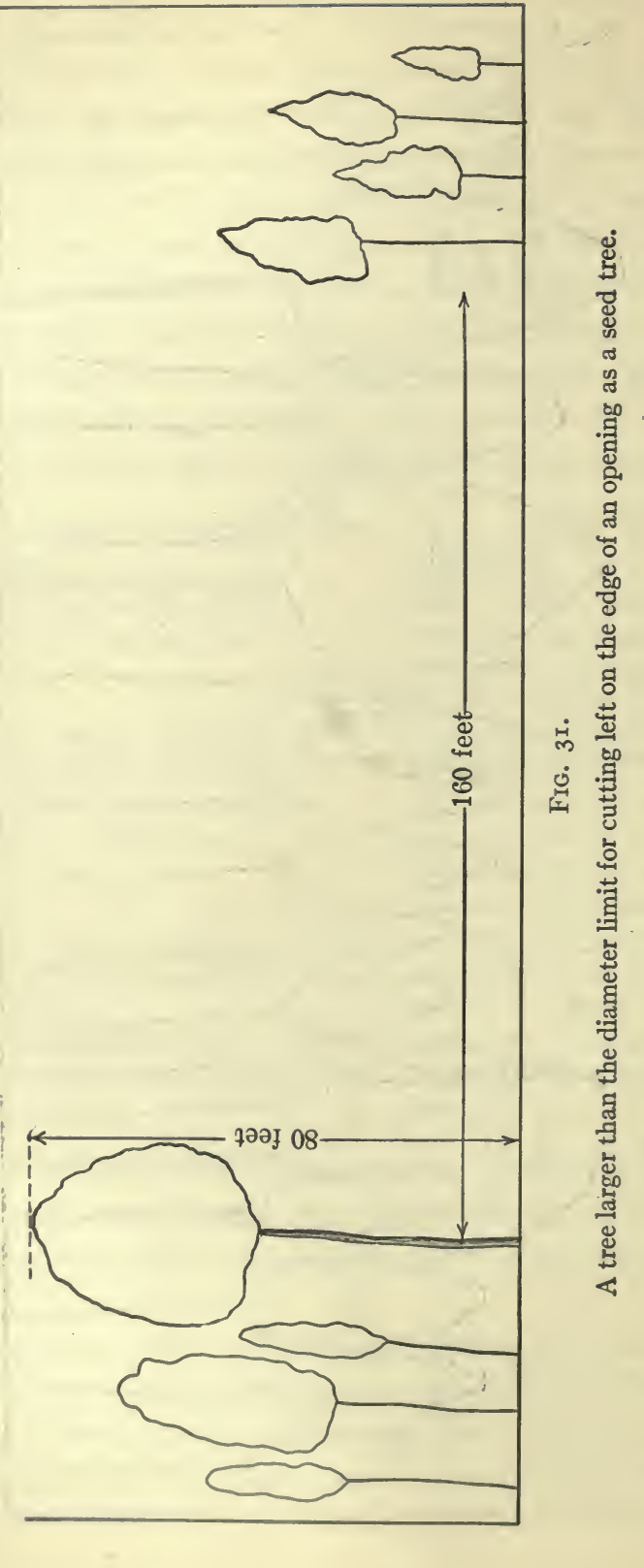


not cut many of the smaller trees may be used in the logging operations, for skids, corduroying roads, etc., or simply destroyed in felling and getting out the timber. A certain amount of destruction is a necessary accompaniment to logging, but such wasteful use and destruction may be so extreme as to threaten the continued existence of the selection forest. In order to provide for enough old trees per acre it is necessary that numerous seedlings start every few years. These seedlings undergo a rapid decrease in numbers due to competition and other natural causes as they grow in size and advance toward maturity. Definite information as to the number of trees per acre of different sizes needed to secure steady production under the selection method is not available for most of our species. As an illustration the following data for yellow poplar have been taken from "Yellow Poplar in Tennessee," by W. W. Ashe. ${ }^{2}$ See also pp. 317-318 in the Selection System in Indian Forests . . . by Caccia. ${ }^{3}$

Number of trees per acre in different diameter classes, required to obtain a continuous yield from a fully stocked group selection stand of pure yellow poplar. The cutting limit is approximately 20 inches.

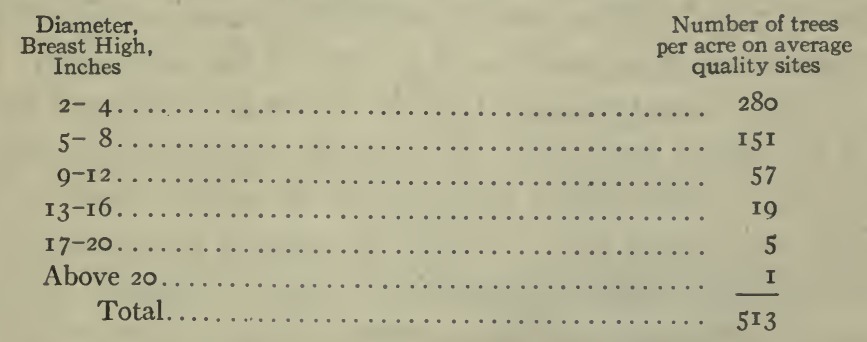

If to these natural causes are added destruction by the lumberman, there may be no representatives left of certain ages to come to maturity. It is essential for successful application of the selection method that waste of small trees be kept at the minimum. 
Graves described a method of limiting the cut ${ }^{4}$ which has been used to some extent in the United States Forest Service reports and elsewhere. Under this method different diameter limits of cutting are assumed, the number of trees of each diameter and the present yield of timber cutting to the limit calculated, and then by means of current diameter growth data the dimension and volume of the trees left standing below the limit are estimated at the end of a stated period, such as 30 years. In speaking of the method Graves says "a limitation of cut, based on this method of study, maintains the rate of growth of the forest and guarantees succeeding cuts at short intervals." Since all the calculations are based on current growth for a relatively short period without consideration of the proper distribution of the entire series of age classes, the method does not guarantee cuts at short intervals except the one immediately following the present cut.

Modifications of the Selection Method.-Group Selection.In defining the selection method it was stated that the trees cut at any one time might be standing singly or in small groups. (See Fig. 32.) There are certain advantages in maintaining a group-wise arrangement of the trees of the same age. Less breakage among younger trees is caused in felling and removing the oldest age class. The cost of logging may be slightly reduced. More light is provided for the development of seedlings and young trees. This is of especial importance in the case of light demanding species. Trees intolerant of shade cannot be managed under a method of single tree selection.

By varying the size of the group great flexibility in application is possible. The oldest groups may contain only two to five trees and from this range up to more than a hundred occupying one to four acres. Where the groups occupy more than a quarter of an acre the stand tends to lose its uneven- 
aged form. With larger groups one of the distinctive characteristics of the selection method is lost, namely the protec-

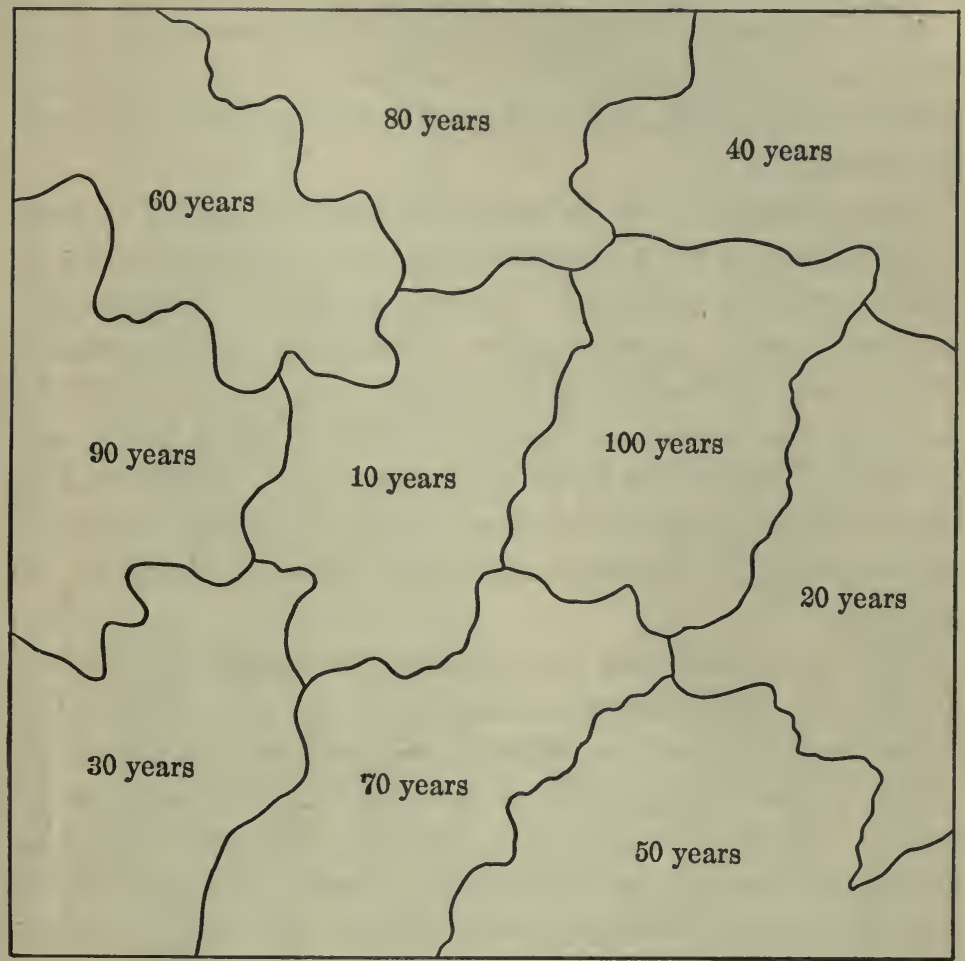

FIG. 32 .

A portion (one acre) of a stand reproduced by the group selection method. Small groups are shown in the illustration averaging one-tenth of an acre in size. Length of rotation is roo years; length of cutting cycle ro years. Compare with Figs. 27 and 28. Ten age classes are represented in this stand each group containing a different number of trees depending upon its age. The numbers indicate the age of the trees in each group.

tion of the site and of seedlings so essential for successful natural reproduction. The groups must be small enough, so 
that seed can be distributed in abundance over the cleared area, and so that surrounding trees may conserve soil moisture and shelter reproduction. (See Figs. 33, 34 and 35.)

With increase in area the groups tend to develop like small evenaged stands and produce trees which have the characteristics of such stands, rather than of trees grown in an unevenaged forest.

Strip Selection. - In the group method the groups of trees of the same age have the general outline of circles, squares or relatively broad rectangles. Several groups of the same age may be found in the same stand. The strip selection method carries further the idea of the groups. All the groups of the same age in a stand are combined in the form of a long narrow strip. There will be at least as, many of these strips as there are age classes in the stand, and in stands of large areas several strips of the same age may be found. (See Figs. 36 and 37.)

Such an arrangement concentrates the logging and results in little if any destruction among the younger trees. The strips should be made so narrow that good soil conditions are preserved and reproduction sheltered by the bordering uncut timber. Each strip is itself of even age, and under intensive management might be considered a separate stand, in which case the method becomes clearcutting with natural reproduction from the side.

The strip selection method is theoretical in the extreme and one not likely to be developed in practice.

Extensive versus Intensive Application of the Selection Method. - When markets are poor and logging expensive, only the biggest and best trees are profitable to cut. Under these circumstances the selection method can be applied only in a crude way and is simple in its operation. Extensive application means long intervals between the cuts, no intermediate 

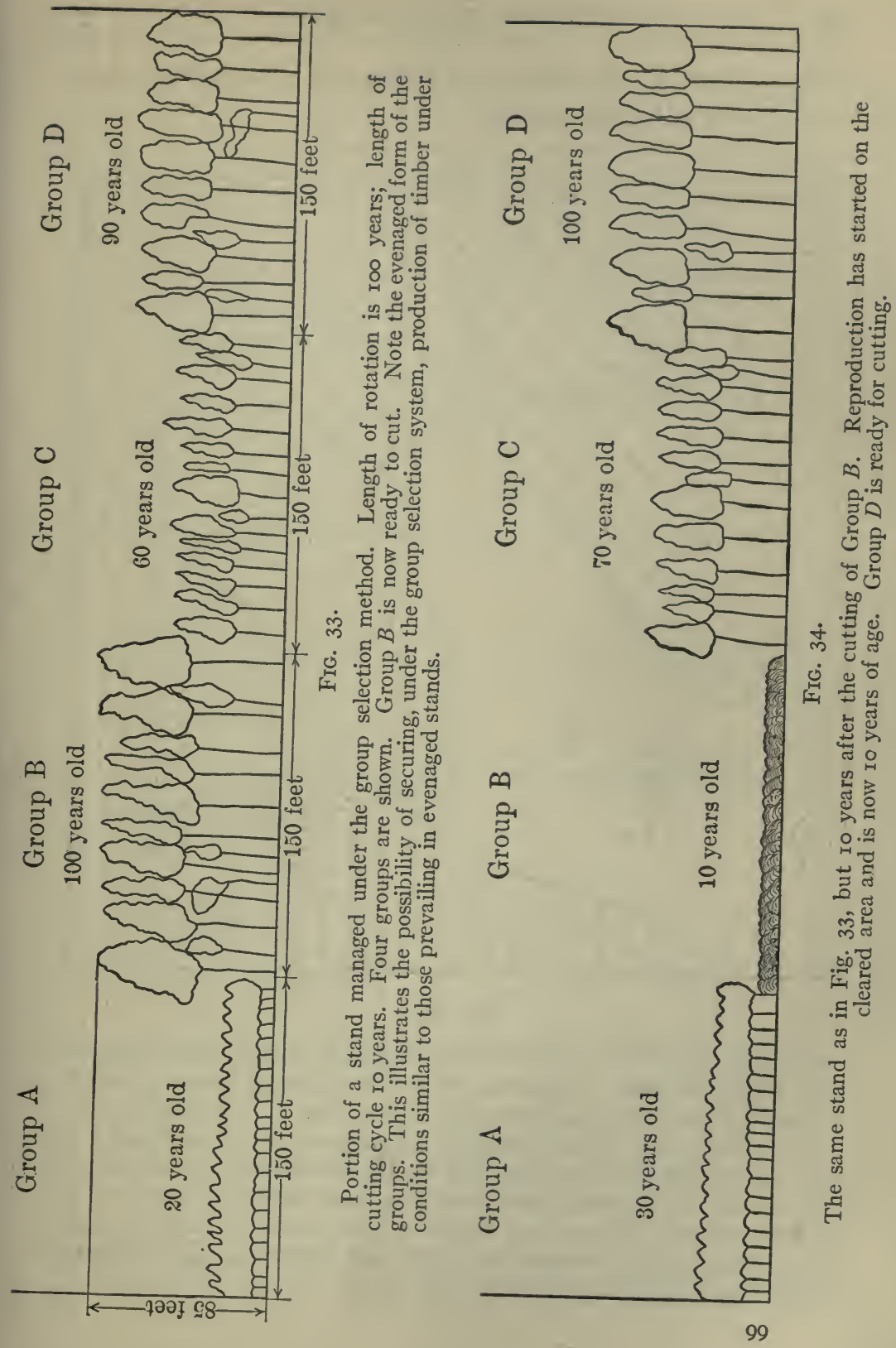
cuttings, growth retarded due to shade and a relatively small increment of valuable material.

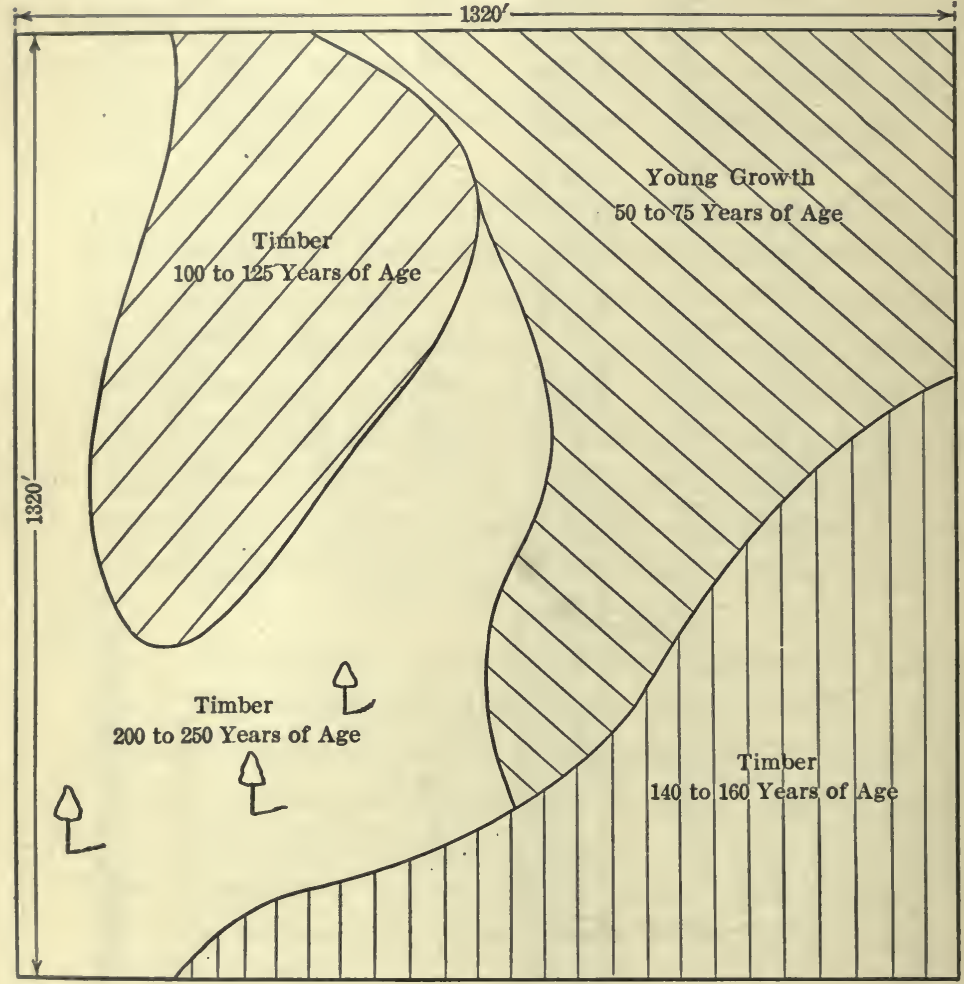

Fig. 35.

A 40-acre portion of a stand of virgin timber to be reproduced under the group selection method. Four groups are represented in the diagram. Length of rotation is 200 years; length of cutting cycle 50 years. The oldest group is cut clear except for a few trees shown in the diagram left to furnish seed over the central part of the area. Such seed trees are needed because the group is too broad to be adequately reproduced from seed distributed from trees in adjoining groups. The principal difference between this operation and the method of clearcutting the whole stand lies in the difference in size of the unit of management (i.e., the stand). See page I.3. 


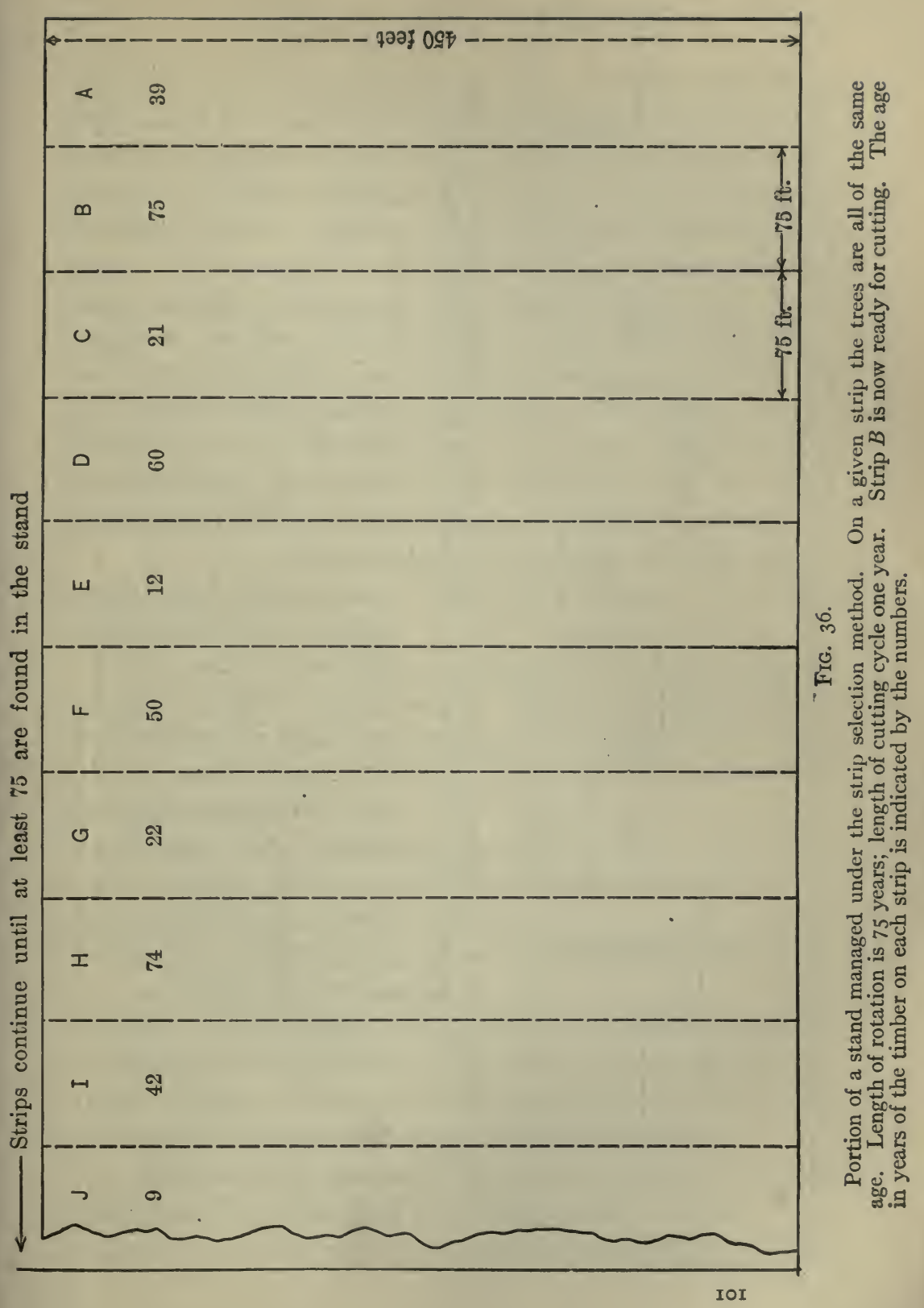




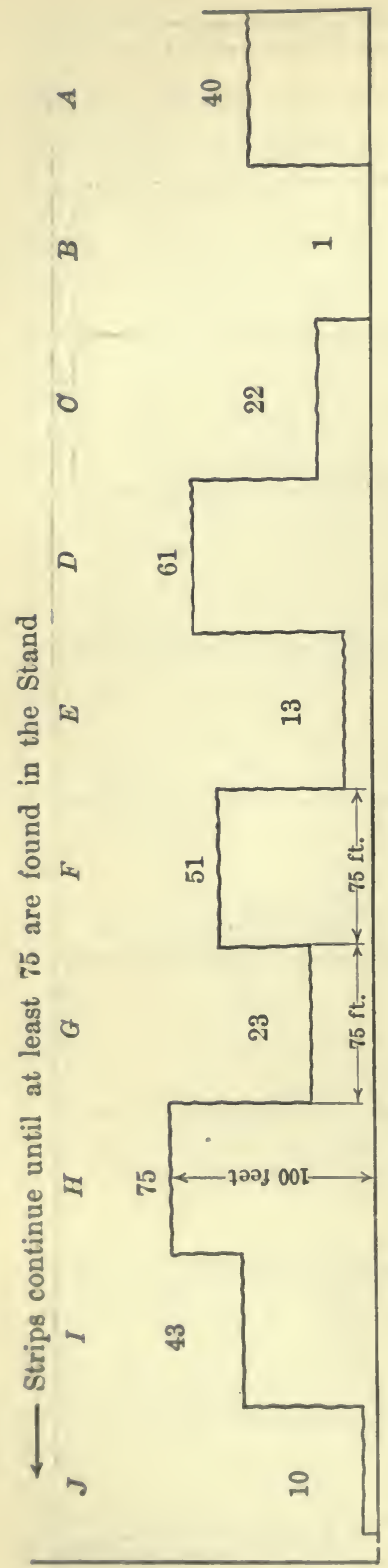

윯

동

인
If economic conditions allow the utilization of trees of all sizes and kinds, then intensive application of the selection method becomes possible. This implies short intervals between cuts, proper silvical attention to each tree or group, the making of intermediate cuttings, the artificial regeneration of failed places, if such exist, and a rela tively high increment of valuable material.

\section{Advantages and Disad-} vantages of the Selection Method. - The selection method with its unevenaged form of forest stands in sharp contrast to the other three previously considered. For this reason it is to be expected that definite arguments in favor of and against the method can be presented.

Advantages.- - I. Affords a high degree of protection to the site and to reproduction and minimizes the danger of snow-slides and land-slides. The forest 
canopy is kept nearly complete, the openings made being small and scattered. No other method affords such perfect protection against erosion, injury to the physical factors of the site and against the development of a grass and weed cover. Seedlings receive shelter from sun, wind and early and late frosts. The continuous cover of trees of all ages presents a strong mechanical barrier to the progress of land- and snowslides. Such slides rarely, if ever, start in a selection forest.

2. Can be applied extensively where markets are poor and only trees of large size are merchantable. Poor market conditions hamper the full development of the selection idea, but do not prevent the partial use of the method, for even with the poorest markets it is the largest trees that are salable.

3. The method best satisfies the æsthetic purpose, due to its picturesque unevenaged form, and avoidance of anything approaching clean cutting.

4. Windfall is eliminated or reduced to a small figure in selection forests. The individual trees have the opportunity to develop large crowns, compared to trees in evenaged stands, and become windfirm. The small trees are well sheltered by the older ones.

5. Reproduction is relatively easy to secure, due to an abundance of seed trees and to the protection afforded the seedbed and seedlings.

6. The selection method is the only one which maintains the unevenaged form of forest.

7. There is less danger of a disastrous fire than in forests of evenaged stands in which the solid blocks of reproduction create enormous fire hazard. In case fire does occur seed trees are always present to stock up the burned area.

8. An ideal method for the small farm woodlot, because it permits annual or frequent harvesting of large timber. Such a woodlot (of five acres for example) is too small to be effec- 
tively organized for annual or short period yield on a clearcutting or shelterwood method.

Disadvantages. - I. Since the mature trees are scattered throughout the whole stand and are intermixed with reproduction and small trees logging costs more than under other methods.

2. Due to the mixture of age classes, it is difficult to prevent in the logging injury to the immature trees which form the forest capital.

3. Grazing cannot be permitted since reproduction is in progress continually.

4. The timber produced averages lower in grade than that grown in evenaged stands. It is more apt to be knotty due to the greater crown development of the individual tree. To some extent the site on which the selection method is ordinarily employed accounts for this. Selection forest has been used principally on poor sites in exposed positions and at high elevations as a protective forest. On such situations the timber produced under any method is of lower quality than that produced on better sites.

5. To apply intensively requires great skill on the part of the forester. This results from the complex nature of the age distribution in the stand.

Whether the method gives a lower increment than other methods of high forest has been a point of controversy abroad for many years. Some authors contend that the greater area of foliage per tree and the more complete use of available nutrients, resulting from the mixing of young and old trees with root-systems penetrating to different depths, must work for greater production under the selection method. The argument against this is that the retardation of the growth of young and middle-aged trees, through shading by older ones, more than offsets these items. It is not until the last half of 
the rotation that trees in a selection stand are completely freed from shading by taller trees. Analyses of the growth of individual trees show marked contrasts between those grown in evenaged and unevenaged stands. ${ }^{3}$ (See Figs. 38 and 39.)

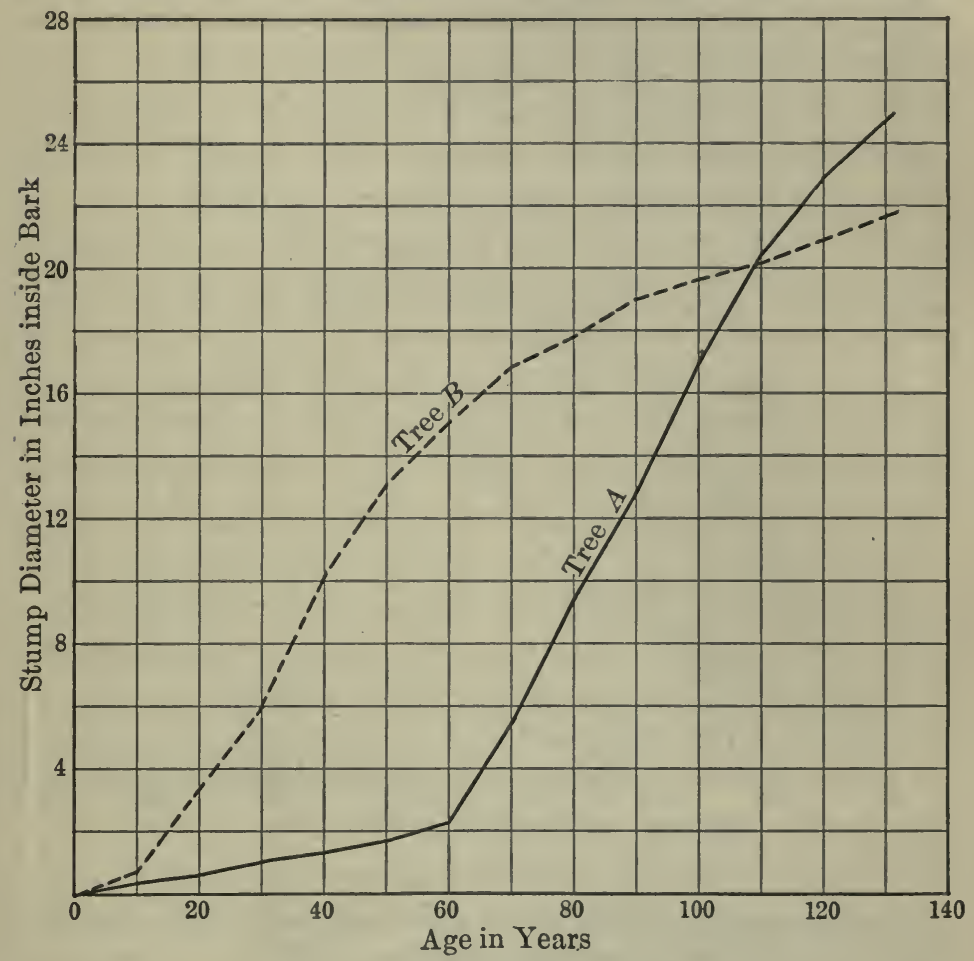

FIG. 38 .

Diagrams showing the diameter growth based on age of two hemlock trees of approximately the same age and size growing on the same site. Tree $A$ grew under conditions prevailing in an unevenaged stand. Tree $B$ grew under conditions prevailing in an evenaged stand. For the first 50-60 years of its life tree $A$ was overtopped.

Much of the difference in opinion as to the relative production of evenaged and unevenaged stands arises from unfair 
comparisons between the two. To gauge the relative production of two methods the same intensity of application must be employed in the management and the two stands must be on the same quality of site. When these conditions are met

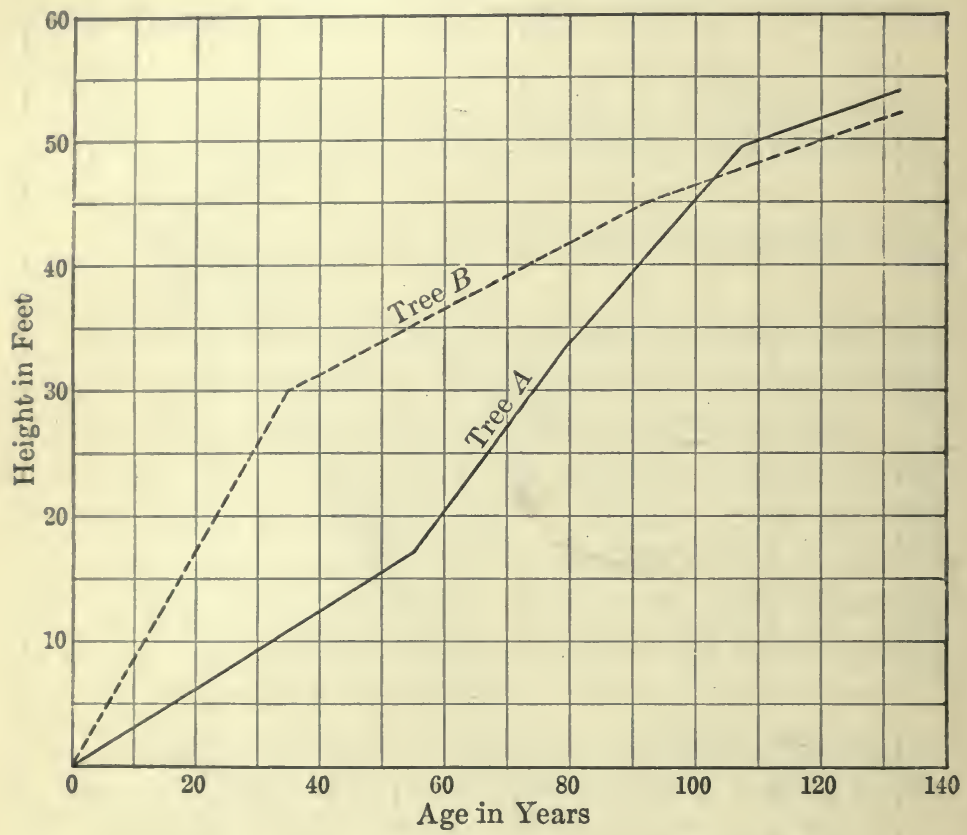

FIg. 39 .

Diagrams showing the height growth based on age of the two hemlock trees used in Fig. 38. Tree $A$ grew under conditions prevailing in an unevenaged stand; tree $B$ under those prevailing in an evenaged stand.

the production of evenaged and unevenaged stands should be equal.

Application of the Selection Method. - In European countries the selection method finds favor principally for use on sites where a protection forest is needed. Switzerland has a higher percentage of protection forests than have other 
countries. Her statistics indicate that 35 per cent of the total forest area and two-thirds of the forest in the Alpine district are handled under the selection method.

In the United States so-called "selection" cuttings have been made in various regions and types. In many cases the name is a misnomer, the character of the cutting indicating plainer than words that the selection method is not being employed. Where true selection cuttings have been made, they are principally in mixed stands, where large sized trees of only one or a few species were merchantable. Where market conditions have improved, making more species and smaller sizes salable, the second cutting made in such stands does not have the character of a selection cutting.

Overmaturity of timber and too great a preponderance of the older age classes present great difficulties to the immediate use of selection in many forests, where eventually it may be the most desirable method.

As explained on page 84, the virgin forest contains an excess of the older age classes. When to this condition is added the fact, that the rotation under management will be much shorter than the normal life of a tree in the virgin forest, this excess of old timber becomes more pronounced.

For example a certain virgin forest contains age classes ranging from young seedlings to trees 500 years of age, with merchantable timber from 100 to 500 years occupying at least 90 per cent of the area. Theoretically these age classes should cover 80 per cent, so that the age class distribution may appear nearly correct. Under management the rotation for this forest will be set at roo years. This being the case, 90 per cent of the forest area is stocked at present with overmature timber past the rotation age. A clearcutting is apt to be the only solution. Selection is out of the question.

For sites in great need of protection, selection is recognized 
as the proper method and is already being applied on a small scale.

Besides its general employment on protection sites, which will come in time, the selection method should be favored by farmers holding small areas of woodland and by owners with whom the æsthetic motive is prominent. This latter class is increasing, and already holds large areas in the aggregate.

There may also be occasional examples where the influence of economic conditions and the silvical habits of the species point to the adoption of the selection method for the production of timber on a large scale. An instance of this character is furnished by lodgepole pine in the Rocky Mountains.

Lodgepole grows on sites which are often spoken of as protection sites, but yet are sites which from their location topographically are not in most instances the real protection sites of the locality. These are found in timbered areas located above the lodgepole type. Stated in another way, a great share of the lodgepole pine type may be used primarily to grow timber without interfering with its protective value. This situation would permit theoretically the use of shelterwood or clearcutting rather than selection. The United States Forest Service after trying various forms of clearcutting and the seed tree methods have swung around to selection as best meeting the market requirements of the region and fitting in with the silvical habits of lodgepole pine. ${ }^{5}$ Certain forms of stand demand immediate reproduction under other methods, but the indications are that for lodgepole pine selection will be on the whole the best method of reproduction and the unevenaged forest the most desirable form. 


\section{REFERENCES}

I. Cermak, Einiges über den Urwald von Waldbaulichen Gesichtspunkten. Centralblatt f. d. g. Forstwesen, Aug.-Sept., I910, pp. 340-370.

2. Ashe, W. W. Yellow Poplar in Tennessee. Bulletin ro-C, State of Tennessee, State Geological Survey, I9I3, p. 40.

3. Caccia, A. M. F. The Selection System in Indian forests as exemplified in working plans based on this system, with a short description of some Continental Methods. The Indian Forest Records, Part IV, Vol. I, Calcutta, I909, p. 3I5, 3I7-3I8.

4. Graves, H. S. Principles of Handling Woodlands. Wiley \& Sons, Inc., New York, I9ז1, pp. 53-54.

5. Mason, D. T. Utilization and Management of Lodgepole Pine in the Rocky Mountains. Bulletin 234, United States Department of Agriculture, Washington, I9I5, pp. 2I-32.

Berthon. Étude D'un Peuplement de Forêt Jardinée. Bulletin de la Société Forestière de Franche-Comté et Belfort, Vol. II, Besançon, IgI2, pp. $4 \mathrm{II}-4 \mathrm{I} 8$.

Chrisiten. Zur Ermittlung des laufenden Zuwachses speziell im Plenterwalde. Schweizerische Zeitschrift fur Forstwesen, Bern, I909, pp. 37-4I and pp. $82-87$.

Clapp, E. H. Silvicultural Systems for Western Yellow Pine. Proceedings of the Society of American Foresters, Vol. 7, r912, pp. r68-г 76.

FankHauser, F. Ueber die Notwendigkeit von Ertrags nachweisungen im Plenterwald. Forstwissenschaftliches Centralblatt, I908, pp. 4I 7-432.

Frothingham, E. H. The Eastern Hemlock. Bulletin 152, United States Department of Agriculture, Washington, I915, pp. 29-30.

FrothinghaM, E. H. The Northern Hardwood Forest: Its Composition, Growth and Management. Bulletin 285, United States Department of Agriculture, Washington, I915, pp. 37-39.

G. Z. Privatwald und Plenterbetreib. Schweizerische Zeitschrift für Forstwesen, Bern, I9II, pp. 247-255.

Larsen, L. T. Sugar Pine. Bulletin 426, United States Department of Agriculture, Washington, I9I6, pp. 30-33.

Munger, T. T. Western Yellow Pine in Oregon. Bulletin 4I8, United States Department of Agriculture, Washington, 1917, pp. 38-39.

MURPHy, L. S. The Red Spruce: Its Growth and Management. Bulletin 544, United States Department of Agriculture, Washington, I9I $7, \mathrm{pp}$. $46-48$.

WAGNER, C. Blenderwald oder schlagweiser Hochwald. Forstwissenschaftliches Centralblatt, Berlin, I909, pp. 23-29. 
Weidman, R. H. A Study of Windfall Loss of Western Yellow Pine in Selection Cuttings Fifteen to Thirty Years Old. Journal of Forestry, Vol. XVIII, 1920, pp. 6r6-622.

Woolsey, T. S., JR. Cutting Western Yellow Pine in Arizona and New Mexico. Proceedings of the Society of American Foresters, Vol. 9, rgr4, pp. 479-503.

Zow, R. Balsam Fir. Bulletin 55, United States Department of Agriculture, Washington, 1914, pp. 65-66. 


\section{CHAPTER VII}

\section{THE COPPICE METHOD}

Definition. - A coppice forest is one composed wholly or mainly of sprouts and the coppice method of reproduction acomplishes the renewal of the forest principally by sprouts, although usually with a mixture of seedlings. The stand is cut clear and reproduction starts immediately by sprouts from the stumps or roots of the old stand and by scattered seedlings on the ground at the time of cutting.

The method is sometimes spoken of as simple coppice or the sprout method.

Form of Forest Produced. - The coppice method produces an evenaged stand, more regular in form than the majority of those established under other reproduction methods. Sprout reproduction originating all in one year explains this regularity.

Details of the Method. - The coppice method requires only one cutting which takes the entire stand leaving a bare area. Within less than a year the sprouts start and the new stand has replaced the old. (See Fig. 40.) It is evident that ability to sprout is an essential requisite for any species if it is to be reproduced under the coppice method. Therefore the method is one more frequently used with hardwoods than with conifers.

Sprouts originate from dormant or adventitious buds and with most species start from the root collar, side or top of the stump. Those from the root collar are the most abundant and develop into the best trees. A few species sprout mainly from the roots. Root suckers cannot in all cases be 


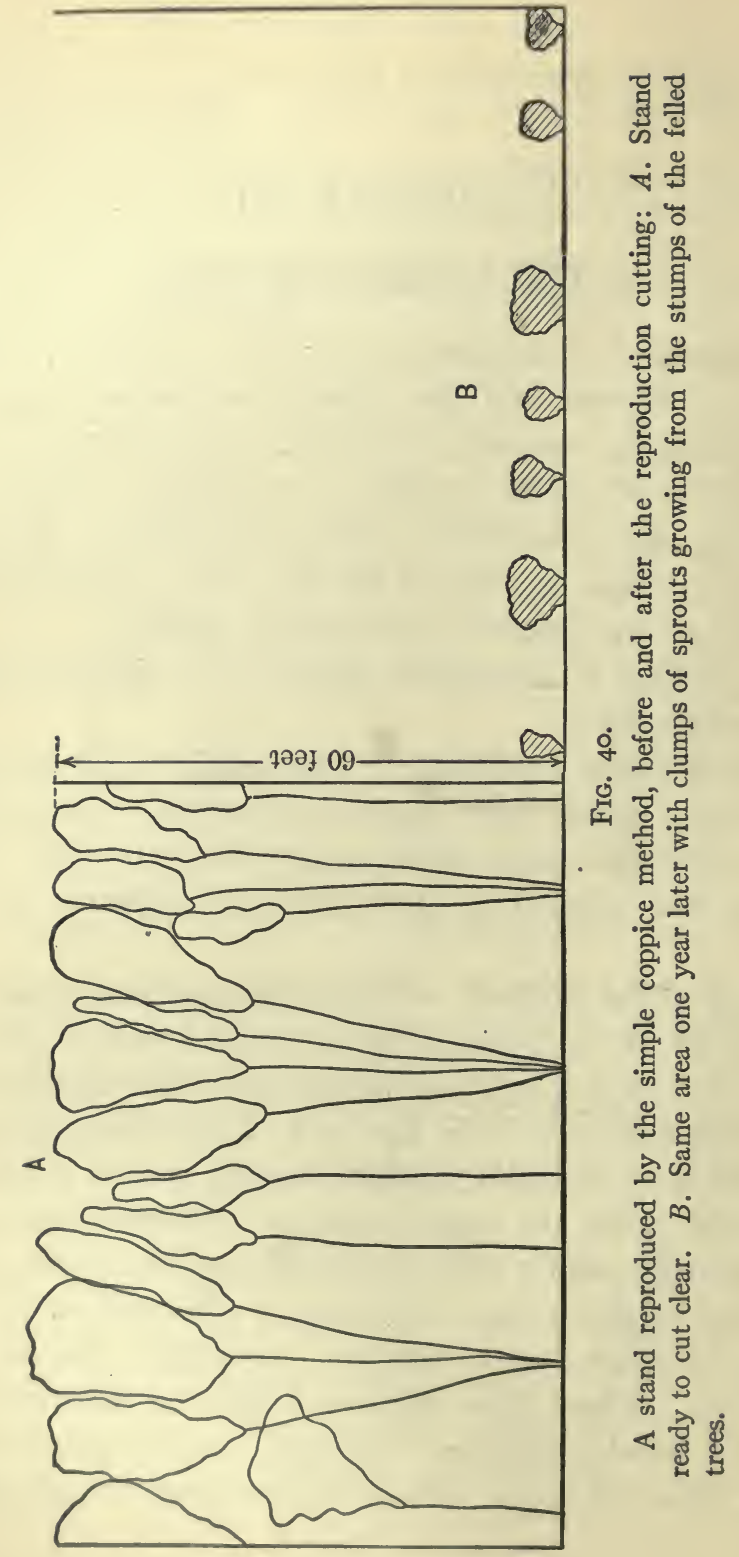


depended upon to reach maturity as they are apt to be affected with decay from the mother root.

It is important to know not only whether a species sprouts but also where the sprouts originate - from the stump or from the roots, and if from the roots whether the root suckers will grow to merchantable size.

A species capable of reproducing by sprouts does not always produce a satisfactory crop of sprouts. This variability in sprout reproduction may be attributed to several factors of which the three following are the most important:

Age of the stump at time of cutting.

Season of the year at which the cutting is performed.

Height and character of the stumps left by the choppers.

Age of the Stump at the Time of Cutting. - As trees grow older and enter the period of seed production their sprouting ability gradually decreases. Beyond a certain age only a few trees of a given species can be counted on to sprout after cutting. The age varies considerably between species. White oak in Connecticut sprouts feebly from stumps over 60 years of age. Chestnut in Maryland reaches its limit of sprouting ability at $\mathrm{r} 20$ years of age. ${ }^{1}$ The thriftier the tree and the nearer its maximum rate of growth when cut the better does the stump sprout. This period of greatest thrift and highest growth rate comes during the first part of the tree's life and may be considered as passed by the thirtieth year.

Season of the Year at which the Cutting is Performed. The best time to do the cutting is in the period when the trees are in the dormant condition. The presence of sap in the wood at the time of cutting increases the liability of the stumps and sprouts to suffer injuries such as tearing of bark, breaking off of sprouts and damage by frost. Zon ${ }^{1}$ found that winter cut chestnut sprouted best; then spring cut. 
Mattoon ${ }^{2}$ states that sprouts from chestnut trees cut in May are inferior in vigor to those from winter cut trees, attaining approximately only half the height and diameter of the latter and suffering from fall frosts.

Stumps cut in early summer may sprout, but sprouts starting so late make feeble growth and are killed by frost. Stumps cut after midsummer are likely to remain unproductive or furnish sprouts only in the following year.

Height and Character of the Stumps Left by Choppers. For the most vigorous sprout reproduction stumps should be cut low, smooth and slanting. A low stump keeps the sprouts right at or close to the root collar as their place of origin. ${ }^{3}$ This in turn enables the sprouts to form independent root systems quickly. The stump itself if cut low is more completely covered by dirt, litter, or snow and thus is better protected against extremes of cold and heat. (See Fig. 4r.)

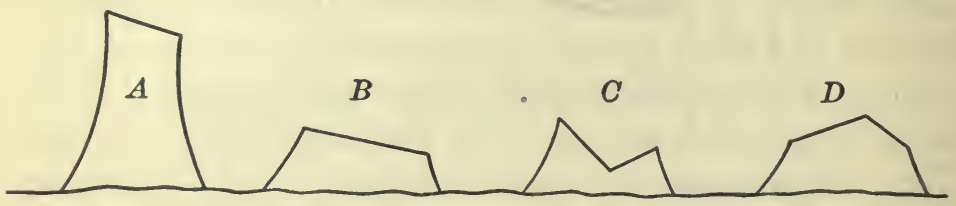

FIG. 41 .

Illustrates good and bad stumps from the standpoint of sprout reproduction. Stump $A$ is too high and is likely to produce sprouts from the top or side. Stump $B$ is the best of the four being low, cut smooth and slanting so as to"shed water. Stump $C$ is very bad as the notch will collect water. Stump $D$ while better than $A$ and $C$ is not so good as $B$.

The axe should be used in preference to the saw for felling where sprout reproduction is desired. A smooth cut, particularly one made on a slant so that water sheds off the stump, increases the time during which the stump will remain sound. It is easy with an axe to prepare such a stump. Felling with the saw leaves stumps with relatively rough 
surfaces, the fibers being torn instead of smoothly cut as with an axe. When a stump is small, as is the case under a low rotation, it may be entirely calloused over and the entrance of rot before this is accomplished may be prevented by a smooth cut stump.

Since sprouting ability decreases with age and is at its best during the first few decades of a stand's life, it follows that rotations for the coppice method of reproduction should be short. How short will depend principally upon the inherent sprouting ability of the species, together with its rate of growth and the age at which salable products can be obtained..$^{3}$

If vigorous sprouting alone were to be considered, rotations less than ro years in length would be desirable. This is much too short to be generally possible, because the products grown would be of small size and salable only under the most intensive market conditions. By extending the rotation to 40 years a good yield of cordwood can be secured.

While this is more profitable than the brushwood produced on a rotation of less than ro years, it is still an inferior product and often unprofitable. In order to secure lumber a rotation of 60 to 100 years will be found necessary, with most of the species which can be reproduced by sprouts.

When a very short rotation (less than ro years) is used, reproduction should be fully stocked and vigorous. With a 40 year rotation there may still be satisfactory sprout reproduction, but with 60 to I0o year rotation sprouts cannot be counted on to establish a fully stocked stand. Even though all the stumps of the trees in the old stand should sprout, the stocking would be incomplete because these old trees were too few in number and stood too far apart to reproduce the area completely by sprouts.

When the rotation is lengthened to 40 or more years it 
becomes necessary to provide for a mixture of seedling reproduction to supplement the crop of sprouts.

Decay from the old stumps infects the sprouts seriously on a long rotation. It is advisable that a certain amount of seedling reproduction be secured from time to time even in a stand fully stocked with sprouts. This maintains the vigor of the stand in spite of the decay which may weaken the sprouting ability of certain of the stools.

Seedling reproduction can be secured artificially by setting out plants in the spots which the sprouts have failed to stock. Strong transplants should be used and after planting be cut back to the ground. They send up vigorous sprouts which compete more successfully with the coppice than could the original transplants. Fortunately when the rotation is lengthened to 40 years or more the parent stand is old enough in most cases to produce abundant seed and natural reproduction can be relied upon to furnish a mixture with the sprouts. The polewood coppice method discussed in detail under "Modifications of the Method" has been developed for use under such circumstances.

It may be necessary to assist the seedling reproduction for a few years in overcoming competition with sprouts. These latter grow faster than the seedlings in early life and may overtop and suppress the seedling reproduction which it is desired to establish.

In the coppice method preparation of the site to secure favorable conditions for germination and for the development of young reproduction is unnecessary. The sprouts are able to compete successfully with underbrush, and are independent of litter conditions and ground cover.

Disposal of the tops left after the clearcutting of the area is not essential from the standpoint of satisfactory reproduction. Considerable accumulations of hardwood brush do not pre- 
vent the sprouting of stumps located under the brush, although occasional stumps may be so deeply covered as to smother the sprouts. Usually where the coppice method is employed a close utilization is possible and the tops that remain are relatively small.

Since the coppice method is a clearcutting operation, it is advisable that large cutting areas be avoided to prevent exposure of the site. This can be arranged by cutting in alternate or progressive strips where danger of exposure makes it advisable.

Modifications of the Method. - The Polewood* Coppice Method. - This method is intended for use on coppice rotations of 40 years or more where a mixture of seedling reproduction is wanted with the sprouts.

The stand is removed in two cuttings instead of the one clearcutting ordinarily employed with coppice. The first cutting is designed to establish seedling reproduction and is in the nature of a seed cutting. It removes the same classes of trees as the seed cutting under the shelterwood method, namely:

Diseased and defective trees.

Overtopped trees.

Trees with overdeveloped and spreading crowns.

Slender small crowned trees liable to be windthrown and those of undesirable species.

Approximately 30 to 60 per cent of the volume of the stand would be taken out in this first cutting. The per cent to be cut depends primarily upon the proportion of the area upon which seedling reproduction is needed. In the average mixed hardwood stand (which is the type where coppice is most com-

* First named and described by Henry S. Graves in "Principles of Handling Woodlands." 
monly used), there are some species which will sprout vigorously, even from the stumps of trees cut when 40 or more years old, and other species which sprout poorly or not at all

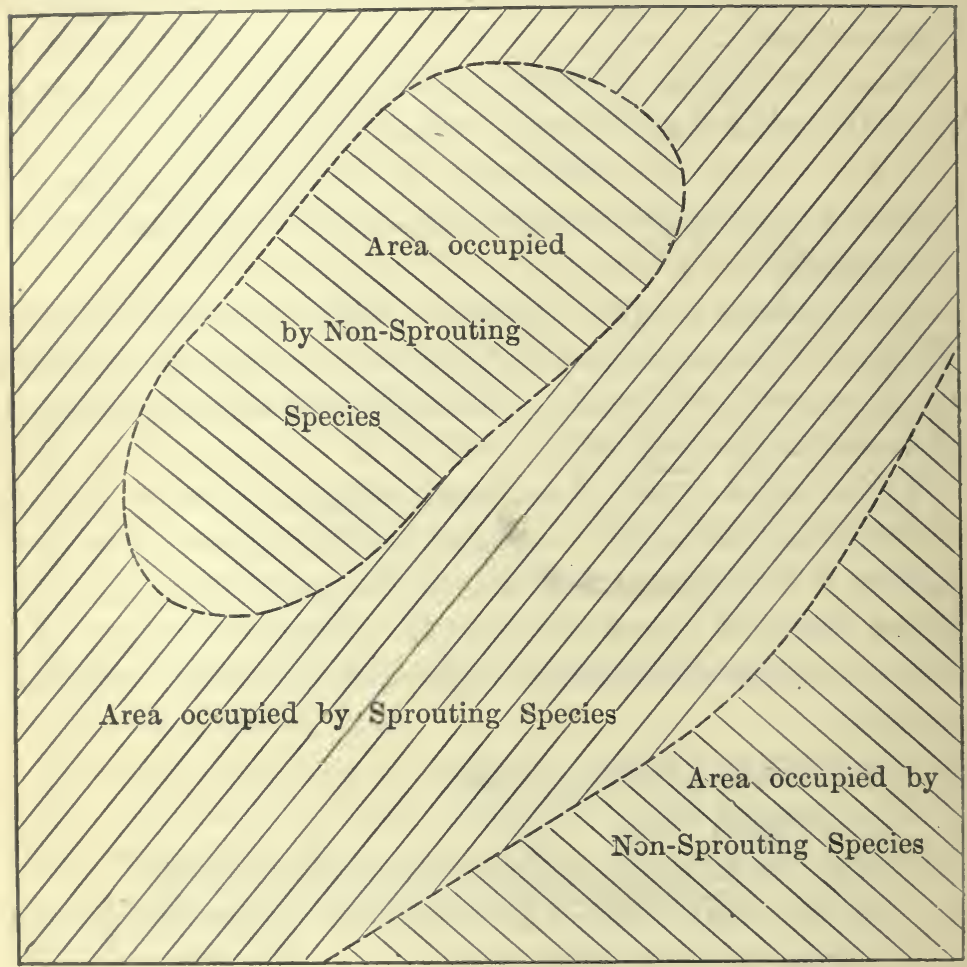

FIG. 42 .

A stand containing non-sprouting and sprouting species mixed groupwise showing the location of the areas occupied by each of the two classes of species. The first cutting will extend only over the areas occupied by non-sprouting species.

from similar stumps. It is necessary that provision be made for seedling reproduction to replace this latter class of species. The distribution of the vigorous and feeble sprouters may 
be uniform or of a groupwise character. When it is groupwise, patches of a quarter of an acre or more may be left unstocked unless seedling reproduction is obtained.

The first cutting is located with reference to the distribution of vigorous and feeble sprouting trees. Where there are enough trees capable of producing vigorous sprouts, seedling reproduction is not needed and a seed cutting is not made in that spot. Elsewhere a seed cutting is made to establish the needed seedling reproduction. (See Figs. 42, 43, and 44.)

The first cutting is made 3 to ro years before the end of the rotation. When seedling reproduction is established the stand is ready for the second and final cutting. This removes the remainder of the old stand. The area is left bare except for the seedling reproduction established previously. Sprout reproduction starts soon from the stumps capable of sprouting and joins with the seedlings to make a completely stocked stand. The sprouts usually equalize in this first year's growth the advantage in height which several years' start had given the seedlings.

Pollarding. - Sometimes trees are severely trimmed or lopped back with the intention of reproducing a growth of sprouts from the portion of the tree remaining. The sprouts are harvested when relatively small and another crop started. This is known as pollarding. The point of pollarding is usually between 4 and 12 feet above the ground.

Pollarding may be described as the coppice method operated on a short rotation and with abnormally high stumps. The method is first started when the original trees are io to 20 years old. A pollard head should remain productive for 60 to Io0 years, but finally becomes useless or unproductive due to the effect of decay. The method is particularly suited for use on lands frequently or deeply flooded, as the pollard head keeps the tender sprouts out of the way of injury 

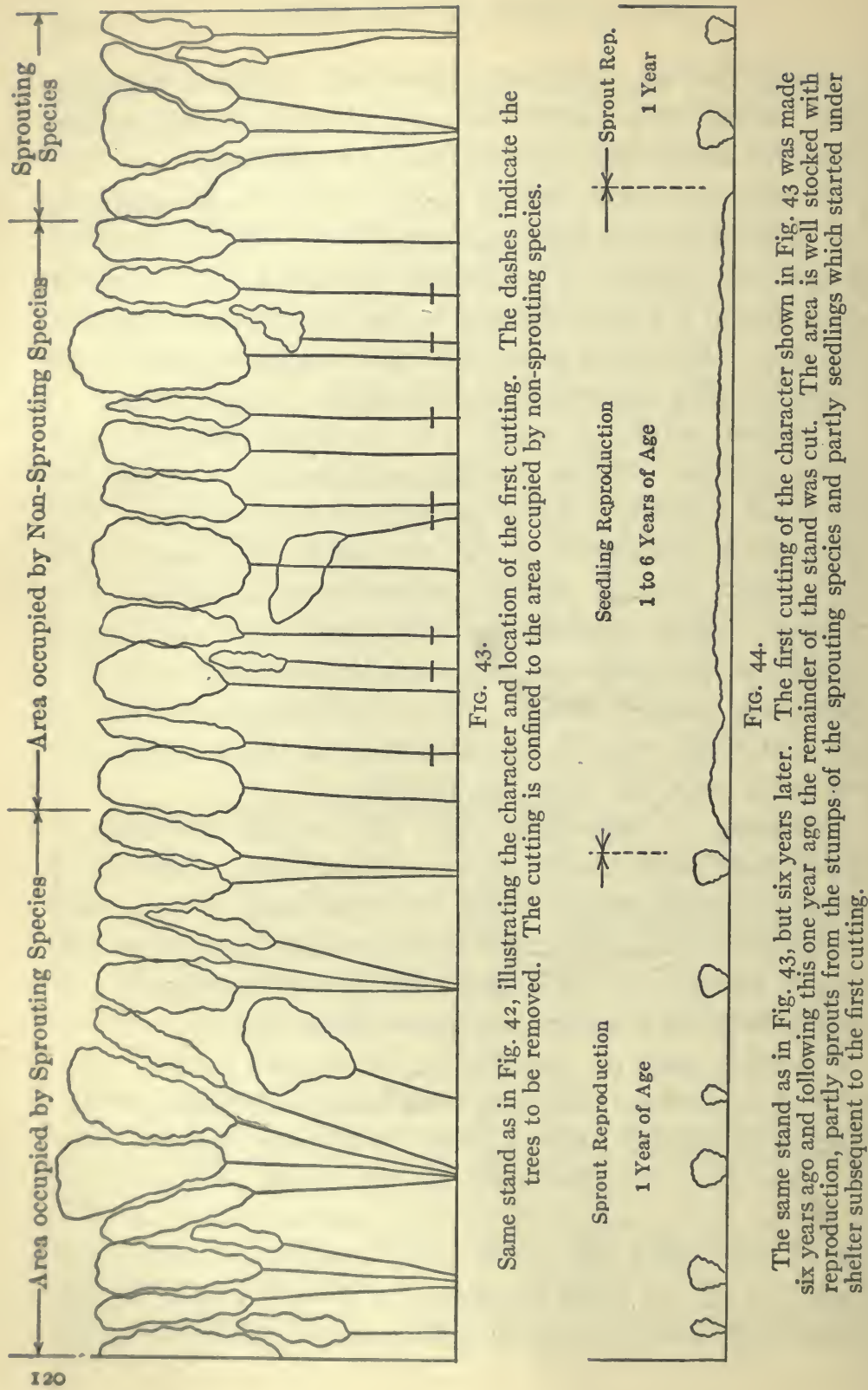
by water or floating débris and prevents their being submerged. Pollarding can be, and usually is, combined to advantage with partial use of the land for grazing or agricultural crops. The pollard heads are arranged far enough apart so that good grass for grazing can develop between them, while the sprouts are above the reach of the animals. The pollard heads may be placed still farther apart in rows where they serve as fence or vineyard posts. Agricultural crops are then grown between the rows of pollard heads. (See Fig. 45.)

Rotations in pollarding must be short, as the individual sprouts cannot develop independent root systems and, if allowed to reach large size, would break off from the pollard
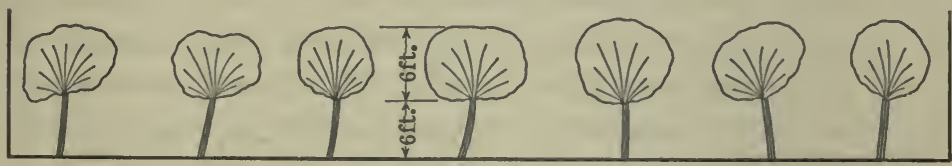

FIG. 45 .

A row of trees managed under the method of pollarding. The young shoots above the pollard heads are one year old and ready to be cut.

head often injuring the latter. From $I$ to 15 years covers the range in rotation with ages less than five most commonly employed.

Advantages and Disadvantages of the Method. - The coppice method with its comparatively short rotation and reproduction from sprouts stands in strong contrast to the four high forest methods which depend on reproduction from the seed. It is to be expected that there will be distinct advantages and disadvantages applying to the coppice method as compared with the high forest methods.

Advantages. - I. Requires only a small growing stock and hence a low financial investment. This is a consequence of 
the short rotation used and holds true particularly for the very low rotations.

2. Although the wood produced is of comparatively small size and poor quality, the net return on the investment is relatively high, due primarily to the short rotation and the small amount of capital invested.

3. The period of most rapid growth (i.e., early youth) is taken advantage of by cutting the stand when this period is past and starting a new crop. Hence the amount of wood produced per year should be greater than under high forest methods. The fact that sprouts grow faster in early life than trees originating from seed supports this theory.

Short coppice rotations, while including the period of most rapid growth so far as low grade products such as cordwood are concerned, are not long enough to grow large amounts of better grade products like lumber. Therefore the advantage of faster growth under the coppice method is true only for products of small size.

4. Subject to comparatively few injuries; because the trees are still young and vigorous at the end of the rotation. Those which may occur can be made good with less sacrifice than under methods which require longer rotations.

5. The securing of reproduction by sprouts is simple and certain as compared with reproduction from the seed.

Disadvantages. - $\mathrm{r}$. Requires that lower grade products such as cordwood be salable. For intensive application on rotations of less than fifteen years it is necessary that a market exist for very small sized material. Except under the polewood coppice method lumber forms only a small percentage of the yield.

2. Coppice is unsatisfactory from the standpoint of the public welfare because:

(a) It fails to provide the lumber needed in the industries. 
This disadvantage is one having particular weight in the management of publicly owned lands.

(b) It does not provide, due to its low growing stock, a reserve supply of forest products for the future or to meet extraordinary demands.

3. It is a method which tends to exhaust the available mineral substances in the soil, because the product consists so largely of small branches and young wood which contain a greater proportion of minerals than larger and older wood. ${ }^{4}$

4. The sprouts are frequently damaged by frost. Young sprouts are apt to continue rapid growth until late in the season and fail to lignify before the fall frosts. The injury results in the killing back of all or parts of the last year's growth of the sprouts which, if not entirely killed, may continue growth the following season. Frost injury may be so serious as to prevent the use of the coppice method on sites subject to frost, such as the higher altitudes.

5. Esthetically coppice is not a desirable method, since it produces a relatively low forest and one too monotonous in its regularity to be attractive.

6. Coppice is considered the poorest method from the protection standpoint. The frequent clearcuttings and the relatively low total height attained by the stand result in exposure of the site. The tendency of coppice to exhaust the mineral contents of the soil is likely to be important on protection sites which are usually shallow-soiled and of poor quality. The prompt start after clearcutting and the rapid growth of reproduction have the effect of preventing the complete exposure of the site, which may follow clearcutting with reproduction from the seed.

Application of the Method. - Coppice with its small growing stock, low investment and quick returns appeals favorably to private land owners, but is not a satisfactory method 
for the publicly owned forest, because of its failure to produce the lumber required as an economic necessity by the community. Before a private owner can avail himself of the coppice method and its attendant advantages, there must exist excellent markets for small sized forest products and valuable species suited to the site and capable of reproducing by sprouts. The lack of one -or both of these essentials prohibits the use of the coppice method in many cases.

The coppice method as employed in European countries has been applied principally in the low lands adjacent to rivers, where the soils were comparatively rich and moist. Mountainous regions and other places where the fall frosts come so early that the sprouts do not have time during the short growing season to thoroughly lignify, are unsuited to coppice production.

In Germany coppice is considered adapted for use at elevations below 800 meters.

Abroad the rotations are very low ranging from one year for willow rods for baskets, up to 5 to 15 years for brushwood, hoop poles and vine props, and oak tanbark and rarely as high as 20 to 40 years for.cordwood.

In the State Forests of France which are reproduced under the coppice method, ${ }^{5}$ the areas may be classified according to length of rotation as follows:

\begin{tabular}{c|c|c|c|c}
\hline \multicolumn{1}{c|}{ Length of rotation } & $\begin{array}{c}\text { Under ro } \\
\text { years }\end{array}$ & $\begin{array}{c}\text { Io-r9 } \\
\text { years }\end{array}$ & $\begin{array}{c}20-29 \\
\text { years }\end{array}$ & $\begin{array}{c}30 \text { or more } \\
\text { years }\end{array}$ \\
\hline $\begin{array}{c}\text { Per cent occupied of the area in } \\
\text { coppice..................... }\end{array}$ & $\mathbf{I . 5}$ & 32 & 56 & 10.5 \\
\hline
\end{tabular}

Greeley ${ }^{6}$ states that 30 per cent of the private forests of France are managed for the production of hardwood fuel on 20 year rotations. 
In North America the principal field for the coppice method lies within the Central Forest region ${ }^{7}$ and in adjacent portions of the northern and southern forest regions. There the requirements for species of good sprouting ability can be met. The coppice method is being applied in many places all through this general district.

Usually certain special market requirements for one or more forest products have led to the development of coppice stands.

The culture of the basket willow is an example of coppice production on the shortest possible rotation - one year. ${ }^{8}$

Clearcutting of hardwood stands with sprout reproduction on rotations of 20 to 40 years for cordwood to be burned in brick yards, lime kilns and brass mills or converted into charcoal for industrial uses has been systematically employed in the past and is still in operation in various parts of the country.

In the prairie region and other sections having a large percentage of agricultural land in comparison to forest soils, the markets for small hardwood material for posts or fuel are sufficiently good to make profitable their production in coppice stands. Often such stands may be established as plantations to be reproduced and handled thereafter under the coppice method.

The Eucalypts which have been introduced into California can be handled successfully in coppice stands.

\section{REFERENCES}

I. ZoN, Raphael. Chestnut in Southern Maryland. Bulletin 53, Bureau of Forestry, United States Department of Agriculture, Washington, rgo4.

2. Matroon, W. R. The Origin and Development of Chestnut Sprouts. Forestry Quarterly, Vol. VII, rgo9, pp. 34-37.

3. Williamson, A. W. Cottonwood in the Mississippi Valley. Bulletin 
24, United States Department of Agriculture, Washington, 1913, pp.17-18 and p. 30.

4. Nisbet, J. Studies in Forestry. Oxford, I894, p. 88.

5. Marrin. Mitteilungen uber forstliche Verhältnisse in Frankreich. Forstwissenschaftliches Centralblatt, Berlin, 1909, pp. 203-208.

6. Greeley, W. B. Private Forestry in France. American Forestry, Vol. 26, 1920, p. 139 .

7. Natural Forest Regions of North America. A map issued by the Office of Geography and the Dendrologist, Forest Service, United States Department of Agriculture, Washington, I9I0.

8. Hubbard. W. F. The Basket Willow. Bulletin 46, Bureau of Forestry, United States Department of Agriculture, Washington, I904.

Bagneris, G. Elements of Sylviculture. Translated from the French (2nd edition), by E. E. Fernandez and A. Smythies, B.A., London, I882, pp. III-I33.

Matroon, W. R. Life History of Shortleaf Pine. Bulletin 244, U. S. Department of Agriculture, Washington, 1915, pp. 20-25.

Reuss, Hermann. Die Forstliche Bestandesbegründung, Berlin, 1907, pp. 349-360. 


\section{CHAPTER VIII}

\section{THE COPPICE WITH STANDARDS METHOD}

Definition. - "A method of reproduction in which seedling trees or selected sprouts (standards) are maintained above a coppice or sprout forest." The definition, taken from "Forest Terminology," ${ }^{1}$ indicates the salient features of the method. Reproduction is from sprouts as in the coppice method, but the area is never cut entirely clear. Selected trees called standards are left standing at the end of each coppice rotation. The method is also known as Compound Coppice.

Form of Forest Produced. - Several age classes are found in compound coppice stands. The young coppice itself is all of one age and presents a uniform appearance. Above the coppice are standards belonging to several different age classes, each one of which is a multiple of the rotation age of the coppice. The form of stand produced is one of several stories, each evenaged but combined to create an irregular stand.

Details of the Method. - The Coppice with Standards method is most easily understood by taking ordinary coppice as the starting point and following step by step the development of a compound coppice stand. When the coppice reaches the end of the rotation instead of being cut clear, certain trees or standards are carefully selected and retained, the balance of the coppice being cut. The sprouts which follow the cutting form a distinct story under and between the standards.

A second rotation of the coppice passes and at its end standards are again selected from among the best trees in the coppice and the remainder is cut. Some of the standards left 
at the end of the first coppice rotation may be taken out but the better ones are left. After this cutting three distinct age classes or stories are represented, - the older standards now twice the age of the coppice rotation, the younger standards of an age equivalent to the coppice rotation, and finally the new generation of sprouts springing up from the recently cut coppice. This process may be continued through as many coppice rotations as desired, increasing by one for each succeeding cutting of the coppice the number of age classes occurring on the area. Eventually the older standards reach the age assigned for their rotation which will be a multiple of the coppice rotation. When this occurs, the oldest age class of standards is cut, at the same time that the coppice is harvested, and the poorest trees removed from the other classes of standards. From this point on, the number of age classes on the area remains constant. (See Figs. 46, 47, 48 and 49.) Where more than one species is reserved as standards, there may be a different rotation for the standards of each species.

Sprout reproduction is relied upon to maintain the coppice. This is possible because of the low rotation. The standards when finally harvested are usually too old to sprout. There may be a small area around the stump of a standard which is not stocked. If such is the case the gap is filled by planting.

Since the standards live through several coppice rotations, the danger of their becoming infected with fungi is great, if they originate from sprouts. Standards of seedling origin are less liable to such injuries than are trees of sprout origin; hence it is desirable that most of the standards have seedling origin. There may be a sufficient mixture of seedling reproduction starting naturally with each new crop of coppice. Indeed the presence of standards capable of furnishing seed tends to bring in more seedling reproduction than occurs in simple coppice stands. When natural seedlings of the right species 


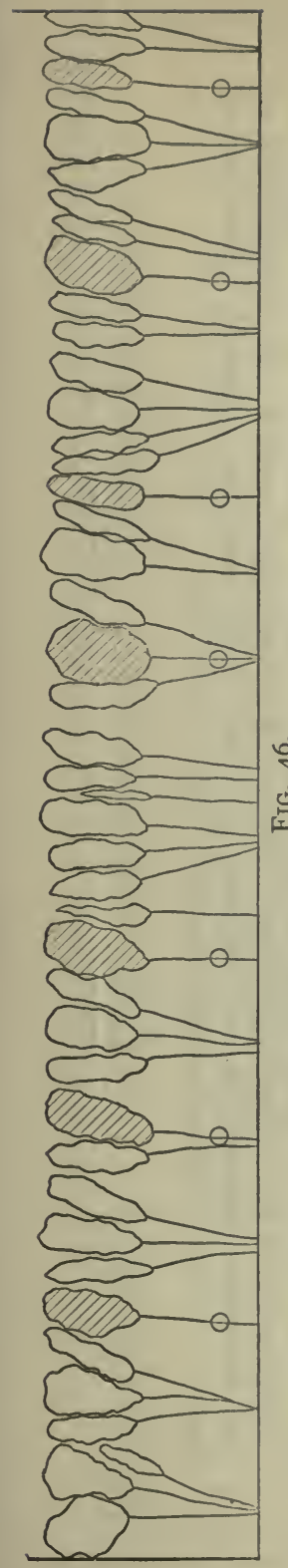

결

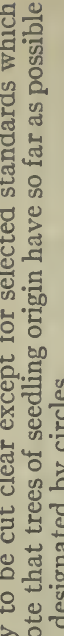

- 귫은

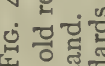

卧 స్త్ర

ฮึ ?

덜

일

च

焉

호용

잉

엉 \&

용면

$<$ 용

त्ठ

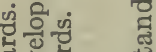

苛 菏

당

娄 0 可

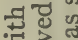

己

ษึ के

年

产

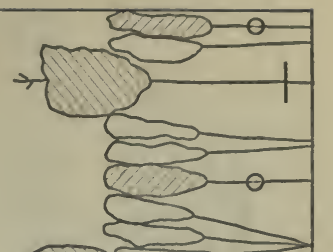

으

चु

로글

0

ํํㄴ

요ㅇㅛㅠ

๑

E

응

돌

สำ

운 웅

. 웜

ㄴ.

8

돌

证

ऊ

ำ ญ्ठ

거

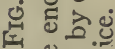
험

-

너요

ث્త్ర

का कै

는.으

त

언

ㄴํㅇ

อ

ำ

so जึञ

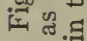

.$\Xi$

น.

엉.

苂讪

क

हี త్ ญ

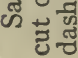




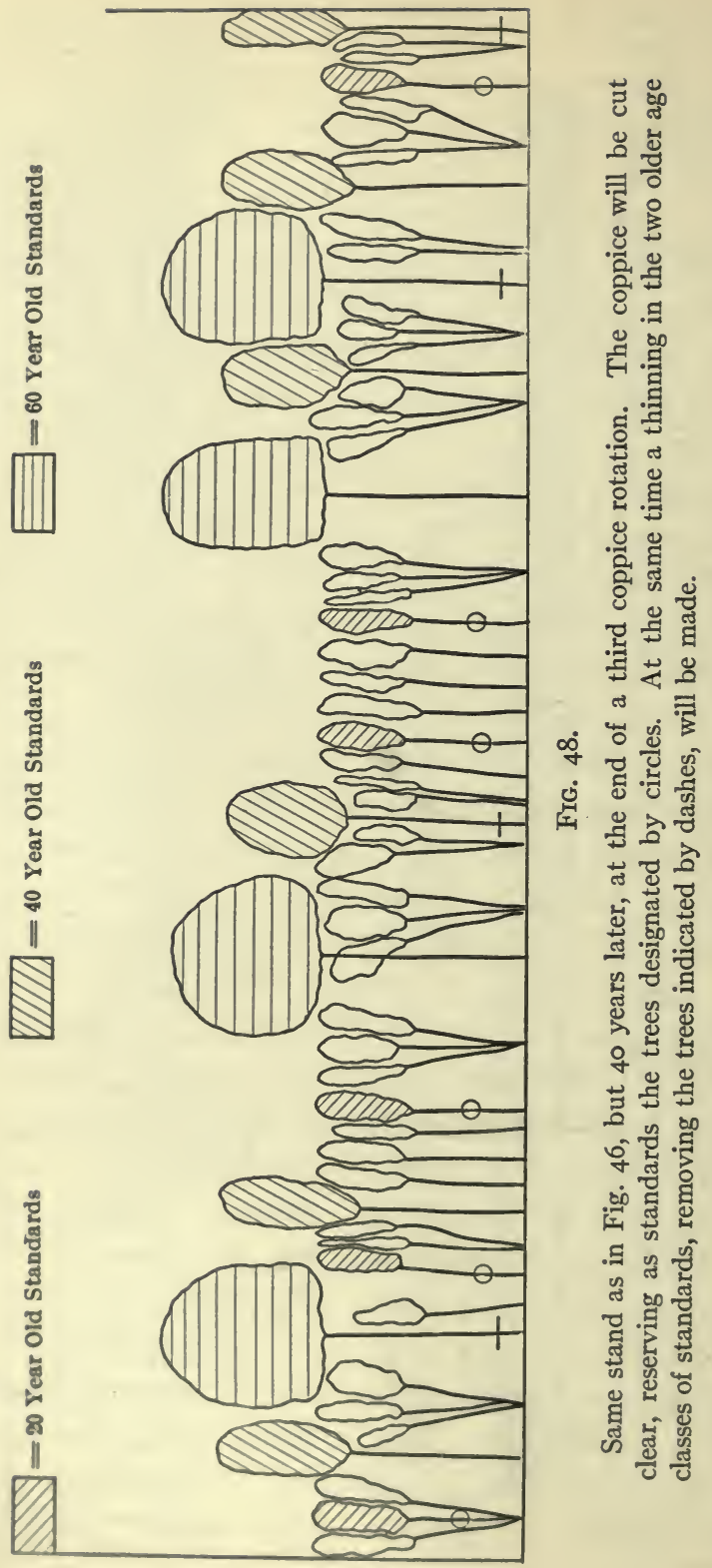




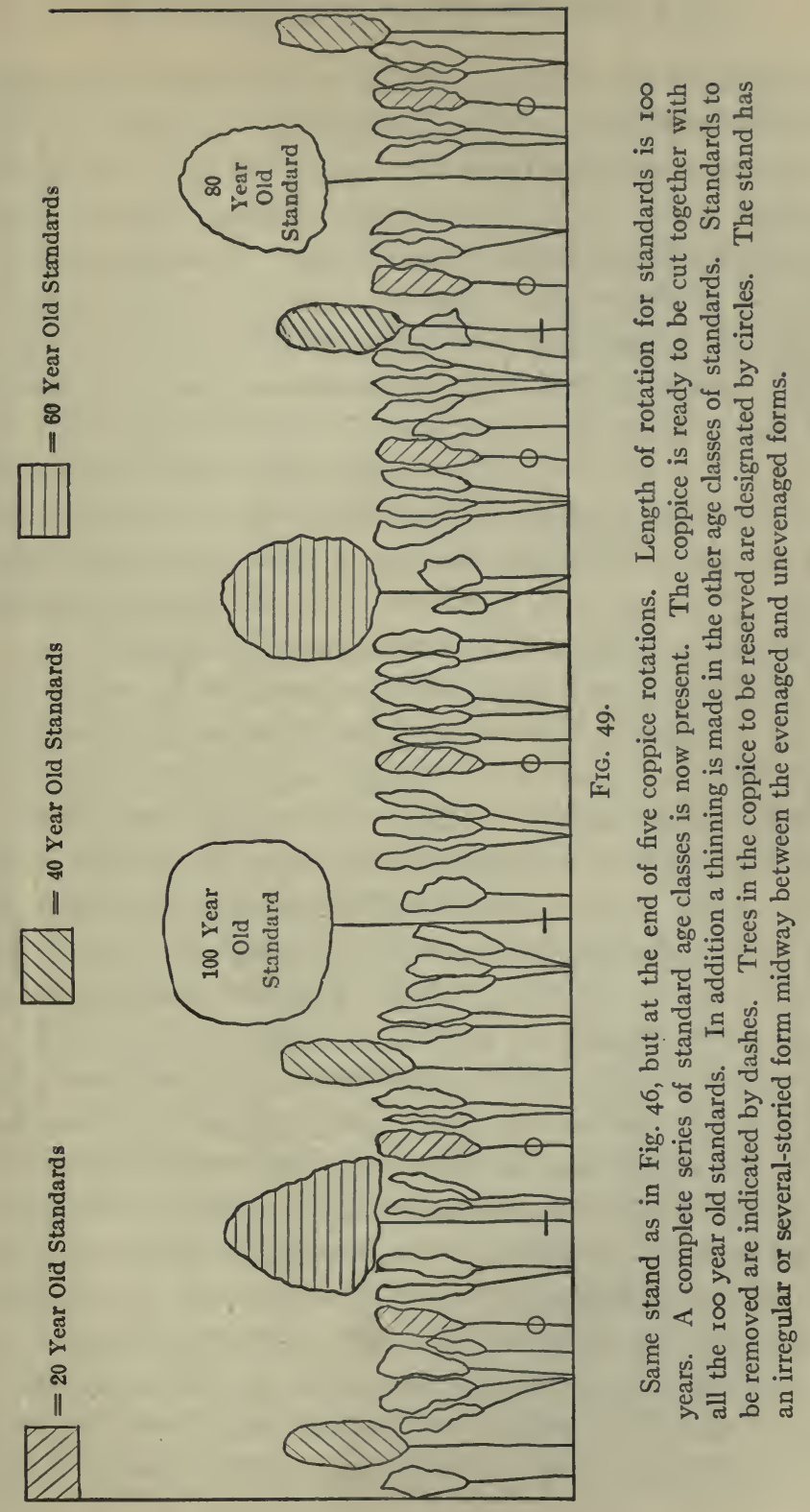


are available, the standards should be selected from among them. If seedlings are lacking, it becomes necessary to make provision for new standards by planting seedling trees among the stools when the coppice is cut. Plants for this purpose should be large, strong transplant stock to compete with the sprouts. If the species planted reproduces vigorously by sprouts, the transplants after being set out can be cut back carefully to the ground level. One or more vigorous sprouts start and compete more successfully with the coppice sprouts than the original transplant could have done. If several sprouts arise the number should be reduced to one. Such sprouts, termed "seedling sprouts," have the rapid initial growth of true sprouts, combined with the relative hardiness against disease possessed by trees of seedling origin.

The standards and coppice may or may not be of the same species. In general light-foliaged species are favored as standards, while trees capable of thriving under a partial cover are desirable in the coppice. The coppice furnishes cordwood and other products of smaller size, hence the species in the coppice must produce wood which has a value while still young. Standards grow until large enough for lumber and should be chosen for their ability to grow throughout several coppice rotations and for the value of their lumber yield. It is often desired to introduce a species not found on the site as a standard. A conifer of high timber producing value may thus be employed as a standard over hardwood coppice.

Rotations for the coppice range up to 25 years, which is as long an interval as should ensue between cuttings among the trees in the various age classes of standards. The coppice rotation may be as much lower than 25 years as markets for the small products permit; but good standards cannot be produced unless the coppice is grown on a relatively long rotation and becomes high enough to provide standards with 
fairly clear boles. The rotation for the standards may be any multiple of the coppice rotation. Rarely would it be advisable to extend such a rotation longer than four or five times the length of the coppice rotation.

In selecting trees to be left as standards, the question arises as to how many should be left per acre. This is contingent not only upon the silvical habits of the species, particularly their light requirements and spread of crown, but primarily upon the relative extent to which the standards as contrasted to the coppice are to be favored.

There may be distinguished three forms of coppice with standards ${ }^{2}$ depending on the relation between the standards and coppice.

(a) Compound coppice approaching simple coppice, where the overwood of standards is distributed by single trees of only a few age classes and occupies a small part of the area. Firewood is the chief product.

(b) Normal compound coppice, in which the sprouts and the standards are of equal importance and both cordwood and timber are produced in quantity.

(c) Compound coppice approaching high forest, in which the standards occupy a large part of the area, usually in groups, and the coppice possesses the importance only of a soil protecting cover. Timber is the principal product.

These three forms indicate the possible field of variation in mixture of sprouts and standards, which is available between a stand composed of coppice sprouts or a high forest.

Area covered by the spread of the crowns is the basis for judging the part of the stand occupied by the standards. The percentage of the total area allotted to the standards should be decided upon before any cuttings are made.

After determining the portion of the total area to be devoted to standards, it should be apportioned equally among 
the several age classes of standards which will be present. If, for example, 0.5 of the area is allotted to standards and there are five age classes of standards on a rotation of $\mathrm{I} 20$ years, with a coppice rotation of 20 years, then O.I of the area should be occupied by the standards of each age. Each age class of standards occupies the same area as it increases in age throughout the rotation. As a necessary corollary each age class of standards must contain more trees when first established than at the end of the rotation, because each individual tree occupies more space with increase in age. In order to keep the area occupied by standards of a given age approximately constant, it is necessary to reduce their number occasionally. (See Fig. 50.)

This is done at the time the coppice is cut clear. Where standards are in dense groups overtopped, intermediate or codominant trees may be cut in a thinning without decreasing the area filled by the age class, but in addition other standards must be cut, which will actually reduce temporarily the area occupied by that class.

The relative number of standards at different ages must be worked out for each species and situation. The following illustration for oak in a European forest is cited by Graves ${ }^{3}$ :

Number of Standards

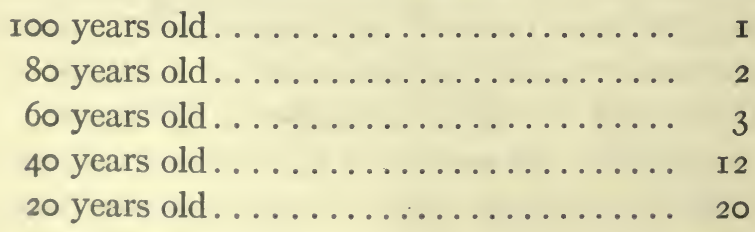

A uniform distribution of standards over the area need not be attempted. They may be left singly, wherever desirable trees for standards occur among the coppice, or in groups. 
This latter plan has especial merit for conifers, introduced artificially, in producing clearer boles.

The isolated position of the standards with full light from all sides, particularly for a few years after the periodic cutting of the coppice, often results in the formation of epicormic

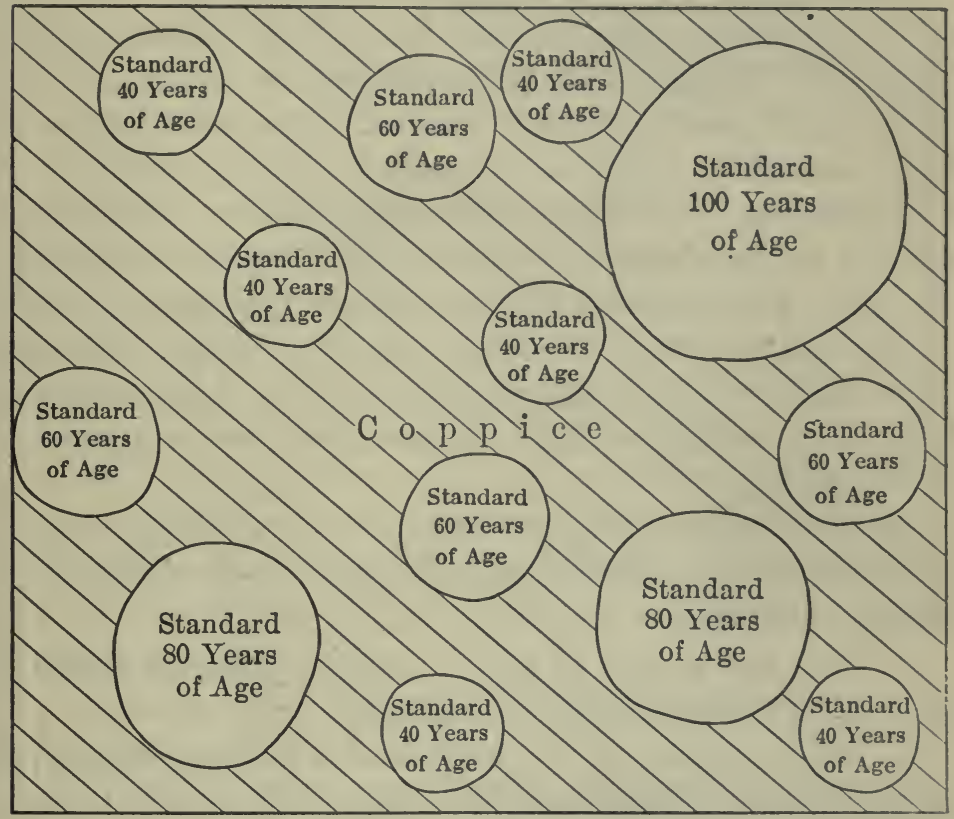

Frg. 50 .

An illustration of the distribution of the area between the coppice and each age class of the standards. The stand is assumed to be at the end of a 20 year coppice rotation just before the cutting. Rotation for the standards is 100 years. In this diagram 0.6 of the total area is in coppice. The balance, 0.4 of the total area, is equally distributed between the $40,60,80$ and 100 year old standards. The new standards, 20 years in age, to be left after the cutting of the coppice are included in the area allotted to the latter. The roo year old standards will be cut in the same operation and the new 20 year old standards will occupy the area otherwise lost to the standard classes by cutting the old trees. 
branches on trees which have not an adequate crown development. ${ }^{2}$ Pruning to remove such branches is advisable, as an otherwise clear stem may be rendered knotty.

Modifications of the Method. - There are none which merit special consideration.

Advantages and Disadvantages of the Method. - Coppice with standards occupies a position intermediate between simple coppice and the high forest methods, though nearest in character to the former, and shares in a lesser degree the advantages and disadvantages of coppice as contrasted with high forest.

Advantages. - I. The benefit of rapid growth of individual trees in an open stand is secured without danger of exposing the soil. The standards grow in isolation throughout a large part of their life, while the coppice protects the site. Equally rapid growth of individual trees cannot be obtained under high forest methods without exposure of the site or expensive under-planting.

This advantage is greatest with species whose timber value per thousand feet board measure is appreciably enhanced as diameter increases.

2. Does not require so large a growing stock or financial investment as do high forest methods.

3. The net return on the investment is relatively high, due to the amount of capital invested and in some cases to high prices received for material of large size.

The following illustration taken from experience in Baden will illustrate the effects of advantages 2 and $3 \cdot{ }^{2}$

\begin{tabular}{|c|c|c|c|}
\hline & $\begin{array}{c}\text { Annual cut per } \\
\text { acre }\end{array}$ & $\begin{array}{l}\text { On a growing } \\
\text { stock of }\end{array}$ & $\begin{array}{l}\text { Volume } \\
\text { growth, } \\
\text { per cent. }\end{array}$ \\
\hline 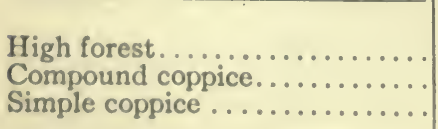 & $\begin{array}{l}\text { Cubic feet } \\
62.86 \\
65.68 \\
58.62\end{array}$ & $\begin{array}{l}\text { Cubic feet } \\
346 \mathrm{r} \\
1642 \\
600\end{array}$ & $\begin{array}{l}\text { I.82 } \\
4.00 \\
9.76\end{array}$ \\
\hline
\end{tabular}


4. Furnishes excellent protection both to the site and to the stand against injuries by frost, heat and wind. In these respects the method resembles selection. Since the younger standards are always on the ground, a partial cover is constantly maintained and the coppice springing up quickly after each cutting affords additional protection. The standards are windfirm, having been gradually accustomed to greater and greater exposure, while by their cover they protect the young coppice from frost, excessive drouth and evaporation.

5. Coppice with standards is æsthetically a desirable method to use. Although less irregular in appearance than a selection forest, a compound coppice stand permits development of fine individual trees, contains several age classes at all stages and does not produce the regular form which is a consequence of the use of certain other methods.

6. The natural factors of the site are utilized to the fullest extent, because the root systems of the coppice underwood and the several age classes of standards penetrate to different depths in the soil, and the crowns are arranged correspondingly at different heights.

7. As compared with simple coppice, compound coppice has the advantage of:

(a) Abundant seed production by the standards, thus providing for an excellent representation of seedling trees among the coppice sprouts.

(b) Permits the production of considerable saw timber and with a larger growing stock provides more adequately for future demands.

Disadvantages. - I. Requires a high degree of skill in the application of silviculture and in the regulation of the amount to be cut. This comes from the complicated form of stand which must be maintained and from the fact that in the man- 
agement of the standards more consideration is given the requirements of the individual tree than is the case under other methods.

2. Although timber is likely to be the principal product, yet, just as with simple coppice, there must be a market for cordwood or other low grade products.

3. The standards being grown in relatively open position may have a poor tree form, short clear length and large branching top. On poor soils this is more to be feared than on deep moist soils. On the former class of soils compound coppice should not be used. This defect can be remedied to some extent by pruning. With hardwood timber, comparatively clear wood of wide dimension is more desirable than trees of smaller size entirely clear of knots. ${ }^{4}$

4. Coppice with standards makes relatively high demands on the fertility of the soil, though not so exacting in this respect as simple coppice. For this reason Schwappach ${ }^{5}$ considers the method suited to rich bottomlands subject to inundation, and states that only on such situations will the volume of money returns equal those secured from high forest.

Application of the Method.-Compound coppice is of ancient origin in Europe, the reserving of standards having been tried previous to 1600 . The method fell into disfavor due to the intensive silvicultural and regulation practice necessitated.

In North America silviculture has not been practiced long enough to furnish complete examples of such a complicated method of reproduction as coppice with standards.

There is good reason to believe that it will be employed throughout much the same general regions as simple coppice and be applied by private owners rather than on public forests, for reasons similar to those given on page I23.

For the production of white oak, white ash, and tuliptree 
in stands of mixed hardwoods, and for the introduction of a small mixture of conifers into stands of hardwood coppice, compound coppice is likely to find favor in the future. The owner of a small area of woodland who desires to grow a little large sized timber in addition to fuel for home use will find the method useful.

Due to the protection from frost afforded the sprouts by the standards, compound coppice can be used at higher elevations than simple coppice. It should be confined to soils of good or at least average quality.

Conversion of Coppice and Coppice with Standards into High Forest. - In European countries, particularly France, the tendency during the last few decades has been toward the conversion of coppice and coppice with standards forests into high forests. The principal cause for this change in method is the relatively low prices prevailing for fuel wood.

The method employed in accomplishing this transformation, ${ }^{6,7}$ and 8. briefly stated, consists in:

First, lengthening the rotation to such ages that the coppice stools when cut will fail to sprout; and

Second, in making reproduction cuttings of the shelterwood type to establish seedling reproduction.

Shelterwood is a desirable method for reproducing most of the species found in the coppice stands. By the process described, the sprout stands can be transformed gradually into excellent high forest.

A similar procedure will undoubtedly be applied to some of the coppice stands in this country. With the virulent sprouting ability, rapid growth and merchantability on relatively short rotations of numerous native hardwood species, it is likely that use of the polewood coppice method will in certain sections of this country obviate the necessity of ever completely converting coppice stands to high forest. 


\section{REFERENCES}

r. Forest Terminology, Journal of Forestry, Vol. XV, r9r 7, p. 9r.

2. Havru, Julius. Der Ausschlagwald, Berlin, 1896 .

3. Graves, H. S. Principles of Handling Woodlands. Wiley \& Sons, Inc., New York, Igri, p. I87.

4. Намм, Julrus. Auen-Mittelwald und Lichtwuchs. Schweizerische Zeitschrift für Forstwesen, Bern, 1907, pp. I49-I55 and pp. 202-208.

5. Schwappach, Adam. Forestry. Translated from the German by Fraser Story and Eric A. Nobbs, London, I904.

6. Hawes, A. F. Conversion of Coppice Under Standards to High Forests in Eastern France. Forestry Quarterly, Vol. 6, I908, pp. I5I-I57.

7. Sмrтt, F. A. O. The Conversion of Underwood and Coppice with Standards into Highwood. Quarterly Journal of Forestry, Vol. 2, London, I908, pp. I54-I65.

8. MacMillan, H. R. Conversion Methods - A Visit to the Forests of Chaux and Faye De La Montrond, France. Forestry Quarterly, Vol. 14, I9r6, pp. 599-604.

Bagneris, G. Elements of Sylviculture. Translated from the French (2nd edition) by E. E. Fernandez and A. Smythies B.A. London, 1882, pp. I33-I 76 .

Kittredge, J., JR. Silvicultural Practice in Coppice Under Standard Forests of Eastern France. Journal of Forestry, Vol. I8, I920, pp. 5I 2-52I.

Mathey, M. A. Traitement et Amenagement d'un taillis sous futaie. Bulletin de la Sociéte Forestière de Franche-Comté et Belfort, Besançon, Igog, pp. $221-227$. 


\section{CHAPTER IX \\ INTERMEDIATE CUTTINGS}

Treatment of the Stand during that Portion of the Rotation not included in the Period of Regeneration

Definition and General Considerations. - The period of regeneration comes at the end of the stand's life and covers, for all evenaged stands, only a small portion of the rotation. Throughout the greater part of its life from the time of establishment on until the reproduction period arrives, cuttings are needed at varying intervals and for different specific purposes, although all with the common aim of correcting the defects of the unmanaged forest and increasing the amount and value of the timber produced.

All cuttings made during this period are termed intermediate cuttings.

Intensive practice of silviculture demands that intermediate cuttings be applied systematically throughout the rotation, in order to realize the highest returns. Unfortunately, intermediate cuttings, which in general do not create permanent openings in the forest canopy, remove material that is of relatively poor quality and small size as compared with the trees left. As a consequence they cannot always be made with immediate financial profit where opportunities for selling such products are lacking. Frequently an actual cash outlay will be required. Such an expenditure may be fully justified by the future returns to be derived, but require too much of a present investment to meet the owner's circumstances. There will be many forests where intermediate cuttings cannot be 
made under the existing conditions for marketing forest products.

The principles of intermediate cuttings apply to stands reproduced under any of the standard methods of reproduction.

Classification of Intermediate Cuttings. - The classification of intermediate cuttings is a matter upon which complete agreement is lacking. As given below, the classification varies somewhat from the one in "Forest Terminology" which can be condensed to advantage. See Appendix.

\section{Classification of Intermediate Cuttings}

Cleaning. - A cutting made in a young stand, not past the sapling stage, for the purpose of freeing the trees from other individuals of similar age but of undesirable form or species which are overtopping or are likely to overtop the former trees. The terms "assistance cutting," 1 " disengagement cutting," 2 "release cutting" and "weeding," 3 are synonymous.

Liberation Cutting. - A cutting made in an immature stand for the purpose of freeing the young growth from older individuals (wolf trees) which are overtopping.

Thinning. - A cutting made in an immature stand for the purpose of increasing the rate of growth of the trees that remain and the total production of the stand.

Improvement Cutting. - A cutting made in a stand past the sapling stage for the purpose of improving the composition and character by removing trees of undesirable species, form and condition.

Salvage Cutting. - A cutting made for the purpose of removing trees killed or damaged by various injurious agencies, of which fungi, insects, and fire are the most serious. 
Severance Cutting. - A cutting made by clearing a narrow strip along the edge of a young stand for the purpose of developing a belt of windfirm trees along the border of the stand.

Pruning. - A cutting which removes branches from standing trees for the purpose of increasing the quality of the final product.

A detailed discussion of the various intermediate cuttings will be found in the succeeding pages.

During the life of a stand there may or may not be need of applying all kinds of intermediate cuttings; but if applied they are likely to occur in the following order:

\begin{tabular}{|c|c|c|}
\hline Kind of cutting - & Time of application & Remarks \\
\hline Cleaning ........... & Ist to 20 th year & Frequently unnecessary \\
\hline Liberation cutting... & Ist year to middle age & Frequently unnecessary \\
\hline Thinning. . & $\begin{array}{l}\text { 2oth year to beginning } \\
\text { of period of regen- } \\
\text { eration }\end{array}$ & $\begin{array}{l}\text { Needed in all fully } \\
\text { stocked stands }\end{array}$ \\
\hline Improvement cutting & $\begin{array}{l}\text { 2oth year to beginning } \\
\text { of period of regen- } \\
\text { eration }\end{array}$ & $\begin{array}{l}\text { Usually required in } \\
\text { mixed stands previ- } \\
\text { ously unmanaged }\end{array}$ \\
\hline Salvage cutting...... & $\begin{array}{l}\text { 2oth year to beginning } \\
\text { of period of regener- } \\
\text { ation }\end{array}$ & $\begin{array}{l}\text { Used only in case of in- } \\
\text { jury to the stand }\end{array}$ \\
\hline Severance cutting.... & $\begin{array}{l}\text { Ist quarter of the ro- } \\
\text { tation }\end{array}$ & $\begin{array}{l}\text { An intensive operation, } \\
\text { little used as yet }\end{array}$ \\
\hline Pruning... & $\begin{array}{l}\text { Ist quarter or half of } \\
\text { the rotation }\end{array}$ & $\begin{array}{l}\text { Advisable only in spe- } \\
\text { cial cases }\end{array}$ \\
\hline
\end{tabular}

Application in Evenaged versus Unevenaged Stands. - In unevenaged stands the details of applying the principles are different from those employed in evenaged stands. The practice in the latter form of stand is the simpler and will be used as the basis in discussing the different kinds of intermediate cuttings except when otherwise specifically stated. In the 
evenaged stand each kind of intermediate cutting is applied as a separate operation, conducted independently of reproduction cuttings or other kinds of intermediate cuttings, and extends more or less uniformly over the whole area. In the unevenaged stand the period of regeneration is co-extensive with the rotation and there may appear to be no opportunity for intermediate cuttings. But reproduction is not in progress continuously in all parts of the stand. Each year certain small patches scattered through the stand are reproduced. When reproduction is once established on these patches, the period of regeneration closes so far as they are concerned. Any cuttings made in these small areas during the remainder of the rotation will be in the nature of intermediate cuttings. With many small areas of different aged trees within the same stand, there may be need for all kinds of intermediate cuttings simultaneously and in addition to the reproduction cuttings which are annually or periodically made. Reproduction and intermediate cuttings within the same stand are thus combined in one operation, although each class of cutting will be on a different portion of the area.

Thinnings, improvement cuttings and salvage cuttings are the principal kinds of intermediate cuttings likely to be made in unevenaged stands. Cleanings and liberation cuttings find less frequent application.

Cleanings. - Cuttings made in young stands (not past the sapling stage) for the purpose of freeing the more promising trees from other individuals of similar age but of undesirable form or species which are overtopping or are likely to overtop the former trees.

The principal purpose is to regulate the mixture to the advantage of the better species in the stand. In young growth composed entirely of one species, no question of regulating the mixture arises and cleanings are not so essen- 
tial. If cleanings are made at all in such stands, the object is to remove trees of poorer form than those that are being overtopped. (See Figs. 5I and 52.)

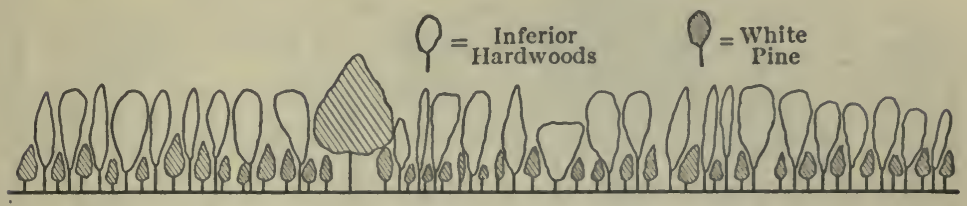

FIG. 5 r.

A stand of white pine and mixed hardwoods in need of a cleaning. The hardwoods and the large pine, which is too limby to make good timber, should be cut. See Fig. 52 .

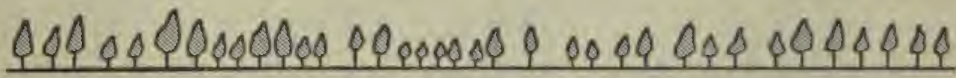

FIG. 52 .

Same stand as in Fig. 5I, but immediately after the cleaning has been made. This cleaning was made early enough in life so that the pine had not yet been deformed by the overtopping hardwoods. The operation results in transforming the stand from one dominated by inferior hardwoods to pure pine.

Cleanings are the first cuttings made in a new stand after its establishment and should take place as soon as the individuals which it is desired to help are threatened with injury. This rarely happens before the third or later than the tenth year. For a few years the shade afforded by undesirable species may be of benefit to the small seedlings of the more valuable species as a protective cover. The situation soon changes and instead of being a benefit the overtopping growth usurps the growing space, hinders the growth and, if allowed to remain, may cause the death of the better trees. (See Fig. 53.) Sometimes one cleaning is sufficient to regulate the mixture. More often two or three cuttings made at intervals of three to five years will be required to accomplish the purpose. This is especially the case when the trees re- 
moved possess sprouting ability. Trees taken out in cleanings belong to all four crown classes but principally to the domi-

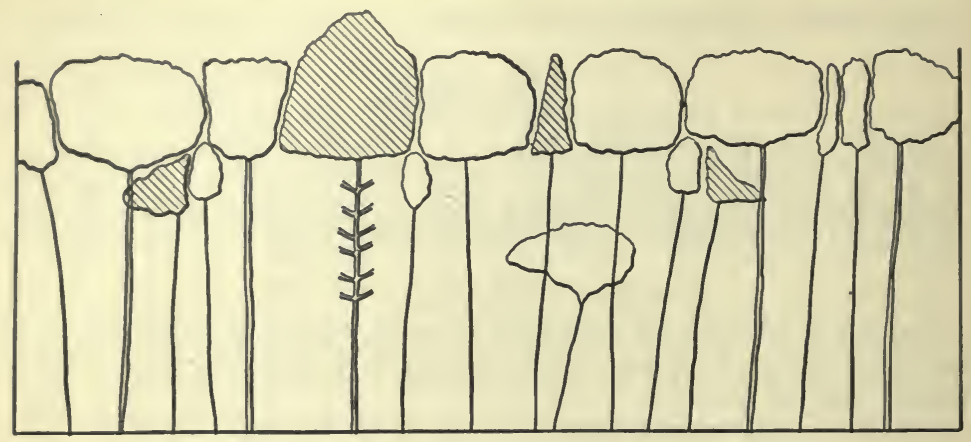

FIG. 53 .

The same stand as in Fig. 5I. The diagram shows the relative position of the pine and hardwoods 40 years later than the time of Fig. 5 I, provided no cleaning is made. Note that only one pine, namely the one which had a start over the hardwoods is now in a dominant position. The yield of this stand is principally cordwood instead of pine lumber, which could have been the chief product if a cleaning had been made. The pines are indicated by cross-hatching.

nant and co-dominant classes. Their removal creates small gaps in the upper canopy. Any openings of this character are quickly filled by the better trees coming up from beneath or expanding their crowns.

Specifically the material removed in cleanings consists of:

Trees of undesirable species.

Sprouts of a desirable species if seedlings of the same species can thereby be freed.

Advance growth of a desirable species if inferior in form to another individual of the same species which might thereby be freed. Scattered trees a few years older than the remainder of the stand because of their comparative freedom from side crowding have rather branchy crowns and will not develop into high grade trees. 
Shrubs and vines. Climbing vines, ${ }^{4}$ both by overtopping and by mechanically constricting and deforming trees, often prove as serious as competing tree species.

Several methods of making a cleaning may be employed. (See Fig. 54.) In the first the material to be removed is cut down fairly low to the ground in the usual manner. With

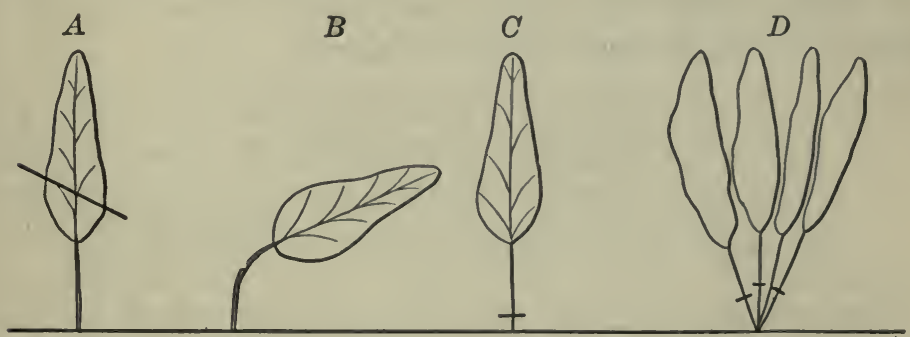

Fig. 54.

Various methods of eliminating the competition of undesirable trees in making a cleaning.

$A$. Lopping off the top. This should be done at a point below the level of the top of the trees to be freed.

$B$. Bending over.

C. Cutting off at the base.

$D$. Cutting off at the base of all trees, except one, on a clump of sprouts. This keeps the subsequent growth of the sprouts in check better than when all the trees in a clump are cut.

species which do not sprout this method is fully satisfactory. If the tree has sprouting ability, strong sprouts shoot up from the stumps and within a year after the cutting may again overtop the valuable species. The shade and competition of the undesirable species may be more oppressive than before the cutting. To avoid this other methods of cutting may be used.

In mixed stands of scrub oak and other hardwoods underplanted with pine, experiments have been tried of cutting the 
hardwoods with the exception of one sprout on a stool. ${ }^{1}$ The single sprout left retarded the development of a heavy sprout reproduction following the cleaning; on the whole the pine was left in better condition where this plan was used than when similar areas were cut clean.

If the trees to be freed are at the time of making the cleaning several feet high (three to six feet for certain species is the height under this plan), the trees removed instead of being cut near the ground may be either:

Lopped off so that they stand a few feet lower than the top of the valuable species and yet a few feet above the ground, or bent over with the top partially broken off at the same relative height as in the first case.

The new shoots which arise from the lopped off or bent over tops have not the vigor and rate of height growth of the sprouts starting from a low stump.

The relative heights and rate of growth of the trees to be favored and those to be cut must be considered in deciding upon the best method of making the cleaning.

A cardinal principle in making cleanings is never to cut more than is necessary to accomplish the purpose sought. Undesirable species should be cut only where threatening the health of better trees. Otherwise large and possibly permanent openings might be created because some of the undesirable trees are frequently needed during the first part of the rotation to complete the density of a stand partially stocked with valuable species. The item of cost is an additional factor rendering it advisable to restrict the amount of material removed in cleanings to the minimum.

The small size of the material taken out results in making a cleaning an operation which is a source of immediate expense, returning a profit only at some future time through an 
increased yield of the valuable species freed. In exceptional cases where the material removed is large enough for cordwood a cleaning will yield a small profit. Actual costs of making cleanings will range from a fraction of a day's labor per acre up to several days. ${ }^{5}$ Rarely can a cleaning be made for less than 50 cents per acre. An expenditure of more than \$10 per acre for cleanings should receive careful consideration. For freeing white pine planted on cut-over hardwood land, two cleanings in the third and sixth years after planting and requiring altogether from less than one to two days' labor per acre are considered necessary and justified by the benefits to be secured. In every case the increased net returns to be obtained as a result of the cleanings should be investigated before such cuttings are made. Cleanings usually can be justified where there is a wide difference in value of final product between the trees freed and those cut and where the yield of the valuable species will be greatly reduced if nothing is done. Plantations of conifers interfered with by hardwood growth furnish an excellent illustration of this principle.

A variety of tools will be found useful in making cleanings. The size of the material, method of making the cuttings and available room for using various tools should determine the selection. The axe is the best tool where the material is large enough for cordwood. In small brush, bushhooks, billhooks and heavy knives of the machete type can be employed to advantage.

Liberation Cuttings. - Cuttings made in immature stands for the purpose of freeing the young growth from older individuals (wolf trees) which are overtopping. Liberation cuttings are made during the same period in the life of the stand as are cleanings, but differ in that the former extend in application into middle age and take out trees larger and older 
than the young stand while the latter remove trees of approximately the same age as those freed. The trees removed in a liberation cutting are either individuals which were left standing when the previous stand was harvested, or (on open lands which have been reforested) trees which started by natural means on the area long before it was reforested.

Trees which have developed with abundant room on open lands are short and stocky in character with short clear length and a wide spreading crown; in other words wolf trees. Those left from previous cuttings while less spreading in habit are likely to be cull trees which it was unprofitable to cut. Trees of this character should not be confused with thrifty reserves which may have been left in the reproduction cuttings to grow through a second rotation.

Liberation cuttings should be made as early in the life of the young stand as possible. The shade and protection of these large trees soon ceases to be beneficial. If left too long, death of all the overtopped young trees may result. Less damage is caused to the young growth and less expense is involved in the removal of the large trees if the operation is accomplished when the young stand is only a foot or two in height. Where the operation has been delayed until the young trees are pressing with their crowns against the crowns of the overtopping trees and bending aside for light the result of the cutting is less satisfactory. (See Figs. 55 and 56 .) In the latter case it is possible that gaps large enough to require filling by artificial means may be created by the competition of the large trees and through damage inflicted in this remowal.

The ordinary practice in making liberation cuttings is to fell the trees, and utilize whatever merchantable material they contain. Carc must be taken to cut up the tops and place them in such position as not to interfere with the young growth. 
Another method employed is to girdle, but leave standing, the overtopping trees. Cutting a ring around the trunk through the bark and well into the sapwood will cause death

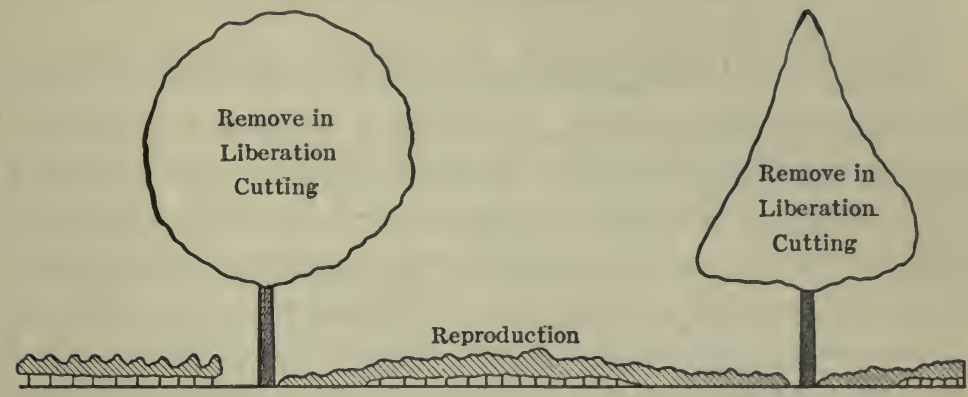

FIG. 55 .

A stand in need of a liberation cutting. The young trees as yet have not been seriously affected by the large overtopping trees.

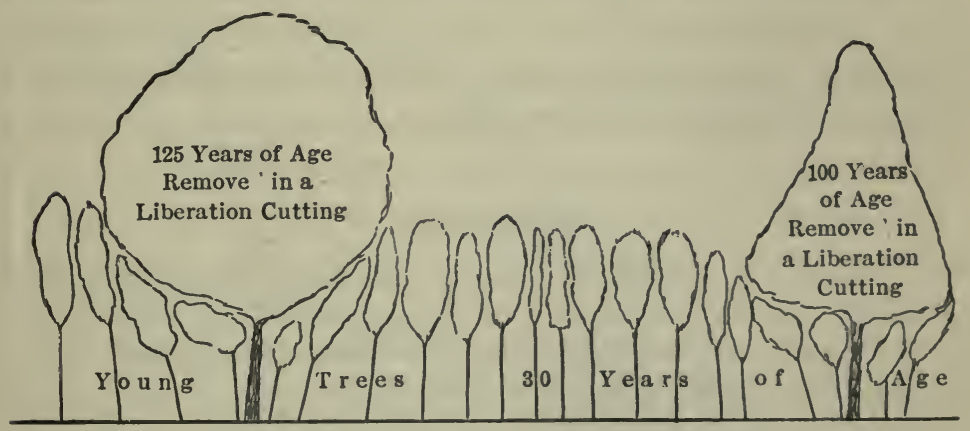

FIG. 56 .

A stand in need of a liberation cutting. The cutting should have been made 20 years ago before the young trees under the old ones had been deformed.

of the tree. Some species are harder to kill by girdling than others and the details of performing the operation should be varied to suit the conditions. The advantages of girdling are its cheapness and avoidance of damage to the young growth 
in felling. As the trees decay and fall to pieces some injury may be done to the young growth but far less than that caused by felling the trees. Girdling is particularly useful where the value of the material in the large trees is less than the cost of removal.

Whether an immediate money return can be secured from a liberation cutting cannot be predicted without a careful inspection of the overtopping trees and the difficulties attending their removal. Cordwood of good size is ordinarily one of the chief products and some of the trees may contain one or more logs merchantable for lumber. The expense of cutting up the branchy trees and bringing together the logs and wood sparsely scattered over an area occupied by young growth is so high as to seriously cut into the revenue received from the logs and wood. Unless cutting and taking out the merchantable material will at least pay all expenses of the work, girdling should be employed. This, although involving a small money outlay, will be found advisable in most cases on account of increased future yield.

\section{REFERENCES}

r. ILLICK, J. S. Preliminary Report of Some Forest Experiments in Pennsylvania. Journal of Forestry, Vol. XVII, I9I9, pp. 304-3II.

2. Sterretr, W. D. Disengagement Cuttings in Mixed Small Sapling Stands. Forestry Quarterly, Vol. XI, I9I3, pp. 62-63.

3. Fisher, R. T. The Yield of Volunteer Growth as Affected by Improvement Cutting and Early Weeding. Journal of Forestry, Vol. x6, 1918, p. 503 .

4. Tillotson, C. R. The Care and Improvement of the Wood Lot. Farmers Bulletin 7Ix, United States Department of Agriculture, Washington, 1916, p. 12.

5. Fisher, R. T., and Terry, E. I. The Management of Second Growth White Pine in Central New England. Journal of Forestry, Vol. 18, 1920, pp. 364-365. 


\section{CHAPTER $\mathrm{X}$}

\section{INTERMEDIATE CUTTINGS (Continued). THINNINGS}

Cuttings made in immature stands for the purpose of increasing the rate of growth of the trees that remain and the total production of the stand are termed thinnings.

Natural Development of the Stand. - The theory of making thinnings finds its basis in the natural process of development of the stand. The average stand starts life with a relatively large number (usually expressed in the thousands or even tens of thousands) of trees per acre. At the end of its life, when ready for the reproduction cuttings, the number has been reduced to a few hundred trees per acre - sometimes less than 100. (See Fig. 57.)

Ruthless competition for light, growing space, moisture and nourishment has accomplished this diminution in numbers. The individual trees which survive are well pruned of branches and contain a high percentage of clear lumber, but among them there are apt to be individuals of undesirable species or of poor form.

The struggle for existence may have been so fierce as to reduce the diameter and height growth. The competition between the trees is well expressed by the changes in relative position in the crown cover which are in constant progress. As the weaker trees are crowded by their associates their crowns are restricted and forced out of the normal shape, they bend aside seeking for light, are finally overtopped and ultimately die. It is a steady progression downward which only the strongest are able to escape. This differentiation is 
technically known as a differentiation into crown classes and standard crown classes are recognized. (See Figs. 58 and 59.)

Classification into Crown Classes. - The classification herewith given is that favored by the Society of American Foresters. See Appendix.

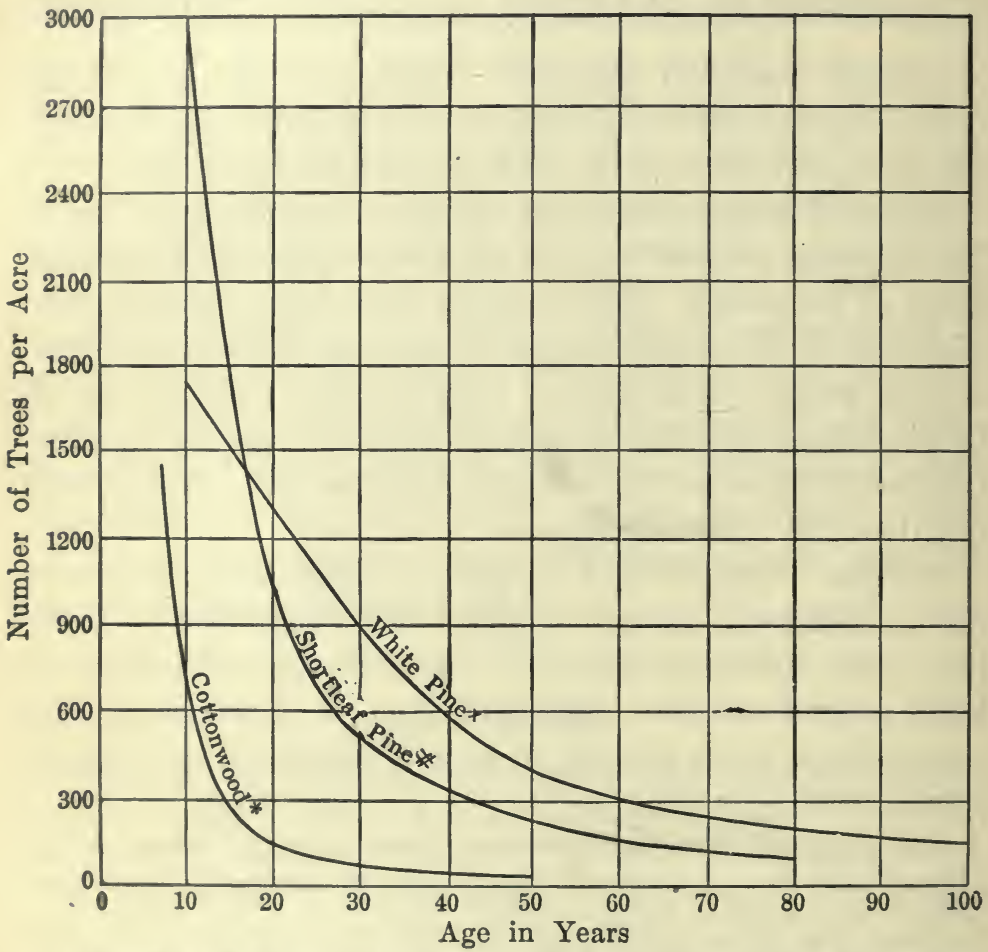

x Curve plotted from data on p. 2r, Bulletin I3, United States Department of Agriculture, entitled "White Pine under Forest Management".

* Curve plotted from data on p. 4I, Bulletin 244, United States Department of Agriculture, entitled "Life History of Shortleaf Pine".

- Curve plotted from data on p. 24, Bulletin 24, United States Department of Agriculture, entitled "Cottonwood in the Mississippi Valley".

Fig. 57 .

Curves showing the reduction in number of trees per acre due to natural causes with increase of age for stands of cottonwood, shortleaf pine and white pine on Quality I soils. 


\section{Standard Crown Classes}

Dominant. - Trees with crowns extending above the general level of the forest canopy and receiving full light from above and partly from the side; larger than the average trees $\mathrm{D}=$ Dominant trees. $\quad \mathrm{C}-\mathrm{D}=\mathrm{Co}$-Dominant trees. $\quad \mathrm{I}=$ Intermediate trees. $\mathrm{Op}=$ Oppressed trees. $\mathrm{S}=$ Suppressed trees.

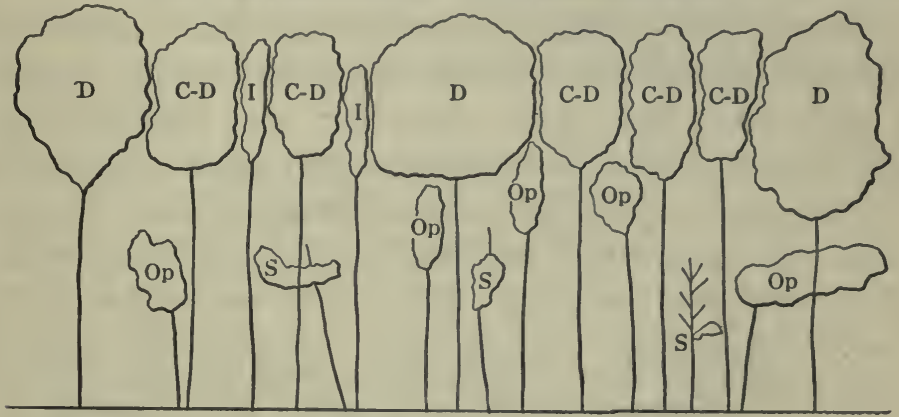

Fig. 58.

Illustrates the relative position of trees of the different crown classes.

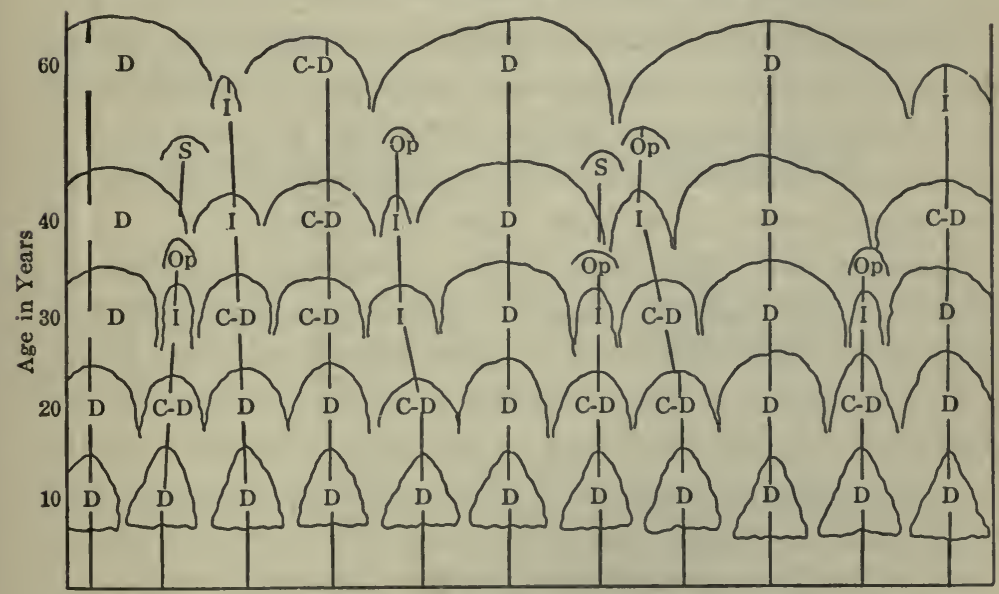

Fig. 59.

Illustrates the passing of trees from the dominant down to the suppressed crown class with advancing age, as a result of the struggle for existence. The letters indicate the crown classes of the trees. 
in the stand, and with crowns well-developed but possibly somewhat crowded on the sides.

Co-dominant. - Trees with crowns forming the general level of the forest canopy and receiving full light from above but comparatively little from the sides; usually with mediumsized crowns considerably crowded on the sides.

Intermediate. - Trees with crowns below, but still extending into, the general level of the forest canopy, receiving a little direct light from above but none from the sides; usually with small crowns considerably crowded on the sides.

Overtopped. - Trees with crowns entirely below the general forest canopy and receiving no direct light either from above or from the sides. These may be further divided into:

Oppressed. - Usually with small poorly developed crowns still alive, and possibly able to recover, and Suppressed, or dying and dead.

The silviculturist, while recognizing the value of the struggle for existence in assisting the production of lumber free from knots, attempts by making thinnings, to avoid its disadvantages of lessened production and inclusion of undesirable species and trees of poor form in the final stand.

Advantages of Thinnings. - The advantages of thinnings applied in the stand as compared with Nature's unrestricted competition can be summed up under the following headings:

I. The length of time required to grow products of the desired sizes can be shortened by the use of thinnings. This is accomplished through an increase in both diameter and height growth coming as a consequence of eliminating strong competition between individual trees. The trees remaining after the thinning have room to expand their crowns and root systems and secure large supplies of food, instead of fighting with numerous associates for part of the same total. 
The productive energy of the site is thus utilized by a smaller number of trees which are thereby enabled to attain a given size more quickly. It should be emphasized that not only is diameter growth increased but also to a lesser extent growth in height. The popular idea that height growth is directly dependent upon, and increases with the density of the stand is unsound. Height growth will be greatest when the trees are kept in the vigorous condition found in the properly thinned stand. ${ }^{1}$

The actual crown surface exposed to direct sunlight is greater in the thinned than in the unthinned stand, making possible faster growth. In the latter the crowns of the trees interlace with a relatively level top surface exposed to the sun with only occasional dominant trees raising a portion of their crown above the general level. After a thinning cuplike depressions exist between the individual trees allowing direct light to reach the sides as well as the tops of the crowns. Thus the crown area receiving direct light is greater. (See Fig. 60.)
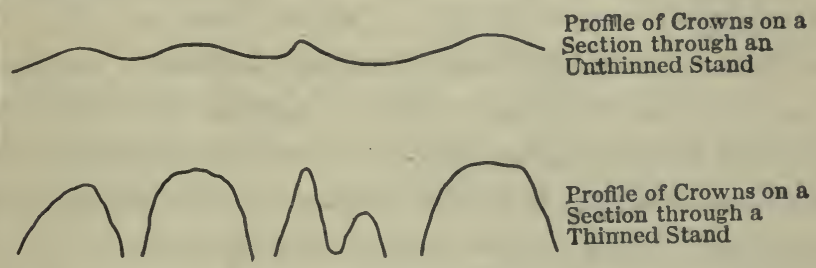

Fig. 60.

Profiles of tree crowns on sections through unthinned and thinned stands.

2. Thinnings raise the quality of the product composing the final crop. Trees of poor form, those containing defects or of relatively inferior species can be taken out and the few best trees left upon which growth will be concentrated. 
The larger diameters, and hence widths of lumber, obtainable from thinned stands heighten the value of the product. Greater crown development following the opening up of the stand by a thinning does not reduce the clear length of the trees. In fact although the crown may be lengthened by thinnings yet greater clear lengths may be produced on account of the greater total height in the thinned stand. ${ }^{1}$

3. By thinnings the total yield both in quantity and in value of product secured from a given area in a specified period will be increased. Various factors contribute to this result.

Thinnings remove and utilize principally trees which in the unthinned stand die in the struggle for existence and decay before the crop is harvested. As thinnings can be applied so as to increase the total quantity secured from thinnings and reproduction cuttings combined during a given period from 50 to roo per cent above the final yield of an unthinned stand the saving in amount of product is considerable.

The yield is increased in value for the reasons:

First, a higher quality of product is produced as explained under heading 2 .

Second, the thinnings furnish financial returns comparatively early in the rotation. With a timber crop which requires a long time to mature the time element involving compound interest charges is a vital factor in determining costs of product on. Early returns mean higher profits.

Third, the shorter rotation within which the same sized products can be grown as on a longer rotation in the unthinned stand has a favorable influence on the financial result similar to that exerted by the early returns from the thinnings.

4. Stands may be made more resistant to windthrow and breakage by ice, snow and wind if thinned. The expansion of the crown and root system following a thinning increases the power of a tree to withstand these agencies. A slender 
weak tree cannot quickly be converted into a resistant individual by one cutting. The change must come gradually. If a weak tree is too suddenly left unsupported the thinning may result in its being broken or overthrown.

5. Thinnings keep the stand free of unhealthy and dying trees in which insects and fungi find the best opportunities for development. The trees remaining in a stand systematically thinned, being exceptionally thrifty, do not succumb to the attacks of insects and fungi as easily as do the weaker trees in unthinned stands.

Time to Start Thinnings. - Theoretically thinnings are needed just as soon as the struggle for existence between the trees in a stand has become serious. This condition may arise within a few years after establishment in a densely stocked stand and is rarely deferred later than the tenth to fifteenth years. The density of stocking, productive power of the site and the spreading habit of the species determine the time for making the first thinning. The item of expense also should be considered. In young stands the material removed may not be valuable enough to pay the cost of the operation. A general rule is not to make the first thinning until the receipts will at least pay the expenses.

The life history of an evenaged stand may be divided into three stages from the establishment of the crop to the beginning of the regeneration period.

The first lasts so long as there is not a marked differentiation between individual trees. Its duration is brief and no intermediate cuttings, with the possible exception of a liberation cutting, are needed. The second begins with the differentiation into crown classes and is characterized as the period of height growth. This lasts for one to two decades during the early part of which cleanings to regulate the composition are required. In the latter part of the period an early thin- 
ning may be desirable in dense stands. During this period the tendency of the trees to expand laterally is not great and hence the loss of growth through keeping the stand dense is small.

The third stage begins when the trees in the stand show a strong tendency for lateral development. It is the longest period of the three and thinnings to increase the growth of the trees and the yield of the stand are demanded. In this stage the trees are capable after thinnings of increasing largely their rate of growth.

It is possible for a stand in need of a thinning to remain so long unthinned that it fails to respond when finally such a cutting is made. In a case of this kind the competition has continued so long and fiercely and the struggle between the individuals has been so even that diameter and height growth have suffered and the crowns, even of the dominant trees, have been reduced to small tufts at the tops of weak slender stems. After a thinning in such a stand the trees left are apt to suffer from drought, sunscald and insect attacks, be thrown or broken by wind and have apparently lost the ability to respond with increased growth. Stands densely stocked, growing on poor soil, are the ones most likely to be in this condition. The appearance of the crowns and boles, particularly the length of crown in relation to the total height of the tree, is the best indication of whether a stand has gone unthinned so long as to be incapable of profiting by a thinning.

Methods of Making Thinnings. - From what has been said previously, it will be evident that the relative position of the crowns of the trees is of primary importance in determining which trees should be removed and which left. The thinning must provide opportunity for expansion of the crowns and root systems of the trees left and must see that sufficient crown spread remains to fully stock the area. Crown classes furnish 
the principal basis for cutting or leaving a tree and the relative position of the crown of each tree must be observed with respect to its associates. The distribution over the area of the trunks of the trees is not so important because this may not coincide with position of the crowns.

The highest production as a result of thinnings can only be secured by leaving the largest number of trees per acre consistent with rapid growth of the individual. The individual tree may grow fastest out in the open, entirely isolated, but this would result in a low production per acre because the area would be only partially stocked. It is necessary to determine the minimum amount of growing space which the tree demands for fast growth and then keep the largest number of trees properly distributed over each acre which this growing space admits. As the stand grows older, the number of trees per acre must decrease because the crown. space required by each tree is steadily enlarging; but the total area occupied by the crown canopy should remain approximately the same. Quick and accurate measurement of the crown spread of the trees on a given area is difficult but the basal (sectional) area at breast-high is easily measured and can be safely substituted as an expression for the total crown spread.*

Using this idea the proper basal area (used as an indication of total crown spread and of the number of trees per acre at each age) for a given species and site should be determined and the stand kept close to this basal area by thinnings. "The total sectional area gives the best (single) indication of density, so much so that the extent of the thinnings

* The growth in volume of trees is dependent upon the activity of the crowns and may be considered proportional to the crown spread. Basal area may, for comparative purposes, be used as an abbreviated expression of the volume of the stand and for the purpose stated above be substituted for crown spread. 
to be carried out from time to time may be indicated by the total sectional area to be maintained on the ground, whereas this could never be done by number of trees." 2

Three distinct ideas in the method of making thinnings can be recognized, each leading to a different selection of the trees to be removed in a given stand. All three base the selection of the trees upon their crown classifications.

The three methods may be termed:

I. The German or ordinary,

2. The French, and

3. Borggreve's method.

Each will be discussed in turn.

The German or Ordinary Method of Thinning. - Sometimes termed "thinning from below."

In this method the principle used is to take out the poorest crown class (suppressed trees) first and then to work upward in consecutive order through the better crown classes increasing the number of classes removed with the severity of the thinning. The weakest trees and those which must be utilized immediately to save them from death and decay are cut and as many more of the intermediate, co-dominant, and dominant as the desired heaviness of the thinning warrants. All trees of the crown class next lowest would be cut before trees from another crown class were taken. After the heaviest thinning some members of the dominant class will remain but none of the other classes. Less severe thinnings leave representatives of other crown classes.

Based on the severity of the cutting, several grades of thinnings are recognized under the ordinary method: (See Appendix.)

Grade A. - Light. Removes suppressed trees.

Grade B. - Moderate. Removes in addition oppressed and poorest intermediate trees. 
Grade C. - Heavy. Removes in addition the remaining intermediate trees.

Grade D. - Very heavy. Removes in addition many of the co-dominant trees.

Interlucation or accretion cutting. Removes in addition the remaining co-dominant and a few dominant trees.

This classification is conservative. Under a more radical one additional trees to those specified might be removed under each of the various grades. (See Figs. 6r to 68.)

The amount removed in thinnings varies from as low as 5 per cent in a Grade A thinning to around 40 per cent of the total cubic volume in Grade D. Experience in this country is based upon the first thinning at different ages in stands previously unmanaged.

Tables of yield in feet, board measure, from thinnings for white pine (Pinus strobus) have been published by the Forestry"Commission of New Hampshire ${ }^{3}$ and the State Forester of Massachusetts. ${ }^{4}$ From these tables the following percentages have been calculated. The thinnings approximated Grade C.

Per Cent of Total Board Foot Volume Cut in Thinnings

\begin{tabular}{|c|c|c|c|c|}
\hline \multirow{3}{*}{$\begin{array}{c}\text { First thinning at } \\
\text { age of: }\end{array}$} & \multicolumn{4}{|c|}{ On site quality } \\
\hline & I & II & I & II \\
\hline & \multicolumn{2}{|c|}{ Based on New Hampshire figures } & \multicolumn{2}{|c|}{ Based on Massachusetts figures } \\
\hline Years & . & & & \\
\hline 25 & 9 & I 2 & $\mathrm{I}_{3}$ & 20 \\
\hline 30 & 20 & 30 & 20 & 30 \\
\hline 40 & 22 & 30 & I5 & 20 \\
\hline 50 & 20 & 25 & 13 & r8 \\
\hline
\end{tabular}

The author has found that in thinning sprout hardwood stands in Connecticut, 40 to 50 years of age, a Grade C thin- 


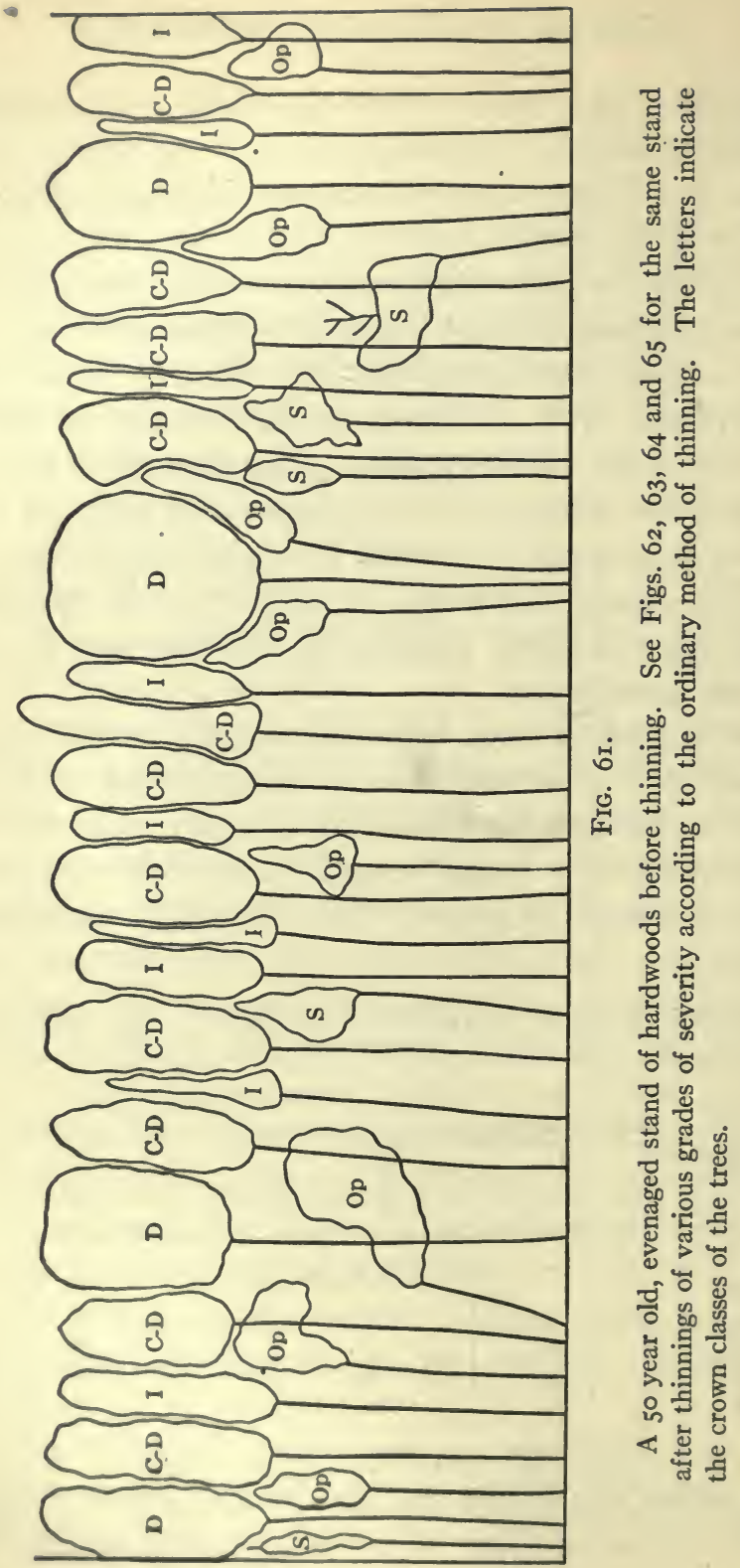




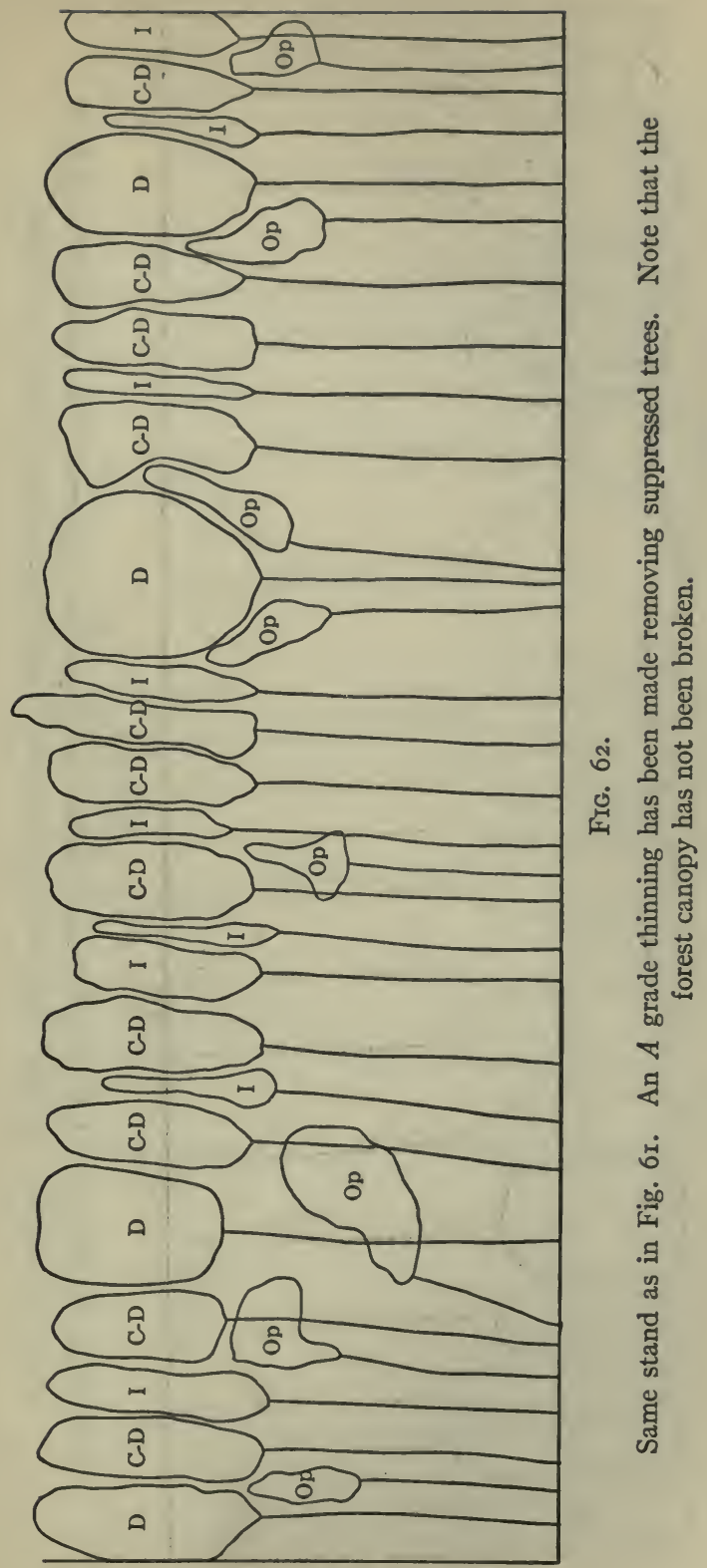




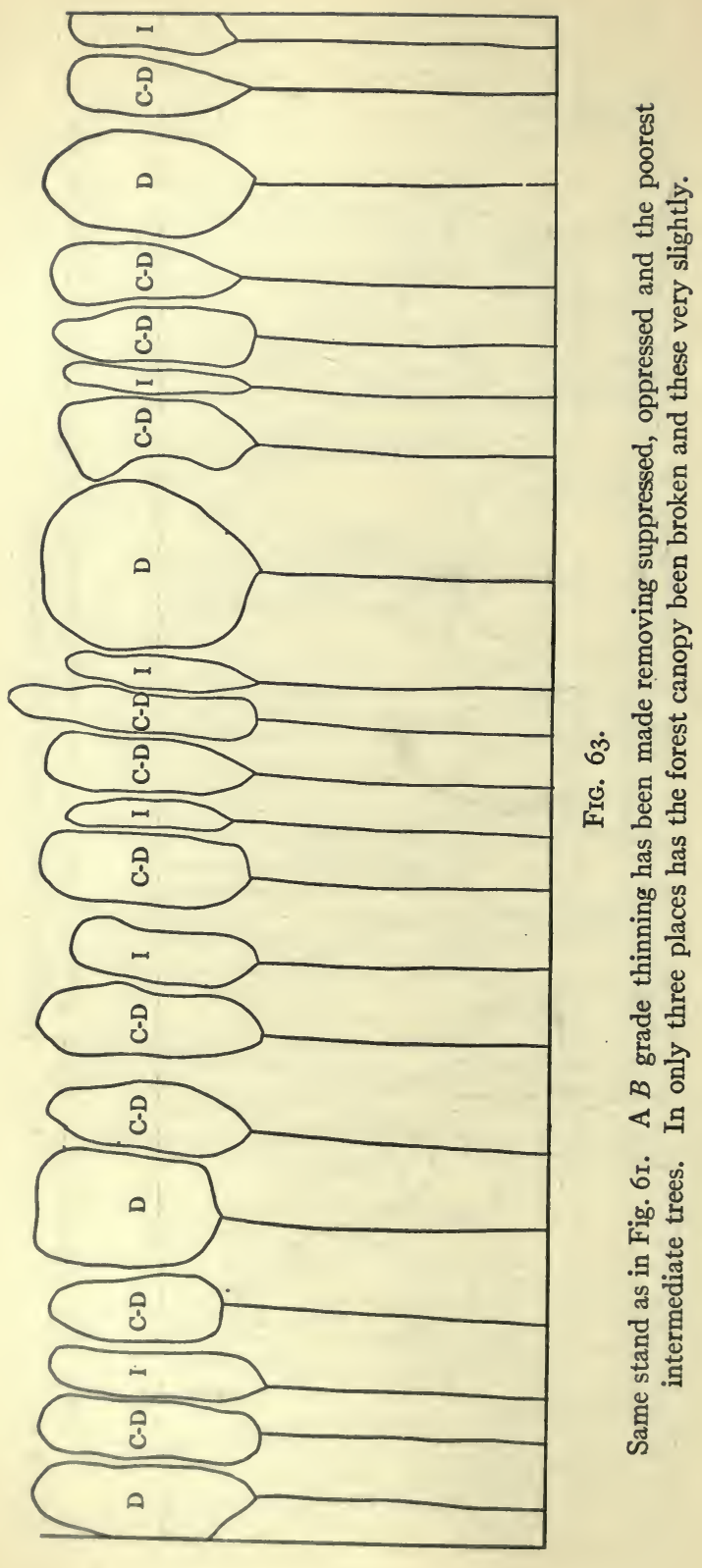




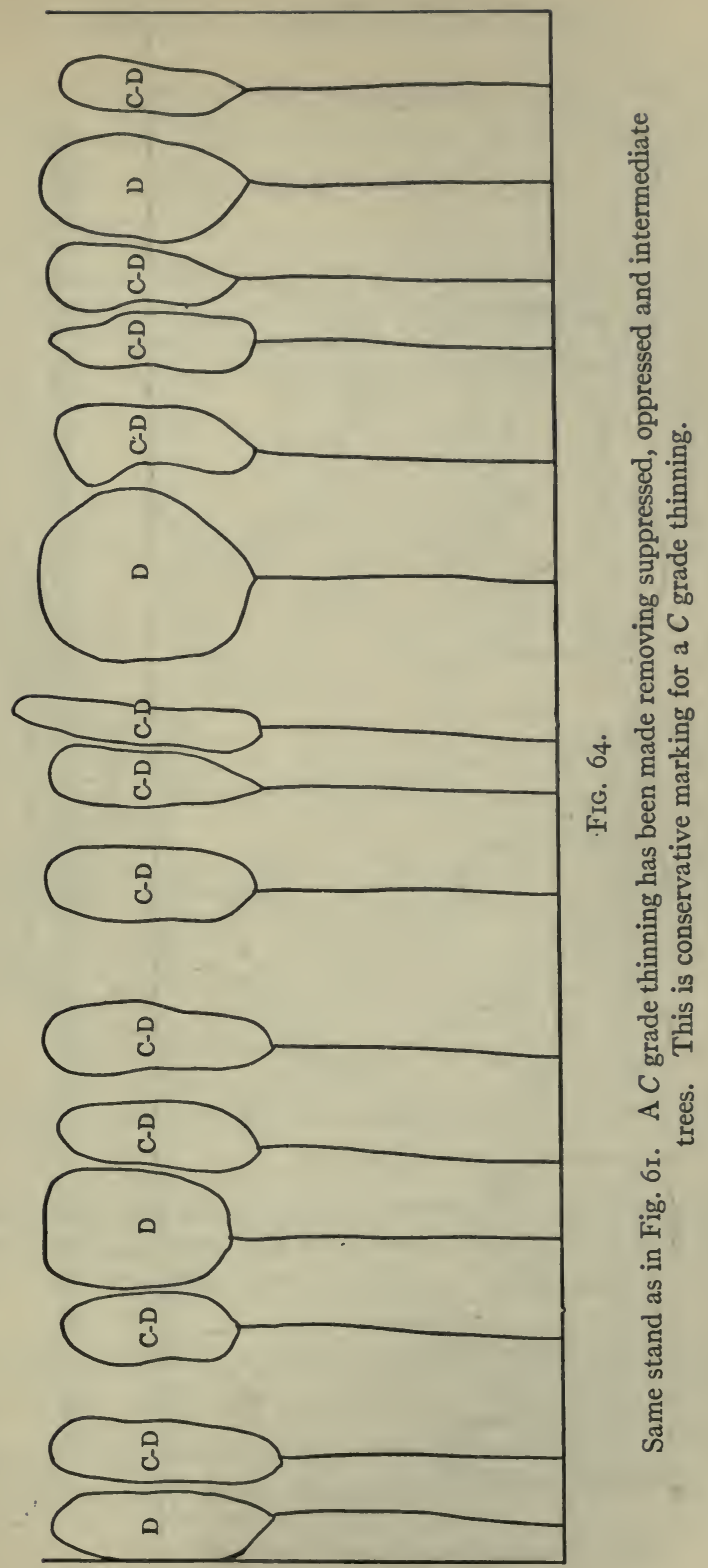




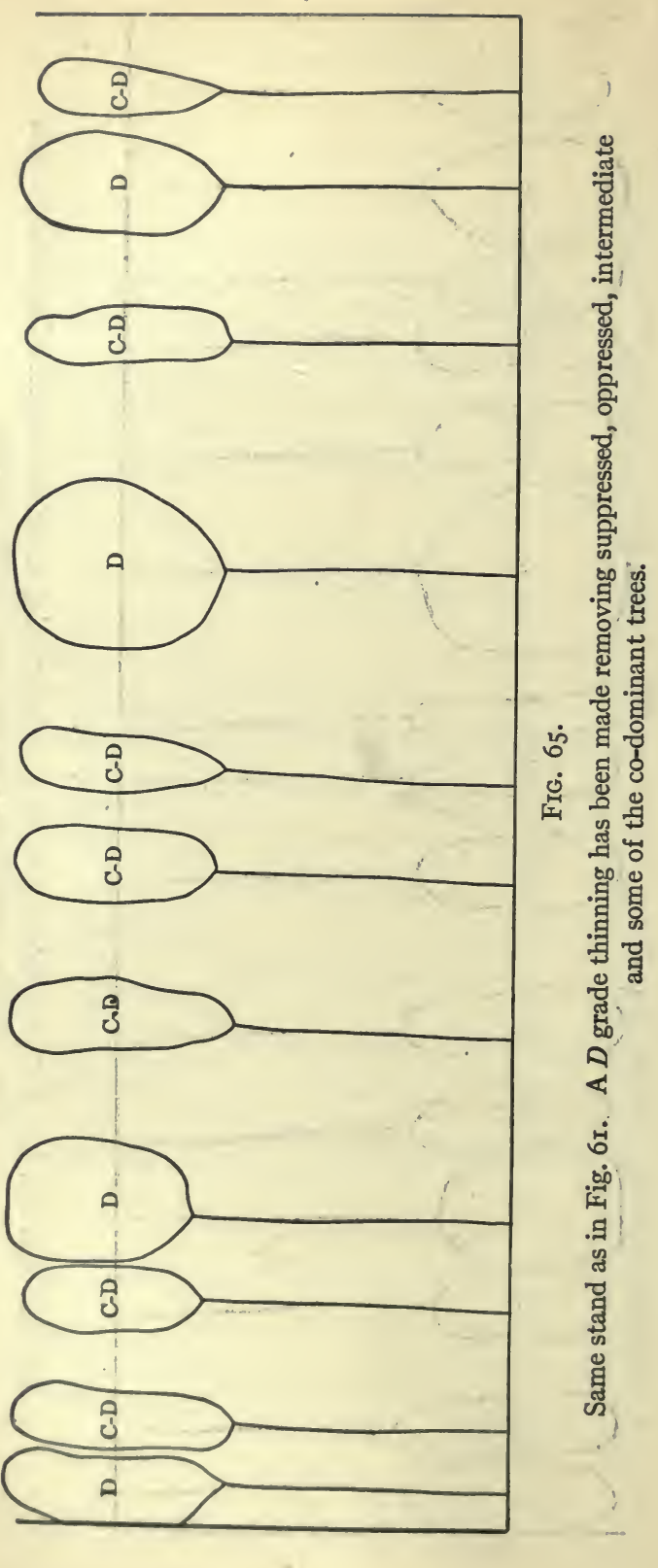


ning in a stand on good soil previously unthinned will remove approximately one-third of the cubic foot volume, while a second thinning five to eight years after the first takes out 20 to 25 per cent.

As an indication of what may be obtained when stands are repeatedly thinned, the following table showing the per cent

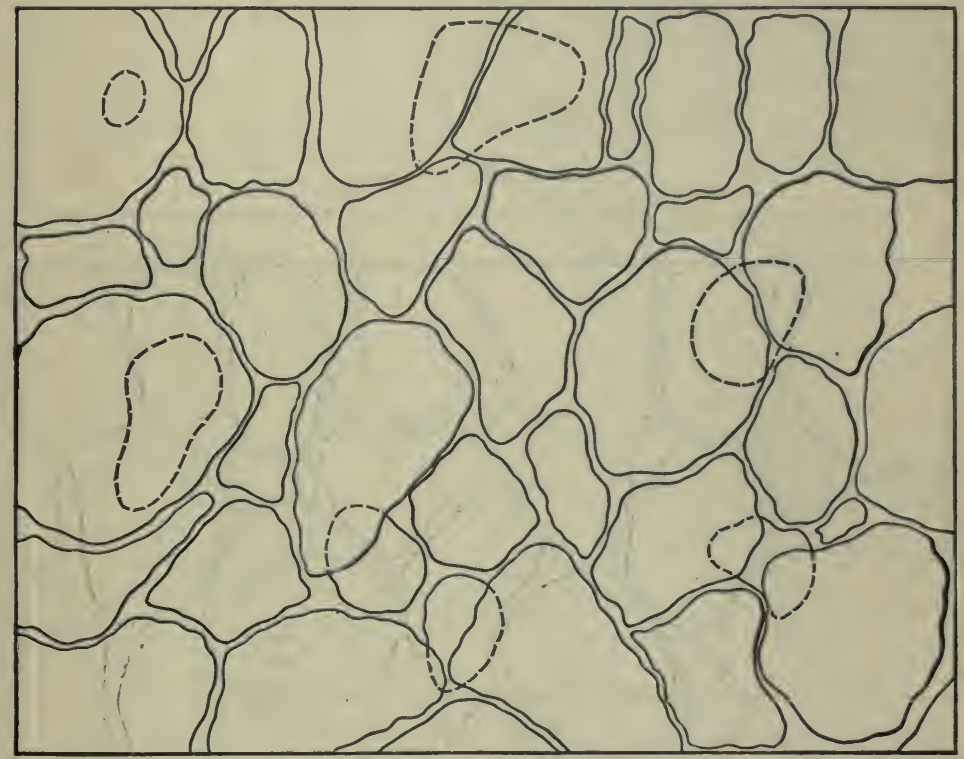

Fig. 66.

Diagram showing the arrangement of crowns in a 50 year old hardwood stand in need of a thinning. The crowns of overtopped trees are indicated by broken lines. Compare with Figs. 67 and 68.

of the total cubic foot volume removed in thinnings has been prepared from yield tables given in Schlich's ${ }^{5}$ Manual of Forestry and secured by him from the original tables compiled by Wimmenauer for oak and Schwappach for pine. 
Per Cent of Total Cubic Foot Volume Removed in Thinnings

\begin{tabular}{|c|c|c|c|c|}
\hline \multirow{2}{*}{ Age } & \multicolumn{2}{|c|}{ Oak } & \multicolumn{2}{|c|}{ Pine } \\
\hline & I & III & I & III \\
\hline \multicolumn{5}{|l|}{ Years } \\
\hline 30 & I5 & I5 & I4 & $\ldots \ldots \ldots$ \\
\hline 40 & I 2 & I3 & I5 & ......... \\
\hline 50 & IO & II & I4 & 6 \\
\hline 60 & 9 & 9 & I I & 5 \\
\hline 70 & 8 & 9 & 7 & 4 \\
\hline 80 & 7 & 8 & 6 & 4 \\
\hline 90 & 7 & 6 & 5 & 3 \\
\hline $1 \infty$ & 6 & 6 & 5 & 3 \\
\hline
\end{tabular}

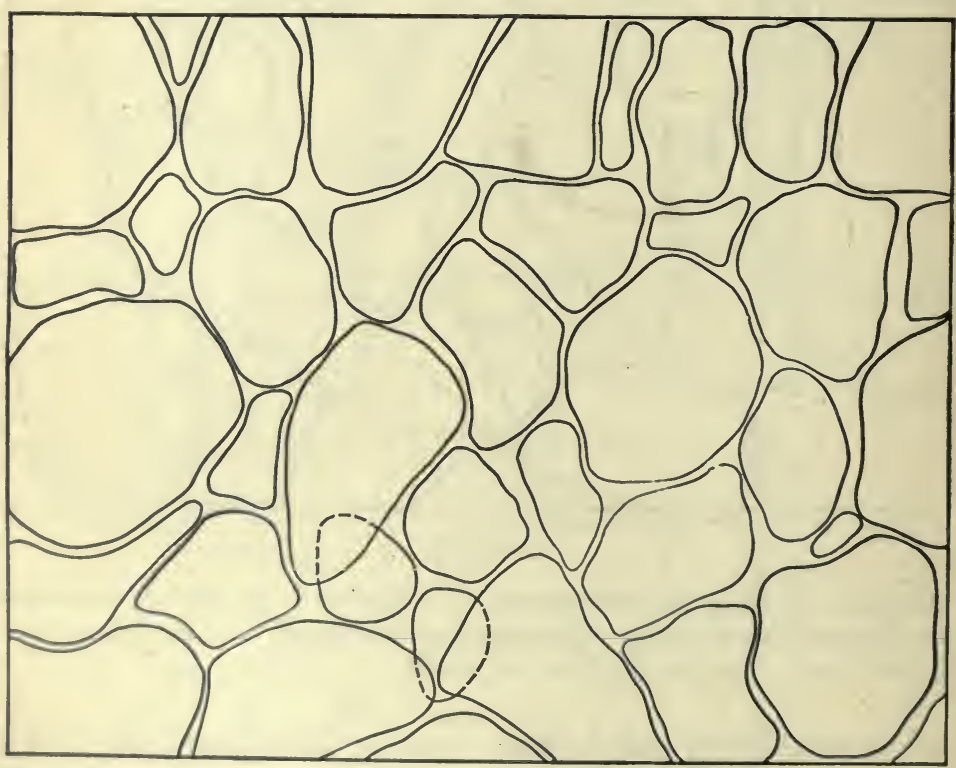

Frg. 67.

The same stand as shown in Fig. 66, but after an $A$ grade thinning removing suppressed trees has been made. Note that the main crown canopy has not been opened by this light thinning. Compare with Fig. 68 . 
Interlucation or Accretion Cuttings. - Accretion cuttings are classed as the heaviest grade of thinnings and like other thinnings are not intended to make permanent gaps in the cover. Their purpose is to obtain exceptionally rapid diameter growth of individual trees, not attainable with lighter thinnings.

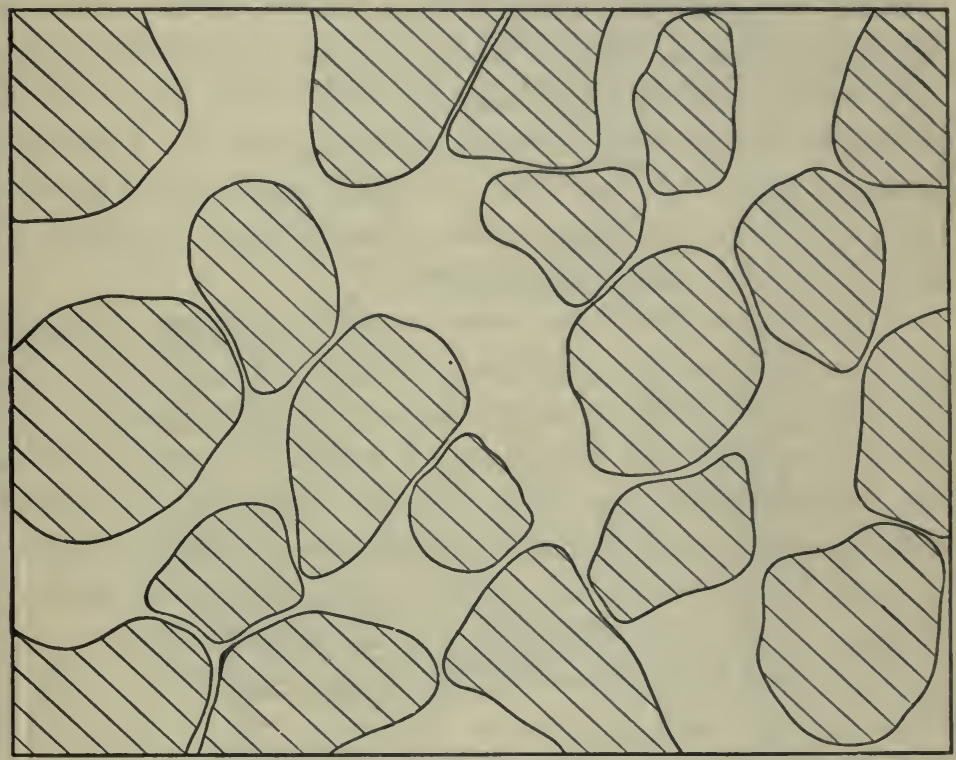

FIG. 68.

The same stand as shown in Fig. 66, but immediately after a $D$ grade thinning, removing overtopped, intermediate and many co-dominant trees. Note that the crown canopy has been opened and every one of the remaining trees given increased room on one or more sides. Compare with Figs. 67 and 77 .

They are needed particularly with light demanding species, for shade enduring trees grow rapidly following lighter thinnings. In making accretion cuttings there is great danger of reducing the volume production per acre, although the increased value of the large trees may offset financially any such reduction. 
Light demanding species with thin foliage may form nearly a complete canopy with their crowns and still allow so much light to reach the ground that the soil may deteriorate or an undesirable growth of grass, weeds or underbrush start. An understory is needed to protect the site whenever accretion cuttings are made in a stand of thin foliaged trees. Such an understory may be established by natural or artificial means.

Accretion cuttings should be used only in the latter half of relatively short rotations on soils where there are abundant moisture and food materials available for increased growth and where an understory can be developed naturally or artificially for a small expenditure.

A distinction should be made between accretion cuttings ${ }^{6}$ used as intermediate cuttings and hence keeping the cover close enough to utilize completely the productive power of the site, and cuttings of a similar nature which permanently break the cover and are essentially reproduction cuttings started early in order to secure increased growth on selected trees.

Nisbit ${ }^{7}$ states that any thinning which removes over ${ }^{5} 5$ per cent of the total basal area is an accretion cutting.

The French Method.8 - ("Eclaircie par le haut" or "thinnings from above.")

Under the French method, so called, every opportunity for rapid growth is given to certain of the best dominant trees by completely freeing them from competition comparatively early in the rotation. As compared with the ordinary method a thinning similar to Grade D or heavier is made in the intermediate, co-dominant and dominant crown classes, while the overtopped trees are allowed to remain except for a Grade A thinning which removes the suppressed trees. (See Figs. 69 and 70.)

In starting the French method a number of trees, sufficient to stock the area at maturity and distributed as uniformly as 


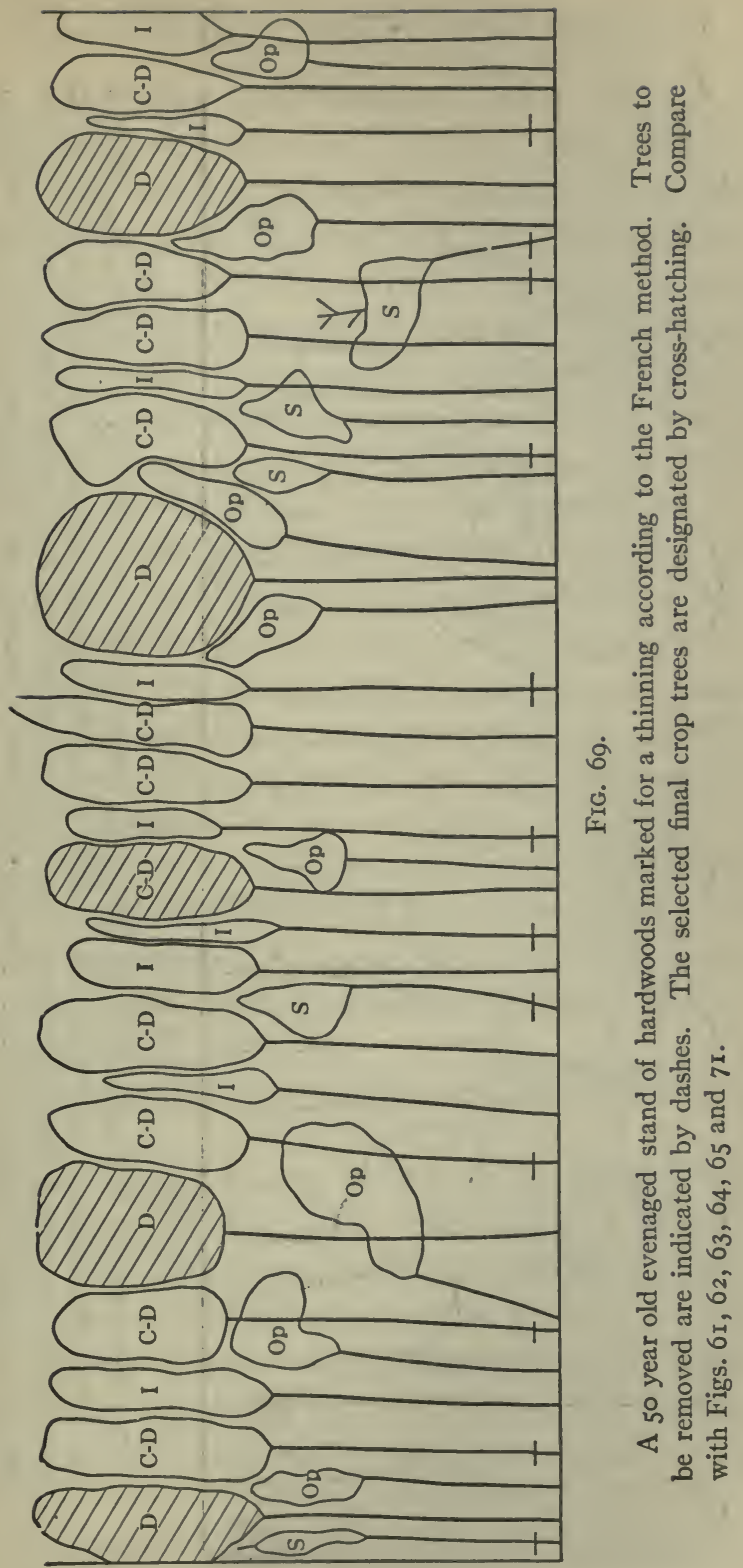




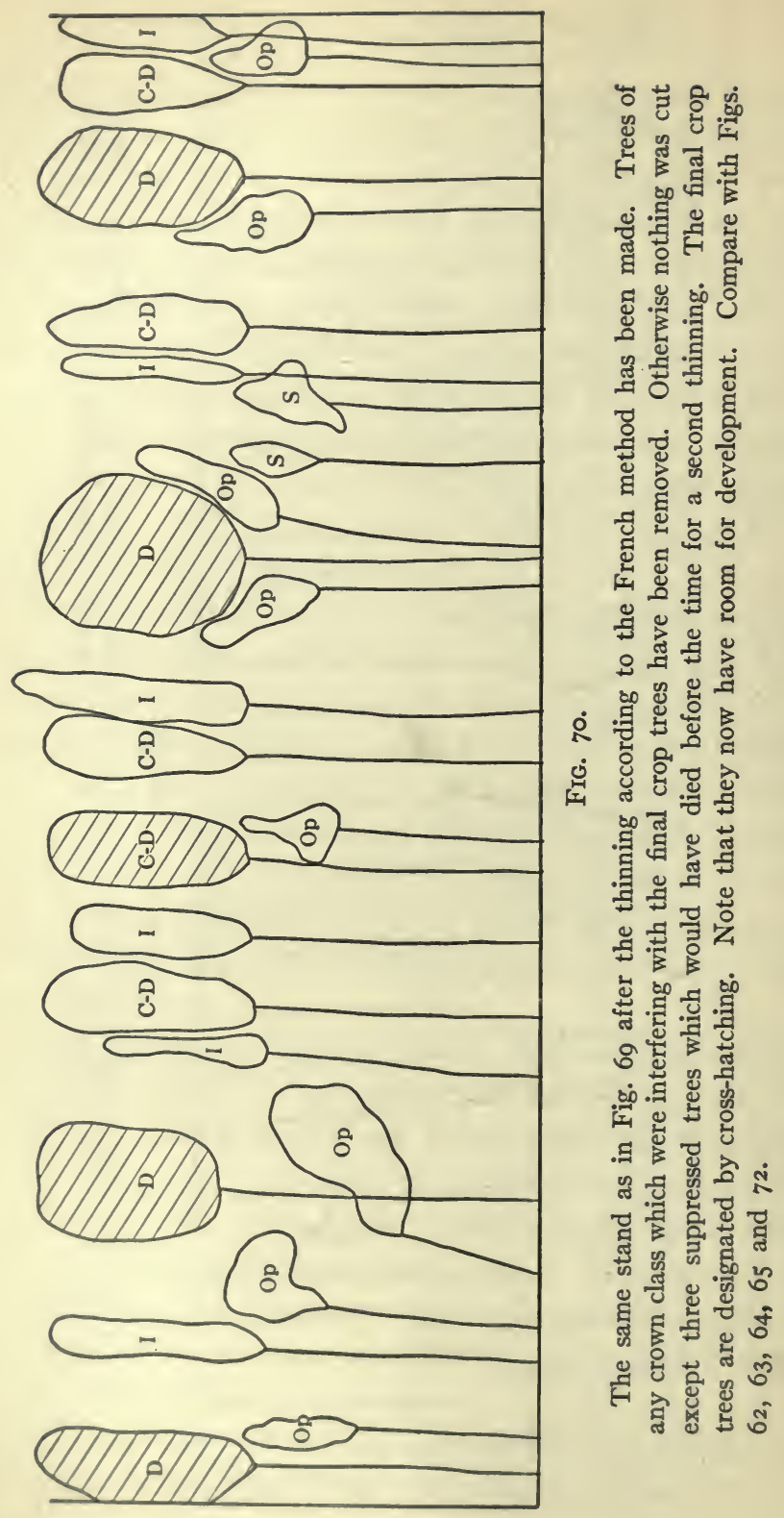


possible, are selected from among the best dominant trees. After the selection of the final crop trees has been accomplished a heavy thinning is made, taking out all trees of any crown class which are interfering with the development of the final crop trees. Such a cutting frequently involves the removal of dominant trees and the leaving of openings in the main canopy which do not close for several years. To prevent undue exposure of the site as a result of the heavy thinning the overtopped trees are left standing to furnish a protective cover. From among the overtopped trees the suppressed, i.e., those already dead or dying, are culled in a light thinning to secure utilization before the trees become worthless.

Where the final crop trees stand fairly far apart the first heavy thinning, in accomplishing its purpose of freeing on all sides the selected trees, may leave dominant, co-dominant or intermediate trees not interfering for the present with the selected individuals. In the subsequent thinnings all trees (not final crop trees) in the upper crown classes would be removed leaving eventually only the final crop trees with an understory composed of the oppressed class. The volume removed corresponds to that taken out in Grade D under the ordinary method.

The advantages of the French over the ordinary method are that:

(a) Bigger timber can be produced in the same time or timber of the required size in a shorter time. This is made possible by the freedom for expansion afforded the crowns of the selected trees. As individuals they have more room than would be possible under the ordinary method because the overtopped stand preserves a close cover and obviates the necessity of the dominant stand maintaining a complete canopy.

(b) The method gives higher immediate cash returns from 
the thinnings, because the material removed averages of larger size and better quality than in the ordinary method except for the heaviest grade of thinning. A comparison of the crown classes removed in each of the two plainly indicates this.

(c) Any light admitted through the openings in the main stand is utilized by the overtopped trees which are able to continue growth, slowly producing cordwood as the principal product. Under the ordinary method any light admitted after a heavy thinning tends to stimulate a growth of grass, weeds and shrubs.

The principal disadvantage of the method, but not a serious drawback, is the fact that the overtopped trees left standing are a hindrance in the work of felling and transporting from the area the material cut.

Thinnings according to the French method should not be started until around the thirtieth year when the period of most rapid height growth is past and the stems have been cleared by natural pruning. The heavy thinning if made before natural pruning was well started would result in making the final crop trees too wide spreading and branchy with short clear boles.

The overtopped trees prevent the production of epicormic branches on the main stems and continue to some extent the natural pruning.

If the stand requires thinning before the French method can be started, a thinning on the ordinary method may be made.

The French method can be applied successfully in either pure or mixed stands. Undoubtedly the best combination from the standpoint of the greatest yield in quantity and quality is found in a stand where the final crop trees are of a light demanding species, while the overtopped stand is formed 
by a dense foliaged, shade enduring, species capable of furnishing best protection to the site, profiting by the chance for growth in a shaded position and functioning efficiently as a pruner of the dominant stems.

For thinning stands of eastern white pine Fernow ${ }^{9}$ advised the method as early as 1903 . He recommended the selection at 30 years of 200 trees to form the final crop and the freeing of their crowns by a thinning for a space of two to three feet on all sides. This would be repeated as often as the crowns touched.

Borggreve's Method. - Borggreve ${ }^{10}$ developed a method of thinning radically differing in principle from either of the two methods already mentioned. His idea is to take out two classes of trees in the thinning:

(a) The largest dominant trees.

(b) The suppressed trees; in order to utilize them before they become a total loss.

The removal of the suppressed trees constitutes a Grade A thinning under the ordinary method, but taking out the largest dominant trees is directly opposed to the principles of the ordinary or French methods, which even in their heaviest cuttings leave the very trees which Borggreve cuts in his first thinning. Selection thinning is another name for this style of thinning.

The selection of the dominant trees to be removed is made on the basis of their form and the quality of the timber they can eventually produce as compared with their associates. This results usually in the cutting of the largest dominant trees, for such trees in attaining their commanding position developed large limbs and possibly forked trunks which the smaller dominant, co-dominant, and intermediate trees have escaped, due to their more restricted opportunities for devel- 
opment. The trees capable of furnishing the largest proportion of clear lumber in the final cut will be found in the intermediate crown class. They have long clear boles which have been thoroughly pruned while still slender and all subsequent growth will be clear lumber. Borggreve in his successive thinnings, removing the relatively poorly formed dominant trees, advances the intermediate trees to the co-dominant and finally to the dominant crown class:- from a position where only a small amount of overhead light was available to a commanding place in the stand with opportunity for rapid growth. In theory trees found in the overtopped class at the time of the first thinning might eventually be advanced to the dominant class. (See Figs. 7x, 72 and 73.)

The success of Borggreve's method hinges upon whether trees which have been crowded and overtopped in the struggle for existence can recover and become thrifty fast growing individuals. Undoubtedly the degree to which the process of suppression has advanced is the determining factor in such recovery. The extent to which overtopped and intermediate trees can be expected to develop into first class dominant trees will vary with the silvical habits of the species and the site and must be determined in each case. With shade enduring species and on the better class of sites there is more opportunity for the use of Borggreve's principle than with light demanding species, which suffer more severely from suppression, and on poor sites when recovery and rate of growth after thinning is slow.

At first thought it might seem that a series of selection thinnings, if continued long enough, must eventually produce an unevenaged stand and thus be properly classed as reproduction cuttings under the selection method, rather than as intermediate cuttings. This is not the case. The selection thinnings are continued only until the reproduction period is 


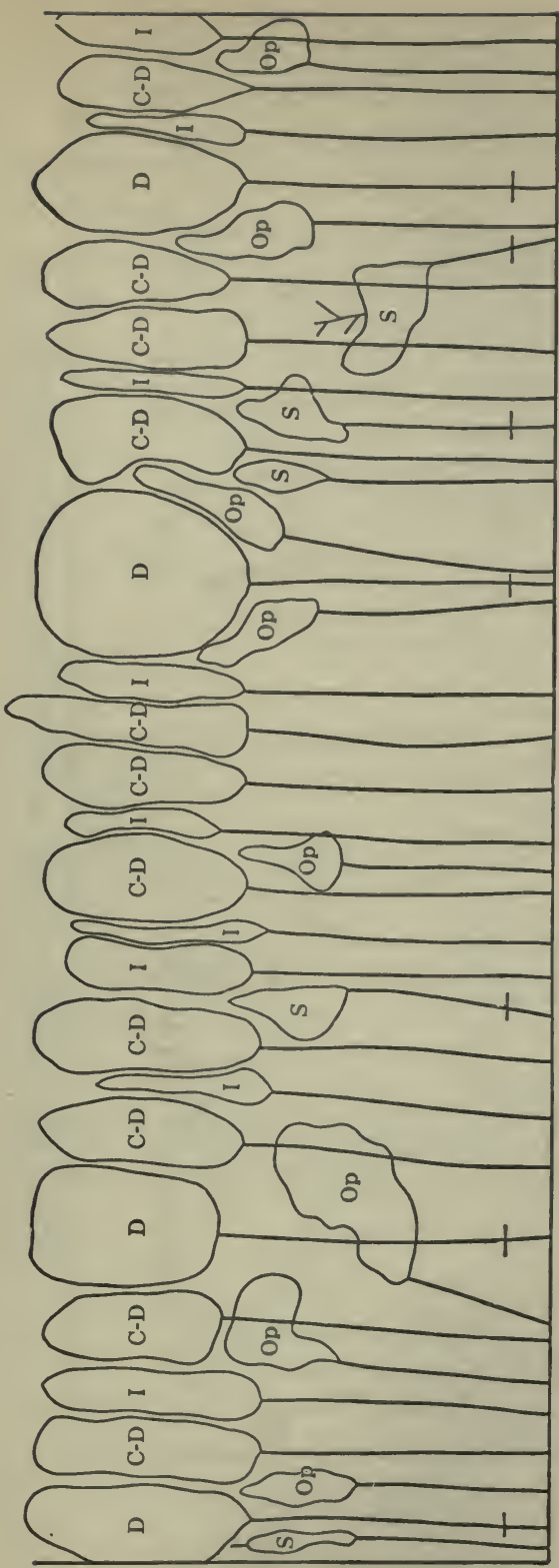

욜

过

पू है

ชृ 응

ठै

\& 20

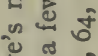

¿ ฐ

$80 .=$

เ્้ :

ค टृ โี

오. 도 웅

믈

$\because$ तु

엉

ल

$\infty 0$ तै तै

. है कू

.

i $\infty$

다 तै

ن ᄂ.

๘ 동. ․․

그

สื

E :

ปี ฮี త్ర

요 ता

है स는

ปี

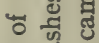

गु తึ

ปี

क

पृ

त् स्兀

잉 은

ช.

긍 앰

능규 믁

\>0

을

$<$ in 는

$<$ 을 


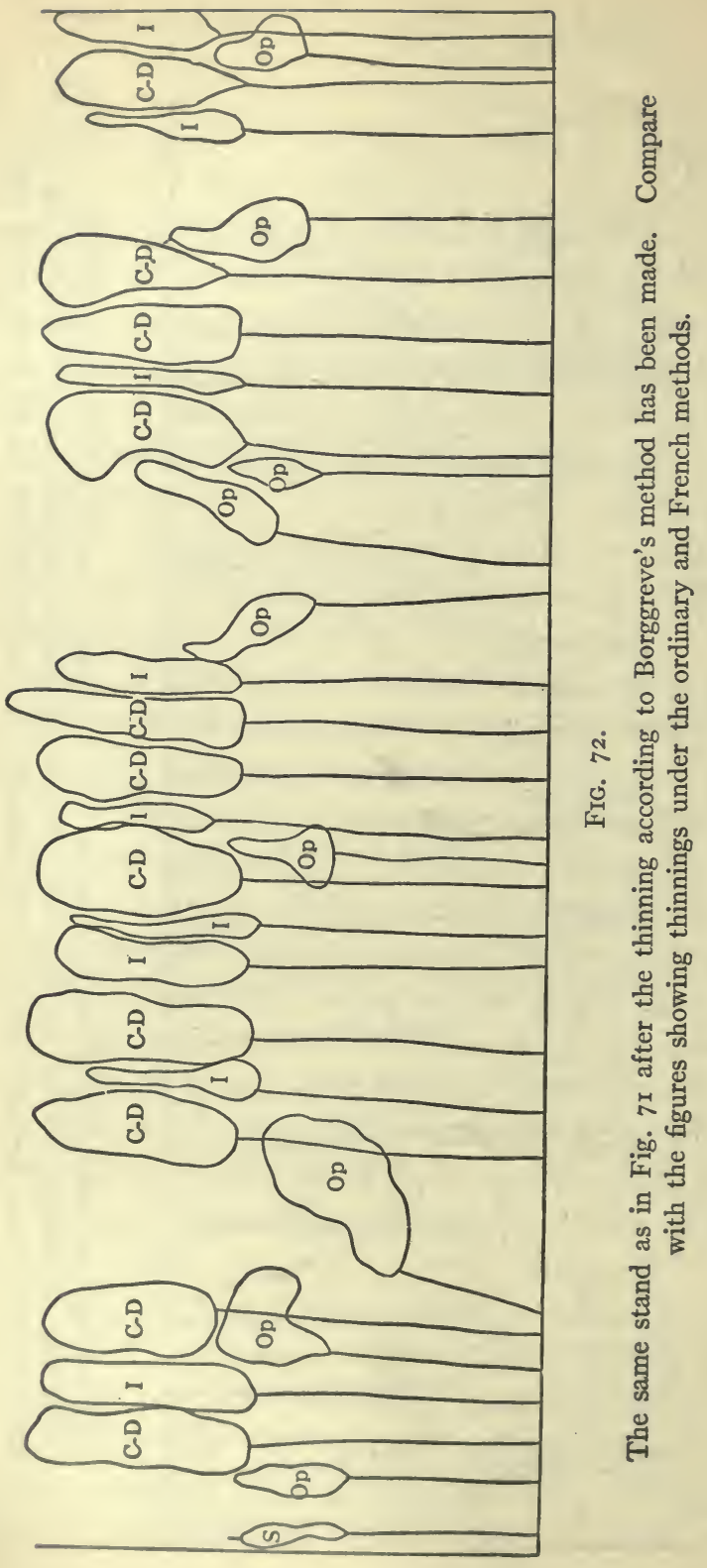




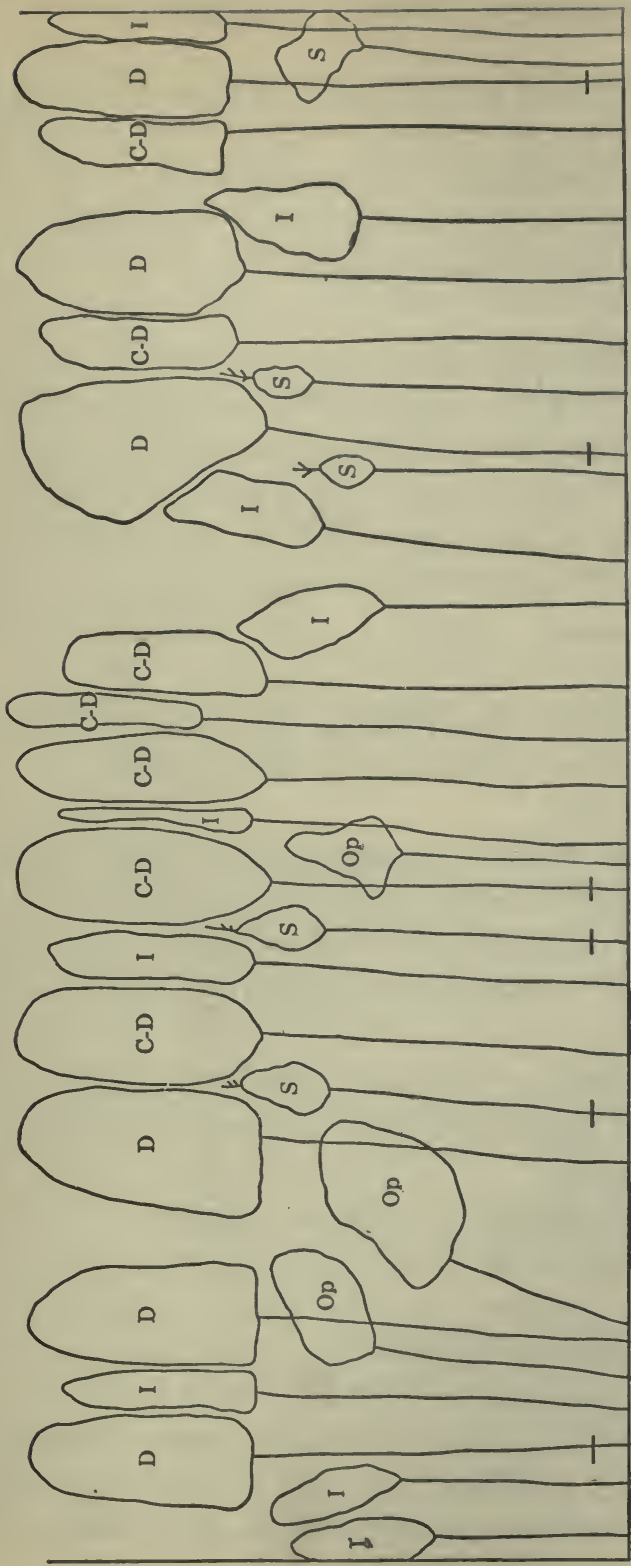

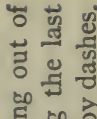

. 500

골. 도요

ช ठ

पै

온 돌

ऽ 동

ค 오을

인

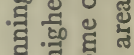

드 용

- 09

¿ 4 के

a

능

$\oplus$ ल क्ञ

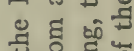

ஸ 넘

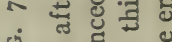

0 थ ल ए

తึ 己

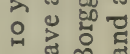

ㄷ્વ

วิ ยู ฮृ

N

들 क ल्:

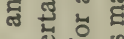

-



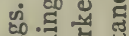

记 胥 क

. 퐇 ص

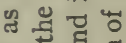

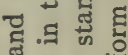

की

ญ्यू हु

हี

ถึ อี ம்

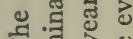

댕ํㅇ 입 
reached and are strictly intermediate cuttings intended primarily for application in evenaged stands. The overtopped stand serves as a protective cover which among other purposes has the effect of preventing the establishment of reproduction under any large openings created in the upper canopy.

It is estimated that from ro to 40 per cent of the volume in board feet of the stand can be removed in a selection thinning. The tendency should be to cut lightly rather than heavily. A high percentage of the volume in board feet should never be removed except in stands where only a few of the larger trees have reached sawable size. In such a stand a light cutting might properly remove a considerable part of the board feet volume.

Borggreve's method has distinct advantages and disadvantages as contrasted with the other two methods.

The advantages are:

I. The thinning returns a greater profit because the trees cut in the main stand are the largest and ordinarily at that moment the most salable trees in the stand. Lumber may be the chief product as compared with cordwood under other methods.

2. A better quality of timber is produced, because only clean boled, small limbed trees are allowed to remain until the end of the rotation.

Among the disadvantages may be mentioned:

I. The rotation must be lengthened to secure timber of a given size. Since the larger individuals are removed in the thinnings and trees at one time in the lower crown classes are developed into the trees for the final harvest, it is evident that a longer time will be needed to produce given dimensions. The average rate of growth of the final harvest trees will be slower than under either the ordinary or French method. An 
increase of 40 to 60 per cent in the length of the rotation should be expected.

2. Reduction of the growth of the stand. The removal of the thriftiest dominant trees leaves large openings which are supposedly filled by rapid expansion of trees of inferior crown classes which remain. Only where the species are extremely shade enduring, the site good and the thinnings kept light will this assumption hold good. In the average stand repeated use of Borggreve's method will reduce the growth and eventually leave a body of trees, formerly in overtopped and intermediate crown classes, which are suffering from exposure to sun, wind and insects and fail to conserve the factors of the site.

3. There is even more difficulty experienced than in the French method in felling the large trees and getting the material from the area without injury to or hinderance from the subordinate stand.

Selection thinnings should not be started until good height growth has been attained and natural pruning is far advanced. The best results from such cuttings will be obtained when they are not initiated until between the fiftieth and eightieth years and are used with rotations of 125 to 200 years for the production of high quality timber. Before the Borggreve cuttings are begun, light thinnings as needed under the ordinary method may be employed. The disadvantages are largely overcome if a late initiation of the method is combined with early thinnings from below and the employment of a long rotation.

Special Methods of Thinning. - Occasionally stands in great need of a thinning are found of such density as to make the removal of individual trees in a thinning operation very difficult and expensive. To overcome this special methods can be employed. Young stands, to to 20 years old, of un- 
merchantable trees so dense as to be in danger of stagnation of growth unless thinned, furnish an illustration. ${ }^{11}$ The individual trees may stand so closely together that it is a laborious task to reach and cut each individual that should be removed in the thinning. Instead of attempting this narrow lanes three to four feet in width may be clear cut, running through the stand at intervals of 5 to ro feet. The cutting can be done in the lanes easily and quickly. (See Fig. 74.)

In dense stands of merchantable size there is space enough to cut through the trunk with the axe or saw, but the severed

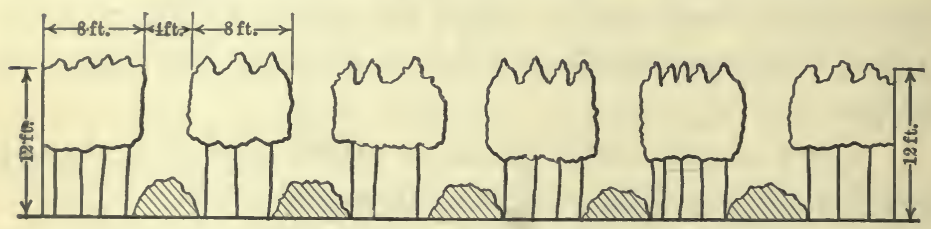

FIG. 74 .

A thinning in an unmerchantable stand I $_{5}$ years of age and so dense as to require immediate treatment. Narrow lanes were cut through the stand and the trees felled into and left lying in these lanes. Not an ideal method of thinning, but done to reduce the cost to a reasonable amount. Windrows of felled trees are indicated by crosshatching.

tree remains standing upright and it is difficult to bring it to the ground. Such a condition occurs only with shade enduring species like red spruce (Picea rubens) having stiff branches, which often persist on the trees for years after death. In a dense stand of red spruce, 30 to 60 years of age, it may be impossible to bring a severed tree to the ground except by dragging the butt away from the stump (usually with the aid of horses), until the top is pulled loose from the surrounding crowns. This is too expensive an operation. Cutting clear of lanes wider than those in young unmerchantable stands is advised. ${ }^{12}$ The lanes may be 8 to ro feet wide with uncut strips Io to 18 feet in between. The difficulty of 
bringing the trees to the ground is overcome and the logging is cheapened because the felled material is concentrated in the lanes.

When the same stand is thinned a second time the lanes can be run at right angles to those cut in the first operation. In principle a thinning of this character is not fully satis-

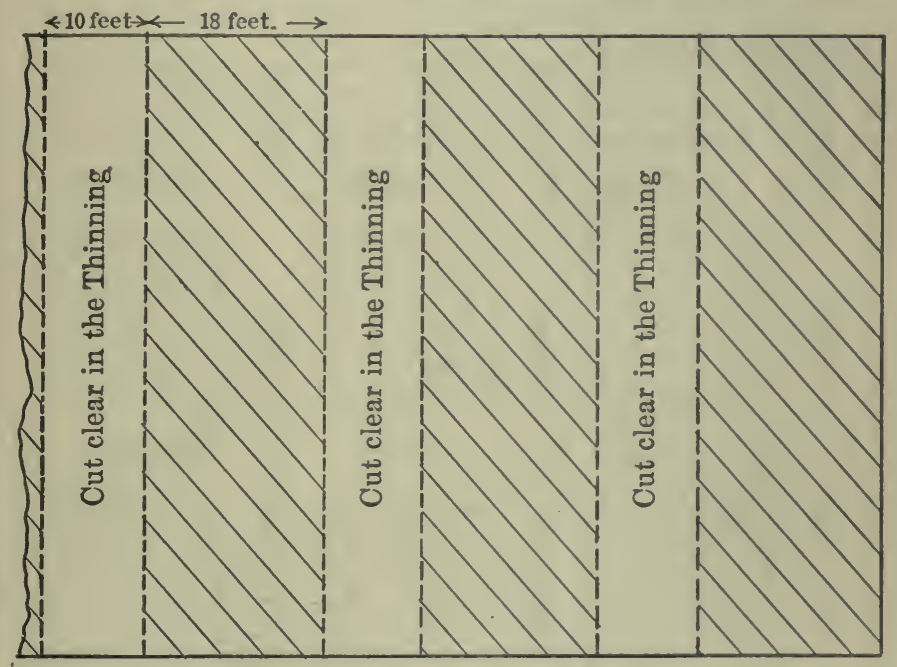

FIG. 75 .

Portion of a dense stand of 60 year old timber treated with a strip thinning Strips ro feet in width have been cut leaving uncut strips 18 feet wide. The trees on the edges of these strips have opportunity for increased growth.

factory but does furnish opportunity for the trees on the sides of the clear cut lanes to increase their rate of growth. " (See Figs. 75 and 76.)

Application of Thinnings. - It has already been indicated that thinnings should be started as early in the life of the stand as the need arises, but that in practice they are likely to be deferred on account of the cost until the time when the material removed can pay for the operation. This is a good 
rule to be broken only in special cases, where the owner is willing to invest the cost of the thinning and where the ultimate financial benefits of the operation are clearly discernible.

As soon as the openings made by the preceding thinning have closed a second cutting should be made. The interval between cuttings may vary from 3 to Io years, or even

$\leftarrow 10 \mathrm{ft}: \rightarrow 18$ feet $\rightarrow$

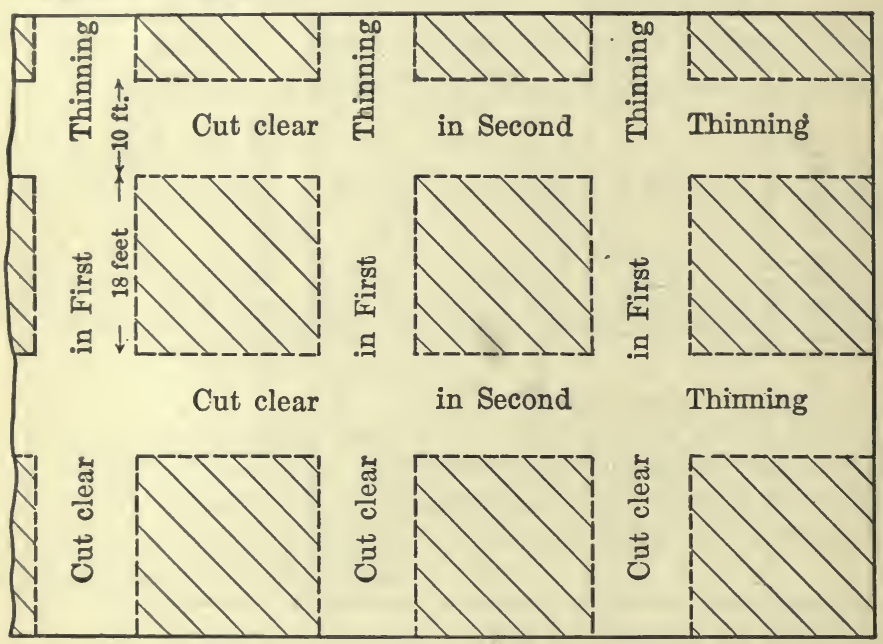

Fig. 76 .

Same stand as in Fig. 75, but ro years later after a second strip thinning has been made. The strips in this case were cut at right angles to the first strips. The timber left (shown by cross-hatching) is in the form of compact groups. The trees on the edges have opportunty for increased growth, but the trees standing in the center of the groups have not been benefited.

longer in exceptional cases, depending primarily upon the severity of the thinning, the quality of the site and the inherent ability of the species to take advantage of the increased opportunity for growth. (See Figs. 68 and 77.)

On a good site thinnings can be repeated frequently, and each thinning may be relatively heavy because of the rapidity 
of growth on good soils. As the stand grows older the interval between thinnings is apt to lengthen, because growth may slow up and the openings in the canopy average larger due to the larger crown spread of single older trees.

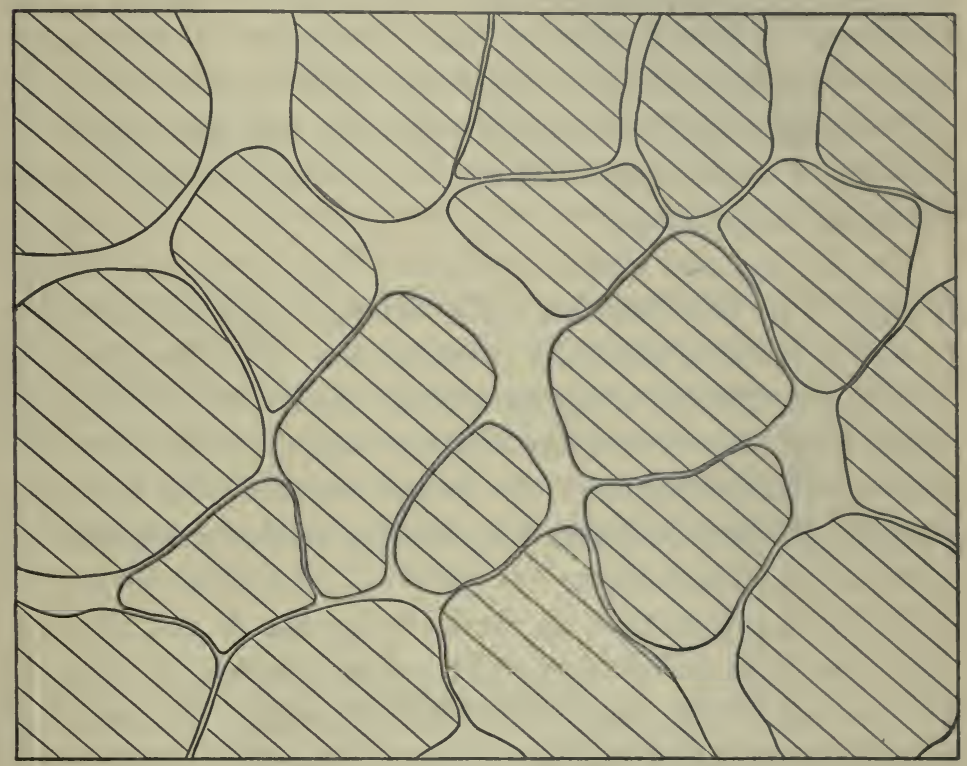

FIG. 77 .

The same stand as shown in Fig. 68 , but ro years after the $D$ grade thinning was made. The crown canopy is almost complete. The stand is in need of a second thinning.

Thinnings should be carried on systematically from early in the life of the stand until the period of regeneration, following a definite policy. What method of thinning should be used and how severe the thinnings ought to be made, must be determined separately for each case. All that can be attempted here is to indicate the procedure in some of the commoner cases. 
Where a large percentage of clear lumber is desired the stand must be kept fairly dense, and moderate thinnings will be in order. If large volume production is wanted without a product of high technical quality, then thinnings at least as heavy as Grade $\mathrm{C}$ under the ordinary system prove the best. Where lumber of wide dimension is demanded, even if somewhat knotty, very heavy thinnings can be made.

Shade enduring trees can grow thriftily with less light than the light demanding species and do not receive such heavy thinnings as the latter.

The German and French methods will be used oftener than Borggreve's. One thinning under the latter method and then reversion to one of the other methods may meet the situation in many somewhat irregular stands, previously unthinned, and in localities where to-day only the bigger trees are saleable. Between the German and the French methods the choice is difficult and may be decided by existing market conditions in favor of the French idea.

The ordinary method in its lower grades A and B does little more than utilize trees which would otherwise be wasted. The growth of the stand cannot be stimulated by removing only those trees which already are conquered in the struggle for existence. Grades C and D are needed to secure this result, and are the grades advised in most cases when the ordinary method is employed.

Use of all three methods combined in the same stand to fit variation in conditions encountered is often the wisest course.

Thinnings can well be increased in severity with advancing age in order to satisfy the demands of the trees for more light and room. Indeed, due to the larger crown spread of the individual trees in an older stand, bigger gaps must be left if any thinning is made.

In applying thinnings the danger from windthrow and 
breakage must be kept in mind. If the work is started early any stand can be made comparatively resistant to storms by systematic thinning. The development must be gradual. If thinned too heavily at first the entire remaining stand may be lost. Dense stands of tall, small crowned trees which have gone for years unthinned reach a stage when it is dangerous to make even a light thinning. Timber of this character ordinarily must be left untouched until ready for regeneration. Danger of windfall after thinnings is greatest on wet ground, thin soil and exposed sites and with shallow rooted species.

Plantations closely spaced $(6 \times 6$ feet or less $)$ will require thinning soon after they close. So many individuals in a plantation are all of about the same size and vigor when they meet that an even but severe struggle takes place, which is apt to leave all the contestants alive and seriously weakened. If thinnings are impracticable, this should be allowed for by using wide spacing in the plantation.

\section{REFERENCES}

I. KUNZE, MaX. Untersuchungen über den Einfluss verschiedener Durchforstungsgrade auf den Wachstumsgang eines Kiefernbestandes. Mitteilungen aus der Konig. Sächsischen forstlichen Versuchsanstalt zu Tharandt. Band I, Heft 2, r9i3.

2. CACCIA, A. M. Forest Research at Cambridge. Quarterly Journal of Forestry, Vol. VIII, I9I4, p. I30.

3. Biennial Report of the Forestry Commission, State of New Hampshire, for the years $1905^{-1906, ~ p p . ~} 238$ and 249.

4. Соок, H. O. Forest Mensuration of the White Pine in Massachusetts, State Forester's Office, Boston, I908, pp. 21 and 30.

5. Schlich, W. Manual of Forestry. 3rd edition. London, 1905. Pp. $345-347,350-351,362-363$ and $366-367$.

6. Wood, B. R. Increment Fellings with Some Possible Applications to the Chir Pine. Indian Forester, Vol. 42, I9r6, pp. 283-286.

7. Nisbet, J. Studies in Forestry. Oxford, 1894. P. 196. 
8. Graves, H. S. Principles of Handling Woodlands. Wiley \& Sons, Inc., New York, rgrr. Pp. 2ro-2rr.

9. Fernow, B. E. A Forest Policy for Massachusetts. Forestry Quarterly, Vol. 2, 1904, p. 66.

ro. Borggreve, Bernard. Die Holzzucht. 2nd edition. Berlin, r89r.

II. SterretT, W. D. Jack Pine. Bulletin 820, United States Department of Agriculture, Washington, I920, p. 33 .

12. Hawley, R. C., and Hawes, A. F. Forestry in New England. Wiley \& Sons, Inc., New York, rgr 2. Pp. 226-228.

Ashe, W. W. Shortleaf Pine in Virginia. The Increase in Its Yield by Thinning. Department of Agriculture and Immigration of Virginia, Richmond, 1913.

Borgman. Forstliche Tagesfragen. Tharandter Forstliches Jahrbuch, Vol. 65, r9r4, pp. 351-376.

Borgman. Forstliche Tagesfragen. Tharandter Forstliches Jahrbuch, Vol. 66, r9r5, pp. 60-93.

Frothingham, E. H. Second-Growth Hardwoods in Connecticut. Bulletin 96, Forest Service, United States Department of Agriculture, Washington, I9I 2, pp. 49-54.

Hawes, A. F. Economic Thinning of White Pine. Forestry Quarterly, Vol. 5, 1907, pp. 368-372.

HECK, C. R. Freie Durchforstung. Berlin, 1904.

Hemman. Ueber die Abhängigheit der Ertragsregelung und Bestandsplege vom Versuchs-wesen. Allgemeine Forst- und Jagdzeitung, I9I 5, pp. Ir 2Ir6.

Hemman. Durchforstungs- und Lichtungstafeln nach den Normalertagstafeln der deutschen Versuchsanstalten. Berlin, r9r3.

Hubbard, W. F. Forest. Thinning and Its Results. Reprint from Forestry and Irrigation for June and July, I904, Washington, r904.

LASCHKE, C. Ö Konomik Durchforstungsbetreibes. Neudamm, rgor.

LASCHKE, C. Geschichtliche Entwickelung des Durchforstungsbetreibes im Wissenschaft und Praxis, Neudamm, 1902.

Matroon, W. R. Shortleaf Pine: Its Economic Importance and Forest Management. Bulletin 308, United States Department of Agriculture, Washington, 1915, pp. 34-35.

MURPHY, L. S. The Red Spruce: Its Growth and Management. Bulletin 544, United States Department of Agriculture, Washington, I917, pp. 53-59.

Scrubert. Die Hochdurchforstung im Laubwalde. Forstwissenschaftliches Centralblatt, September-October, r9o9, pp. 46I-474.

SchWAPpaCr. Bestandespflege in Buchenbeständen der Oberförsterei Freienwalde. Zeitschrift für Forst- und Jagdwesen, Berlin, r91 2, pp. 386-390. 
Sterretr, W. D., Forest Management of Loblolly Pine in Delaware, Maryland and Virginia. Bulletin II, United States Department of Agriculture, Washington, 1914, pp. 38-40.

Über Nachhaltige Massenentnahmen ohne Flächenverrechnung. Forstwissenschaftliches Centralblatt, 1915, pp. 23-26.

Williamson, A. W. Cottonwood in the Mississippi Valley. Bulletin 24, United States Department of Agriculture, Washington, I913, pp. 39-42.

Wimmenauer. Durchforstungsversuche in Buchen- und Kiefern-bestanden. Allgemeine Forst- und Jagdzeitung, March, 1914, pp. 84-90.

Woolsey, T. S., JR. Strip Thinnings. Proceedings of the Society of American Foresters, Vol. 6, r9Ir, pp. 38-4I. 


\section{CHAPTER XI}

\section{INTERMEDIATE CUTTINGS (Continued)}

Improvement Cuttings. - Cuttings made in a stand past the sapling stage for the purpose of improving the composition and character by removing trees of undesirable species, form and condition.

The operation resembles both a cleaning and a thinning in character. It is needed only in stands in which cleanings were not made early in the rotation. Most of the unmanaged stands containing more than one species are in need of such a cutting.

In a stand of this kind trees of undesirable species or poor form are likely to be in dominant position overtopping more valuable individuals and many intermediate and overtopped trees overcome in the struggle for existence need cutting. The removal of dominant trees of undesirable species and poor form is like unto a cleaning, while the cutting of the trees of lower crown classes in a measure resembles a thinning. (See Fig. 78.)

In the selection of the trees to be taken out in the combined operations the principles laid down for the making of cleanings and thinnings should be followed.

One improvement cutting may be sufficient to regulate the mixture in the stand and if so then subsequent cuttings will be in the nature of thinnings. There may be so many trees of undesirable species or poor form in the dominant stand that their removal all at one time would result in too severe opening up of the canopy. A second and even a third improve- 


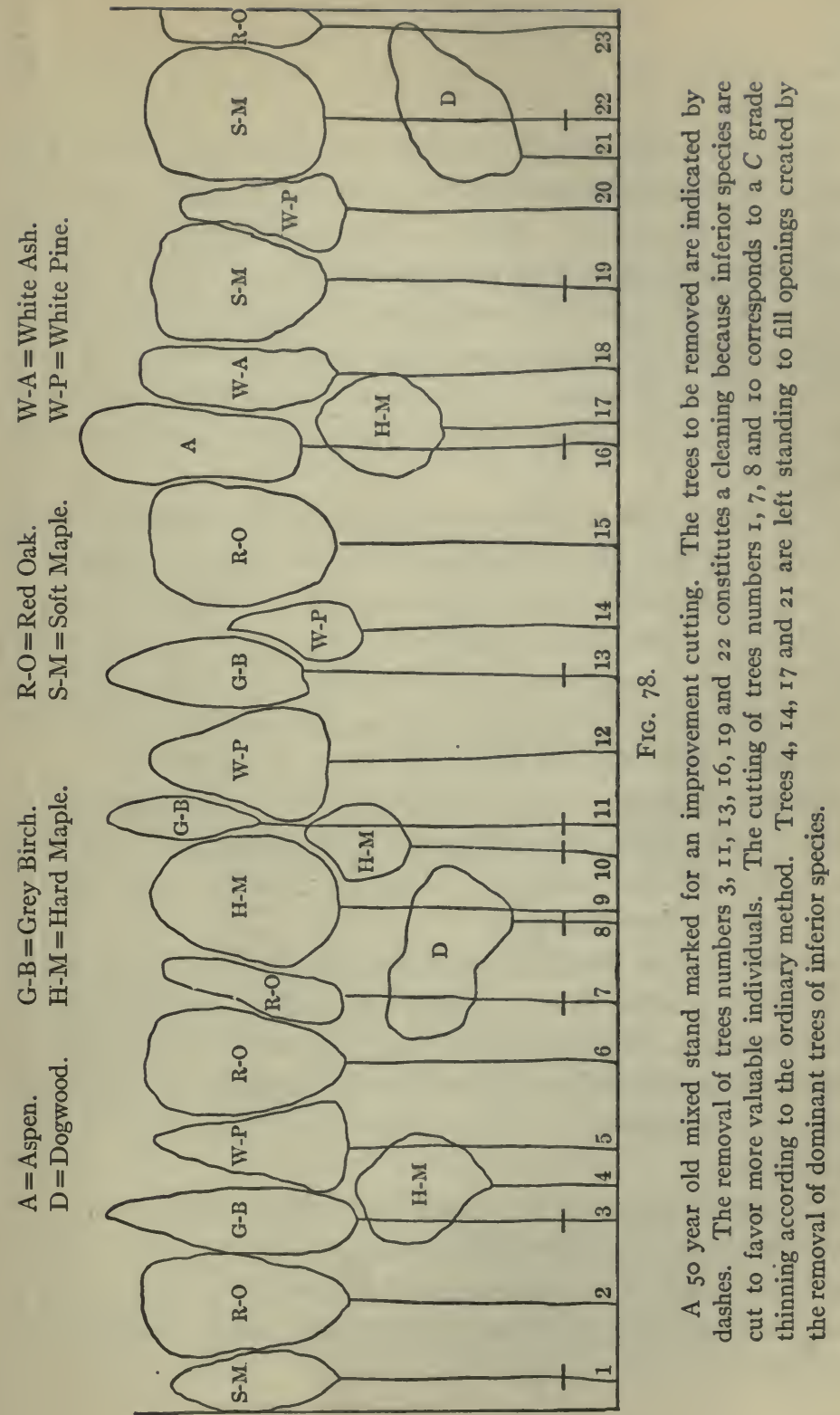


ment cutting may have to be made before the mixture is satisfactory.

In stands managed from early youth cleanings made at the proper time will eliminate the necessity for improvement cuttings at a later date. Where economic conditions prohibit early cleanings there will be opportunity for the use of improvement cuttings. In contrast with cleanings improvement cuttings yield material always large enough for cordwood and hence may yield a profit. Like thinnings they should be made only when the products secured will pay the expense of the operation.

It is much better from the silvicultural standpoint that cleanings rather than improvement cuttings be employed. Where undesirable species are allowed to occupy, until of salable size, a dominant position for a series of years, during which severe competition between individuals is in progress, the growth of the overtopped but more valuable species will be checked and their development seriously curtailed

Salvage Cuttings. - Cuttings made for the purpose of removing trees killed or damaged by various injurious agencies are termed salvage cuttings. "Damage cutting" is a synonymous term. (See Fig. 79.)

Damage in the forest due to fungi, insects, fire, wind, snow and other agencies is occurring continuously and frequently reaches serious proportions in a given stand. The removal of trees injured by their neighbors in the struggle for existence does not constitute a salvage cutting, but falls under thinnings.

Salvage cuttings, as the name indicates, attempt to utilize the injured trees with the idea of minimizing the loss. There is no skill required in selecting the trees to be taken out other than ability to recognize those that have injuries necessitating removal. 
The severity of the cutting depends entirely upon the proportion of the stand occupied by the damaged trees. On this basis a salvage cutting may range in character from a thinning to a clearcutting.

Salvage cuttings are not made unless the material taken out will at least pay the expense of the operation. Excep$\mathrm{A}=$ Fire scars. $\mathrm{B}=$ Stagheaded tree. $\mathrm{C}=$ Canker. $\mathrm{D}=$ Killed by insects.

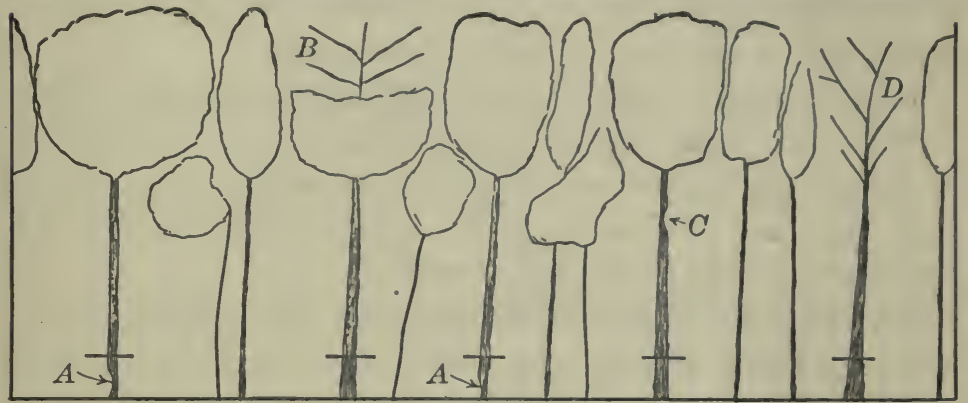

Fig. 79 .

A stand in need of a salvage cutting. The injured trees are indicated by dashes. So many trees require cutting that the remaining stand will be irregular and open. Reproduction will be needed to fill the openings.

tions to this statement occur when it becomes essential for the safety of the surrounding forest to remove unmerchantable trees attacked by insects or fungi.

Even though the damaged material can be salvaged at a profit the injuries which made the operation necessary ordinarily occasion an ultimate loss. This is true especially when stands in the first half of the rotation are damaged. The loss is due partly to deterioration of the injured trees before being salvaged, partly to a reduction in the density of stocking, with the possibility that a portion of the area may be unproductive, and partly to the cutting of the injured trees before they had attained the size and could furnish the products desired by the owner. 
Wherever extensive injury has occurred, and provided the condition of the stand permits, reproduction cuttings should be initiated and a new stand established. It is better to remove the remaining healthy trees along with the damaged ones rather than leave the former in too open a stand.

Nearly all heavy salvage cuttings are followed by reproduction of some sort or by a growth of grass, weeds or brush. Where fire was the source of the damage the subsequent reproduction is apt to be of undesirable species.

Artificial regeneration is often needed after a salvage cutting.

While fire, fungi, insects, wind, etc., may be looked upon as accidental factors, yet injuries from these causes are of such common occurrence as to make salvage cuttings an expected and frequently used operation.

Severance Cuttings. - Cuttings made by clearing a narrow strip along the edge of a young stand for the purpose of developing a belt of windfirm trees along the border of the stand. (See Figs. 80 and 8r.)

In a forest under management, consisting of evenaged stands of many different ages, the cutting of one stand may expose another adjacent stand, where it abutts closely to the one harvested, to injury by wind and to a lesser extent along the border to sunscald.

To avoid such injuries the creation of narrow cleared lanes between adjacent stands by severance cuttings is advisable. The effect of the cutting is to stimulate crown and root development of the trees bordering the lane. They become more windfirm and through the maintenance of a living crown low down on the stems on the border of the lane protect the boles from sunscald and prevent the free entrance of strong winds into the interior of the stand. The high "underbrush likely to spring up at the edges of the lane increases the protection. 


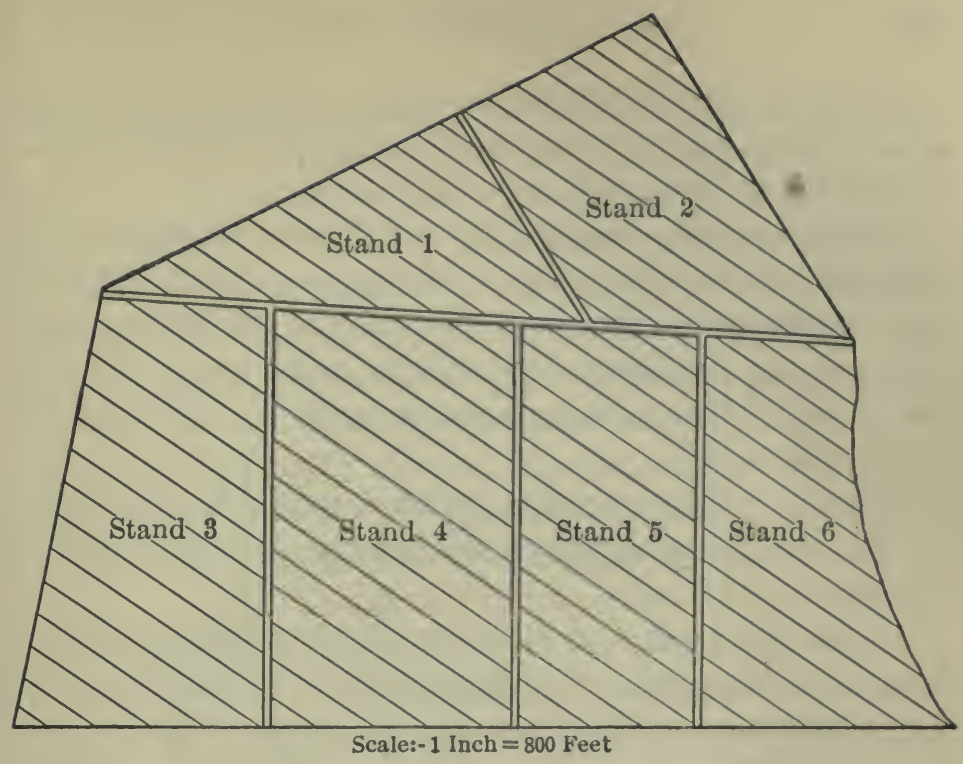

FIG. 80.

Diagram of a small forest property divided into six stands separated from one another by severance cuttings.

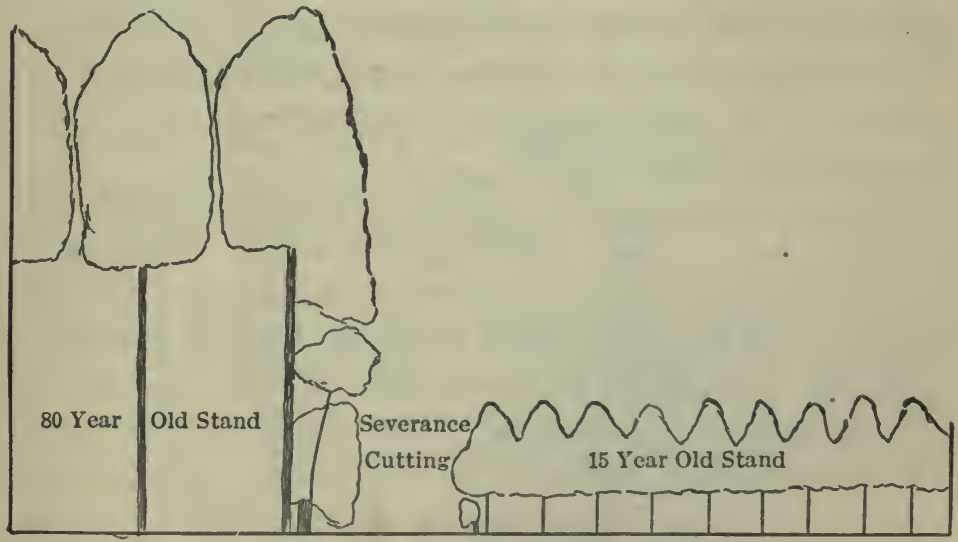

FIG. 8r.

Severance cutting between an 80 year and $a_{6} I_{5}$ year old stand. Note the dense growth of shrubs and overtopped trees which, together with the tree crowns, forms a wind mantle along the side of the stand. 
Severance cuttings should be made early in the rotation before natural pruning has progressed far, as the development of windfirm individuals is a gradual process.

Until a forest is organized for continuous production and definitely divided into stands severance cuttings will find slight application. Fire lines developed in the effort to prevent and control forest fires will in many tracts serve as severance cuttings, although not recognized as such at the present time.

Pruning. - This operation removes branches from standing trees for the purpose of increasing the quality of the final product.

For the production of clear lumber the death and early removal of all limbs from the main stems of trees are essential. This may be accomplished in the forest naturally by means of the crowding and shading of the individual trees. In fact good natural pruning is the chief advantage of the dense stands. Under certain conditions Nature's process is fully satisfactory and produces a high percentage of clear lumber. It requires great density of stand, with correspondingly slow growth of the individuals and a comparatively long rotation to accomplish nature's results.

Nothing better can be expected where silvicultural practice must be of a crude and extensive nature. When intensive methods are possible, applied silviculture aims to reduce the density of the stand found in nature, with the purpose of obtaining a reduction in the length of time necessary to produce lumber of a given size. (See chapter on Thinnings.) The long rotations, which, in the virgin forest, have accumulated stores of clear lumber developed under Nature's method of pruning, cannot be tolerated in the managed forest due to their poor financial showing. In order to produce a reasonable percentage of clear lumber on a short rotation in stands 
kept growing at their fastest rate, artificial pruning often will be required. In plantations the argument has especial weight. Here in order to save expense trees are set out at the rate of 800 to 2500 per acre, with the average number around I000 to r200. As compared with the stands of several thousand trees per acre frequently starting on areas naturally reproduced, this is a small number and results in a stand not very densely stocked. Such plantations, if they are to yield clear lumber in appreciable amount, demand artificial pruning.

The inherent ability of the species to prune naturally is of fundamental importance in determining the need of artificial pruning. Light demanding species on the whole prune more quickly and completely than shade endurers; but this is not an infallible rule. Certain species, of which red oak (Quercus $r u b r a)$ is one, prune naturally much better than other species which are more light demanding.

Forest pruning may consist in the removal of either dead limbs or live limbs. It is evident that there can be no harm to the tree through pruning dead limbs. The removal of live limbs may be the source of injury in two ways:

(a) Fungi and insects are afforded opportunity to enter the tree through the branch scars. Where only small branches are cut the wounds may heal over quickly and injury be prevented.

(b) The balance existing between the crown and the root systems is disturbed and as a consequence the growth is likely to be retarded. The extent to which this may occur depends upon the proportion of the live crown which is removed in the pruning.

As an example of the effect of live pruning on height growth the following figures relating to an experiment conducted by the author in a white pine (Pinus Strobus) plantation are 
given. The pruning was done between the I9I6 and I9I7 growing seasons.

Figures of Height Growth to Show Efrects of Pruning

\begin{tabular}{|c|c|c|c|c|c|}
\hline \multirow{2}{*}{ Treatment } & \multirow{2}{*}{$\begin{array}{l}\text { Number } \\
\text { of trees }\end{array}$} & \multicolumn{4}{|c|}{ Annual height growth in feet for the year } \\
\hline & & 1915 & 19r6 & 1917 & I9r8 \\
\hline $\begin{array}{l}\text { Pruned.............. } \\
\text { Unpruned......... }\end{array}$ & $\begin{array}{l}\text { II } 2 \\
\text { I } 69\end{array}$ & $\begin{array}{l}\text { I. } .87 \\
\text { I. } 53\end{array}$ & $\begin{array}{l}2.13 \\
1.75\end{array}$ & $\begin{array}{l}\text { I. } 45 \\
\text { I. } 95\end{array}$ & $\begin{array}{l}\text { I. } 43 \\
2.13\end{array}$ \\
\hline
\end{tabular}

The pruning was done in a plantation spaced $6 \times 6$ feet after its eighth growing season. The main stand ranged from 6 to I 2 feet in height and had not completely closed. The branches clear to the base of the trees were still alive. All but the last three and in a few cases the last two whorls of live branches were removed, reducing the crown by about 50 per cent. As a result of this very severe pruning the height growth of the pruned trees decreased approximately one-third.

Pruning of live limbs to a limited extent (for not over Io per cent of the depth of the live crowns) is not likely to have injurious effects, if done in young stands when the branches are small.

Pruning should not be extended to all the trees in the stand, but only to the relatively small number of the best dominant trees which will form the final crop. It is an unprofitable investment to prune trees which will die a natural death or be removed before the end of the rotation. The number selected for pruning is likely to fall between roo and 200 trees per acre.

Pruning becomes more expensive as it is carried higher up the tree, because the trees either have to be climbed or the 
pruning carried on with tools mounted on long poles. In practice it is customary to prune high enough to produce clear lumber for the first 16 to 25 feet above the ground. A large proportion of the tree's volume will be contained in the butt log. If the financial returns made possible by pruning are large, then it may pay to prune an additional log or two, but for the present the securing of a clear butt $\log$ is as far as the operation is likely to be extended.

Pruning should be started early because the limbs to be cut will then be smaller and the core of knotty wood already produced will be of small diameter. There is little use in starting in the last half of the rotation to prune trees which are already of merchantable size and whose limbs are large and expensive to cut. The belt of clear wood added on such trees may not be thick enough to pay for the operation. Instead the pruning should commence when the lower branches first start to die and at intervals of a few years be continued on up the tree, until the desired length is freed of branches. This applies whether dead limbs only are cut or dead and some live branches in addition. It will require several (three to four) prunings to clear the trunk of branches for 16 to 25 feet above the ground, but as one hundred or more trees on an acre are pruned the work can be economically conducted. Considering the saving in cutting small branches instead of large ones, the cost of several partial prunings as contrasted to one complete pruning should be cheaper.

Where dead limbs only are pruned the work may be performed during any convenient season of the year. In pruning live limbs it is best to conduct the operation when the tree is dormant. This is the period recommended for pruning in orchard management as giving the best results in subsequent wood growth, healing of the wounds and freedom from infection by fungi. 
Various tools may be used in forest pruning. For general use on branches of all sizes and particularly on work at a distance from the ground higher than a man's head, the small pruning saws commonly used in horticultural work cannot be excelled. The writer prefers a curved saw with teeth on both edges and with the teeth on one edge arranged to cut on the downward pull. Saws leave a rough surface but do not injure the tree.

A sharp axe or hatchet is an excellent tool in skilled hands, but when carelessly used is liable to wound the trunk of the tree above and below the severed branch. Pruning shears can be used for small branches less than one-half to one inch in diameter. A cutting tool leaves a smooth surface. In removing branches out of reach from the ground the pruning tool must either be mounted on a pole or else a ladder used to climb with. For distances up to 16 to 25 feet the long pole is more economical than use of a ladder. A chisel mounted on a pole is an effective tool.

With any tool the cuts should be made close to the trunk, smooth so as to heal over quickly before fungi or insects enter, and without tearing or loosening the bark from the branch stub.

Pruning requires a present expenditure for the purpose of increasing the unit value of the final product. The probable returns to be expected can be estimated more accurately than in some other lines of silvicultural work, so that it should be easy in any case to decide upon the advisability of the operation. The cost of pruning is apt to be between 2 and Io cents per tree.

An example of a rather radical system of pruning is that advocated by Knapp ${ }^{1}$ for white pine (Pinus strobus). His plan involves the pruning of 100 to I 50 trees per acre up to the height of $I 7$ feet. The pruning is started before the lower branches die, or become over one-half inch in diameter, and 
removes two or three whorls of branches at intervals of three to four years. The live crown is maintained at onehalf to one-third the total height of the tree. At the age of 20 years the tree is 26 feet high, 4 inches in D. B. H. with a top three inches outside the bark at I 7 feet above ground and live crown eight feet in diameter. From this point on all branches are kept alive by thinnings and a diameter growth maintained, at top of the first $\log$, of 0.4 or 0.5 inch per year. The cost of this pruning amounts to ro cents per tree at 20 years or $\$ 4$ to $\$ 5$ per thousand feet board measure at end of a 50 year rotation. The value of one-half the lumber is raised from $\$ 20$ to $\$ 40$ per thousand, which indicates a handsome return from the pruning.

As intensive silviculture develops, pruning is an operation which will be employed as a regular part of the management, particularly in plantations. Where pruning is to be employed, it may be possible to lower planting costs by use of a wider spacing in the plantations than could be employed if dependence had to be placed upon natural pruning for the production of clear stems. ${ }^{2}$

\section{REFERENCES}

r. KNAPp, Fredertck B. Silviculture of White Pine (Pinus strobus). Bulletin 106, Massachusetts Forestry Association.

2. Frothingham, E. H. White Pine under Forest Management. Bulletin I3, United States Department of Agriculture, I9I4, pp. 38-39.

Fisher, R. T. The Yield of Volunteer Growth as affected by Improvement Cutting and Early Weeding. Journal of Forestry, Vol. I6, I9I8, pp. 493-506.

ILLICK, J. S. Sandy Ridge Improvement Cutting. Journal of Forestry, Vol. I5, I9I7, pp. I04-I05.

Nisber, J. Studies in Forestry. Oxford, 1894. Pp. 203-209.

RETAN, G. A. Note on an Improvement Cutting. Forestry Quarterly, Vol. I4, I9I6, pp. 777-778.

Schurch, W. Manual of Forestry. 4th edition. London, 1910. Pp. 298-303. 


\section{CHAPTER XII}

\section{METHODS OF CONTROLLING CUTTINGS}

In silvicultural operations, including both reproduction and intermediate cuttings, rarely are all the trees on any large area removed at one time.

The felling and removal of the trees ordinarily falls into the hands of a lumberman who may have bought the timber or contracted to log it. His interests lie in logging the timber as cheaply as possible without much attention to preserving the trees (from the reproduction stage up to mature timber) which are to be left on the area. Under the circumstances it is essential that the forester devise means to control the work of the operator to the extent of preventing the cutting or destruction of trees which should remain.

Two methods are available: either control through inspection or control through marking of the trees.

Control through Inspection. - Definite instructions as to the character of cutting desired can be given to the man in charge of logging the area and his work controlled by inspection of the operations. ${ }^{1}$ Control by inspection has the advantage of leaving more responsibility with the operator who may be sensitive to having his authority curtailed. If the men in charge of the logging are in sympathy with the silvicultural viewpoint good results may be secured by this method. Otherwise it will be difficult to accomplish even the minimum silvicultural requirements. Much depends on the frequency and carefulness of the inspections, particularly during the first season. 
Control through Marking of the Trees. - This is accomplished by designation (usually marking) of either the trees to be cut or of those to be left. The operator is responsible only for the work of removing the designated trees with due care for those left standing, their selection falling under the province of the silviculturist. Satisfactory silvicultural results are more -likely to follow than when dependence is placed upon inspection alone. Woolsey ${ }^{2}$ states that "the actual selection of individual trees can lose or save many hundreds of dollars in each million feet marked." The method of marking should be employed wherever there is any doubt about securing satisfactory results through the control by inspection. The necessity for care to avoid unnecessary damage to standing trees on the part of the logger still exists. In fact his attitude must be one of sympathetic coöperation in the silvicultural plan if the best results are to be attained. There is less opportunity allowed him for seriously interfering with the style of cutting. As operators gain experience in making cuttings in the practice of silviculture the tendency will be for them to prefer the method of marking rather than control by inspection alone, because of the fact that the marking method relieves them of considerable responsibility and allows their attention to be centered upon the logging end of the work. Inspection is necessary under the marking method to see that the cutting is properly executed, but the whole success of the method does not so vitally depend upon frequent and close inspection as under the first method.

Either the trees to be cut or those which are to remain may be marked. The relative number of trees to be cut or left is instrumental in determining which of the two classes should be marked. When relatively few trees are to be cut it is cheaper to mark the trees to come out, while if this condition is reversed, the trees to remain are marked. Where an 
area is to be cut clear, simply marking the boundaries of the area so treated is sufficient.

If the trees to be cut are marked a blaze going through the bark into the wood is the common designation. The blaze is made on the trunk at a convenient height above ground, approximately breast-high, so as to be readily seen, or else is placed on a root swelling or on the trunk so low as to appear on the side of the cut stump.

The advantage of having the blaze placed on the stump is that it serves as an excellent check upon the operator's work. Two blazes may be placed on the tree, one where it can be readily seen and the other on the stump. The tendency is toward the reduction of expense by the use of only the stump blaze.

A plain blaze is of little use as a check on the operator because it may be difficult to determine by whom such a blaze was made. For this reason it is customary to stamp a letter or symbol on the blaze.

An axe is the marking tool commonly utilized. Where the blazes are to be stamped, a special marking axe is employed with the desired letter or symbol placed on the head.

Marking with blazes trees which are to be retained is not advisable, due to the possibility of insects or fungi obtaining access to the tree through the wounds. This is a reason why it may be desirable to mark the trees to be cut even though they may outnumber those left.

Where it is desired to designate the trees to remain, paint often is employed. In applying paint care must be taken to remove the loose bark before the paint is put on. Sometimes a spot of paint is placed on the trunk and stump or a ring painted around the tree. As a check on the cutting, paint is less effective than stamped blazes because it is more easily counterfeited. 
Marking is not an expensive operation, costing only a few cents per thousand feet board measure. The cost is figured per thousand feet board measure of timber cut, and depends primarily upon the size of the timber, amount cut per acre, topographic and surface conditions of the area, and density of the underbrush and young growth. A stand containing individual trees of large size, in which a heavy cutting is made, on level land free from underbrush, reproduction, rocks or other obstructions will cost less per thousand feet cut than when conditions are reversed.

The system of marking suggested for use in connection with each of the various kinds of reproduction and intermediate cuttings is indicated in the table below:

Character of cutting

Reproduction cuttings:

Clearcutting method.....

Seed tree method.........

Shelterwood method:

Preparatory, seed and removal cuttings.....

Final cutting...........

Selection..............

Coppice.................

Polewood coppice:

First cutting...........

Final cutting...........

Coppice with standards. .
System of marking

Mark the boundaries of the area to be cut clear.

The seed trees which are to remain should be designated in such a manner as not to cause wounds. Paint is excellent for this purpose. Marking the seed trees will cost less than marking all the trees to be cut.

Mark all trees to be cut.

Mark the boundaries of the area on which the final cutting is to be made.

Mark all trees to be cut.

Mark the boundaries of the area to be cut clear.

Mark all trees to be cut.

Mark the boundaries of the area on which the final cutting is to be made.

Mark with paint, the young standards to be retained when the coppice is cut. Mark all trees to be removed among the other standard classes. 


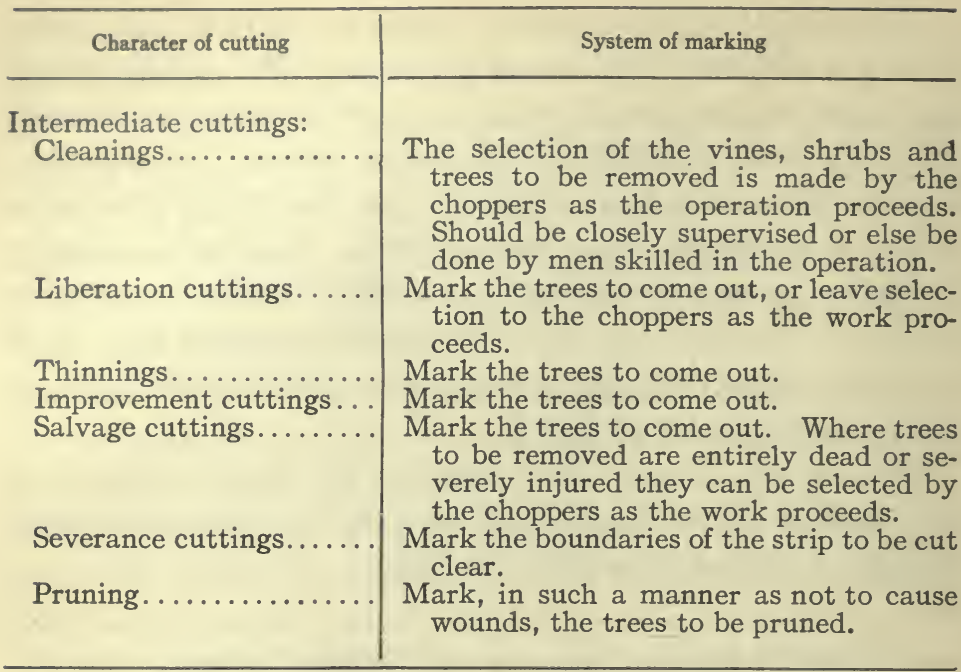

Marking Rules. - Marking rules in their simplest form comprise a set of instructions for marking timber. To be of practical use they must refer specifically to a single species or to a single forest type and usually to a given forest area.

Marking rules have been used principally by the United States Forest Service in their publications concerning various commercial trees and in the application of silviculture in the national forests. See references at end of chapter.

Such rules may range from simple instructions as to the classes of trees to be marked up to statements, summarizing the important silvical characteristics of the species and outlining the methods of reproduction and treatment throughout the rotation, to be used for the given trees or type.

Marking rules are intended primarily for the assistance of the forest officers in charge of the marking on timber sales. If only one kind of cutting, such as a Grade $\mathrm{C}$ thinning or a 
clearcutting for reproduction, was required uniformly over the area very brief instructions would suffice. This is not the situation which prevails on the national forest sale areas or elsewhere, except in small stands. Usually on the area to be operated at one time there will be several stands, or at least great diversity of conditions within the one stand, which make necessary a variety of different cuttings all combined in a single operation. To intelligently mark such a stand requires information as to all phases of the silvicultural plan of management for the tree and type concerned.

Marking rules when most highly developed supply the necessary information in concise form, and are in fact summarized plans of silvicultural management. It is desirable that such marking rules or silvicultural plans be drawn up for all species of commercial importance.

One of the best examples of this type of marking rules has been issued by the office of Silviculture, in District I of the United States Forest Service, for stands of the Western White-Pine type on the Cœur d'Alene National Forest under date of January 15 , I9I 7.3

This set of marking rules is of sufficient general interest as a model of what should be included as to merit the brief résumé which is here given. The sentences in italics are taken verbatim from the original article.

Marking Rules for Stands of the Western White-Pine type on the Cour d'Alene National Forest. Jamuary 15, I9I7.

\section{Part I}

Classification of Western White-Pine Stands. - Evidently based on composition and form of stand, age, size and condition of the trees. The stands are divided into two main divisions with a total of five subdivisions. 


\section{Part II}

Objects of Marking. - Contains a statement of the marking rules for the Western White-Pine type as a whole issued by H. S. Graves, Forester, in December, rgi6.

These rules outline the general policy of marking but are not definite enough for application on individual areas without supplemental instructions from the District Office.

The objects of marking for each of the subdivisions established under the classification into stands are stated in a general way and then full details given for their application, forming the silvicultural plan of management for the type. Intermediate and reproduction cuttings, provisions for the start and development of reproduction, the removal of undesirable species and slash disposal receive consideration.

\section{Part III}

Scientific facts concerning the life history of western white pine which have a bearing upon marking. The subjects treated are the following:

Reproduction after cutting, Germination of seed, Development after germination, Seed production, Seed production from individual trees, Seed distribution, Competitive strength, Recovery after thinning, Fire resistance, Windfirmness, Relation of size and age and Associate species.

\section{Part IV}

General Treatment of Associate Species of White Pine.Brief directions as to the treatment of trees of the eight associate species.

\section{Part V}

Contains a statement to the effect that these marking rules are of general application to the type and more specific rules 
should be drawn up for each logging chance. The procedure of making such specific rules involves the preparation of a type and stand map and the gathering of data in reference to the size, age and condition of the timber.

Control of Waste and Destruction in Logging. - Waste and destruction of timber in the logging is likely to occur in any operation. From the silvicultural standpoint such losses are important because they decrease the yield from the area at the present cutting, and may lessen the possible production in the future. The waste and destruction may be classified under the following headings:

(a) Material left in the tops, through failure to utilize the trunk up to the minimum merchantable top diameter.

(b) Material left in the stumps through failure to cut the stumps to the lowest possible limit.

(c) Material left in windfalls and dead trees through failure to utilize the merchantable portions of such trees.

(d) Destruction of the unmerchantable growing stock either for material to use in the logging operations for skids, corduroy roads, bridge construction, etc., or in order to facilitate the logging work.

Nowadays waste under the first three headings is considered evidence of an inefficient logging operation. As a business proposition the lumberman may be expected to remedy this defect in his operations, so soon as it comes to his attention, without necessarily adopting the practice of silviculture. Close utilization of material in tops, windfalls and dead trees is indirectly of silvicultural benefit by reducing the amount of inflammable material in the forest and by removing trees which might harbor destructive insects and fungi.

In judging whether material is being wasted in high stumps, big tops and dead and down trees careful consideration must 
be given to what constitutes merchantability in that particular locality. "Local conditions governing the logging operations or existing in the available markets may neccessitate two different sets of standards, as to minimum top diameters, maximum height of stumps, and extent to which dead and down material can be utilized, for operations only a few miles apart.

Destruction of the unmerchantable growing stock is of more vital silvicultural importance than the other classes of waste. Reduction in the growing stock, from reproduction right on up to trees just under merchantable size, is likely to result in a lower production in the future crops. The lumberman, as such, rarely is interested in saving the unmerchantable growing stock at the expenditure of any trouble or actual outlay. Where unmerchantable trees will reach merchantable size within a few years he may see a fairly early profit in saving such trees, but in reproduction and young growth as a whole he has no interest. Intention to practice silviculture must exist if the unmerchantable growing stock is to receive protection.

A certain portion of the unmerchantable growing stock may have to be sacrificed in the logging operation. This will depend upon the difficulties of logging, the quantity and location of the young trees and the intensity of the silviculture. The proportion which must be sacrificed should be determined in advance of the cutting and destruction kept within prescribed limits.

Destruction of the unmerchantable growing stock was stated on page $2 \mathrm{II}$ to be carried on either for material to use in the logging operations or to facilitate these operations.

Material for use in logging operations is taken from the young trees for skids, construction of skidways, corduroy roads, and other logging requirements. This material is essen- 
tial but oftentimes can be secured with little if any added cost from inferior species, tops or cull material.

In facilitating logging operations, seedlings and small trees are cut if interfering with the choppers, sawyers, or skidding crews, while merchantable trees are apt to be dropped in the direction of their easiest fall, regardless of the young growth which may thereby be smashed. With practice on the part of the operators a large proportion of this class of destruction can be eliminated.

Destruction of unmerchantable growing stock is most likely to occur in unevenaged stands where the young and the old trees are intermixed on the same area. Under the clearcutting method there is little temptation to injure the younger age classes in the logging operations.

Frequent inspection systematically conducted and supplemented by itemized reports with reference to the waste of material or destruction of unmerchantable growing stock furnishes the best method of control.

\section{REFERENCES}

I. CARY, A. Practical Forestry on a Spruce Tract in Maine. Circular I3I, Forest. Service, United States Department of Agriculture, Washington, 1907, p. Iо.

2. Woolsey, T. S., JR. Marking Western Yellow Pine. Forestry Quarterly, Vol. 7, 1909, p. 27 I.

3. Marking Rules for Stands of the Western White-Pine Type on the Cœur d'Alene National Forest. January 15, 1917, pp. 878-885 included in an article entitled "Development in the Marking of Western White Pine (Pinus monticola) in Northern Idaho" prepared by C. K. McHarg, J. Kittredge and J. F. Preston, Journal of Forestry, Vol. XV, 1917, pp. 87I-885.

CARTer, E. E. The Silvicultural Results of Marking Timber on the National Forests. Proceedings of the Society of American Foresters, Vol. III, I908, pp. I8-28.

Frothingham, E. H. Principles Governing the Marking of Northern Hardwoods in National Forest Timber Sale Practice in the White Mountains. 
Included in, The Northern Hardwood Forest: Its Composition, Growth and Management. Bulletin 285, United States Department of Agriculture, Washington, I9I5, pp. 42-44.

Mason, D. T. Marking Rules for Lodgepole Pine Stands on the Deerlodge National Forest. Included in, Utilization and Management of Lodgepole Pine in the Rocky Mountains. Bulletin 234, United States Department of Agriculture, Washington, I915, pp. 25-28.

Mernecke, E. P. Forest Pathology in Forest Regulation. Bulletin 275, U. S. Department of Agriculture, Washington, I9I6, pp. 57-58.

Munger, T. T. Instructions for Marking Timber in the Yellow Pine Region, District 6. Included in, Western Yellow Pine in Oregon. Bulletin 4I8, United States Department of Agriculture, Washington, r9r 7, pp. 46-47. Weir, James R., and Hubert, Ernest E. Pathological Marking Rules for Idaho and Montana. Journal of Forestry, Vol XVII, I9I9, pp. 666-68I. 


\section{CHAPTER XIII \\ SLASH DISPOSAL}

Definition. - Slash is understood to include all the débris left in the forest as the result of a cutting (or other agencies) and comprises the tops, branches and unutilized portions of the trees cut together with other trees uprooted or broken off in the process or as a consequence of the logging. A broad definition of the term includes also dead trees and windfalls on the ground previous to the logging. Slash is created not only as a result of cutting, but also as a result of other destructive agencies, the most important being fire, and wind, which may cause the death and overthrow of a large portion of the stand.

Silvicultural Effects of Slash. - Slash as defined above consists of such a variety of material that it is best to divide the total into several classes of material before discussing its silvicultural effect.

Classification of slash:

(a) Material which decays rapidly. Includes small branches and tops and foliage.

(b) Large branches and tops.

(c) Logs and unused portions of the bole.

The relative amounts of the different classes of material on a given area show wide variations depending primarily upon the conditions governing utilization of forest products. With intensive utilization the slash that remains may consist only 
of foliage and small branches. In rare cases even this material may find utilization as brushwood.

Slash may be distinguished as originating from either coniferous or broadleaf species of trees. Of the two the coniferous slash makes the denser cover, remains sound longer and on the whole is a greater menace than hardwood slash. The latter often makes an unsightly tangle loosely occupying considerable space but is not potentially so much a source of danger as the lower lying, more compact coniferous slash. Hardwood slash absorbs moisture faster, and goes to pieces more quickly. This process may be so rapid as not to justify any expenditure for hastening the result.

For these reasons disposal of coniferous slash is more commonly undertaken.

The silvicultural effects of slash in a narrow sense may be restricted to the direct effect upon the soil and reproduction. Under this interpretation slash disposal has separate and distinct silvicultural, fire, entomological and pathological aspects. As a matter of fact the production of better tree crops is the basis of the forester's interest in treatment of slash. Forest fires, insects and fungi are destructive agencies whose action is directly and primarily to affect production of tree crops. Hence the influence of slash upon these destructive agencies is of silvicultural importance and together with its more direct influence upon soil and reproduction is properly combined under the silvicultural effects of slash.

Slash in Relation to the Soil. - The effect of slash upon forest soil is beneficial. It prevents erosion and land-slides by holding the litter and soil in place and by mechanically obstructing the movement of water and soil. Through the process of decay it adds to the organic matter in the soil and as a consequence should tend to increase its productivity. Where an excess supply of undecomposed litter covers the 
ground the beneficial influence of slash is at a minimum. On bare soils and on steep slopes at high altitudes the protective value of slash is greatest.

Slash in Relation to Reproduction. - Slash exerts an influence upon reproduction sometimes beneficial and sometimes unfavorable, depending upon the amount and character of the slash and the silvical conditions in the individual case. Where slash is so abundant as to occupy a considerable portion of the area it is certain to have an important relation to reproduction.

Its beneficial effect is to encourage the start and early development of reproduction. This may be accomplished: (I) By the conservation of the moisture in the surface soil through the protection afforded by the slash against sun and wind, (2) By the creation of desired seedbed conditions through shading and through the increase in humus and litter (derived from the foliage of the felled trees), (3) By the protecting shade afforded young plants, and (4) By the mechanical protection given the seedlings against the trampling and browsing of animals.

The harmful influence of slash upon reproduction is its action as an obstacle to germination or to early development of the young plants. Slash, where it lies thickly, may mechanically stop the growth of reproduction which started previous to the cutting. Sufficient heat for germination of seeds to take place may be lacking due to the amount of slash, or the seedbed created may be unfavorable. If germination takes place there may be lack of light under the slash to insure survival of the reproduction.

Slash in Relation to Forest Fires. - Unquestionably slash is dangerous from the fire standpoint for it is one of the most important sources of inflammable material. In addition to the slash the litter, ground cover, underbrush, living trees and 
snags or standing dead trees furnish quantities of inflammable material. Where no cuttings or extensive damage by fire, insects or other agencies have occurred the slash provides the larger portion of the potential fuel. The foliage and the small branches are easily ignited and may burn rapidly but the larger limbs and logs cannot be kindled so quickly or burn so rapidly; although when once started they will create more heat, burn for a longer time and in general, other conditions being equal, make a severer fire than could occur on the same area if without slash. With conifers which retain their foliage for some time after felling, the slash may be easily ignited for several months by simply touching a lighted match to the foliage. This is particularly the case on heavily cut areas where the cutting itself results in opening the stand to the drying action of sun and wind thereby increasing the inflammability of the fuel.

Ordinarily the litter or ground cover provides that portion of the available fuel which is most easily ignited. A fire is apt to start in this material (even on areas covered with slash) and then spread quickly to the slash itself. The larger material included in the slash, when once set on fire, may make an exceptionally serious conflagration, which may gain such impetus as to sweep through adjacent green timber.

The prevalence of fires on cutover areas should not be attributed wholly to the presence of slash Grasses and weeds may spring up after heavy cuttings and provide fuel for the flames.

Besides furnishing a large part of the inflammable material, slash renders the fighting of fires difficult and dangerous. A slash covered area cannot be traversed quickly and the fighters may be caught if in the path of the fire. More labor is required to prepare lines for checking the fire and it may be impossible to use methods of control which on areas free from slash would be feasible. 
Slash in Relation to Insects. - Insects, particularly bark beetles, find in the slash a place where they may breed and develop and then migrate to adjacent living timber. Newly cut slash offers favorable opportunities for strong swarms of insects to develop until they are able to attack successfully living timber. The destructive insects breed almost exclusively in the tops, logs and larger limbs included among the slash and not in the very small limbs. ${ }^{1}$ Portions of the tree from which the bark has been removed do not furnish favorable breeding grounds for the insects destructive to live timber. There are various insects which work in dry wood and in rotting logs, but the insects developing in slash, which are to be feared as a menace to standing timber, will breed in the freshly cut logs and limbs having the bark on. It should be recognized that not all the destructive insects found on cutover land have necessarily developed in the slash. Some may have been bred in stumps or in standing dead and dying trees.

Slash in Relation to Fungi. ${ }^{2,3}$ - The slash acts as host for a variety of fungi all of which are beneficial in hastening decay of the slash. Sporophores may be produced on the slash and from them spores scattered which in the case of many dangerous species of fungi cause infection of standing trees. ${ }^{4}$ Those fungi which are most virulent and destructive to living trees develop principally in the larger pieces of the slash. Their spores may be carried many miles to affect living trees distant from the cutover area.

In warm and humid regions favorable to the development of fungi, the danger to trees on the area, and in the adjoining forest, of infection by destructive diseases developing first in the slash is very great.

Slash in Relation to Forest REsthetics. - From the standpoint of forest æsthetics the presence of slash is a nuisance. 
It spoils the appearance of the forest. There are many places where this factor has little weight. In connection with the handling of public forests the idea of partial utilization and development for recreational purposes is gaining ground. This means that increasing attention will be given to forest æsthetics.

Methods of Slash Disposal. - Methods of such widely diverse character have been developed for treatment of slash as to meet the requirements of all conditions encountered in the field. The principal methods for treating slash are discussed here.

Disposal of Slash by Piling. - This requires the placing of the slash in piles instead of leaving it scattered over the area. The logger in the ordinary course of his work, to keep the slash from hindering operations, throws it into loose piles or windrows. This is essential where the amount of slash is large and the timber is removed from the felling area by animal power. Such treatment should not be confused with a piling method under which the slash is piled systematically and the area it occupies greatly reduced.

'Before slash can be piled the large tops and limbs must be cut up and reduced to small enough size to be easily handled and closely piled. The piles should be small and compact. Large piles are more dangerous to burn than small ones and usually require the brush to be carried farther. Loose piles are difficult to burn cleanly and occupy too much space. Piles may be made circular or rectangular in form. If rectangular, stakes should be set and the slash packed in tightly between the stakes.

Mitchell ${ }^{5}$ states: "Round piles usually burn better than long ones, since they are ordinarily more compact. . . . Experience has also shown that to burn to the best advantage the height of a pile should equal, if not exceed, its diameter, 
and that, as far as possible, the butts of the limbs should be placed toward the center of the pile."

It is frequently unnecessary and often impracticable without considerable expense to place the entire volume of the slash in piles. The more inflammable portion, consisting of the small branches with such twigs and foliage as are retained, should be piled and in addition such of the larger branches and portions of the bole as are conveniently located with reference to the piles or may be needed to weight down or keep the piles from being flattened out by heavy snows.

Most of the large branches, cull logs, windfalls and other unutilized trees are not put into the piles, unless this is necessary to prevent the breeding of destructive insects. They may be left lying in contact with the ground where they absorb moisture and decay more quickly than if elevated.

Piling of slash while the cutting is in progress and before the logs are skidded has the advantage of facilitating this operation since the ground is somewhat cleared of débris. More effective results from labor are likely to be secured where the piling is a part of the logging job $^{5}$ and can be supervised without additional expense.

Brush piles should be located so as not to be in the way of skidding operations and (if they are to be burned) at safe distances from reproduction and larger trees. If the piling is not done until after the completion of the logging many of the piles can be located in roadways and yards. Where it is desired to destroy undesirable reproduction, underbrush or trees of inferior species the piles should be located so as to kill this material.

The method of piling is further subdivided depending on the final disposition of the piled material into the following submethods.

(a) Piling and Burning. - The piles are burned as a special 
piece of work distinct from the piling. The piles must be carefully built because they may have to stand several months before the time for burning arrives.

During dry seasons of the year it is often dangerous to carry on any slash burning operations. As a precaution the piles made in such periods are not burned until later and only when climatic conditions are such as to render the operation safe. An ideal time to burn brush piles is immediately after the first snowfall, which is apt to be so light as not to prevent easy burning of the piles, although affording protection to surrounding trees.

Burning of a large number of brush piles is at best a risky operation. There is the danger of the fire becoming uncontrollable and spreading from pile to pile until finally the fire has gained such momentum that it cannot be held on the cutover area but spreads into adjacent uncut timber. Reproduction and young timber standing in proximity to the piles may be injured or destroyed by the heat of the fire even though it does not spread from pile to pile.

If a group of adjoining piles is burned all at one time the air becomes so heated and such a draft is created that the remaining live trees and reproduction on the area may be killed. A better arrangement is to burn piles here and there and not to set fire to the adjacent piles until those first lighted have been consumed. If a wind is blowing the burning should be started among the piles on the leeward side of the cutover area.

Where a large number of brush piles must be lighted a special brush burning torch is useful. The torch should be rigid and strong enough to be thrust into the piled slash without injury to the handle or to the torch proper and be capable of burning for some time. One of the best torches ${ }^{6}$ can be made out of a piece of pipe. 
If the piles are small and well built they may burn completely without any attention after lighting. Otherwise the partially consumed piles must be visited while still burning and "chunked up" by having the unconsumed brush around the edges thrown onto the fire.

(b) Burning as the Logging Proceeds. - Fires are started upon which the slash is thrown. The piling and burning is thus accomplished in one operation.

This method is the most economical from the standpoint of the lumberman and the forester. The work of piling and burning is done in conjunction with the removal of the timber. The felling crews may do the work or special men may be assigned to the duty. Fires should be started in openings away from reproduction and young trees. When a tree is limbed out the branches are thrown directly upon the fire, and do not have to be cut up so small as when placed in piles.

The actual cost of burning the brush is likely to be reduced when conducted in this manner. This method is preferable to piling and burning in a separate operation, but can be employed only under climatic conditions favorable to safe burning. When the logging is done in the hot dry seasons of the year piling and burning later is the alternative.

Disposal of Slash by Broadcast Burning. - In broadcast burning fires are started and allowed to burn over the area occupied by slash. It is a cheap method of disposal for it requires no piling and very little handling of the slash. Around the edges of the cutover area firelines should be cleared of slash and other inflammable material. If the area is extensive interior fire lines may be needed dividing the area into blocks. How large these blocks should be will depend on the conditions in each case, among which amount and inflammability of the slash and the difficulties of controlling the fire are 
of primary importance. Rarely should the block be larger than forty acres. Should there be on the area any trees which it is desired to save then the slash must be pulled away from them.

A fire hot enough to consume the slash is likely to destroy all reproduction and trees on the area covered by the fire. It may consume all of the litter. Broadcast burning sometimes is employed in connection with a clearcutting method depending for reproduction upon seed stored in the duff. It is then essential that the litter which contains the stored seed be protected from the fire. This can be accomplished by burning at a time when the slash is fairly dry but the litter, less exposed to the effects of sun and wind, still remains wet. The fire may burn the upper portion of the litter but not the whole. The slash must be dry enough to secure a clean burn.

Broadcast burning is a dangerous method of slash disposal because unless carefully controlled the fire is likely to gain momentum and escape to adjoining timbered areas. For this reason the time of burning must be chosen so as to secure favorable climatic conditions. The ideal time for burning may be stated as a period with little or no wind, what there is coming steadily from one direction, relatively high humidity, low temperature and cloudy weather immediately preceding a period of rain or snow. This combination is difficult to attain with certainty, but the nearest approach to the ideal is likely to be found by selecting for the operation a night in the early spring or late fall when there is a probability of rain or snow to follow.

A force of men should be on hand to set the fires and watch their progress and in addition if the area to be burned over is extensive it is advisable to have arrangements completed in advance of the burning with a larger force of men to come out at once in case the fire escapes. The crews in nearby 
lumber camps are logically the men for such an emergency force.

In conducting the broadcast burning fires are set at several points on the leeward side of a block which is to be burned over. The fires so started are prevented from crossing the fire line and forced to burn against the wind. It is best to burn only one block at a time and to have men patrolling the cleared lines to prevent the fire crossing. On areas where the slash was heavy and contained large sized cull material the fire may remain smoldering for several days

Disposal of Slash by Lopping. - Lopping consists in the cutting up of the slash into smaller pieces. In order to have practical value the term must be made more definite in accordance with the specifications holding in the given locality. For example the top lopping law of New York State requires that all limbs three inches and over in diameter be severed from the trunk and that tops be lopped down to the three inch point.

In theory lopping is designed to cut the slash up into pieces of such size and shape as will lie in close contact with the ground, where they will absorb moisture and decay more quickly.?

The lopping method may include scattering the lopped portions of slash so as to avoid piles and windrows or it may leave the lopped portions just as they lie without further handling. During the hauling out of the logs the lopped tops are likely to be thrown together into loose heaps. If a scattering method is used the scattering must be done as the final step after the logs have been yarded.

The best time to carry on the lopping is in connection with the trimming of the bole and bucking up the logs.

Lopping is classed as a cheap method of slash disposal compared with methods involving piling. This is not the fact 
in all cases. Where careful scattering of the slash is included following the lopping the cost is likely to be higher than piling and burning. The cheapest lopping involves no scattering of the slash.

The lopping method improves soil conditions by allowing the tops to decay and increase the humus content and acts mechanically to prevent erosion. Skidding the logs is made easier and cheaper where the slash is cut into small pieces and hence easily moved. A tendency toward closer utilization is developed, because where the bole must be trimmed of branches up to a small diameter limit in the lopping the operator is likely to use more of the bole than he otherwise would. Fire fighting is easier in lopped than in unlopped slash because of the ease and speed with which the former can be handled.

A strong disadvantage is the fact that until the lopped tops decay a serious fire hazard may exist. ${ }^{8}$ The length of time necessary for the tops to absorb moisture or decay sufficiently to cease being a fire hazard varies with the climatic conditions, the amount of the lopped material, and its position with respect to contact with the ground.

Disposal of Slash by Pulling the Tops. - Pulling the tops consists in dragging the entire unutilized tops of the trees to positions on the area different from those occupied by the tops when the trees were felled. The operation is accomplished by hitching one or more animals to each top. Tops are dragged in cases where they lie in dangerous proximity to standing trees or reproduction or else where they are needed to cover spots likely to be eroded such as gullies or slopes. In some cases the tops are of assistance to reproduction by affording either slight shade, the desired seedbed or protection from the trampling or browsing of animals whom the tops keep off. The pulled tops because of standing relatively high 
above the ground and being able, when burning, to carry flames into the crowns of trees, constitute a more serious fire menace to standing trees than do lopped tops. ${ }^{9}$

The method does not remove any of the slash from the felling area, it simply changes the position of a portion, usually a small proportion of the material.

Light Burning. - Light burning is not a method of slash disposal. It consists in the annual or periodic burning over broadcast of forest areas before instead of after cutting operations. Slash as previously defined is created mainly as a result of such operations.

Light burning is an intentional use of surface fires to keep the ground free of the highly inflammable material which is made up of litter, ground cover, underbrush and reproduction.

The theory is that if such material is burned at relatively frequent intervals a fire, hot enough to injure the less inflammable but more valuable material, namely the standing timber, cannot start. This would be logic did it not overlook the injury to the productive power of the forest caused by light burning. It may be summarized under the following headings:

(a) Injury to the Soil.--Light burning proposes to prevent the accumulation of litter which is essential for the production of humus, this in turn being of vital importance in maintaining the physical properties of the soil in best condition. Annual burning removes the litter as fast as it forms and has a serious effect on the humus content. Periodic burning at intervals of three to five years is nearly as bad, since it requires several years for litter, after its fall, to decompose into humus. Sandy soils with level topography are least injured, while heavy soils of fine texture and on slopes which may erode suffer the greatest injury.

(b) Injury to Reproduction.-A fire hot enough to consume 
the litter and ground cover will kill small reproduction as fast as it starts.

In unevenaged stands the result would ultimately be the destruction of the forest. In certain evenaged stands where reproduction is not desired except in the regeneration period, a temporary restriction of reproduction may be of benefit. Light burning has been used with satisfactory results for this purpose in management under shelterwood of chir pine forests in India, ${ }^{10}$ although not without the criticism that some other agency than fire should be employed for the same purpose. ${ }^{11}$ Such a case is an exception which but proves the rule.

(c) Injury to Trees above Reproduction Size.-Surface fires damage standing trees in ratio to their size and inherent powers of resisting heat. Large trees and those with thick corky bark may escape injury while small thin barked trees are killed. The aggregate amount of the damage from even a single light burn ${ }^{12}$ is serious and from repeated burns results in heavy inroads upon the growing stock.

(d) Reduction in Density of Stocking.-As a consequence of the injuries to reproduction and growing stock the density of the stand is reduced, and the quality and quantity of production per acre lowered.

In conducting a light burning operation a time is selected when the material is dry enough to burn readily, but not so dry as to threaten to ignite the forest itself, and with climatic conditions favorable for controlling the fire. The advocates of light burning minimize the damage done and state that it can be avoided by raking the litter away from the larger trees. It is impracticable to do this on a large forest area and to carry on similar raking around the smaller trees and reproduction is manifestly out of the question. If light burning is conducted in such a careful manner as to save reproduction and avoid injury to other standing trees, it 
becomes an expensive method of protection when repeated at short intervals.

With longleaf pine in the southern United States it is possible that light burning may be applicable. Longleaf is so fire resistant, reproducing often in spite of fire, and grows on sites relatively so free from injury by fire in a region where the total suppression of surface fires is extremely difficult that it is an open question whether light burning cannot be cmployed to advantage.

\section{Application of Slash Disposal Methods under Various Kinds of Cuttings}

Reproduction Cuttings. - Cutting under the Clearcutting Method. This is one of the few cuttings with which broadcast burning can be employed. There are no trees left on the felling area to be injured in the fire. Slash is heavy after a clearcutting, in some cases lying several feet deep over the greater part of the area, and consequently expensive to handle. Ordinarily a clearcutting method is not used unless the species desired in the new stand reproduces well on a bare site free of underbrush and litter. Taking all these effects into consideration, broadcast burning frequently is seen to be the cheapest and most satisfactory method of slash disposal. Conditions may be such that it is unsafe to burn broadcast or is not in harmony with the silvical requirements, whereas a piling and burning method might be used. If broadcast burning is not used a piling method is employed. Of the piling methods piling and burning as the logging proceeds is preferable. Piling and burning later would be chosen only when climatic conditions made it unsafe to burn during the logging operation.

Piling without burning is undesirable on a clearcut area because so much room is likely to be taken by the piles. 
Lopping of tops is not suitable due to the relatively large amount of slash on the area.

Cuttings under the Seed Tree Method. - The area is left quite bare with relatively few trees scattered singly or in groups. There are not enough of these seed trees to make impracticable the use of broadcast burning. The expense of the operation will be increased by the necessity of clearing the slash away from the seed trees and in burning over the area more carefully. Otherwise what has been said of cuttings under the clearcutting method applies for the seed tree method.

Cuttings under the Shelterwood Method.-Broadcast burning is impracticable as it would result in destruction of reproduction and probably of some of the mature trees remaining on the area after all but the final cutting. Piling, lopping or pulling tops are available. Where the method is intensively applied the slash may be so small in quantity as to require no disposal. If the stand is of open character and the site in need of protection even large tops may be dragged away from the standing trees and left intact. The slash frequently is not too heavy to admit of lopping and scattering, so as not to interfere with reproduction. This has the advantage of not requiring the use of fire, which is apt to injure reproduction already started and the remaining mature stand.

The lopped trees may form an impediment to the start and development of reproduction; in which case piling and burning either as the logging proceeds or separately is advisable. Care is necessary to conduct the burning without injury to reproduction and mature trees.

Cuttings under the Selection Method. - Where single tree selection is used the amount of slash in any one place is small. Lopping the tops without scattering fits the situation, particularly as single tree selection is likely to be used on protec- 
tion sites. In group selection the trees so far as possible are felled in toward the center of the group. The tops can here be piled and burned without injury to the forest.

Since the selection stand contains trees of all ages in mixture the difficulty of burning slash without injury to the forest is greater than under most other reproduction methods.

Broadcast burning cannot be used without destroying the unevenaged forest.

Cuttings under the Coppice Methods. - Utilization is necessarily close in order to make possible the simple coppice method of reproduction. The rotation is short and the largest trees in the stand when cut are relatively small. Only a small amount of slash consisting of small branches and foliage is left after the cutting. This material rots easily and is not abundant enough to smother sprout reproduction.

An added reason for allowing the slash to rot on the area rather than burning it up is to prevent deterioration of the soil under coppice management.

The polewood coppice method provides for a longer rotation and hence produces larger trees with bigger tops. Even so the accumulation of slash is not enough to require the expense of piling and burning. In sprout stands of hardwoods the chief fire hazard comes from the inflammable leaf litter and not from the slash. Surface fires serious enough to kill mature trees can develop in hardwood leaf litter. Presence of slash may increase the severity and the difficulty of fighting the fires, but not sufficiently to justify the expense of piling and burning the slash.

Slash disposal after cuttings under the coppice with standards method is not advisable for the same reasons which apply for the simple and polewood coppice methods.

Intermediate Cuttings. - The slash remaining after inter- 
mediate cuttings is small, both in size of pieces and in total quantity.

Intermediate cuttings cannot be made without the existence of fairly good markets; which in turn permits of close utilization. Ordinarily the slash does not require disposal.

In liberation cuttings the slash should be lopped and scattered wherever it is lying upon reproduction.

Severe thinnings, improvement cuttings, or salvage cuttings, particularly in coniferous stands, may create a slash heavy enough to need disposal. A piling and burning method is suggested.

Severance cuttings should be followed by piling and burning all of the slash in order to secure a clean line.

Selecting the Method of Slash Disposal. - As explained on page $2 \mathrm{I} 6$, the total silvicultural effect of slash disposal is a composite of the combined effects upon the soil, reproduction and upon the chief enemies of the forest, fires, insects and fungi. What is best in slash disposal for one of these may be injurious for another. In other words in their requirements for treatment of slash to produce the most satisfactory results these various interests may conflict.

From the standpoint of forest fires complete removal of the slash, which furnishes a substantial part of the fuel for fires, represents the ideal treatment. Of greatest importance is the removal of the smaller, highly inflammable portions of the slash, while the larger pieces can often be safely left. In the control of destructive insects the situation is reversed; although as an ideal complete removal of slash would be desirable, still the part of the slash of vital importance is that including the large pieces.

The greatest benefit to the soil, usually follows through retention of all the slash; and it is possible that leaving the slash just as it is will be the best method of treatment. 
In the final choice of a method for treating the slash a compromise must be struck between conflicting viewpoints, in such a way as to produce the most favorable total effect. In arriving at this decision the factor of cost and the character of other control or remedial measures, which will be undertaken against injurious agencies, must be considered. Since silviculture aims at the highest production not only quantitatively, but financially, it follows that cost must always be kept in mind.

The cost of slash disposal may be figured either on an acreage basis or by the thousand feet board measure of timber cut. In the final analysis the cost should be expressed on the acreage basis. When broadcast burning is used the total cost per acre is nearly independent of the amount of timber cut per acre, while in other methods of disposal the cost per acre is in proportion to the amount of timber cut. Since the amount of timber cut per acre varies from less than one thousand to over one hundred thousand feet board measure, costs of slash disposal (except in the case of broadcast burning) for comparative purposes are commonly expressed on the thousand board feet unit basis. This allows of ready change to per acre figures when the amount cut per acre is known.

The cost of slash disposal per thousand feet board measure is greater for trees with heavy crowns, than for light crowned trees, for small as contrasted with large trees, when the cut per acre is light as compared with a heavy cut and on rough ground than on smooth ground.

It is evident that there will be a wide range in the cost of . slash disposal due to the factors already mentioned.

In general the cost of slash disposal should range from one or two cents to a dollar per thousand feet board measure of timber cut. The minimum figures would be attainable only under the broadcast burning method with a cut of fifty to 
one hundred thousand feet board measure per acre or in regions of open forests not subject to crown fires. The maximum of a dollar ought not to be required, except where in small timber a method of piling and burning at different times was conducted in a most thorough manner or where lopping with careful scattering was employed.

The average costs of slash disposal fall between ro and 50 cents per thousand feet board measure. Cox ${ }^{13}$ gives the average cost of slash disposal in the state of Minnesota as Io cents per thousand feet of timber cut. This amounts to an approximate annual expenditure of $\$ 300,000$ on a basis of three billion feet cut yearly. Hirst ${ }^{14}$ estimated in I9I6 that for the small sized timber in the rough country of northern New England slash disposal would not average less than $5^{\circ}$ cents per thousand board feet.

On individual operations where costs go much higher, it is advisable to investigate the efficiency of the labor or to seek other ways (either of slash disposal or along entirely different lines) of accomplishing the desired silvicultural result.

Mason ${ }^{15}$ suggests that in lodgepole pine stands properly regulated grazing may obviate the need of expenditures for slash disposal. Koch ${ }^{16,17}$ has favored extra patrol on cutover areas as a substitute for more expensive slash disposal. The following quotation from the Report for I9I9 of the Minnesota State Forestry Board ${ }^{18}$ is pertinent.

"In some cases where the timber still standing is of exceptional value, owners have been permitted to substitute three years of adequate patrol for brush burning."

A present expenditure of several dollars per acre for treatment of slash may be fully justified by the saving of losses which, if slash disposal were omitted, might be incurred. In this connection Hopping, ${ }^{1}$ discussing conditions in California, says: "No matter what the species of tree the slash resulted 
from, that slash breeds under ordinary circumstances the insect or insects destructive to standing timber. The annual loss from this cause alone far exceeds any cost incurred from the burning of the slash at the proper time. Therefore the consideration of the burning or non-burning of brush must be taken up from a broad protection standpoint and not from the standpoint of fire risk or cost alone."

Similarly, the danger of fungi spreading from slash to living timber may justify relatively large expenditures for special treatment of the slash. The dangerous fungi develop in the cull logs and other large sized pieces of slash, which are not disposed of in the methods of slash disposal other than broadcast burning. This latter method cannot always be used, because of the presence of reproduction and immature timber. The special treatment ${ }^{4}$ necessary may take the form either of:

(a) Attempts to dry out the slash and thus create unfavorable conditions for the development and fruiting of fungi. To accomplish this the cull logs and large material of all kinds must be elevated above the ground and in some cases be stripped of bark.

(b) Destruction by fire of the large pieces of slash. The small brush can be utilized for this purpose, so far as it will go, by piling it on top of and around large material which then will be partially consumed in the burning.

Both classes of treatment are expensive and will increase the cost of slash disposal. A combination of the two is likely to produce the most effective results.

\section{REFERENCES}

r. Hopping, Ralph. The Entomological Aspect of Slash Disposal. Proceedings of the Society of American Foresters, Vol. X, 1915, pp. 183-185.

2. Long, W. H. A New Aspect of Brush Disposal in Arizona and New Mexico. Proceedings of the Society of American Foresters, Vol. X, 1915, pp. 383-398. 
3. Long, W. H. Investigations of the Rotting of Slash in Arkansas. Bulletin 496, United States Department of Agriculture, Washington, I9I7.

4. Hubert, Ernest E. The Disposal of Infected Slash on Timber-Sale Areas in the Northwest. Journal of Forestry, Vol. XVIII, I920, pp. 34-56.

5. Mrtchels, J. A. Methods and Costs of Brush Piling and Brush Burning in California. Proceedings of the Society of American Foresters, Vol. VIII, r9r3, pp. 340-353.

6. Cox, Wm. T. The Best Brush Burning Torch. Forestry Quarterly, Vol. XI, r9r3, pp. 372-374.

7. Stephen, JoHn W. Lopping Branches in Lumbering Operations. Extract from the Fifteenth Annual Report, State of New York - Forest, Fish and Game Commission, Albany, I909, pp. 94-ro2.

8. Wrlson, Ellwood. Logging Débris an Imperative Problem. Canadian Forestry Journal, Vol. XIII, I9r 7, p. I445.

9. Chapman, H. H., with comments by Pearson, G. A. The Development of a Brush Disposal Policy for the Yellow Pine Forests of the Southwest. Journal of Forestry, Vol. XVII, I9I9, pp. 693-702.

ro. Glover, H. M. Departmental Firing in Chir (Pinus longifolia) Forests in the Punjab, Rawalpindi Division. The Indian Forester, Vol. XI, Dehra Dun, I9r4, pp. 292-306.

Ir. Fischer, C. E. C. The Need of Fire Protection in the Tropics. The Indian Forester, Vol. 38, Dehra Dun, r9r2, pp. I9r-22r.

I2. Show, S. B. Light Burning at Castle Rock. Proceedings of the Society of American Foresters, Vol. X, 1915, pp. 426-433.

13. Cox, Wм. T. Defending the Forest. The North Woods and Wild Life, Vol. 6, I917, p. 9.

I4. HiRst, E. C. Biennial Report of the Forestry Commission for the Years Igr5-rgr6, State of New Hampshire, Concord, rgr6, pp. 34-35.

15. Mason, D. T. Brush Disposal in Lodgepole Pine Cuttings. Proceedings of the Society of American Foresters, Vol. X, I9r5, pp. 399-404.

r6. Koch, Elers. The Economic Aspect of Slash Disposal. Proceedings of the Society of American Foresters, Vol. IX, r9r4, pp. 356-359.

. I7. Koch, Elers. Some Suggestions on Brush Disposal. Forestry Quarterly, Vol. XI, I913, pp. 519-526.

18. Minnesota State Forestry Board, Annual Report to the Governor for the Year r9i9, p. ro.

Munger, T. T. Western Yellow Pine in Oregon. Bulletin 4I8, United States Department of Agriculture, Washington, 191 7, pp. 47-48. 


\section{CHAPTER XIV \\ FOREST PROTECTION}

General Considerations. - It has been indicated (see page 6) that one part of silviculture deals with protection of the forest against various injurious agencies. These agencies are so numerous and many are so destructive that the production of profitable tree crops is impossible unless adequate protection be afforded.

It is necessary that the silviculturist be continually on the watch for evidence of the presence and activity of injurious agencies. The character of the damage caused by and the appearance and characteristics of the injurious agencies likely to be operating in a given forest must be understood. Each locality will have problems of protection peculiar to itself but the same broad types of enemies are of general occurrence.

A most systematic presentation of the agencies against which forest protection must be effected is that contained in Schlich's ${ }^{1}$ Manual of Forestry, Vol. IV, which is an English adaptation of Der Forstschutz by Hess. ${ }^{2}$

The main headings and subdivisions from Schlich's Manual of Forestry, Vol. IV, are herewith given to indicate the scope of forest protection.

\section{Forest Protection ${ }^{1}$}

Part I. Protection of forests against man.

Forest boundaries.

Protection of forests against irregularities in utilizing forest produce.

Protection of the forest against offences.

Protection against forest rights. 
Part II. Protection of the forest against animals.

Protection against game.

Protection against other rodents.

Protection against birds.

Forest insects.

Insects useful to forests.

Injurious forest insects.

Part III. Protection against plants.

Protection against forest weeds.

Protection against fungi.

Part IV. Protection against atmospheric influences.

These include frost, insolation, wind, violent rain, hail, snow and rime.

Part $V$. Protection against non-atmospheric natural phenomena.

Protection against damage by water.

Protection against avalanches.

Protection against shifting sand.

Protection against forest fires.

Part VI. Protection against certain diseases.

These include red-rot, white-rot, stagheadedness, abnormal needle-shedding and damage from acid fumes.

Protection from grazing animals (domestic) is curiously enough not placed in "Part II, Protection of the forest against animals," but under "Part I, Protection of forests against man," under the subdivision "Protection of forest against irregularities in utilizing forest produce."

The relative importance of a given branch of protection changes from region to region. This is illustrated by the 
space in Schlich's Manual, Vol. IV, devoted to the consideration of forest fires. Out of approximately 600 total pages less than 20 pages are occupied by fire protection. In America this line of protection at the present time receives primary consideration. While the emphasis placed on the various branches of protection will shift from country to country, yet it is true that the same kind of injurious agencies described by Fisher ${ }^{1}$ and Hess are to be encountered in America. Much can be learned from these two standard works.

The four most important agencies against which forest protection is required in America are:

Fires

Insects

Fungi

Grazing animals (domestic).

Forest protection in its application to the control of injurious agencies and the prevention of losses is a highly specialized subject (or group of subjects). The classification and description of injurious agencies, the scientific facts which must be known in determining control methods and the administrative problems connected with control and prevention of losses call for the development of specialists in several of the more important branches of forest protection.

It is impossible (and out of place) within the limits of a work on general silviculture to treat fully of forest protection.

All that can be attempted here is to select the more destructive injurious agencies and to present (in the succeeding chapters) for each the following information:

(a) Description of the damage caused.

(b) Character of the injurious agency. 
(c) Condensed statement of the methods of protection, with particular reference as to how and to what extent cuttings and special silvicultural treatment of the stand can be utilized to assist control and prevention of loss.

\section{REFERENCES}

I. Fisher, W. R. Forest Protection. Schlich's Manual of Forestry, Vol. IV, London, 1895 .

2. Hess, Richard. Der Forstschutz. 3rd edition. Leipzig, I896-Igoo.

Furst, Hermann, translated by John Nisbet. The Protection of Woodlands against Dangers arising from Organic and Inorganic Causes. Edinburgh, I893.

Lovejoy, P. S. Forest Biology. Journal of Forestry, Vol. XV, I9I7, pp. 203-214. 


\section{CHAPTER XV}

\section{PROTECTION AGAINST FOREST FIRES}

Effects of Forest Fires. - Forest fires are in the main injurious to forest production. In certain instances, beneficial results may accrue. There exists such a wide disparity between the relative importance of the injurious and beneficial influences that the latter have often been overlooked. In this chapter the effects of fires are assumed to be injurious unless otherwise specifically stated.

Annual Fire Loss. - A general statement covering the total damage done by forest fires in the average season or in any one year for a territory as large as the United States must be a mere approximation owing to lack of statistics for many portions of the country and to incomplete estimation of the damage. Plummer ${ }^{1}$ makes the statement that "Forest fires in the United States have caused an average annual loss of about seventy human lives, the destruction of trees worth at the very least $\$ 25,000,000$ and the loss of stock, crops, buildings and other improvements to the amount of many millions more. To these must be added enormous losses from the destruction of young tree growth, deterioration of the soil, damage to water-courses and adjacent property by low water and flood, interruption of business, and depreciation of property."

This estimate, published in I9r 2 , was based on a careful search of all the sources of information. It may be taken as representative of the period in the United States before the awakening of public interest and the development of scien- 
tific methods of fire protection, which began after the fire season of I9I0. The last statistics issued by the United States Department of Agriculture ${ }^{2}$ were for I9I5 and gave the loss for that year in timber and improvements alone as $\$ 7,000,000$ with 40,000 fires and 6,000,000 acres burned over, or I.I per cent of the total forest area of the country. I9I5, however, was a favorable year with relatively few serious fires.

An excellent example of what has been accomplished since fire protection was begun in the way of reducing the annual loss is furnished by the Oregon State Board of Forestry. ${ }^{3}$ Since 1907 , records covering the state of Oregon have been kept with the following results:

A period without good protection I908, 09, I0, average annual fire loss........................ \$663,935

A period with well organized protective system, I9II-I6, average annual fire loss.................. 16,250

To this was added during I9I I-I6 an average annual charge

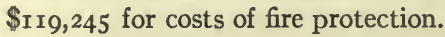

The costs of protection plus the loss are far below the loss alone before an efficient protection system was installed. Many similar examples can be drawn from the records of other organizations.

The losses from fires (other than forest fires) during the last 30 years rose from $\$ 102,940,000 *$ in I 888 to $\$ 242,302,000$ in I917. I 906 with $\$ 450,75^{1}, 000$ has the highest loss for any one year, while I897 with \$101,265,500 is the lowest year. The annual average loss for the first five years of this period was \$ $20,534,000$ as compared with $\$ 201,701,000$ for the last five-year period. This is an increase of 67 per cent. During the same period great improvements in fire prevention and control were introduced and the sums spent $\cdot$ for the purpose increased.

* These figures are based on reports compiled by the Standard Publishing Company, Boston, Mass., and furnished by J. H. Kelsey, statistician. 
While the increase of losses in conjunction with rise in expense for protection may appear discouraging, such is not the case.

The enormous increase in the number of buildings and greater concentration of values, due, for example, to more expensive buildings, and to larger stocks of goods carried by business firms, would account for a larger number of fires and for higher losses.

The wealth of the country has risen far more rapidly than have losses from fires. Hence the percentage of loss to total value has fallen.

Similar results may be anticipated (and already are being received in many forest regions) when forest property is protected from fire. Whether the actual amount of damage will increase annually as the value of forest property rises remains to be seen. Past statistics of damage are based on a period when virtually no protection was afforded forest property. The establishment of a protective system may be expected to have the immediate effect of reducing the losses below figures for the no protection period, although the latter are incomplete and too low. After the protection system is well established, it may be that as forest property values rise forest fire losses also will go up in amount, though falling in per cent of total protected value due to higher efficiency in protection.

Classification of the Injuries Caused by Forest Fires. The injury caused by forest fires may be classified under eight heads, of which the first four have a direct relation to the results of applied silviculture attained in any forest.

I. Injury to trees containing merchantable material.

2. Injury to young growth including reproduction.

3. Injury to the soil. 
4. Injury to the productive power of the forest.

5. Injury to forage.

6. Injury to stream flow and industry.

7. Injury to other property.

8. Injury to human life.

Injury to Trees Containing Merchantable Material. - The damage may range from slight fire scars at the base to "complete consumption of the tree. The latter occurs rarely even in exceptionally severe fires. Frequently large trees are'killed outright. Death is caused by the killing of the cambium or living layer between the bark and the wood. A temperature of $54^{\circ} \mathrm{C} .{ }^{4}\left(\mathrm{I} 29.2^{\circ} \mathrm{F}\right.$.), is sufficient to kill the cambium. If the cambium is killed all the way round, the tree is girdled and dies. Dead cambium can usually be told by its dark color in contrast to its light shade when in normal condition. It is not necessary that the bark be burned off to cause death of the tree. Heat which only scorches the outer bark is often sufficient to kill the cambium.

During the early part of the growing season when cell division in the cambium layer is at its height the cambium is more sensitive to heat than later on in the summer or during the dormant period. ${ }^{5}$

Power of resistance to fire differs for each species of tree. These differences between species are due primarily to the character and thickness of bark. Layers of cork, which act as non-conductors of heat, are developed to a greater or less extent in the bark. A tree which develops thick corky bark is better protected than one with thinner and less corky covering. Tree bark may be soft, flaky, easily inflammable and apt to burn through to the wood underneath, or it may be hard, ignited with difficulty and rarely burned through.

Old trees of any given species are better protected against 
fire than the young trees because with age the bark thickens and tends to become more corky. Trees which secrete resin in the bark or exude pitch as a result of insect attacks are easily injured. Where the pitch is plentiful a fire may run up the tree killing the cambium on one side for many feet above the ground and leaving a long scar called a cat's face.

Conifers suffer more severely from fire than hardwoods.

When heat from a fire reaches the roots of trees severe injury or death results. This is the case because tree roots are less thoroughly protected by thick bark than the portions above ground, and probably are more sensitive to heat. Trees with shallow root systems suffer more than the deep-rooted species.

Old trees can be found all hollowed out at the base by fires. In some cases spaces big enough to admit one or more men have been burned out. Such hollows are rarely if ever the work of one fire but represent the effects of several fires. Once the bark has been burned away on one side succeeding fires burn more readily in the exposed wood.

Where trees containing merchantable material are killed outright they should be cut and utilized before the timber decays or is attacked by insects. This is not always possible if the trees are few in number, scattered or located in inaccessible places. Frequently fire killed timber can be salvaged for a large percentage of its value before the fire. Burned timber in some cases is valueless a year after the fire, in other cases remains sound for several years. Climatic conditions, the species, and the question of whether the bark falls from the trunk soon after the fire are the main factors influencing the length of time during which fire killed timber remains sound.

In a dry climate with a species relatively free from insects and fungi and under circumstances causing the tree to shed its bark deterioration is delayed. 
In one case which came to the writer's attention large white pines (Pinus Strobus) growing in Nehasane Park in the western Adirondacks and killed by a fire in 1903 , were utilized 12 to I4 years after the fire. Although riddled with worm holes 90 per cent of the timber was sound enough for building purposes where appearance was not an essential. The timber was old growth and hence was nearly all heart-wood which fact had much to do with its lasting qualities.

Where merchantable trees are injured but not killed by fire it may be advisable to cut them. Small fire scars exposing the wood offer advantageous points of attack for fungi and insects. $^{6}$ Extensive burns in the base of a tree weaken it and may result in breakage by wind. Whether it is safe to leave an injured tree and for how long a time cannot be determined without a knowledge of the species, particularly its insect and fungous enemies.

The final loss (chargeable to fire) of merchantable material in fire scarred trees through breakage by wind, decay and insects frequently exceeds the value of the timber consumed or directly killed by the fire.

Injury to Young Growth including Reproduction. - Trees under merchantable size and reproduction, with thinner bark and crowns near the ground, are more easily killed and consumed by fire than trees of merchantable size.

Fire acts in the same way on small trees as on large ones but inflicts relatively greater injuries on the former.

Even where small trees are only partially girdled by a fire their potential value is greatly reduced. Many years must elapse before the trees are merchantable. During this time insects and fungi have abundant opportunity to enter through the fire scars or elsewhere as a consequence of the weakened condition of the trees and frequently render them worthless or of poor quality by the time merchantable dimensions are attained. 
Injury to the Soil. - Forest fires in their action on the soil affect its physical rather than its chemical properties. Mineral soil itself is rarely changed chemically by the action of forest fires.

Its physical properties may be radically altered. From the standpoint of tree growth the physical properties of the soil are recognized to be of more importance than the chemical. Physical properties of soils are influenced by fires through decrease in the humus content. Humus is in fact the key to good physical condition of the soil.

A severe fire which kills most of the trees opens the forest canopy, burns off the litter and exposes the soil to the drying influences of sun and wind. The humus in the soil disappears and without litter or trees to furnish litter no more humus is formed. The soil on bare burned areas consequently deteriorates in physical condition.?

Heavy soils become dry, hard, impervious to water and often crack open. Sandy soils become hotter, more porous and leachy. The mineral salts left in the wood-ashes are apt to be blown or washed off the surface or leached away through the soil.

A fire of the lightest type which consumes the litter but does not directly injure the standing trees causes little or no injury to the soil. The loss of the accumulated litter does not prove serious provided a forest canopy exists to provide more without delay. Light fires burning over the same ground every year consume the annual leaf-fall and thus keep the ground bare of litter. Under these circumstances, when the humus in the soil is once exhausted the soil deteriorates. Hence repeated light fires seriously injure the soil.

In some places forests are growing with boulders or solid ledges of rock only a few inches below the surface. Here the soil consists largely of organic material and may be completely 
consumed by a severe fire. The bare rock may be left exposed and in such a case the soil has been entirely destroyed.

A soil lacking humus and bare of litter is subject to erosion. This carries away the most fertile portion of the soil. In extreme cases the entire surface layers of soil may be eroded leaving exposed the subsoil or even the underlying rock.

Injury to the Productive Power of the Forest. - Loss may be sustained either in reduced quantity or quality of production. This is primarily dependent on the condition of the soil, and the extent to which the individual trees have been damaged.

Fire injury to the productive power of the forest may be classified as follows:

(a) Injury due to replacement of good by poor species or to failure of the burned areas to restock.

Frequently the natural reproduction following a fire is of species inferior to those previously occupying the ground. In some cases this situation is reversed and a more valuable species, preferring an open burned-over seedbed, seizes the opportunity to restock the burn. This is an example of the beneficial influence of fire.

In numerous instances no natural reproduction follows the fire and the burn becomes barren.

(b) Injury due to reduction in the density of stocking.

Fires which do not destroy the whole stand may break the canopy and have the general effect of making the stand more open by reducing the number of trees below the density required for highest production.

(c) Injury due to the poor growth of individual trees.

Trees partially girdled at the base have lost part of their equipment for transporting food materials and for building wood structure. This throws an added burden on the cambium layer of the ungirdled portions. Increased growth may take place here, as a result of the enlarged food supplies 
which pass through, or in response to the greater mechanical strains following the injury. Except on cross sections through the burned part of the tree the growth will show a decrease. Analyses of fire injured trees made several years after the fire show, as contrasted to growth before the fire, increases in rate of growth on the stump section and reduction on sections above the wounds.

(d) Injury due to forced cutting of merchantable material before financial maturity.

Where trees without present merchantable value are killed it is quite evident that a sacrifice is involved which may be estimated on the basis of the future value of the stand discounted to the present time. Equally true is it that the loss in the case of fire killed trees of merchantable size is not alone the reduction in present value but should include the sum lost by not allowing these trees to grow longer and be harvested at the time of their financial maturity.

Injury to Forage. - Fires burn readily in dry grass and other plants of forage value. In some cases fire may be of temporary value in burning off a mat of dry dead vegetation and enabling stock to get at the tender green shoots beneath. In the final analysis fire tends to kill the roots of the plants, thus reducing the density of stocking, and to replace good species by those of inferior value for forage. ${ }^{8}$ Serious damage to forage can be prevented by grazing so regulated that masses of dry and inflammable forage do not accumulate.

Inflammable forage is in some forests the principal fuel for the rapid spread of fires. If this forage is used by stock while green the fire danger is reduced.

Injury to Stream Flow and Industry. - Under "Injury to Soil" erosion was shown to be a consequence of forest fires. Damage from erosion is felt not only on the lands eroded but in the lower course of the stream down which the eroded 
material is transported. River channels and reservoirs are filled with detritus and deposits of rock and soil are left on lands near the stream. Where the soil deposited is of fine texture and fertile the lands covered may be benefited. The harmful effects of erosion far outweigh any such advantage.

A bare soil prevents the forest from performing its function as a regulator of stream flow. Lacking the sponge-like cover of litter and humus a bare soil causes rapid surface run-off of water instead of absorbing it and feeding it out slowly from springs. Floods with their attendant damage are thus caused and low and high water stages made more pronounced.

This fluctuation in water level together with the eroded material in the channel interferes with navigation, and often necessitates expensive dredging operations. Power plants and factories relying on water power require a continuous and uniform supply of water rather than one which fluctuates widely in volume.

Smoke from forest fires has interfered with industry and caused extra expense by producing dark days and dry fogs. ${ }^{1}$

Injury to Other Property. - Buildings, live stock, and property of all kinds are at times threatened by forest fires and serious losses result. The principal loss is to property found within the forest or in small clearings surrounded by woods. Whole towns have been wiped out by forest fires.

Injury to Human Life. - Rarely if ever in the United States does a year pass without loss of human life as a direct consequence of forest fires. The greatest loss of life on record in any one fire took place in the Peshtigo fire of October, I87I, in Wisconsin. Fifteen hundred persons perished in this fire. ${ }^{1}$

Character of Forest Fires. - Forest fires are divided into three classes: ground, surface and crown fires.

Ground fires occur only where thick accumulations of humus or duff are found and burn in this layer of organic 
material. On account of the depth of the humus (often one to over two feet in thickness) ground fires apparently burn underground in the soil itself. Actually only the vegetable matter is consumed and the fire is burning above the soil or in pockets formed by decaying roots. Such fires are sometimes termed "duff" fires. ${ }^{9}$

When the surface is wet by a light shower, but the duff beneath is dry, a ground fire may burn the lower layer of organic material, leaving the surface intact supported by a network of plant roots. When the fire is burning underground, in this way, its exact location is difficult to determine. Cases are on record where ground fires burned for several months in swamps. Such fires are said to have lasted through an entire winter under a blanket of snow.

The feeding roots of the trees extend throughout the thick humus layer and are easily killed by the ground fire. Such a fire ordinarily kills all the trees on the area burned over.

Deep deposits of humus are formed only under conditions which retard its normal decomposition. In swamps and lowlands, with excess of water, the organic matter does not readily decay. At high altitudes and in northern latitudes, on account of the cold damp climate even upland sites may develop thick beds of duff. This is particularly the case with coniferous stands.

Ground fires are relatively rare as compared with other kinds of fires because the material on which they feed does not dry out except in seasons of drought, and sites on which they may occur form a small percentage of the total forest area.

Surface fires are those which burn on or near the ground in the humus, litter, ground cover and underbrush. They are the commonest kind of fire and occur in all parts of the country.

Crown fires burn in the crowns of the trees. In tall timber 
the main fire may be one to two hundred feet above the ground. They are restricted almost entirely to coniferous forests which have inflammable foliage and retain it throughout the year; although there are certain species of broadleaved shrubs and dwarf trees with evergreen foliage of an inflammable character upon 'which crown fires might feed. In the case of broadleaved species the foliage, while on the trees, remains green and does not occur in such close arrangement as in the case of conifers. One instance is known where a crown fire ran through a stand of oak and chestnut. The fire occurred in the fall and the chestnut trees due to injuries by chestnut blight retained the dry chestnut burrs and much of the foliage. The foliage of the oak also had shriveled up and remained on the trees. This combination furnished enough inflammable material for the crown fire.

Crown fires apply heat to the tender twigs throughout the top and usually are fatal to the trees affected.

A crown fire is accompanied by a surface fire. In fact the burning material on the ground greatly assists in creating a steady volume of heat and enables the fire to progress, as a crown fire, over places where without this assistance it would stop. Advantage is taken of this fact in fighting crown fires by burning off the inflammable surface material ahead of the crown fire.

Fires ordinarily start as surface fires. Then where deep deposits of humus are reached a ground fire develops.

Crown fires sometimes originate as a result of lightning striking some tall dry stub and setting it afire, or more commonly start from a surface fire. Dry moss hanging from the trunk or branches, inflammable pitch on the bark, the burning tops of a mass of reproduction, or even the flames from a hot grass fire may serve to carry the fire upward and ignite the crowns. 
At first a surface fire burns out from its starting point in circular form, and would so continue were it not for various factors which at once begin to control its development. The wind is of primary importance and soon gives the fire an elliptical shape, the leeward side progressing most rapidly while the windward side burns slowly or dies out.

Crown fires advance only in the direction of the wind. Burning brands and embers are carried forward by the wind and set other fires in advance of the original one. Thus several fires both surface and crown are apt to be burning and may combine. Carried by the wind a crown fire may leap a quarter of a mile or more from one side of a valley to the other, sometimes leaving unburned the timber in the center.

Ground fires progress slowly, not being affected by the wind, with rather uniform destructiveness and consume all the inflammable material in their path. Such a fire may burn over several acres in a day or may cover only a fraction of an acre.

Surface fires range from a slow advance in a forward direction of less than a mile per day to an average of several miles per day and in the case of some grass and brush fires may attain a speed of several miles per hour.

Crown fires progress with great rapidity, in fact speed is essential for the existence of a crown fire. It is more difficult to secure definite figures for the spread of such fires as contrasted to the other two classes. Graves ${ }^{5}$ states that six to seven miles per hour is probably a maximum rate.

In the past the most severe fires have occurred in the northern part of the United States above the $43 \mathrm{rd}$ parallel of latitude in three districts: (I) New York and the New England States, (2) the Lake States and (3) the Pacific northwest including Western Montana, Idaho, Washington 
and Oregon. Climate and forest conditions are responsible for this grouping. Throughout the southern half of the country, fires, while prevalent, are of a less severe character.

To bring out the location and extent of large fires in the past a map prepared by the United States Forest Service, ${ }^{1}$ showing historic fires, is reproduced. (See Fig 82.)

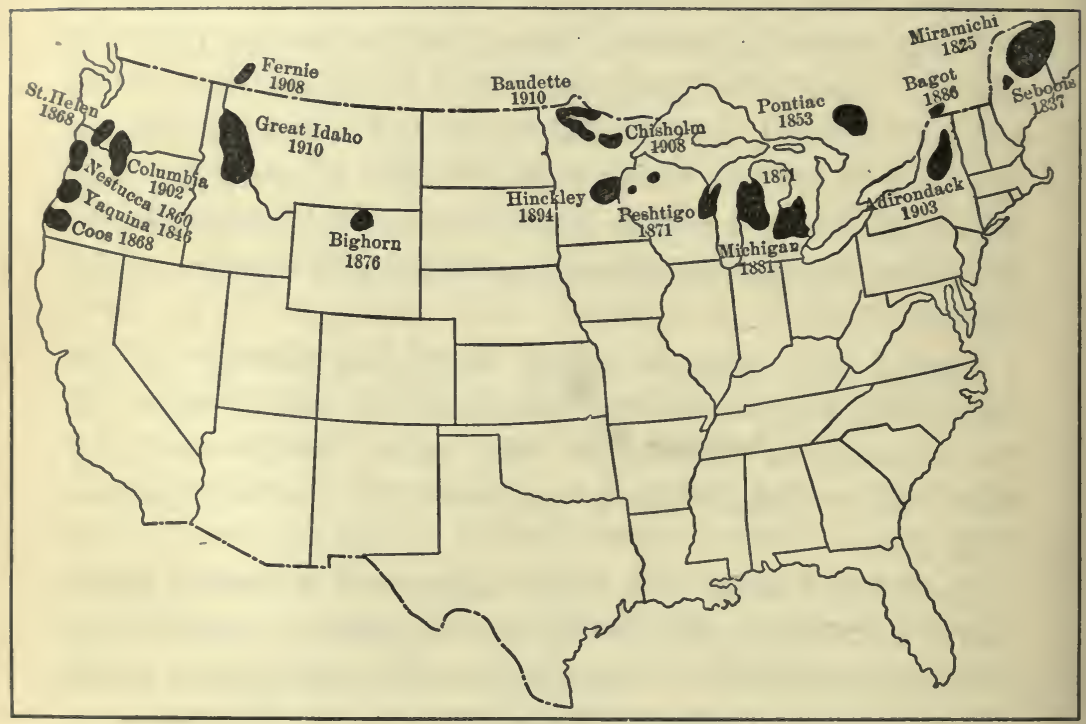

Fig. 82.

Map showing the location of the principal historic forest fires which have occurred in the United States since the year r800. Copied from "Forest Fires," by F. G. Plummer, Bulletin Ir7, Forest Service, United States Department of Agriculture, page 22.

Factors Influencing the Spread and Severity of Forest Fires. - All silvicultural operations should so far as practicable be conducted in a manner that will minimize the creation of conditions favorable for the spread of forest fires. Unfortunately most of the factors influencing the spread and severity 
of forest fires cannot be influenced by silvicultural treatment although those relating to the presence and condition of inflammable material are susceptible to partial control.

The most important factors governing the rate of spread and the severity of fires are listed below and separately discussed. The spread and severity of fires are so interrelated as to warrant consideration together.

\section{Chief Factors Influencing the Spread and Severity of Forest Fires} Inflammable material: Amount, Dryness, Density. Topography: Atmospheric conditions: Wind, Precipitation, Humidity.

Inflammable Material. - Fires are dependent both for their severity and rate of spread upon the available fuel ${ }_{d}$ supply. This consists of the humus, litter, ground cover, underbrush, fallen limbs and trees, tops left after logging and the standing trees large and small. In other words all the vegetable products living or dead may furnish fuel for the flames.

Amount. - The severity of the fire is more directly dependent upon the amount of fuel than is the rate of spread. A fire may run rapidly under certain conditions even if the fuel supply is scanty, but such a fire cannot be a severe and damaging one.

Dryness. - While in a forest there is normally a superabundance of potential fuel, this is not available for consumption unless it is dry. Dryness then is often, though not invariably, the key to the amount of available fuel. Certain parts of the forest, such as the living trees and shrubs, rarely if ever dry. out sufficiently to burn readily. Green foliage unless of a resinous nature burns with difficulty even in pro- 
tracted dry periods. The litter composed of fallen leaves and twigs dries quickly and is easily kindled by a spark. Coniferous needles burn faster and create a hotter fire than the litter from broadleaved treés. - Grasses and other herbaceous vegetation become as dry as tinder at certain times of the year. During extended droughts the humus and even deep peaty deposits in swamps may become thoroughly dry. Large limbs and dead trees do not dry out as quickly as the litter but ultimately may attain an exceedingly dry condition. This is particularly true with standing dead trees from which the bark has disappeared.

Density. - The uniformity and compact arrangement of the inflammable material has great influence on the spread and severity of the fire. Fastest spread occurs when the material is of light inflammable character, and arranged uniformly so that the fire suffers no check but not so compactly as to prevent the ready access of air.

Severity of the fire, other conditions being equal, increases with the density of material. Density makes for 'slow."advance of the fire but keeps the fire in one place for a relatively long time. This results in more complete consumption of the material and in greater injury. For example, a fire burning through a field of scrub oak brush covered with dry leaves will rush forward rapidly; but much material will be unconsumed and injuries to standing trees may be slight because the flames, though hot, do not remain long in one spot. If this same brush is cut and left lying in an evenly distributed compact layer on the ground and then burned at the same degree of dryness as when standing, the fire will advance more slowly, consumption of material will be more complete and injury to the living trees greater.

A ground fire burning in finely powdered humus with restricted oxygen supply necessarily burns slowly but all dry 
material can be reached and consumed and all trees affected are killed.

A crown fire burning in the tree tops where the individual limbs and trees are frequently not touching requires a high wind to carry the flames from point to point and very dry easily ignited material. It may kill all the trees in its path, but yet for the heat units produced a crown fire is not so destructive as a quiet burning ground fire with its fine grained material.

Topography. - The slope, aspect and surface conditions each affect spread and severity. In a rugged country, due to the frequent and wide variations in topography, the progress of a fire is extremely irregular. Regions without distinguishing topographic features favor a more uniform development of all sections of the fire.

A fire burning uphill advances rapidly. The heated air rising vertically and radiating horizontally ${ }^{9}$ passes near (particularly in the case of very steep slopes) the ground ahead of the fire and by its heating and drying action hastens ignition and increases the intensity of the fire. Trees are injured worst on their uphill sides, both because humus and litter are apt to accumulate there, and because the flames protected by the tree trunks from the draft burn longer in proximity to the tree. When a fire runs up a slope to the summit of a narrow ridge burning brands are likely to be carried over and dropped farther ahead than is the case on level ground. Fire progresses down hill very slowly and relatively feebly, burning as it must against the upper draft of heated air. Where the available fuel is of such a character as to roll down hill easily, burning sticks or cones may set fires some distance below the original fires. Fires so set are apt to sweep up the slope quickly until they meet the other fire. Cones furnish the most dangerous mate- 
rial for carrying fire down a slope. Where slopes become precipitous and barren of vegetation they form effective barriers to the spread of fire.

A stream or narrow strip of moist ground at the bottom of a ravine may serve to stop a fire. The latter has burned slowly down the slope and on approaching the stream has not sufficient momentum to leap this obstacle.

Slopes with northern aspect do not suffer so severely as those with southern exposure. This is explained by the greater dryness of the fuel due to the heat of the sun on the more exposed southern slopes.

A smooth surface on which the inflammable material occurs uniformly distributed tends to make the fire burn more evenly and intensely. Bare rocks tend to delay and break up the front of the fire.

Atmospheric Conditions. - Atmospheric conditions in influencing forest fires act either through affecting the dryness and inflammability of the fuel or by fanning the flames and increasing the speed of the fire.

Wind. - The wind is a factor of primary importance in determining the spread and severity of fires. By its powerful drying and evaporating action it increases the inflammability of fuel and also furnishes the draft necessary for the rapid spread of the flames.

The velocity of the wind is the most important single factor determining the rate at which a fire advances.

The steadiness of the wind has great influence particularly in crown fires. For such fires a wind of high velocity is required to carry the flames from tree to tree. It must also be steady because when the wind slackens the fire dies down in the tops and burns along the surface, from which it may jump to the crowns when the wind rises.

The occurrence of a high wind may be inferred as an ac- 
companiment of every severe surface or crown fire. Figures taken from the report of the State Forester of Connecticut for I9I6 illustrate the effect of high winds. Two weeks of dry windy weather culminating in two days of high winds on May IIth and I 2 th proved to be the worst fire season of the year. "Of the sixteen fires reported during the year as exceeding one hundred acres in extent, ten occurred on these two days. The total acreage of these ten fires was reported as approximately twelve thousand, - nearly 60 per cent of the entire acreage burned in the state during the year." 10

Precipitation. - Moisture is the controlling factor governing the inflammability of fuel. During rainy periods or seasons when the ground is covered with snow fires rarely if ever are able to run.

In seasons of low precipitation the danger from fire is great and rises rapidly with a lengthening of the drouth. Very slight precipitation is soon evaporated and is of small and temporary value in reducing inflammability.

Relative Humidity. - The relative humidity of the atmosphere has an important effect on the inflammability of fuel, 9 since the latter either absorbs moisture from the air as the relative humidity rises or evaporates moisture as it falls. The chief significance from the forest fire standpoint of cloudy versus sunny days, of hot versus cold days and of day versus night is found in the changes in relative humidity which ensue.

Methods of Forest Fire Protection. - The methods of obtaining protection from forest fires may be summarized under four heads.

I. The elimination of the causes from which forest fires originate.

As the gathering of statistics on forest fires has progressed, the numerous causes from which forest fires originate have been classified under eight major sources. The last published 
figures on the subject are those arranged by J. G. Peters ${ }^{11}$ and issued by the United States Department of Agriculture for the calendar year 1915. The following table showing the list of causes together with the percentage of the total number of fires originating from each cause is taken from this publication.

Causes of Forest Fires in the United States for the Calendar YEAR I9I5

Causes

Percentage of the total num. ber of fires.

Lightning. ....................... r4

Railroads........................... $\mathrm{r}_{5}$

Lumbering . . . . . . . . . . . . . . . . . .

Brush burning .................... $\mathrm{r}_{2}$

Campers...................... r 2

Incendiary....................... 7

Miscellaneous....................... ro

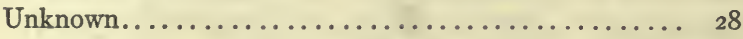

Total......................

2. The reduction of the fuel (inflammable material) upon which forest fires feed.

3. Quick detection of the forest fires which start.

4. Prompt suppression of the forest fires discovered.

To what extent can the silvicultural treatment of the forest assist toward securing fire protection? Assistance can be rendered in the reduction of the inflammable material available for the fires. Close utilization of defective trees and the disposal of slash as described in Chapter XIII, will remove an important class of inflammable material. Avoidance of large clearings on sites with a high fire hazard may be helpful. The selection method of reproduction producing an unevenaged stand with a constantly maintained cover, thereby protecting the ground cover and litter from excessive drying out, tends to reduce the inflammable material and is preferable from the fire standpoint to other reproduction methods. 
Suppression may be made easier by the disposal of slash, in that a forest unincumbered with slash is more readily traversed and fires more effectively fought where slash is lacking.

The employment of severance cuttings, creating cleared lines at intervals throughout the forest, also serves to facilitate access and affords vantage points from which fire-fighting may be begun.

Development (by artificial regeneration) of belts of fire resistant species, parallel to railroad lines or in other locations of high fire hazard, may be used where management can be intensive for preventing the start or spread of forest fires.

With such exceptions as have just been given, elimination of the causes, quick detection and prompt suppression of forest fires cannot be influenced to any large extent by silvicultural treatment of the forest.

\section{REFERENCES}

I. Plummer, Fred G. Forest Fires. Bulletin II7, United States Forest Service, Washington, I9I 2.

2. Peters, J. G. Forest Fires in the United States in I9r5. Circular 69, Office of Secretary, United States Department of Agriculture, I9I7, p. 3.

3. Oregon Forest Facts. State Board of Forestry, Salem, Oregon, I9I7.

4. Mayr, Heinrich. Waldbau auf Naturgesetzlicher Grundlage. Berlin, 1909, p. I2.

5. Graves, H. S. Principles of Handling Woodlands. Wiley \& Sons, Inc., New York, I9Ir.

6. Long, W. H. Effect of Forest Fires on Standing Hardwood Timber Circular 216, United States Forest Service, Washington, I9I3.

7. Nisbet, J. Studies in Forestry. Oxford, I894. Pp. IOI-IO7.

8. Cary, Austin. Ticks and Timber. American Forestry, Vol. 26, I920, pp. $92-94$.

9. Osborne, W. B. Jr. The Western Fire Fighters Manual, Chapter VII, Fire Fighting, 1919, pp. 17-22.

ro. Filley, W. O. Report of the Forester in Part VI of the Annual Report for 1916 of the Connecticut Agricultural Experiment Station, New Haven, p. 380. 
II. Peters, J. G. Forest Fires in the United States in 1915. Circular 69, Office of the Secretary, United States Department of Agriculture, Washington, I917, p. 2.

DuBors, C. Systematic Fire Protection in the California Forests. Forest Service, United States Department of Agriculture, Washington, rgr4. Munger, T. T. Western Yellow Pine in Oregon. Bulletin 418, United States Department of Agriculture, Washington, I9r7, pp. 9-1 2. Silcox, F. A. Fire Protection in District I. Forest Service, United States Department of Agriculture, Washington, rgr 5. Troup, R. S. Pinus Longifolia, Roxb. A Sylvicultural Study. The Indian Forest Memoirs, Vol. I, Part I, Silviculture Series, Calcutta, Igr6, pp. 67-78. 


\section{CHAPTER XVI}

\section{PROTECTION AGAINST INSECTS}

Extent of the Damage Caused by Insects. - The extent of the annual loss due to insect depredations is more difficult to accurately estimate than the fire loss: because the latter statistics (incomplete to be sure) are gathered by nearly all forestry organizations; while for the former equally detailed records of losses are unheard of. General estimates made by entomologists on the basis of observation and consultation with other experts furnish the best available information. Dr. A. D. Hopkins ${ }^{1}$ published in I9IO, an estimate that the annual loss in the United States from forest insect depredations amounted to more than $\$ 100,000,000$, or a reduction of ro per cent in the value of the annual output of forest products in the rough. His estimate, when applied only to the value of the standing timber killed and damaged, put the annual loss based on a ten year average) at $\$ 62,500,000$. These figures do not include damage to manufactured forest products.

It is probable that insects do more injury in the average year than that caused by forest fires. ${ }^{2}$

Character of the Injury. - Insect depredations range from the deforming, weakening or destruction of single trees up to the killing of a large proportion of the timber in regions thousands of square miles in extent. ${ }^{3}$ and 4 The latter type of injury may be readily observed but damage to single trees and small groups of timber often goes unnoticed, although in the aggregate it must reach a tremendous total, and may exceed the loss in the large outbreaks. 
Seed crops are sometimes destroyed by insects working in the cones and seeds. This was the case with the Norway pine seed crop in I9I9, throughout northern New York. Insects interfere with the growing of plant material in nurseries; they may destroy reproduction starting on cutover areas. Numerous species prey on the young and middleaged stands and are a constant source of annoyance and expense to the forester in producing forest crops. In stands approaching maturity epidemics are likely to develop which may destroy the entire stand.

Every part of the tree has its insect enemies and each species of tree is likely to be attacked by distinct species.

Insects are classed by Furst ${ }^{5}$ on the basis of the part of the tree attacked into:

Boring insects, which bore into the bark, cambium layer, sapwood, heartwood and pith.

Defoliating insects, which destroy foliage.

Root destroying insects.

Bud destroying insects.

Seed destroying insects.

Insects which produce deformities or malformation.

Each insect is likely to prefer or be restricted in its attack to trees of a certain age; either preying upon young reproduction, upon saplings and poles, or upon mature individuals.

The injury inflicted may be of a physiological or of a technical nature. ${ }^{5}$ Under the former come injuries such as defoliation and girdling which interfere directly with the physiological life processes of the tree; while under the latter are included injuries such as those by wood boring insects, which may ruin or reduce the value of the tree for commercial products but which do not interfere directly with its growth.

Insect epidemics are of more common occurrence and of 
more serious consequence in the case of coniferous than in hardwood forests. Pure stands of conifers are particularly susceptible. There appear to be two reasons for the greater damage to conifers. First more species and more destructive insects attack the conifers; and secondly conifers do not recover so easily from insect injuries as do hardwoods, because the latter replace injured parts more readily. ${ }^{6}$ As an illustration, complete defoliation, by the gipsy moth ordinarily causes death of a conifer, whereas a hardwood tree may survive several defoliations.

The killing of trees by insects increases the amount of inflammable material in the forest and hence the fire danger. Insect epidemics are often followed by disastrous fires made possible by the fuel in the insect killed trees. On the other hand fires injuring the standing timber may lead to the development of a big insect outbreak, altho this is not always the case. ${ }^{7}$ Insects may be responsible for injuries by fungi, which find access to the tree through the galleries and holes in the bark.

Insects Responsible for the Damage. - The wood boring insects, particularly the bark beetles and grubs, constitute one of the two most destructive classes of insects; while defoliating insects form the other. ${ }^{4}$ For detailed lists and descriptions of injurious (and beneficial) insects the literature treating with forest insects should be consulted.

Forest insects may be classed as injurious, beneficial or neutral. The beneficial insects function either as parasites living within injurious insects or as predaceous insects feeding externally upon the injurious insects. Neutral insects are those present in the forest which have no distinctly beneficial or injurious influence.

The Causes of Insect Attacks. - Insects attack trees for one of two purposes; either to obtain food of which defoli- 
ating insects furnish examples, or to secure places to breed, as is the case with certain bark beetles. More species of insects occur in warm climates and at low elevations than at high altitudes and cold climates.

Within the last three decades attention has been called to insect depredations because of the awakening of interest in forestry. But extensive insect attacks are not of recent origin. Insects were always present in the forest and at intervals developed sufficiently to cause widespread destruction. ${ }^{4}$ Under ordinary conditions a given species of insect will be found occurring in relatively small numbers, attacking single trees or small groups of trees here and there throughout the forest. When for some reason conditions become particularly favorable for rapid multiplication, the insects may increase enormously in numbers and extend their ravages until a considerable portion of the timber over a large area is attacked.

Causes for such infestations existed in the original forest long before the country was settled by man. Hopping, ${ }^{8}$ on page 2 of his "Manual of Insect Control for California," states that: "In the past, epidemics of infestation were probably caused by high winds uprooting or breaking trees, lightning, fires, snowbreak, etc., or by favorable climatic conditions. Man has now supplied other causes such as uncontrolled fellings, girdled trees, cull logs, limbs and brush left over one season. Many of the brush openings in timber supposed to be caused by fire are primarily the result of epidemics of insect infestations."

It is evident that the chances for insect outbreaks on a large scale must be increased through the operation of the new and additional causes which have followed in the train of settlement, and that if such outbreaks are not to occur, preventive or control measures must be undertaken. 
Up to the present time such measures have not been undertaken on an adequate scale and insect epidemics have become more frequent. Where the epidemics occur in mature timber the loss at the present day should be far less than in the past, because logging operations can be directed so as to utilize the insect injured timber. Extensive attacks upon reproduction and middle aged timber or to inaccessible bodies of mature timber afford the greatest hazard because such losses cannot be salvaged.

Methods of Control and Prevention. - Eventually the necessity of developing a systematic plan for the control and prevention of injury by insects will be accepted as just as fundamental as is similar action to secure fire protection.

The intensive methods of prevention and control possible in the protection of shade and orchard trees cannot be applied to forest crops, because of their high cost in relation to the value of the resource threatened. Dr. Hopkins ${ }^{1}$ estimates that at least 30 per cent of the estimated loss due to insects can be controlled or prevented by proper forest management without appreciable extra cost.

The complete extermination of an injurious insect is practically impossible. As Hopkins ${ }^{1}$ explains this is unnecessary. "Experience has demonstrated that it is only necessary to reduce and weaken its forces 75 per cent or more. It cannot then continue an aggressive attack, but must occupy a defensive position against its own enemies until conditions resulting from avoidable negligence and mismanagement by the owners of the forests and manufacturers of forest products favor its again becoming destructive."

Methods of prevention and control may be summarized under the following headings:

(a) Protection and increase of the natural enemies of the injurious insects. 
So far as possible natural agencies which control insects should be fostered. This will include the protection and augmentation in numbers of beneficial insects, mammals, birds and diseases which destroy injurious insects.

Of these the beneficial insects are apt to be the most effective single natural factor for control. Insect diseases (such as the wilt disease of the gipsy moth ${ }^{9}$ ) may suddenly destroy vast numbers of insects; but such diseases only become virulent when the insect numbers have increased to an enormous total. Hence diseases do not check insect epidemics until extensive injury has taken place. Birds may be effective in preventing the start of an epidemic, but will be too few in number to cope with a serious outbreak when once started.

Dr. Felt ${ }^{10}$ says in Volume I, page 25 , of his book entitled "Insects affecting Park and Woodland Trees": "The control of insects, particularly in forests, must be effected very largely through the activity of natural agents, which should be encouraged in every possible way. It is ordinarily impractical to attempt much in either a preventive or a remedial way, in the forests of the United States." In view of the insect control and prevention work which has been successfully conducted by the United States Forest Service and other organizations, it would seem that Dr. Felt's last statement presents a pessimistic viewpoint.

(b) Disposal of slash and other material in which insects find favorable conditions for breeding.

Insects breed in all parts of the slash but particularly in the larger sized portions. The stumps of felled trees, trees windthrown or broken by snow and standing trees in unhealthy condition, offer good breeding places. Trees already infested with insects but not taken in a logging operation require treatment. 
On cutover areas slash and stumps furnish the principal breeding places. In areas of uncut timber the scattered trees or groups of trees already infested with insects are the ones to be treated.

The details of treatment for the slash and standing trees must be worked out scientifically to meet the circumstances of each individual case. In general all small material can be completely burned, while large portions of the trunk and limbs should have the bark peeled and burned in such a way as to thoroughly char the peeled logs. They then become unfavorable breeding places. Stumps may have to be peeled down to the ground and charred by having the peeled bark burned in proximity to the stump. Standing trees may be felled and treated as just described or left standing and a portion of the trunk of the standing tree peeled of bark. With some species, such as the southern pine beetle, ${ }^{11}$ it may be unnecessary to peel the stump or the entire trunk.

Other effective methods of disposing of insect infested material are to place the logs in water, utilize the trees for cordwood or to cut the logs into lumber and burn the slabs and bark before the insects emerge.

The peeling and burning is most effective if accomplished after the insects have entered but before they have emerged from the slash, stumps, or standing trees. Sometimes so called "trap" trees may be felled for the purpose of attracting insects. The insects prefer this freshly cut material and will enter such trees and be destroyed in the subsequent peeling and burning operations.

When branches or terminal shoots of young trees are attacked by boring insects (as in the case of the white pine weevil, Pissodes strobi), the injured portions may be cut off and burned; and in the case of seedlings the entire plants may be pulled up and destroyed. 
(c) Special silvicultural measures to prevent the creation of conditions favorable to injurious insects.

Since most species of insects prefer unhealthy, weakened trees in which to breed, it follows that efforts should be directed toward maintaining the forest crop in a healthy condition. If possible thinnings should be made early and repeated frequently. All unhealthy trees should be cut. In mixed stands, where there is a difference in susceptibility among the species in mixture to the attacks of a dangerous insect, present or likely to appear, thinnings and other cutting operations can be directed toward the removal of the species most liable to injury. ${ }^{12}$ This is the principal and most practicable measure for controlling the gipsy moth in the forest. 13 and 14

The fertility of the site should be improved if possible of accomplishment. This is especially desirable on dry warm sites, for in such localities insects thrive. Large clearings, particularly when they are to be restocked with pure coniferous stands, should be avoided. To reduce insect injury small cutover areas and mixed stands are desirable.

In foreign countries intensive methods of collecting and destroying the insects in the egg, larva, pupa or final stages by means of hand picking, various trapping devices, such as bands of viscous substances encircling the tree trunks, the use of trenches, lights, etc., have been employed. Similar methods are already used on a limited scale in the United States principally in connection with nursery management.

The value of the timber protected must be high to justify such methods of control in the forest.

The development of effective control and preventive measures requires detailed knowledge of the local habits of the injurious insects which is best secured by a forest entomologist. The local forester can quickly learn the essential facts for 
his forest. It is imperative that he be always on the lookout for signs of insect depredations and discover the attack before it has reached a serious stage. There are various signs by which insects reveal their presence, such as fine dust from their borings on the ground or on tree trunks, holes in the tree trunks, excrement, exudation of pitch, the withering or coloring of foliage, a bare appearance of the tree tops, bitten off and partially devoured foliage on the ground, and the presence in the stand of an unusually large number of insectivorous birds.

\section{REFERENCES}

I. Hopkins, A. D. Insects in Their Relation to the Reduction of Future Supplies of Timber, and General Principles of Control. Circular No. I29, Bureau of Entomology, U. S. Department of Agriculture, Washington, I9Iо.

2. Pearce, W. J. The Relation of Insect Losses to Sustained Forest Yield. Journal of Forestry, Vol. XVIII, I920, pp. 406-4II.

3. Hoprins, A. D. On the Study of Forest Entomology in America. Bulletin 37, N. S. Division of Entomology, U. S. Department of Agriculture (Proc. 14th Annual Meeting Assn. Econ. Ent.), Washington, 1902, pp. 20-25.

4. Hopkins, A. D. Notable Depredations by Forest Insects. Yearbook of U. S. Department of Agriculture for 1907, Washington, 1908, pp. 149-164.

5. Furst, H. The Protection of Woodlands, translated by John Nisbet, Edinburgh, I893, pp. I 29-130:

6. Fisher, W. R. Forest Protection. Schlich's Manual of Forestry, Vol. IV, London, I895, p. I40.

7. Report of the Entomologist for I9I9. U. S. Department of Agriculture, Washington, I919, p. I 2.

8. Hopping, Ratpr. Manual of Insect Control for California District 5, 1914. Manuscript.

9: ReIfF, William. The Wilt Disease or "Flacherie" of the Gipsy Moth. Published under the direction of F. W. Rane, State Forester, Boston, Mass., I9II.

Io. FELT, E. P. Insects Affecting Park and Woodland Trees. New York State Museum, Memoir 8, 2 vols. Albany, 1905-06. (Includes Bibliography for each of the insects described.)

Ir. Hopkins, A. D. The Dying of Pine in the Southern States: Cause, Extent and Remedy. Farmers' Bulletin No. 476, U. S. Department of Agriculture, Washington, I9I I.

I2. FIske, W. F. The Gipsy Moth as a Forest Insect, with suggestions 
as to its control. Circular r64, Bureau of Entomology, U. S. Department of Agriculture, Washington, I913.

I3. Burgess, A. F. The Gipsy Moth and the Brown-tail Moth and Their Control. Farmers' Bulletin 845, U. S. Department of Agriculture, Washington, 1917, p. 22.

14. Clement, G. E. and Munro, Willis. Control of the Gipsy Moth by Forest Management. Bulletin 484, United States Department of Agriculture, Washington, I917.

Brunner, Josef. The Zimmerman Pine Moth. Bulletin 295, U. S. Department of Agriculture, Washington, I9I5.

Burgess, A. F. and Collins, C. W. The Value of Predaceous Beetles in Destroying Insect Pests. Yearbook, U. S. Department of Agriculture. for I9II, Washington, I9I 2, pp. 453-466.

Burgess, A. F. The Dispersion of the Gipsy Moth. Bulletin IIg, Bureau of Entomology, U. S. Department of Agriculture, Washington, I9r3.

BuRgess, A. F. Report on the Gipsy Moth Work in New England. Bulletin 204, United States Department of Agriculture, Washington, 1915.

Burgess, A. F. Suppression of the Gipsy and Brown-tail Moths and Its Value to States not Infested. Separate No. 706 from the Yearbook of the U. S. Department of Agriculture, Washington, I9I 7 .

BURKe, H. E. Injuries to Forest Trees by Flat-headed Borers. Yearbook

U. S. Department of Agriculture for r909. Washington, I910 pp. 399-4I5.

BURKE, H. E. Flat-headed Borers Affecting Forest Trees in the United

States. Bulletin 437, U. S. Department of Agriculture, Washington, r9r7.

Busck, August. The European Pine Shoot Moth; a Serious Menace to Pine Timber in America. Bulletin 170, U. S. Department of Agriculture, Washington, I9I5.

Collins, C. W. Dispersion of Gipsy-Moth Larvæ by the Wind. Bulletin 273, U. S. Department of Agriculture, Washington, 1915.

Cook, H. O. and KNeELAND, P. D. Instructions for Making Improvement Thinnings and the Management of Moth-Infested Woodlands. Published under the direction of F. W. Rane, State Forester, Boston, Mass., I9r4, pp. 16-29.

Fisher, R. T. and Terry, E. I. The Management of Second Growth White Pine in Central New England. Journal of Forestry, Vol. XVIII, I920, pp. $363-364$.

Graram, S. A. The White Pine Weevil and Its Relation to Second Growth White Pine. Journal of Forestry, Vol. XVI, I9I8, pp. I92-202.

Graham, S. A. The Place of Entomology in Forest Working Plans. Minnesota Forest School Annual, I920. St. Paul, 1920, pp. 27-32. HaAsis, F. W. Dying of Young Pines in Circles about Anthills. Journal of Forestry, Vol. XV, I917, pp. 763-769. 
Hawley, R. C. and Record, S. J. Do Ants Kill Trees About Their Colonies? American Forestry, Vol. 22, 1916, pp. 685-6.

Hopkins, A. D. Insect Enemies of Forest Reproduction. Yearbook of Department of Agriculture, Washington, 1905. pp. 249-256.

Hopkins, A. D. and WeBB, J. L. Some Insects Injurious to Forests. Bulletin 58, Bureau of Entomology, U. S. Department of Agriculture, Washington, I9ro.

Hopkrns, A. D. Contributions toward a Monograph of the Bark-Weevils of the Genus Pissodes. Technical Series, No. 20, Part I, Bureau of Entomology, U. S. Department of Agriculture, Washington, I9ri.

Hopkins, A. D. Insect Injuries to Hardwood Forest Trees. Yearbook of Department of Agriculture for 1903. Washington, 1904, pp. 313-328.

Hopkins, A. D. Damage to the wood of fire-killed Douglas fir and methods of preventing losses, in western Washington and Oregon. Circular 159 , Bureau of Entomology, U.S. Department of Agriculture, Washington, I9I 2.

HopkINS, A. D. Report on Investigations to Determine the Cause of Unhealthy Conditions of the Spruce and Pine from I880-1893. Bulletin 56, West Virginia Agricultural Experiment Station, Morgantown, I899.

Hopkins, A. D. Insect Enemies of the Spruce in the Northeast. Bulletin 28, N. S. Division of Entomology, U. S. Department of Agriculture, Washington, I90I, pp. I-48.

Hopkins, A. D. Bark Beetles of the Genus Dendroctonus. Bull. 83, Part 1 , Bureau of Entomology, U. S. Department of Agriculture, Washington, I909.

Hopkrns, A. D. The Genus Dendroctonus. Technical Series No. r7, Part r. Bureau of Entomology, U. S. Department of Agriculture, Washington, 1909 .

Hopkins, A. D. Preliminary Classification of the superfamily Scolytoidea Technical Series, No. I7, pt. 2, Bureau of Entomology, U. S. Department of Agriculture, Washington, I9I5.

MarlatT, C. L. The Annual Loss Occasioned by Destructive Insects in the United States. Yearbook, U. S. Department of Agriculture for 1904, Washington, I905, pp. 46I-474.

Mosher, F. H. Food Plants of the Gipsy Moth in America. Bulletin 250, U. S. Department of Agriculture, Washington, 19r5.

Swarne, J. M. Canadian Bark-Beetles. Descriptions of New Species. Part I, Bulletin I4 (Technical Bulletin), Entomological Branch, Department of Agriculture, Dominion of Canada. Ottawa, r9I7.

SwaIne, J. M. Canadian Bark-Beetles. A Preliminary Classification, with an Account of the Habits and Means of Control. Part I, Bulletin I4 (Technical Bulletin), Entomological Branch, Department of Agriculture, Dominion of Canada. Ottawa, r918. 


\section{CHAPTER XVII}

\section{PROTECTION AGAINST TREE DISEASES}

Fungi. - The tree diseases of greatest importance from the silvicultural standpoint are induced by parasitic plants, principally fungi. Chief consideration will be directed to diseases of this class.

The silviculturist is interested primarily in parasitic fungi, in contrast to saprophytic fungi since the latter attacking only dead or dying material are not the cause of tree diseases.

For a comprehensive account of all classes of tree diseases reference should be had to books devoted to the subject such as those by Hartig ${ }^{1}$ and 2 and Rankin. ${ }^{3}$

Parasitic fungi are able to attack living trees, but must have a suitable opportunity for gaining access. In young trees, before the formation of cork in the bark is accomplished, fungi are able to gain access through the uninjured bark, if climatic conditions are favorable. Older trees can be attacked only through a wound or opening in the protective bark covering. Such wounds may be created in a variety of ways; as for example by fires, lightning, frost, storms, insects or branch stubs left by natural pruning. With western white pine, branch stubs furnish the principal points for attack; ${ }^{4}$ with white fir (abies concolor) fire, frost and lightning are largely responsible. ${ }^{5}$

The presence of fungi is revealed readily by the appearance of the fruiting bodies springing from the soil or parts of the tree above the ground. Where sporophores are lacking there may still be fungi within the trees. Swellings, or pitch 
flows from branch stubs serve as indications, while soundings on the trunk often furnish information. An increment borer is useful for taking borings to determine the internal condition of the tree.

A humid atmosphere, at least in the zone in which the fungi are developing, favors their growth because both the mycelium and the sporophores dry out very easily and require large amounts of water.

The regions where fungi are found in greatest profusion have humid, relatively warm climates, which produce a dense forest; and within such regions the stands growing on damp soils are likely to show the greatest injury. The effect of climatic factors such as temperature, sunlight, and moisture apparently is not the same for all "groups of fungi ${ }^{6}$ and 7 and still furnishes a field for investigation. With advancing age the amount of injury and the production of sporophores increases. ${ }^{4}$

Extent and Character of the Injury. - Both insects and fire are more destructive in their effects upon the forest than are fungi. Yet the latter have the capacity for inflicting injury on a large scale. Witness the chestnut blight, Endothia parasitica, which has exterminated commercially the chestnut (Castanea dentata) over thousands of square miles along the Atlantic seaboard in a period of less than 20 years. The rapidity of this attack and the completeness of the destruction over a large region are not characteristic of the work of most species of fungi.

On the average they work more slowly than fire and insects, are disseminated unnoticed, may exist within their tree hosts for many years before revealing their presence and of ten consume several decades in accomplishing the death and destruction of a single tree.

The extent of the damage caused by fungi is more difficult 
to determine than for forest insects and published figures mainly refer to losses for single species and specified regions. Estimates of the loss on individual areas are already being made with reasonable accuracy ${ }^{8}$ by forest pathologists. Weir, ${ }^{4}$ in I909, estimated the loss to the merchantable stand of western white pine alone to be in excess of $\$ 7,000,000$ annually.

The injury (as with insects) may be:- either, of a physiological nature, resulting in interference with the life processes of the tree and the death or deformation of a part or the whole tree; or of a technical character resulting in injury to the commercial products in the tree, but not necessarily interfering with the life processes, at least until the technical value of the tree is practically destroyed. All parts of the tree may be attacked both above and below the ground by one or more of the numerous species of fungi. Rankin ${ }^{3}$ divides tree diseases into:

Seedling diseases and injuries,

Leaf diseases and injuries,

Body and Branch diseases and injuries, and Root diseases and injuries.

The seriousness of the damage varies greatly with the type of fungus. "Of most consequence are those epidemic diseases of fungoid origin which cause rapid death of their host, and spread with great rapidity over wide areas. Such, through repeated attacks, may render the cultivation of certain plants impossible in a locality." This quotation from Tubeuf ${ }^{9}$ indicates his judgment as to the most destructive type of fungi. Wood destroying fungi he classes as nearly equal in the losses caused.

The destructiveness of the former classes of diseases ${ }^{10}$ lies in the fact that they may kill outright trees of all ages commercially exterminating a species. Where the species ex- 
terminated is the chief tree for management in the region, as was the case with the chestnut on the eastern seaboard, the loss is directly to the productive power of the entire forest area. Wood rotting fungi, while they may totally destroy the timber value of the stand, require decades to accomplish this, and do not attack the trees until fairly well along in life, since they attack the heartwood which is not formed in youth. Their destruction of timber in the virgin forest may be enormous, but in the managed forests, which will follow present day cuttings and can be harvested while still relatively sound, the loss can be kept within reasonable bounds.

In addition to these two types other less important species cause partial injuries or deformities which at the least result in loss of increment. ${ }^{5}$ The action of root destroying fungi is a large factor in accounting for losses from wind. ${ }^{11}$

The influence of fungi is not entirely injurious. They may be beneficial in destroying harmful insects and in accomplishing the rotting of the slash, ${ }^{6}$ thereby reducing the fire hazard and increasing the humus supply.

Methods of Control and Prevention. - Tree diseases cannot be controlled by fostering their enemies for practically none such exist. Against most species of fungi direct action is impracticable due to the expense involved. General silvicultural measures comprise keeping the stand in thrifty condition, the use of thinnings, ${ }^{12}$ avoiding the making of wounds on the trees and eliminating infected trees.

One of the two most destructive types, namely the woodrotting fungi causing heart rots, can be partially controlled. The control work actually executed in the United States has been conducted principally against the chestnut blight, the white pine blister rust, fungi causing heart-rots, or nursery diseases of coniferous seedlings. A discussion of the latter may be relegated to the realm of nursery management. 
Fungi causing heart-rots can be controlled in the timber crops succeeding the present one by the methods outlined below:

(a) Use of a rotation sufficiently short so that the heart-rots do not have the opportunity to destroy more than a small percentage of the timber.

(b) Prevention of infection of the new crops. ${ }^{13}$ This is likely to require:

I. Disposal or treatment of the infected slash in such a manner as to prevent the production of sporophores. (See page 235.) Slash can be treated either by the use of fire or methods which will insure its drying out and thus check development of the fungi. ${ }^{14}$

2. Felling of all standing infected trees and treatment as given under $\mathrm{I}$.

3. The retention of thrifty trees free from infection, if a portion of the old stand is left for seeding purposes.

The white pine blister rust, ${ }^{15}$ cronartium Ribicola, introduced from Europe previous to I909, has threatened within the last ten years to develop into an epidemic similar, though less rapid in its spread, to the chestnut blight. The methods of control ${ }^{16}$ consist in removing all species of ribes, one of the hosts of the disease, and thus restricting its spread. The cost per acre of eradicating ribes ${ }^{17}$ averages less than \$o.54 per acre and will, as methods of work improve and are standardized, be lowered appreciably.

Re-eradication every five to ten years appears to be necessary but at costs lower than that of the first eradication. Eventually eradication of ribes must be considered a regular operation in growing eastern white pine and be pursued systematically. While termed "eradication" the work in reality reduces the quantity of ribes in a given area, but should not be expected to secure absolute eradication. 
Other diseases may in the future warrant similar measures of control.

Efforts to control the chestnut blight, although pursued for some years involving large expenditures of money, were illadvised and resulted in abandonment of the work.

\section{Tree Diseases and Injuries Other than Those Produced by} Fungi.-Among tree diseases and injuries not previously considered may be mentioned stagheadedness, root-rot, abnormal needle shedding, injury by acid fumes ${ }^{18}$ from smelters and other manufacturing plants, bark-scorching and cracking, injuries from frost, hail, snow, wind and lightning.

In a practical way little can be done to control or prevent these diseases and injuries.

Protection against frost should be assured to the reproduction of sensitive species by affording shelter in early youth. For such species the shelterwood or selection methods of reproduction are advantageous. Early frosts in the fall and late frosts in the spring are particularly to be guarded against. Injury consists in the freezing of seedlings and young organs on older trees, uprooting of seedlings and production of frost cracks and cankers.

To prevent injury from bark-scorching, exposure on the southern and western sides of trees and stands, susceptible to the injury and which previously have been densely grown, should when possible be avoided.

Snow is particularly damaging to young evenaged densely stocked stands of conifers. It can be minimized by the systematic use of thinnings and by employing the selection method in elevated regions subject to heavy snowfall.

Losses from wind can be reduced by starting moderate thinnings early and repeating often, by not using reproduction methods which unduly expose a portion of the stand (like the seed tree method) and by keeping the trees healthy 
and sound, thus preventing the weakening attacks of fungi. Under intensive management shortening of the rotation, regeneration of the forest in directions against the prevailing winds and the development of protecting strips of windfirm trees, along the exposed sides of stands subject to wind injury, will assist in preventing loss.

Stagheadedness can be prevented by maintaining the litter and forest canopy, or by underplanting if the canopy is thin or broken.

\section{REFERENCES •}

I. HARTiG, Robert. Lehrbuch der Baumkrankheiten. 2d edition, Ber- lin, 1889 .

2. Hartig, Robert. Textbook of the Diseases of Trees, translated by W. Somerville and H. Marshall Ward, London, I 894.

3. Rankin, W. H. Manual of Tree Diseases. New York, I9r8.

4. Weir, J. R. A Study of the Rots of Western White Pine. Bulletin 799, U. S. Department of Agriculture, Washington, rg19.

5. Meinecke, E. P. Forest Pathology in Forest Regulation. Bulletin 275, U. S. Department of Agriculture, Washington, I9I 5, p. I2.

6. LoNG, W. H. Investigations of the Rotting of Slash in Arkansas. Bulletin 496, U. S. Department of Agriculture, Washington, I9I7, pp. 9-Ir.

7. Long, W. H. A New Aspect of Brush Disposal in Arizona and New Mexico. Proceedings of the Society of American Foresters, Vol. Io, I9I5, pp. 383-398.

8. Weir, J. R. and Hubert, E. E. Forest Disease Surveys. Bulletin 658, U. S. Department of Agriculture, Washington, I9I8.

9. Tubeuf, Karl F. von. Diseases of Plants induced by Cryptogamic Parasites, London, 1897 , p. 83.

io. Millen, F. H. Disease Control and Forest Management. Journal of Forestry, Vol. XV, 1917, pp. 974-977.

II. Hubert, E. E. Fungi as Contributory Causes of Windfall in the Northwest. Journal of Forestry, Vol. XVI, 1918, pp. 696-714.

I2. Weir, J. R. and Hubert, E. E. The Influence of Thinning on Western Hemlock and Grand Fir Infected with Echinodontium Tinctorium. Journal of Forestry, Vol. XVII, I9I9, pp. 2I-35.

I3. WEIr, J. R. and HubERT, E. E. Pathological Marking Rules for Idaho and Montana. Journal of Forestry, Vol. XVII, 1919, pp. 666-68I.

14. Hubert, E. E. The Disposal of Infected Slash on Timber-Sale Areas in the Northwest. Journal of Forestry, Vol. XVIII, 1920, pp. 34-56. 
15. Spaulding, Perley. The Blister Rust of White Pine. Bulletin 206, Bureau of Plant Industry, U. S. Department of Agriculture, Washington, IgII.

16. Report on White Pine Blister Rust Control. Bulletin 2, American Plant Pest Committee, Boston, rgr8.

I7. Detwiler, S. B. White Pine Blister Rust Control in Igrg. The American Plant Pest Committee, Boston, Igrg.

I8. Schrenk, H. von and Spaulding, Perley. Diseases of Deciduous Forest Trees. Bulletin I49, Bureau of Plant Industry, U. S. Department of Agriculture, Washington, I 909 .

Anderson, P. J. and BABCock, D. C. Field Studies on the Dissemination and Growth of the Chestnut Blight Fungus. Bulletin 3, Pennsylvania Chestnut Tree Blight Commission, Harrisburg, I913.

Anderson, P. J. and Rankin, W. H. Endothia Canker of Chestnut. Bulletin 347, New York State Agricultural Experiment Station. Ithaca, I9I4. Anderson, P. J. The Morphology and Life History of the Chestnut Blight Fungus. Bull. 7, Pennsylvania Chestnut Tree Blight Commission, Harrisburg, I9I4.

Buckout, W. A. The Effect of Smoke and Gas upon Vegetation. The Pennsylvania State College, rgo2.

Clevenger, J. F. The Effect of the Soot in Smoke on Vegetation. Smoke Investigation Bulletin 7, Mellon Institute of Industrial Research and School of Specific Industries, Pittsburgh, I9I3.

Long, W. H. Three Undescribed Heart-rots of Hardwood Trees, Especially of Oak. Journal of Agricultural Research, Vol. I, I9I3-I4, pp. I09-I28.

Long, W. H. The Death of Chestnuts and Oaks due to Armillaria Mellea. Bulletin 89, U. S. Department of Agriculture, Washington, rgr4.

LoNG, W. H. A preliminary Report on the Occurrence of Western Red-rot in Pinus Ponderosa. Bulletin 490, U. S. Department of Agriculture, Washington, IgI 7 .

Meinecke, E. P. Forest Tree Diseases common in California and Nevada. A manual for Field Use. Forest Service, U. S. Department of Agriculture, Washington, IgI4.

Meinecke, E. P. Basic Problems in Forest Pathology. Journal of Forestry, Vol. 15, I9I7, pp. 215-224.

Metcalf, Haven and Collins, J. F. The Present Status of the Chestnut Bark Disease. Bulletin I4I, Part V, Bureau of Plant Industry, U. S. Department of Agriculture, Washington, I909.

Metcalf, H. and Collins, J. F. The Control of the Chestnut Bark Disease. Farmers! Bulletin 467, U. S. Department of Agriculture, Washington, IgII. 
Mickleborougr. A Report on the Chestnut Tree Blight. The Fungus Diaporthe Parasitica, Murrill. Department of Forestry, Commonwealth of Pennsylvania, Harrisburg, I909.

MURrill, W. A. Northern Polypores, New York, I9I4.

Paur, B. H. The Pine Blister. Bulletin I , New York State Conservation Commission, Albany, I9r6.

Final Report of the Pennsylvania Chestnut Tree Blight Commission. January I to December I5, I9I3. Harrisburg, I9I4.

Reynolds, H. A. A Plan to Frustrate the White Pine Blister Rust in Future Commercial Plantings. Bulletin II 8, Massachusetts Forestry Association, Boston, I9I6.

Schrenk, H. von. Some Diseases of New England Conifers. Bulletin 25, U. S. Department of Agriculture, Washington, I900.

Schrenk, H. von. The Diseases of the Hardy Catalpa. Bulletin 37, Bureau of Forestry, U. S. Department of Agriculture, Washington, I902.

Schrenk, H. von. A Disease of the White Ash Caused by Polyporus Fraxinophilus. Bulletin 32, Bureau of Plant Industry, U. S. Department of Agriculture, Washington, I903.

SChrenk, H. von. The "Bluing" and the "Red Rot" of the Western Yellow Pine, with special reference to the Black Hills Forest Reserve. Bulletin 36, Bureau of Plant Industry, U. S. Department of Agriculture, Washington, I903.

Shear, C. L., Stevens, N. E. and Tiller, R. J. Endothia parasitica and related species. Bulletin 380, U. S. Department of Agriculture, Washington, I9I7.

Spaulding, Perley. The Present Status of the White-Pine Blights. Circular 35, Bureau of Plant Industry, U. S. Department of Agriculture, Washington, I909.

Spaulding, Perley. European Currant Rust on the White Pine in America. Circular 38, Bureau of Plant Industry, U. S. Department of Agriculture, Washington, I909.

Spaulding, Perley. New Facts Concerning the White Pine Blister Rust. Bulletin II6, U. S. Department of Agriculture, Washington, I9I4.

Spaulding, Perley. The White Pine Blister Rust. Farmers' Bulletin 742, U. S. Department of Agriculture, Washington, I9I6.

WeIr, J. R. Observations on the Pathology of the Jack Pine. Bulletin 2r2, U. S. Department of Agriculture, Washington, I9I5.

Weir, J. R. Some Factors Governing the Trend and Practice of Forest Sanitation. Forestry Quarterly, Vol. I3, I9I 5, pp. 48I-489.

WeIR, J. R. Mistletoe Injury to Conifers in the Northwest. Bulletin 360 , U. S. Department of Agriculture, Washington, I9r6.

Weir, J. R. Larch Mistletoc: Some Economic Considerations of Its Injurious Effects. Bulletin 317 , U. S. Department of Agriculture, Washington, 1916. 
WeIR, J. R. A Needle Blight of Douglas Fir. Journal of Agricultural Research, Vol. ro, Washington, r9r7, pp. 99-ro4.

WEIR, J. R. Effects of Mistletoe on Young Conifers. Journal of Agricultural Research, Vol. I2, Washington, I9r8, pp. 7 r5-r8.

Weir, J. R. and Hubert, E. E. A Study of Heart-rot in Western Hemlock. Bulletin 722, U. S. Department of Agriculture, Washington, I9I8. 


\section{CHAPTER XVIII}

\section{PROTECTION AGAINST DOMESTIC ANIMALS; GRAZING}

Introductory. - The common domestic animals exerting direct influence upon the forest are cattle, horses, mules, asses and burros, swine, sheep and goats. Poultry may also be included though of minor importance.

These animals are distributed through all parts of the United States. ${ }^{1}$ Based on number of animals the region from eastern Nebraska to eastern Ohio and from the southern part of the Lake States to St. Louis may be considered the center of the industry. Sheep furnish an exception to this statement, about 40 per cent of the sheep being found in the Rocky Mountain States.

The use of forest areas for grazing purposes is of common occurrence throughout the country, but is done to much greater extent in some parts than in others. The entire West, with the exception of those few sections favored with abundant precipitation and mild climate, is dependent upon forested grazing lands or upon elevated areas of open land, so interspersed among forested areas as to require management as part of the forest property. The best summer forage is in or adjacent to these forested areas. The same land must often be utilized for the two purposes of timber production and grazing.

In the remainder of the country, where domestic animals are not forced to take refuge in the forest to escape unfavorable climatic conditions and where density of forest growth 284 
largely eliminates forage, the use of the forest for grazing purposes on a large scale is less universal. In regions such as the west coast of Washington and Oregon, with climatic conditions favorable to the development of dense forests, there is very little forage to be found under the heavy forest canopy.

The Effects of Grazing. - All forests are not equally susceptible to injuries from grazing. Hardwood forests are more easily injured by browsing but recover better than do conifers. Due to the fact that the animals prefer to browse upon hardwoods, grazing usually favors conifers as contrasted to hardwoods in mixed stands.

Shallow rooted species are likely to receive more injury through trampling than deep rooted trees.

The effects of grazing may be subdivided into:

Effect upon the soil.

Effect upon reproduction.

Effect upon trees past the reproduction stage.

Effect upon the control and prevention of forest fires.

Effect Upon the Soil. - The physical condition of the soil is injured by the trampling of the animals which compacts and hardens the soil. Erosion is often started on steep slopes and on other lands where the ground cover is closely browsed or destroyed. Trampling, particularly by animals with sharp hoofs, has a loosening and cutting effect upon the surface of the soil which may be washed away in succeeding rains. Grazing as a cause of erosion is of great importance in the western half of the United States, as indicated by the following quotation from Sampson and Weyl 2: "Serious erosion on western range lands is due chiefly to the destruction of the vegetation as a result of overgrazing and mismanagement of live stock." 
Sheep with their short tread and sharp feet are particularly injurious to the soil.

Effect Upon Reproduction. - The branches and terminal shoots of seedlings suffer from browsing. As a result they are deformed and lose increment. Sometimes seedlings are killed. If not killed the seedlings eventually may grow in height until their crowns are above the reach of animals. In such cases the deformities received in early youth are outgrown by the time the tree is ready for cutting. ${ }^{3}$

Hogs eat the seeds of certain species such as the oaks, and in the case of the long leaf pine, uproot and devour the roots. Indeed hogs are a primary factor in preventing longleaf pine reproduction. ${ }^{4}$

Many seedlings are injured by being trampled upon, and by having their roots exposed and barked.

Sometimes bark is gnawed or peeled from seedlings. Goats in particular perform this type of injury. They are considered the most destructive to reproduction of all the domestic animals.

In addition to injuring or destroying existing reproduction, animals through their effect on the soil may create seedbed conditions unfavorable for the start of reproduction. Their influence upon the seedbed may be beneficial, especially that of hogs. The latter in their search for food mix the litter and soil and may expose the mineral soil.

Where in a mixed stand, species with palatable seeds are less desirable in management than others with inedible seeds and preference for a mineral seedbed, hogs may be of distinct benefit. Shortleaf pine in mixtures of oak is favored by the grazing of hogs for this reason.

The loss of all or a portion of the reproduction may result in inadequate density of stocking, which in turn means lower increment or reduced quality of product. 
Effect Upon Trees Past the Reproduction Stage. - When trees have once elevated their crowns above the reach of animals they are free from serious direct injury by domestic animals. There may be some injury done by trampling and barking exposed roots or by rubbing (principally due to cattle) and by the compacting of the soil so as to hinder aëration. The chief loss is a reduction of the increment of the stand resulting from the injurious effects of grazing upon soil.

Effect Upon the Control and Prevention of Forest Fires. Grazing has a distinctly beneficial influence upon the forest fire problem. ${ }^{5}$ Grasses and forage plants when present in the forest constitute the most readily inflammable portion of the fuel for fires. When this is removed by grazing the fire hazard is reduced, the start of a fire being rendered less easy and in some cases its rapid spread made impossible. The beneficial influence of grazing upon fire protection may offset all injury caused to the soil and the forest.

In the past the idea has prevailed in certain sections of the country that annual fires set in the late winter or early spring to keep down brush and to burn off the dead herbage, thus permitting the stock to reach the tender new shoots, were of benefit to the grazing industry. ${ }^{6}$ The fallacy of this theory has been exposed and it is now recognized that a decrease of the better and an increase of the inferior varieties of forage plants is a consequence of annual burning.

In the past stockmen have been responsible for setting many fires intentionally with the mistaken idea of improving the grazing, to keep down the brush and in the South to destroy the cattle tick. The situation is steadily improving and within a relatively short period any injurious influence of grazing upon the control and prevention of fires will be a thing of the past.

Benefits versus Injuries from Grazing. - The extent of the 
injury to the production of tree crops is exceedingly difficult to estimate, since the major portion of the loss accrues to young reproduction and to soil conditions. So far as is known no general estimates of the damage have been made.

Grazing is beneficial to the community as a whole producing enormous annual receipts expressed either as rents for grazing privileges or values of domestic animals supported.

Damage to the forest often is considered incidental and a necessary consequence of the grazing industry. On the other hand, there are many areas where the forest must be considered first and only such an amount of grazing allowed as will not injure the forests or alter their influence. The National Forests fall within this class of land and require such management of the grazing as shall not interfere with the primary purposes of timber production and watershed protection. $^{8}$

Too little consideration has been given the question of relative benefits, likely to follow from the use of given areas of land for production of trees or for grazing purposes, and the extent to which the two can be combined profitably upon the same areas. Until this information is secured, it may be difficult to determine whether certain of the harmful effects of grazing upon the forest should be tolerated or prevented.

Woodward, who is working on the problem of the relative profits from grazing and tree crops, intimates, in a letter to the author, that for southern New Hampshire the net annual returns per acre from grazing are less than can be secured in growing white pine on the same land.

Secrest ${ }^{9}$ states, with reference to conditions in Ohio, that the value of the average woodland pasture is not over fifty cents per acre per year. Higher returns than this should be secured through tree crops.

Methods of Control and Prevention. - Methods of con- 
trolling and preventing injury from grazing may be summarized under the following two headings:

Protection by excluding domestic animals from the area to be protected.

Protection by close regulation of the grazing in the area to be protected.

Protection by Excluding Domestic Animals. - Domestic animals may be excluded from an area throughout the entire rotation or only for the regeneration period. Exclusion for the entire rotation might be necessary in protection forests, where serious damage from erosion might occur or the life of the forest be threatened. Elsewhere such an extreme measure rarely is justified. Exceptions will be found in forests where grazing is exceedingly injurious. In such forests it may be necessary permanently to exclude stock, even though the forests be managed primarily for timber production rather than for protection purposes.

Most of the direct damage to the forest is done during the reproduction period. Hence keeping out animals at that time will often reduce the total injury to an insignificant amount. Barnes ${ }^{10}$, page 2I 2, of his book "Western Grazing Grounds and Forest Ranges," in discussing injury by sheep to areas being reproduced says: "Such areas can therefore be temporarily closed, and once the young timber is past the danger stage can be again opened for grazing."

Selection stands are continually undergoing regeneration and in need of constant protection from grazing.

Protection by Close Regulation of the Grazing. - This method is in successful operation over a large part of the National Forests. The following quotation from Western Grazing Grounds and Forest Ranges, page 209, by Barnes, ${ }^{10}$ indicates the situation: "There are few of the national forests which to-day are not open to grazing of some kind of stock in 
every part, although on some of them it has been considered advisable to close certain areas to grazing of all kinds." Grazing is allowed, but the numbers, season for grazing, methods of handling the animals, etc., are carefully regulated.

Experience in the western United States has demonstrated, that the injurious effects of grazing increase rapidly with the number of head of stock grazed on a given area. If overgrazing is avoided, the damage to the average forest and soil is so small as often to be safely disregarded. Until forage becomes scarce, the animals do not browse the less palatable food furnished by trees. By properly regulating the number of animals sufficient forage is provided for all animals.

Sometimes the slash can be disposed of in such a manner ${ }^{11}$ around stumps or groups of reproduction as to protect the young trees from the animals.

Outside of the national forests little if anything has been done to regulate grazing in forested areas. There is a large field for its application on tracts of all sizes from the smallest woodlot upward.

The general trend of the live stock industry over the whole country is toward more intensive methods of handling. As this affects the forest, it means a restriction of the general running of live stock over wild wooded areas and the increase of feeding in buildings and well kept pastures. In parts of the West where the national forest lands furnish the requisite summer forage, the use of forested lands as grazing grounds will continue indefinitely on a large scale. Elsewhere the setting aside of separate areas for forest use and for pasturage purposes is likely to find increasing favor. 


\section{REFERENCES}

I. Thirteenth Census of the United States taken in the Year I9ı. Bureau of the Census, Department of Commerce, Vol. V, Washington, 1913, pp. 327-472.

2. Sampson, A. W., and Weyl, L. H. Range Preservation and Its Relation' to Erosion Control on Western Grazing Lands. Bulletin 675, U. S. Department of Agriculture, Washington, 1918, p. 35.

3. Hill, R. R. Effects of Grazing upon Western Yellow-Pine Reproduction in the National Forests of Arizona and New Mexico. Bulletin 580, U. S. Department of Agriculture, Washington, I9I 7, p. 20.

4. Hardtner, H. E. A Practical Example of Forest Management in Southern Yellow Pine. Proceedings of the Southern Forestry Congress, Chapel Hill, I9I6, pp. 7I-80.

5. Mason, D. T. Brush Disposal in Lodgepole-pine Cuttings. Proceedings of the Society of American Foresters, Vol. Io, I9I 5, pp. 399-404.

6. CARY, A. Ticks and Timber. American Forestry, Vol. 26, I920, pp. 92-94.

7. Sparhawk, W. N. Effect of Grazing upon Western Yellow Pine Reproduction in Central Idaho. Bulletin 738, U. S. Department of Agriculture, Washington, r9r8, pp. 22-25.

8. Jardine, J. T., and Anderson, M. Range Management on the National Forests. Bulletin 790, U. S. Department of Agriculture, Washington, rgrg.

9. Secrest, E. The Rôle of Artificial Regeneration in the Re-enforcement of Hardwood Woodlots. Journal of Forestry, Vol. XVI, r9r8, p. 329.

Io. BaRnes, W. C. Western Grazing Grounds and Forest Ranges, Chicago, 19r3.

i r. Sampson, Arthur W. Effect of Grazing upon Aspen Reproduction. Bulletin 74I, U. S. Department of Agriculture, Washington, I9I9.

Chapline, W. R. Production of Goats on Far Western Ranges. Bulletin 749, United States Department of Agriculture, Washington, I9I9.

Coville, F. V. Forest Growth and Sheep Grazing. Bulletin 15, Division of Forestry, United States Department of Agriculture, Washington, I898.

DuBors, C. Systematic Fire Protection in the California Forests. Forest Service, United States Department of Agriculture, Washington, 1914, p. 89. Hatton, J. H. Live-Stock Grazing as a Factor in Fire Protection on the

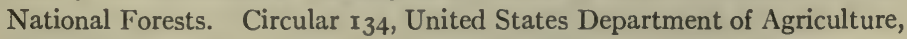
Washington, I920.

Hodson, E. R. The Effect of Grazing on the Caribou National Forest. Forestry Quarterly, Vol. 8, I910, pp. I58-168. 
Ivy, T. P. Forestry, Livestock and Cut-over Lands of the South. American Forestry, Vol. 26, I920, pp. 299-302.

Jardine, J. T. Efficient Regulation of Grazing in Relation to Timber Production. Journal of Forestry, Vol. I8, I920, pp. 367-382.

Reynolds, R. V. R. Grazing and Floods. Bulletin 9I, Forest Service, United States Department of Agriculture, Washington, I9II.

Rотн, F. Grazing in the Forest Reserves. Yearbook of the United States Department of Agriculture for Igor, Washington, I902, pp. 333-348.

The Use Book. Forest Service, United States Department of Agriculture, Washington, I9I8, p. 76.

Trllorson, C. R. The Care and Development of the Woodlot. Farmers' Bulletin 7II, United States Department of Agriculture, Washington, I9I6, pp. I3-I6. 


\section{CHAPTER XIX}

\section{PROTECTION AGAINST ANIMALS - OTHER THAN INSECTS AND DOMESTIC ANIMALS}

The principal animals, not previously considered, causing damage to tree crops include deer, beaver, porcupines, rabbits, mice, squirrels and birds. Injuries resulting from the work of these animals are less extensive in the aggregate than those produced by any of the four injurious agencies described in the preceding chapters. However, in individual cases, relatively large losses may ensue from the attacks of any one of these animals.

Deer.-Deer cause injuries of the same type as those produced by domestic animals. The numbers of deer are ordinarily too small to effect serious damage except on occasional, scattered trees. Other than by restricting the number of deer in a forest through shooting them, injury by deer cannot under present economic conditions be prevented.

Beaver. - Beaver by girdling and felling trees, often of merchantable size, kill a good many trees in the vicinity of their ponds and dams. Certain species, particularly the aspens, are preferred and the beaver will go a considerable distance to find the favored species if not available close at hand. They may destroy the entire stand adjacent to their ponds by raising the water level thus submerging the root systems of standing trees or at least increasing the moisture content of the soil. Beaver are relatively scarce and in only a few regions are they a nuisance.

Porcupines. - Damage by porcupines consists in the gnawing of bark on standing trees. The injury may occur 
on any part of the stem or on the branches as the animals climb the trees. When gnawed completely around that portion of the tree above the injury dies.

Killing the porcupines is the best remedy. A bounty placed on the animals will stimulate reduction in their numbers.

Rabbits. - Gnawing of the bark in winter, often causing the girdling and death of the tree, is done by rabbits. Seedlings and small trees are chiefly affected. Hardwoods are preferred rather than coniferous species. Rabbits are sometimes so numerous and so destructive as to prevent reproduction. In such a case virtual extermination may be necessary to control the pests.

Squirrels. - Squirrels eat seeds and fruits and bite off young shoots and buds. In many instances they devour practically all of the seed crop of given species. Consequently squirrels are often an important factor in the securing of natural reproduction.

Shooting of squirrels should be encouraged as the most practicable method of protection.

Mice. - Seeds are devoured by mice, which are particularly to be feared in nursery seedbeds. Mice, during the winter when food is scarce, gnaw the bark of seedlings and young trees either above or below ground, often girdling them and causing death. The mice are most abundant on grass covered areas with sunny aspect. Periodically the mice are likely to increase and girdle a large proportion of the trees on restricted areas. In nurseries intensive methods of combating mice are warranted and can be successfully applied. In the forest poisoning may be justified when the mice are abundant, and the injury concentrated.

Birds. - The beneficial influence of birds in destroying insect enemies outweighs their injurious effects upon the forest. Birds feed upon the seeds of forest trees, bite off the 
tops of seedlings and in the case of woodpeckers peck holes in the trees. On the whole birds should be protected and encouraged to increase in the forest. The injury to seeds and seedlings is most noticeable in nurseries where it can be successfully prevented by protecting the seed beds with wire netting.

\section{REFERENCES}

Fisher, W. R. Forest Protection. Schlich's Manual of Forestry, Vol. IV, London, r895, pp. 84-ז 3 r.

Lautz, D. E. Cottontail Rabbits in Relation to Trees and Farm Crops. Farmers' Bulletin 702, U. S. Department of Agriculture, Washington, I9r6. Lautz, D. E. Field Mice as Farm and Orchard Pests. Farmers' Bulletin 670, U. S. Department of Agriculture, Washington, I9r5.

Dearborn, N. Seeding-eating Mammals in Relation to Reforestation. Circular 78, Bureau of Biological Survey, U. S. Department of Agriculture, Washington, rigr.

BERRY, S. Work of California Gray Squirrel on Conifer Seed in the Southern Sierras. Proceedings of the Society of American Foresters, Vol. 9, 1914, pp. $95-97$.

Jotrer, E. Squirrels and Sugar-pine Reproduction. Proceedings of the Society of American Foresters, Vol. 9, 1914, pp. 98-ror.

Miller, J. M. Cone Borer versus Squirrel. Forestry Quarterly, Vol. I2, 1914, pp. 238-239.

McAteE, W. L. Woodpeckers in Relation to Trees and Wood Products. Bulletin 39, Biological Survey, U. S. Department of Agriculture, Washington, rigr.

PhiLlirs, F. J. The Dissemination of Junipers by Birds. Forestry Quarterly, Vol. 8, pp. 6o-73.

SterLing, E. A. Adirondack Birds in Their Relation to Forestry. Forestry Quarterly, Vol. I, pp. 18-25. 


\section{CHAPTER XX}

\section{PROTECTION AGAINST AVALANCHES, LAND-SLIDES, FLOODS AND SHIFTING SAND}

Avalanches. - The forest needs protection against injury from avalanches or snow-slides and is itself a protective agent in preventing damage from avalanches to property outside the forest.

Injury from avalanches is a possibility over a small fraction of the forest area, situated on steep mountain slopes in regions of heavy snowfall and usually adjacent to timberline.

Avalanches when once started may break down and thus destroy the forest in their path. They do not start within the properly managed forest but originate above timberline and on cutover or burned areas. Long grass, ground cover, brush and reproduction assist in preventing the start of avalanches. Once started avalanches are difficult to stop, hence protective measures should be directed toward preventing their origin.

Above timberline protective measures include the encouragement of all woody plant vegetation, the preservation of a grass sod and at the most dangerous points the construction of ditches, walls and fences.

Below timberline protective measures require the maintenance of a protection forest. Munger ${ }^{1}$ mentions four requirements for treatment of such a forest.

I. Complete fire protection. This encourages the development of ground cover, underbrush and reproduction. 
2. Exclusion of grazing with the same object in view of keeping the soil densely covered.

3. Careful cutting of timber on steep slopes with a gradient exceeding 50 per cent. Single tree selection is the proper method of reproduction to use. Clearcutting should be prohibited.

4. Prompt reforestation of denuded areas, in order to reëstablish forest conditions.

Land-slides. - Land-slides occur through the action of water in the subsoil or on the surface on steep slopes, particularly when an impermeable layer of rock or soil prevents the further entrance of the water into the ground. They carry down the soil and the forest leaving a bare exposed slope. Injury from land-slides may be expected in mountainous regions of abundant precipitation.

The same protective measures applicable in the forest against avalanches should be employed to prevent the start of land-slides.

Floods. - The influence of floods within the forest is both harmful and beneficial. Damage is done by destroying young plants, wounding larger trees through the action of ice and floating débris and gullying and carrying away the fertile soil. Deposits of rich silt may be spread periodically over the ground which greatly increases the productivity of the site and is distinctly beneficial.

On forest lands subject to floods species capable of withstanding inundation should be grown. Pollarding which keeps the young shoots above the floods is a suitable method of treatment. Selection and coppice with standards under both of which methods part of the stand always remains on the area are better suited to the conditions than other reproduction methods.

A complete forest cover assists in preventing floods, but 
special measures are required to adequately control floods. Consideration of this subject is outside the scope of the present work.

Shifting Sands. - Shifting sands are capable of destroying entire forests, and conversely the establishment and maintenance of forests upon areas of shifting sands is the only method of rendering them productive and preventing injury to adjacent property.

The reclamation of shifting sands is not here pertinent. The important point in the prevention of injury to established forests from shifting sands is to preserve intact the humus, litter, and ground cover and thereby afford no opportunity for the sand to move.

Grazing should be excluded or closely regulated to prevent over-grazing. The selection method is preferable, though if the forest floor is unbroken and reproduction starts promptly other reproduction methods are allowable.

\section{REFERENCES}

I. Munger, T. T. Avalanches and Forest Cover in the Northern Cascades. Circular 173, U. S. Department of Agriculture, Washington, I9Ir.

Fisher W. R. Forest Protection. Schlich's Manual of Forestry, Vol. IV, London, 1895, pp. 496-538. 


\section{APPENDIX}

\section{FOREST TERMINOLOGY *}

\section{Terms in Forestry}

COMPILED BY A COMMITTEE OF THE SOCIETY OF AMERICAN FORESTERS

Absolute forest land. Land fit only for forest growth.

Syn.: absolute forest soil. G., Absoluter Waldboden. F., sol forestier. Absolute form factor. See Form factor.

Acid humus. See Humus.

Accretion. See Increment.

Advance growth. Young trees which have sprung up spontaneously in openings in the forest, or under the forest cover (before reproduction fellings are begun).

Syn.: volunteer growth.

G., Vorwuchs. F., semis préexistant.

Afforestation. See Forestation.

Age class. All trees in a stand or forest whose age falls within stated limits, usually divided in 20-year periods ( 5 years in coppice), but in old stands may be of wider range, and may be stated in extent of area or in percentage of the whole stand or forest, or, in selection forest, by number of trees. A stand in which the trees fall between the age of I to 20 years would be referred to as age class I. See also Development class.

G., Altersklasse. F., classe d'age.

Gradation of age classes refers more specifically to this formation of age classes. See also Tree class.

G., Altersabstufung. F., gradation d'age.

Distribution of age classes refers to either the local distribution of age classes (G., Verteilung der Altersklassen, Altersklassenlagerung); or

* Reprinted from the Journal of Forestry Vol. XV, I9I 7, pp. 7I-IOI. 
to the percentic or absolute representation of the different age classes in area or amount, or (in selection forest) in number of trees (G., Altersklassenverhältniss).

Disruption of age classes refers to the attempt to provide safety against fire or insects, by locating the age classes in small areas.

G., Altersklassenzerreissung.

Normal age classes. See Normal.

All-aged forest. (Obs.) See Uneven-aged forest, Selection forest. Annual plans. See Working plan.

Area tape. A tape from which the basal area may be read directly when it is placed around the tree.

Artificial reproduction. See Reproduction.

Aspect. The direction toward which a slope faces. The eight main points of the compass, N., NE., E., SE., S., SW., W., NW., are distinguished in forest description.

Syn.: exposure.

G., Lage. F., exposition.

Assortment. The classes of wood materials into which the harvested crop may be divided, as logs, fuel wood, pulpwood, railway ties, etc., or according to size into timberwood (stoutwood, above 3-inch diameter); brushwood (below 3-inch diameter); cordwood, split and billets, etc. See also Grading.

G., Sortiment. F., categorie.

Ball planting. See Forest planting.

Bark blazer or gouger. See Scribe.

Barren. An area which is devoid of trees (moss barren), or bearing only stunted trees, then denoted by the character of the tree growth, as pine barren, oak barren, spruce barren.

Basal area. The area of a cross section of a tree, usually expressed in square feet, and usually referring to the section at breast-height. The sum of the basal areas of trees in a stand is the basal area of the stand, and is usually expressed in square feet per acre.

G., Stammgrundfläche. F., surface terrière.

Base capital. See Capital.

Biltmore stick. A graduated rule, usually of wood, the graduations of which indicate (when the rule is held tangentially to the tree) the diameter of the tree at the point where measured. The rule is constructed on the principle of similar triangles. See also Caliper. 
Blank. An opening in the forest where, from any cause, very few or no trees are growing.

G., Blösse. F., vide.

Blaze, $v$. The process of marking a tree by means of a sharp instrument, removing part of the bark.

Blaze, $n$. A spot made on a tree by chipping off a piece of bark.

Block. See Under subdivision.

Blow-down. See Windfall.

Board foot. A unit of measurement represented by a board one foot long, one foot wide and one inch in thickness, or its equivalent in volume. In finished or surfaced lumber the board foot measure is based on the measurement before surfacing or other finishing, or on the superficial measure only.

Board measure. A term expressing the board foot content of round or manufactured timber; and for expressing the volume of logs, trees or stands in terms of the estimated amount of lumber which may be cut therefrom according to various $\log$ rules $(q . v$.). Usually abbreviated B.M.; units of larger quantities stated in thousands, are abbreviated M. B. M.

Board rule. 1. A tabular statement showing the board foot contents for various widths and lengths of squared timber, or of sawed timber.

2. A graduated stick for determining the contents of squared timber. The number of board feet in squared timber of given widths and lengths, or of sawed timber, is shown upon the rule. See Scale stick.

Syn.: lumber rule, lumber scale.

Board scale. See Board measure.

Bole. See Stem.

Border cutting. See Reproduction, Strip-selection method.

Breast-height. A height of $4 \frac{1}{2}$ feet above the average ground surface or above the root collar, the diameters of standing trees being ordinarily measured at this height (abbreviation d. b. h.).

G., Brusthöhe. F., hauteur d'homme.

Breast-height form factor. Sce Form factor.

Broadcast seeding method. Sce Direct seeding.

Broken. See Crown density.

Brushwood stage. See Development class.

Budget regulation. See Regulation of cut. 
Bunch planting. See Forest planting.

Burn, n. An area over which fire has run to the noticeable injury of the forest.

Caliper, $n$. An instrument for measuring diameter of trees or logs. It consists usually of a graduated beam, at right angles to which are attached one fixed and one sliding arm. See also Biltmore stick and Tree compass.

G., Kluppe. F., compas forestier.

Caliper, v. To measure diameters.

G., Kluppieren. F., mesurer le contour.

Canopy. See Crown cover.

Capital. This factor of production in the forestry business is variously figured according to what parts of the investment are referred to and what basis of valuation is applied.

Fixed capital refers to such kinds of capital as are not used up in production, like the soil.

Working or Operating capital refers to money capital needed to supply current expenses in operating a forest.

Soil capital refers to the value of the soil figured in various ways.

Stock capital refers to the value represented by the wood material of all stands comprising a forest or working unit.

Forest capital refers to soil capital and stock capital combined.

Base capital may be used following the precedent of Pressler in his index percent for the combined soil and working capital.

These capitals may be based upon various kinds of values, and to secure a definite meaning, the term must be qualified by the method, by which its value was determined. See Value.

Chance. A term in common local use, more or less synonymous with Logging unit, which see. Not favored as a term in forest management.

Circumference tape. See Diameter tape.

Clean-boled. Being free or cleared of branches. Used to designate timber with a satisfactory length of clear bole.

G., Astrein. F., dépourvu de branches.

Clean cutting. See Reproduction, methods of.

Cleaning. See Intermediate fellings.

Clear and Clearing. 1. Clearing in common parlance, an area from which all or nearly all forest growth has been removed. 
2. The process of removing all of a mature crop or stand at one operation.

G., Schlagräumung. F., vidange.

3. The natural loss of branches through withdrawal of light.

Syn.: self-pruning.

G., Asterinigung. F., élagage naturel.

Clear length. That portion of the stem of a tree free from limbs from the ground to the lowest branch or branch stub.

Climax type. See Forest type.

Closed. See Crown density.

Co-dominant. See Crown class.

Compartment. See Subdivision.

Compartment system. (Obs.) See Reproduction methods, Shelterwood.

Composite forest. 1. A forest in which both seedlings and sprouts are used in reproduction. The seedling growth forming the overwood or standards; the sprout growth, the underwood.

2. A forest of seedlings and sprouts grown up together naturally.

Syn.: sprout-seedling forest; coppice with standards.

G., Mittelwald. F., Taillis sous futaie ou composé.

Conservative lumbering. (Obs.) Has been used to designate any attempt to introduce into logging operations the idea of providing for a future crop, or at least a second cut.

Control book. See Working plan control.

Conversion, $n$. A change from one silvicultural method to another as from coppice method to high forest.

G., Überführung, Umwandlung. F., conversion.

Conversion period. The period during which the change from one system or method of silvicultural management to another is, or is to be, effected.

Coppice forest, coppice. A forest consisting wholly or mainly of sprouts.

Syn.: sprout forest.

G., Niederwald. F., taillis simple.

Coppice method. See Reproduction, method of.

Coppice shoot or sprout. A sprout originating from a coppice stock as opposed to a seedling stock. See Seedling sprout.

Coppice with standards. See Reproduction method and Composite forest. 
Coupe (French). Cutting or Cutting area. Not favored as a term in forest management.

Cross section. A cut across the trunk or branch of a tree. See Basal area.

G., Querschnitt. F., section transversale.

Crown. In silvics, the upper part of a tree, including the living branches with their foliage.

G., Krone. F., cime.

Crown canopy. See Crown cover.

Crown class. All trees in a stand occupying a similar position in the crown cover. The crown classes usually distinguished are:

Dominant. Trees with crowns extending above the general level of the forest canopy and receiving full light from above and partly from the side; larger than the average trees in the stand, and with crowns well-developed but possibly somewhat crowded on the sides.

Co-dominant. Trees with crowns forming the general level of the forest canopy and receiving full light from above but comparatively little from the sides; usually with medium-sized crowns more or less crowded on the sides.

Intermediate. Trees with crowns below, but still extending into, the general level of the forest canopy, receiving a little direct light from above but none from the sides; usually with small crowns considerably crowded on the sides.

Overtopped. Trees with crowns entirely below the general forest canopy and receiving no direct light either from above or from the sides. These may be further divided into oppressed, usually with small, poorly developed crowns, still alive, and possibly able to recover; and suppressed or dying and dead.

Crown cover. The canopy formed by the crowns of all the trees in a forest, or, in an uneven-aged forest, by the crowns of all trees in a specified crown class.

Syn.: canopy, crown canopy, leaf canopy.

G., Kronendach, Beschirmung. F., couvert, voûte foliacée.

Crown density. An expression of the relation of crown area (or crown cover) to the land area involved, measuring the extent of shading exercised by the crowns, with due regard to the habit of the species, site, and age. It is usually expressed in decimal fraction of complete cover.

G., Beschirmungsdichte. F., épaisseur du couvert. 
The degrees of crown density in a forest may be expressed by the following terms, and fraction of a full crown cover.

Closed: 8 to I (crown cover complete).

G., geschlossen. F., plein.

Dense: .6 to .8 of the ground shaded by the crowns.

G., dicht. F., dense.

Medium or broken: .4 to .6.

G., lückig. F., entrecoupé.

Open: less than .4 of the ground shaded by the crowns.

G., licht. F., clair.

Cruise. See Estimate.

Cull, v. 1. To remove trees, especially merchantable ones, from a forest without regard to silviculture. See Lumber manufacturing terms.

2. In grading, to place in the lowest grade.

Cull, $n$. A low grade of lumber or a rejected tree in timber estimating.

Culled forest. See Cut-over forest.

Current increment. See Increment.

Cut, $n$. The amount of material cut or to be cut according to plan.

Syn.: felling budget.

G., Forstetat, Hiebssatz. F., budget des forêts.

Cut over, v. To cut most or all of the merchantable timber in a forest.

Cut-over forest. Forest from which most or all of the merchantable timber has been cut.

Syn.: logged-over.

Culled forest is a cut-over forest from which certain specics or sizes only have been taken, e.g., culled for pine and spruce.

Cutting. 1. In nursery and planting practice a portion of the stem or root of a live tree used for propagation.

G., Steckreis. F., bouture.

2. The process of felling trees.

G., Schlag, Hieb. F., coupe, abatage.

3. An area on which the trees have been cut or are to be cut.

Syn.: cutting area; felling area.

G., Abhiebsfläche, Schlag. F., surface coupée.

Syn.: felling. There being a difference of opinion as to the preference between these synonyms in the sub-committee and the collating committee, the latter gives them equal value, recommending, however, the use of felling (as of greater term quality) wherever a substantive 
meaning is prominent and where real forestry terms are involved, as in severance felling, felling cycle, felling series, felling plan, reserving cut and cutting where the common verbal.sense is prominent, as in cutting height, cutting limit.

Cutting area. See Cutting.

Cutting height. See Stump height.

Cutting limit. See Diameter limit.

Cutting plan. See Felling plan.

Cutting series. See Felling series.

Cutting cycle. See Felling cycle.

Damage cutting. See Salvage cutting or felling. New term.

Damping off. The succumbing of seedlings to a certain fungus disease.

Deforestation. A term used to indicate the denuding of a forest area.

G., Entwaldung. F., déboisement.

Dendrometer. An instrument combining height and diameter measure.

Capable of measuring from the ground diameters at any point.

Dense, $a$. See Crown density.

Density of crop. See Stock density.

Development class or stage. Similar to age class and tree classes. Mere descriptive words may be used instead of age and measurement to designate a stage of development of a stand:

Seedling stage or seedling growth, a stand of seedlings.

Thicket stage or brushwood, a stand of saplings.

Polewood stage, a stand of poles.

Young timber stage, a stand of standards.

Old timber stage, a stand of veterans.

Diameter breast-high. The diameter of a tree at $4 \frac{1}{2}$ feet above the ground. (Abbreviation, d. b. h.) The additional abbreviations $o . b$. and $i . b$. are used to designate whether the diameter is measured outside or inside the bark.

Diameter class. All trees of a stand whose breast-high diameters fall within prescribed limits, the intervals varying usually from I to 4 inches, fractions being rounded off to the nearest full inch of the limit. The diameter classes may be stated by numbers of trees in each class on the unit of area or by the percentage of the total contents of the stand represented in each, or by area occupied, or in any other way. Diameter classes take the place of age classes in the selection forest. G., Stärkeklasse. F., catégorie de grosseur. 
Distribution of diameter classes. In its strict sense, the location and area of each stand of a given diameter class in the forest; in a general sense, the per cent of area occupied by each diameter class in the stand.

Diameter growth. See Increment.

Diameter limit. The smallest (and occasionally largest) size to which trees or logs are to be measured, cut, or used. The points to which the limit usually refers are stump, breast-height, or top.

Diameter tape. A tape from which the diameter may be read directly when it is placed around the tree.

Dibble, $n$. A tool for making holes for planting seeds or young trees. G., Setzpfahl. F., plantoir.

Dibble in, v. To plant sceds or young trees in holes made with a dibble. Die hammer. See Marking hammer.

Direct seeding. A method of establishing a forest artificially by sowing seeds on the area to be forested.

Broadcast seeding method is an application of direct seeding in which seeds are sown over the entire area to be forested.

Partial seeding may be done in strips, furrows or trenches, plats or spots (see Seed spot).

G., Saeen, Saat. F., ensemencement, semis.

Disengagement cutting or felling. See Intermediate cuttings.

District, v. To make a subdivision of a forest into units on map or ground. Syn.: divide.

District, $n$. An administrative subdivision. See Subdivision.

Dominant. See Crown class.

Duff. See Forest floor.

Empirical yield table. See Yield table.

Equalization period. The period during which it is planned to attain approximately normal stock conditions.

G., Einrichtungszeitraum.

Estimate, ข. To determine the approximate contents of trees or stands of timber.

Estimate, $n$. An approximate determination of size, contents, value or anything else; more specifically of the volume of a tree or stand.

Syn.: cruise.

Even-aged. Applied to a stand in which only small age differences appear, differences varying with the average age of stand. In young 
stands, age differences should not be more than to or 20 years; in mature stands, not more than 30 or 40 years.

G., gleichalteriger Bestand. F., peuplement uniform.

Expectation value. See Value.

Exposure. See Aspect.

Factors of locality. See Site.

Fail spot or place. A place where natural or artificial reproduction has failed.

G., Fehlstelle. F., vide.

Felling. Syn.: cutting. The term felling is preferred by the collating committee for its better term quality, especially where substantive meaning is prominent. See under Cutting.

Felling age. See Rotation.

Felling area. An area on which the trees have been cut or are to be cut.

Felling budget. See Cut.

Felling cycle. The planned interval between fellings or cuts on the same forest area. See also Reproduction, Selection method.

Syn.: period of return.

Felling plan. See under Working plan.

Felling series. An aggregation of stands into a proposed or actual sequence of felling areas, the object being a distribution of felling areas for administrative reasons or to secure a final satisfactory distribution or location of age classes, especially to avoid damage by windfall and insects due to uniformity of stand and size of felling area. It is intended to interrupt a regular sequence of age classes.

Syn.: cutting series.

G., Hiebszug. F., série de coupes.

Final cutting. See Reproduction, Shelterwood method.

Final yield. See Yield.

Financial maturity. See Maturity.

Financial rotation. See Rotation.

First growth. See Old growth.

Forest, $n$. In common usage, a large tract of land covered with trees; more exactly, a tract of land, more or less extensive, covered more or less densely with trees of useful character, viewed from the standpoint of economic use and development. A species of woodland or woods, which is the generic term for the wooded condition of the land. 
Timberland or Timber is used to designate ability to furnish at once logs or material for commercial purposes.

Woodlot. Any small tract of forest, usually the forested portion of a farm.

Forest. In finance, refers to the combination of soil and stand. Forest, $v$. To establish a forest either by natural or artificial means. Forest capital. See under Capital.

Forest cover. All trees and other woody plants (underbrush) covering the ground in a forest.

Forest economics. A comprehensive term including all matter referring to the position of forests in public affairs.

Forest economy. A comprehensive term including all matter dealing with the business aspects of forest management.

Forest expectancy value. See under Value.

Forest finance. That branch of the science of forestry which relates to the forest as an investment. It includes two distinct subjects, forest valuation and forest statics; the first concerning itself with valuations of soil and growing stock, increment, and damage; the second concerns itself with a comparison of the financial results of different methods of treatment and other questions of profitableness and financial effects.

G., Waldwertrechnung $=$ forest valuation: forstliche Statik $=$ forest statics.

Forest fire. See under Protection terms.

Forest floor. A term used in forest description to designate only the deposits of vegetable matter on the ground in a forest.

Litter includes the upper, but slightly decomposed portion of the forest floor; humus, the portion in which decomposition is well advanced. See Humus. An intermediate layer of more or less decomposed organic matter below the litter may be designated as $d u f f$.

Forest influences. All effects resulting from the presence of the forest upon health, climate, streamflow, and economic conditions.

Forest inventory. See Forest survey.

Forest management. The practice or application of forestry in the conduct of the forest business.

G., Forstbetriéb. F., exploitation des forêts, aménagement.

The collating committee prefers to see the term used as defined, instead of as an equivalent to forest economy as a collective name for 
the subjects which deal with business problems (see Forestry) as separated from forest crop production.

Forest mensuration. That branch of forestry which deals with the determination of the volume of stands, trees, logs and other timber products, and with the study of growth and yield of trees and stands.

G., Holzmesskunde. F., dendrométrie.

Forest organization. The branch of forestry wnich concerns itself with the organization of a forest property for management and its maintenance, ordering in time and place the most advantageous use of the property, with the ultimate aim of securing a sustained yield.

Syn.: forest regulation.

G., Betriebsregulierung, Forsteinrichtung. F., aménagement.

Note: In the past both forest regulation and forest organization have been used indiscriminately. In the absence of any English word exactly equivalent to the German "Forsteinrichtung," both terms may well continue to be used.

Forest per cent. In finance, the rate of interest earned by the forest capital. Current annual forest per cent (index per cent) and mean annual forest per cent are distinguished.

In economics, the proportion of land of a given State or country covered by forest.

Forest plantation. Forest growth established by setting out young trees or by sowing seed.

G., Pflanzung, Kultur. F., plantation.

Forest planting. The artificial establishment of a forest by setting trees, or with certain species by planting cuttings. In general sense including also direct seeding (quid vide). Terms of forest planting are as follows:

Planted and Planting area. Land which has been artificially stocked with forest trees, or is to be so stocked.

Planting plan. A detailed scheme for forest planting on a given area.

Planting stock. Trees or cuttings used in forest planting. The age and history of the trees are indicated by figures, e.g., 2-o, two-year-old seedlings, or $2-I$, two-year-old seedlings which have remained one year in transplant beds or rows.

Ball planting. A method of transplanting young trees with balls or lumps of earth around the roots.

G., Ballenpflanzung. F., plantation en motte. 
Bunch planting. (Obs.) A method of planting in which two or more plants are set in one hole.

Hole method. A method of planting forest trees in which the trees are set in a hole; to be distinguished from the slit method.

G., Lochpflanzung. F., plantation par potets.

Slit method. A method of forest planting in which a slit or cleft is made with the planting tool, the tree inserted and the soil firmed into place after withdrawal of the tool; to be distinguished from the hole method. According to the implement in use, the method is designated mattock-slit or spade-slit, etc.

G., Klemmpflanzung, Spaltpflanzung. F., plantation en fente.

Mound planting. A method of planting on wet ground, in which the seeds or young trees are planted on mounds, ridges, or hills.

Syn.: hill planting, ridge planting.

G., Hügelpflanzung. F., plantation en buttes.

Row planting. An arrangement of trees in forest planting in which they are set in rows.

Syn.: regular planting.

G., Reihenpflanzung. F., plantation en lignes.

Trench planting: A method of planting in which the young trees are set in trenches or furrows.

Pit planting when plants are set in small depressions or pits instead of continuous trenches.

Syn.: furrow planting.

Repair planting. After-culture, filling out fail places by planting.

G., Nachbesserung. F., regarnissage.

According to the arrangement, row planting is designated as follows:

Rectangular planting. An arrangement in which the trees are set at the corners of successive rectangles.

G., Quadratpflanzung, Quadratverband. F., plantation en carré.

Triangular planting. An arrangement in which the trees are set out at the corners of successive triangles.

G., Dreieckverband. F., plantation en triangle.

Quincunx planting. An arrangement in which the trees are set in the center and at the corners of successive squares.

G., Fünfverband, Kreuzpflanzung. F., plantation en quinconce. Seeding lath, seeding trough. Planting tools used to secure an even distribution of seed in drills of the seed bed (nursery practice). 
Seed horn, seed flask, etc. Planting tools designed to distribute a uniform amount of seed in direct seeding in seed spots.

Forest policy. The attitude toward forests and general method of administration of public interests in forests by the State.

Forest regulation. See Forest organization.

Note: In the past both forest regulation and forest organization have been used indiscriminately. In the absence of any English word exactly equivalent to the German "Forsteinrichtung," both terms may well continue to be used.

Forest rent. See under Rent.

Forest rental value. See under Value.

Forest survey. The gathering and tabulation of all data in regard to forest lands including plane and topographic surveying, mapping, timber estimates, forest description, grazing data and land classification, type and site determination, involving all the work of every kind (including the construction of volume, growth and yield tables) necessary for the making of a working plan. Forest surveys may be partial or complete, more or less intensive or extensive, and of varying degree of accuracy.

Syn.: stock-taking in part.

Forest tree nursery. An area upon which young trees are grown for forest planting.

Seedling and Transplanting nursery, permanent and temporary, may be distinguished.

G., Saatkamp, Baumschule. F., pépinière.

Forest type. A descriptive term used to group stands of similar character as regards composition and development due to given physical and biological factors, by which they may be differentiated from other groups of stands. The term suggests repetition of the same character under similar conditions.

A type may be termed temporary to express the expectation of a change, if its character is due to passing influences (logging, fire, etc.); permanent if no change is expected and the character is due to physical and biological (natural) factors alone; climax if it is intended to indicate the character as the ultimate stage of a succession of temporary types.

A Cover type is a forest type now occupying the ground, no implication being conveyed as to whether it is temporary or permanent. 
Forest utilization. That branch of forestry which concerns itself with the operation of harvesting and marketing the forest crop and other resources of the forest.

G., Forstbenutzung. F., technologie forestière.

Forestation. The establishment of forest naturally or artificially upon areas where it is at present absent or insufficient. If distinction is desired, "afforestation " may be used to designate the planting of open ground, "reforestation" to designate previous wooded condition.

Forester, $n$. 1. One who is trained to practice forestry as a profession.

G., Forstmann. F., forestier.

2. A title or designation of position.

Forestry. The science and art of managing forests in continuity for forest purposes, i.e., for wood supplies and forest influences.

G., Forstwirtschaft, Forstwesen, Forstwissenschaft. F., science forestière, foresterie.

The main branches of forestry are Forest policy, Silviculture, Forest economy or Forest management (q.v.) (including Forest mensuration, organization or regulation, administration and finance), Forest protection and Forest utilization.

Form class. Classification of trees according to taper, from very tapering to full-boled (for use with Schiffel's form quotient).

Form constant. The numerical difference between the form quotient and the form factor $(C=Q-F)$. The form constant remains practically the same for a given species, no matter of what height or diameter.

Form factor. The form factor of a tree is the ratio between its volume and that of a geometric solid, usually a cylinder, having the same diameter and height. The volume of the solid (or cylinder) is taken as a unit, "I," the volume of the tree or trees is expressed as a decimal. Form factors are classified according to the point of diameter measurement (base, d. b. h., top), the portion of the tree included (tree-stem, merchantable portion, etc.), the geometrical figure used as a basis of comparison (cylinder, cone, frustum), the unit of measure used (cubic foot, foot B. M.), and may refer to single trees or stands. In this classification eleven qualifications have been so far considered. Common usage implies breasthigh measurement, cylindrical comparison, cubic foot unit and single stems. The term Absolute form factor is used if the base diameter is measured at the base of the tree; Normal 
form factor, if the measurement is made at a varying height which bears a constant ratio to the total height of the tree.

G., Formzahl. F., coefficient de forme.

Form height. 1. The product of height and form factor, tabulated for convenience of calculating cubic contents of trees or stands.

G., Formhöhe, Richthöhe.

Form quotient. The quotient of the breasthigh diameter of a tree into the diameter measured at any height above the d. b. h., usually at $\frac{1}{4}, \frac{1}{2}$, or $\frac{3}{4}$ of the height of the tree.

Freeing (setting free). See Intermediate (disengagement and liberation) cutting.

Fully stocked. The condition of a stand containing as many trees or material as it normally can for the species, site, and age. See Stock, Overstocked.

Full-boled. As applied to the trunk of a tree, approaching the cylindrical form. See Form class.

G., vollholzig. F., à fut soutenu.

Gradation of age classes. See Age class.

Grading. In description mensuration, and utilization the process of differentiating the crop into assortments $(q . v$.$) or classes of material.$

Ground cover. A term used in forest description to designate all herbaceous plants growing in a forest; such as ferns, mosses, grasses, and weeds.

G., Bodendecke. F., couverture du sol.

Group method. See Reproduction method.

Growing stock. See Stock.

Growth. See Increment.

Growth table. A tabular statement showing the growth data of individual trees or stands. See Increment.

Habit. The general form or arrangement of stem, roots, and branches, or of the entire tree, possessed in common by a species in a given habitat.

Heel in, $v$. To store young trees prior to planting by placing them against the side of a trench and covering the roots with earth.

Height class. One of the arbitrary divisions of the trees of a stand on the basis of height. The division is usually by intervals of ro feet.

G., Höhenklasse. F., classe de hauteur.

Height measure. See Hypsometer. 
High forest. A forest originating from seed.

Syn.: timber forest.

G., Hochwald; Samenwald. F., futaie, haute futaie.

Hole method. See under Forest planting.

Hold-over. A tree reserved from harvest to grow through a second rotation. See Reserve.

G., Ueberhälter. F., reserve.

Humus, $n$. That portion of the forest floor $\left(q . v_{0}\right)$ in which decomposition of the litter is so far advanced that its original form is not distinguishable. Humus in a condition favorable to forest growth is said to be mild, neutral, or sweet. Humus harmful to forest growth, owing to the presence of humic or similar acids or colloids produced by decomposition under excess of moisture and lack of air, is said to be sour. Humus incompletely decomposed is called raw humus.

G. and F., Humus.

Hypsometer. An instrument for measuring heights, especially of trees.

Improvement felling. See under Intermediate cuttings.

Income. In forest finance, the gross income represents money returns from which no expenses have been deducted; net income results by deducting all actual expenses charged in book account, including interest on borrowed capital, but not the calculated interest on investment, which enters in determining profit.

G., Geldertrag, Einkünfe, Erlös. F., revenu.

G., Rohertrag, Rohgeldertrag, Brutto Geldertrag, Erlös im Ganzen, Gesamtgeldein nahmen.

Final income, returns from final harvest.

G., Haubarkeitsertrag, Abtriebsertrag.

Intermediate income, returns from stands not yet mature.

G., Nebennutzungs:, Zwischennutzungs-, Vornutzungs-ertrag, -geldertrag.

Income rotation. See Rotation.

Income table. See Yield table.

Increment. Syn.: accretion.

The increase in diameter, sectional, basal area, height, volume, quality or value of a tree or stand. If distinction between the two terms is desired, accretion should be reserved for directly measurable, increment for calculated increases.

Increment is differentiated with reference to time as current anmual 
increment $=$ the increment for a specific year (abbreviation, c. a. i.) (G., laufend jährlicher Zuwachs); periodic increment $=$ the increment during a specific period of years; mean annual increment $(m . a . i)=$. the total increment divided by the age (G., Gesammtalterszuwachs); pcriodic annual increment $(p . a . i$. $)=$ the increment for a specified period of years divided by the number of years in the period; usually used in lieu of the current increment (G., periodischer Durchschnittszuwachs).

Quality increment is the increase in value per unit of volume due to its augmented intrinsic worth with size or age.

G., Qualitätszuwachs.

Price increment is the increment in the sale value of forest products independent of quality increment, due to market conditions.

G., Teuerungszuwachs.

Value increment is the increase in value of a tree or stand due to combined volume, quality and price increment.

G., Wertszuwachs.

Increment may be expressed in absolute numbers or as increment per cent per annum based on present or on past quantity as 100.

See also Index per cent.

Increment borer. An instrument for determining the rate of growth in diameter of standing trees. It consists of a hollow auger, which, when bored into a tree at right angles, extracts a core on which the annual rings show.

Syn.: accretion borer; Pressler borer.

G., Zuwachsbohrer. F., sonde de Pressler.

Index per cent. The increase in value of a tree or of a stand, due to the combined volume, quality and price increments, expressed as an annual per cent of its present value. The interest rate at which a given stand pays interest by its value increment on its current value plus Base capital (q.v.) as capital; used to determine financial maturity or felling age by comparison with a demanded business rate.

G., Weiserprozent; Forstprozent. F., taux maximum du revenu.

Index stand. A mature stand used as a basis for conclusions, or an index of condition (volume) of the stand in former years, or of other immature stands, on the supposition that the stems of the mature stand represent the dominant stand of the earlier periods on the same site. 
G., Weiserbestand. F., peuplement type.

Index tree. A mature tree utilized as an index of condition of immature trees. See Index stand.

Interlucation. New term. A severe opening up of a stand to light beyond the degree of severe thinning in order to secure a large increase of diameter on the remaining stand before final harvest. Usually accompanied by underplanting. See Intermediate cuttings.

Intermediate. See Crown class.

Intermediate. Refers to operations or occurrences taking place during the rotation before the final harvest of a stand, such as Intermediate cuttings or fellings ( $q . v$.), Intermediate yield or Income or Returns.

Intermediate cuttings or fellings. Cuttings made in a stand between the time of its formation and its final harvest. It includes cleanings, improvement cuttings and thinnings.

G., Zwischennutzung; Vornutzung. F., exploitation intermédiaire.

Cleaning. Cutting made in a stand not yet past the sapling stage for the purpose of removing trees of undesirable form or species, which are injuring or are likely to injure those of greater promise.

Syn.: weeding.

G., Reinigungshib, Durchplaenterung, Durchläuterung. F., coupe de nettoiement.

A disengagement cutting or felling. A cleaning in a stand of small saplings with the specific purpose of checking or removing trees of undesirable species which are overtopping desirable trees or may later shade them.

G., Kronenfreihieb. F., dégagement de la cime.

Improvement cutting or felling. A cutting in a forest which has passed the sapling stage, the main object being to remove trees of undesirable form, condition and species. It is always a felling for the purpose of bringing the stand into better condition and composition for silvicultural management.

G., Verbesserungshieb. F., coupe d'amélioration.

Salvage cutting or felling. Removal of trees killed or injured in a forest by fire, insects, fungi, or other harmful agencies, with the purpose of utilizing merchantable material and preventing the spread of insects and disease.

G., Totalitätshieb. F., coupe accidentelle.

Liberation cutting or felling. Is an improvement cutting by which 
young growth is freed (set free) from oppression by removal of wolf trees.

G., Freistellen. F., dégager.

Severance felling or cutting. The clearing of a narrow strip on the border of a young stand to stimulate the root development and retention of branches of the bordering trees, producing a windfirm mantle, and thus preparing them for subsequent exposure to wind when an older stand on the windward side of the strip has to be removed before the utilization of the younger stand.

Thinning. A cutting made in immature stands after the sapling stage for the purpose of increasing the rate of growth of those trees which are left.

G., Durchforstung. F., éclaircie.

Degrees of thinning are indicated by the following grades. They may be gauged by volume and by number of trees removed.

Grade $A$ - light. A removal of dead and dying trees.

Grade $B$ - moderate. A removal, in addition, of all suppressed trees and the poorest intermediate trees.

Grade C-heavy. A removal, in addition, of the rest of the intermediate class of trees.

Grade D-very heavy. A removal, in addition, of many of the codominant trees.

German and Austrian experiment stations recognize four grades; Gayer ${ }^{1}$ recognizes three grades, as follows:

Light (G., Schwach). Removal of dead and wholly suppressed.

Medium (G., Mittelstark). Removal of suppressed and the greater portion of the dominated trees (intermediate class).

Heavy (G., Stark). In addition, cutting operations in the co-dominant class.

Interlucation. A severe opening up of a stand. See fuller definition under its letter.

Selection thinning. A thinning in which always the stoutest trees are removed, as in the selection method of regeneration (Borggreve). Intermittent management. The management of a forest for a periodic instead of annual yield.

G., Aussetzender Betrieb.

${ }^{1}$ Der Waldbau, Dr. Karl Gayer, Berlin, 1888. 
Interplant. To set out young trees among existing young seedling growth, planted or natural; applicable also to planting land partly occupied by brushwood.

Intolerant. Incapable of enduring much shade, varying with species, age, and site.

Syn.: light demanding.

G., lichtbedürftig. F., tempérament robuste.

Large pole. See Tree class.

Large sapling. See Tree class.

Lath screen. See Shade frame.

Leader. The terminal shoot of the main stem.

Leaf canopy. See Crown cover.

Leaf litter. See Forest floor.

Leaf mold. See Humus.

Liberation cuttings. See Intermediate cuttings.

Lift, $v$. To loosen and remove seedlings from the seedbed in a nursery.

Light-demanding. See Intolerant.

Litter. See under Forest floor.

Locality. See Site.

Log rule. 1. A tabular statement indicating the estimated or calculated amount of lumber which can be sawed from logs of given lengths and diameters.

2. A graduated rule (usually made of wood) for measuring the diameters and volumes of logs, the number of board feet in logs of given diameters and lengths being shown upon the rule. (Usually called Scale stick $(q$. v.)).

Log scale. See Scale stick.

Logging unit. A part of a forest which can conveniently be made the basis of an individual logging operation.

Syn.: chance; logging chance.

Lot. See Subdivision.

Low pole. See Tree class.

Lumber rule. See Board rule.

Lumber scale. See Board rule.

Management. See Forest management.

Marginal seeding. See Reproduction (strip) method.

Marking hammer. A tool used for marking trees or logs or other products with various characters, signs, numbers, etc. 
Mature forest. A forest or stand which has reached its age of utilization (commercially). The meaning of maturity differs with the object of management, and to the forester is a matter of calculation on various bases. Biologically, maturity would refer to the age of seed production; physically, to cessation of height growth. Financial maturity is attained when the highest forest income or interest (which occurs when the index per cent is equal to the demanded business per cent), or forest rent, or soil rent, or otherwise financially best results can be secured. After this point of maximum result is passed the forest income decreases and the forest is said to be "financially overmature." See also Rotation.

Syn.: ripe.

G., finanzielle Hiebsreife.

Mean annual forest per cent. See Forest per cent.

Mean annual increment. See Increment.

Mean sample tree. A tree of representative form which in diameter, height, and volume is an average of the trees in a group or stand.

Medium. See Crown density.

Merchantable. A term to designate the portion of trees or stands which can be marketed under given economic conditions, usually refers to $\log$ material only.

Merchantable length refers to the marketable length of $\log$ in a tree. Merchantable volume refers to the marketable volume.

Merchantable form factor. See Form factor.

Middle forest. (Obs.) See Composite forest.

Mild humus. See Humus.

Mixed forest. Forest composed of trees of two or more species. In practice usually a forest in which at least 20 per cent are trees of other than the leading species.

G., gemischter Bestand. F., peuplement mélangé.

Model forest. See Normal forest.

Mother tree. See Seed tree.

Mound planting. See Forest planting.

Natural pruning. See Pruning.

Natural reproduction. See Reproduction.

Net income. See Income.

Normal. Used as in common parlance in varying sense as conforming to a standard, rule or principle, a model, or as denoting an average of conditions, or the best of conditions. 
G., normal. F., normal.

Normal age classes. The presence of a complete series of age classes corresponding to the rotation (see Age class).

Normal age class distribution. Such distribution of age classes as will permit annual or periodic fellings to be made without damage to adjoining stands.

Syn.: normal age class arrangement.

Normal increment. The best average increment attainable by given species on given sites, as represented in normal yield tables.

Normal forest. A standard with which to compare an actual forest to bring out its deficiencies for sustained yield management; the conception of an ideally regulated or organized forest; a forest with normal increment, normal age classes in size and distribution, and normal stock.

Normal growing stock or Normal stock. The amount of material represented by the stands in a normal forest; practically, the contents of the normal age classes as represented in normal yield tables.

Normal yield table. An accepted standard yield table with which to compare actual yields. The statements of a normal yield table are derived as an average from the best producing fully stocked areas for given species and sites. If a normal forest were not merely an idea, but actually attainable, the normal yield table would represent its productivity and stock.

Normal stand. A stand fully stocked and in proper growing conditions, conforming to the yield table and having normal increment.

Normal form factor. See Form factor.

Nurse tree. A tree which protects or fosters the growth of another in youth.

G., Schutzholz. F., essence d'abri.

Nursery. See Forest tree nursery.

Old growth. See Virgin forest.

Open, $a$. See Crown density.

Oppressed. See Crown class.

Organization. See Forest organization.

Over-cut. The cutting of a quantity of timber in excess of the annual growth of the forest or of the annual felling budget.

Overmature forest. Forest on which, as the result of age, growth has 
almost entirely ceased, and decay and deterioration have begun. See also Mature forest.

Over-stock. A growing stock greater than the normal growing stock. In natural regeneration, a condition of an excessive number of individuals hindering each other in development and retarding desirable differentiation into crown classes.

Overwood. See Composite forest.

Park forest. A forest in which the trees stand apart from one another or in detached groups. A very open forest in which usually also the characteristic forest floor is replaced by grasses.

Periodic annual increment. See Increment.

Periodic increment. See Increment.

Permanent type. See Forest type.

Physical factor. Any inorganic component of a site capable of influencing its forest-producing power, such as altitude, slope, aspect, soil, and subsoil. See Site.

Physical type. See Site.

Pit planting. See Forest planting.

Planted forest. See Forest plantation.

Planting area. See Forest planting.

Planting board. See Transplant board.

Planting plan. See Forest planting and working plan.

Planting stock. See Forest planting.

Pole. See Tree class.

Polewood. See Development class.

Pollard, $n$. A tree whose crown has been cut back to invite the production of shoots.

G., Kopfholz. F., têtard.

Pollard, v. Lopping the top of a tree to invite the production of shoots from the top.

G., köpfen. F., éteter, écimer.

Possibility. (Obs.) See Regulation of cut.

Preparatory cuttings. See Reproduction, Shelterwood method.

Preparatory stage. See Reproduction, Shelterwood method.

Present yield table. (Obs.) See Yield table.

Price increment. See Increment.

Profit. See Income.

Progress map. See Working plan control. 
Protection forest. A forest whose chief value is to regulate streamflow, prevent erosion, hold shifting sand, or exert any other indirect beneficial effect. It may or may not produce timber.

G., Schutzwald, Bannwald. F., forêt de protection.

Pruning or clearing, $n$. The removal of branches from standing trees by natural (self-pruning) or artificial means. The clearing of the stem through the death and fall of branches for want of light is known as natural pruning, or clearing ( $\left.q . v_{0}\right)$.

G., Astreinigung. F., élagage natural.

G., Aufästung; F., élagage, terms of artificial pruning.

Puddle, $n$. A mixture of soil and water about the consistency of cream in which the roots of young trees are dipped to retard drying out during planting.

Puddle, v. To dip the roots of young trees in a mixture of soil and water. Pure forest. Forest composed principally of trees of one species. In practice usually a forest in which 80 per cent or more of the trees are of one species.

G., reiner Bestand. F., peuplement pur.

Quality increment. See Increment.

Quality of site. See Site and Site class.

Quality of stand. The quality of stand is its actual condition from the viewpoint of production as compared with normal condition.

G., Bestandesbonität. F., qualité du peuplement.

Quincunx planting. See Forest planting.

Range. See Subdivision.

Reconnaissance. A preliminary, extensive forest survey of a limited degree of accuracy.

Reforest, v. To renew a forest, either by natural or artificial means.

Syn.: restock.

G., aufforsten. F., reboiser.

Reforestation. The natural or artificial restocking of an area with forest trees; most commonly used in reference to the latter. See Forestation.

G., Aufforstung. F., reboisement.

Regeneration, $n$. See Reproduction.

Regeneration period. See Reproduction period.

Regulation of cut. The fixation in advance of the annual or periodic cut, which in the normal forest would be equivalent to the annual growth. See Cut. 
Syn.: regulation of felling budget; regulation of yield.

G., Etatsbestimmung, Ertragsbestimmung. F., fixation de la possibilité.

The following classification of methods of regulating the cut may be recognized:

Allotment methods, when a rotation is fixed and for a given year or period of the rotation a certain area, a certain amount of stock, a certain number or size of trees is allotted to be cut.

Normal stock or Formula methods, when the amount of cut is determined by comparison of actual with normal conditions and the cut is in part regulated by a volume formula for a rotation or equalization period.

Individualizing or Stand methods, when each stand is investigated for its financial maturity and designated for cutting, provided other age classes are in existence to assure continuity of crops.

Removal cutting. See Reproduction, Shelterwood method.

Removal stage. See Reproduction, Shelterwood method.

Rent. In forest finance, the income per acre secured as an annual return from a forest or stand under management, calculated either as forest rent or soil rent.

Forest rent is the net income $(q . v$.$) from a forest organized for sus-$ tained yield, without interest charges on the forest capital-bookkeeper's balance - the forest, i.e., soil with a stand or growing stock, being conceived as the forest capital, and the rent as the total interest earned by it.

G., Waldrente.

Soil rent is that part of the income (or balance) from a managed forest which remains as interest on the soil capital alone after all expenses with compound interest have been deducted, the soil alone being conceived as the capital.

G., Bodenrente.

Reproduction. 1. The process by which a forest is renewed.

Natural reproduction is the renewal of a forest by self-sown seeds or by sprouts. See also Advance growth.

Syn.: regeneration.

G., natürliche Verjüngung. F., régénération naturelle.

Artificial reproduction is the renewal of a forest by direct seeding or planting. 
Syn.: reforestation.

G., künstliche Verjüngung.' F., régénération artificielle.

The collating committee recommends the use of plain regeneration for natural reproduction and reforestation for artificial reproduction.

2. Seedlings or saplings from sprouts or from self-sown seed.

Syn.: young growth.

Reproduction cutting. (Regeneration culting.) Any cutting intended to invite or assist regeneration.

G., Verjüngungshieb. F., coupe de régénération.

Reproduction method. (Regeneration method.) An orderly procedure or process by which a forest is renewed or established, either naturally or artificially. The following methods may be distinguished:

1. Clearcutting, with artificial reproduction.

2. Clearcutting, with natural regeneration.

3. Seed tree method.

4. Selection.

5. Shelterwood.

6. Coppice.

7. Coppice with standards - Composite forest.

These methods are defined and explained as follows:

1. Clearcutting with artificial reproduction. Removal of the entire stand in one cut with artificial reproduction or reforestation by direct seeding or by planting (q. v.). See also Seed tree method.

G., Kahlschlagwirtschaft. F., méthode par coupe unique.

2. Clearcutting, with natural reproduction. Removal of entire stand in one felling, regeneration taking place by seed from the marginal stand or seed in the ground. 'Differentiation may be made according to the form of felling area into strip and group method.

Strip method. Cutting a strip, and, when regeneration has taken place by marginal seeding, seaming an additional strip and proceeding in this manner from year to year or period to period. A variant called Strip method in echelons (G., Kulissenhieb, Springschlag. F., coupe par bandes alternes) opens strips in several places at the same time and then proceeds similarly by seaming.

G., Saumhieb. F., coupe par bandes.

Group method. Proceeds by removing groups of trees making more 
or less irregular openings and enlarging these until the entire stand is removed.

G., Kesselhieb, Löcherhieb. F., coupes par trouées.

3. Seed tree method. Removal of the entire stand at one cut, but leaving a small number of seed trees singly or in small groups, to be eventually removed. If the seed trees are held over for another rotation, this may be called Reserve tree method.

G., Ueberhaltbetrieb. F., traitement en futaie avec reserve sur coupe définitive.

4. Selection method. That method of cutting in which single trees, usually the largest, or small groups of such trees, are removed and reproduction secured under the remaining stand and in the openings. When groups of trees are taken, it is termed Group selection method. A special form of the selection method is termed Selection border felling or strip selection (G., Blendersaumschlag) when selection fellings are made in narrow strips, in most instances beginning on the north border and progressing southward, followed by clear cutting when young growth is fairly established with the expectation of additional marginal seeding. The resulting forest is uneven-aged in narrow lines.

G., Plenterbetrieb, Femelbetrieb. F., jardinage, régime de la futaie jardinée.

5. Shelterwood method. A method of securing natural reproduction under the temporary shelter of the seed tree crown cover, by means of a series of cuttings throughout the stand, aimed to admit a gradually increasing supply of light to the seedlings. The principle of the method lies in the protection (shelter) which the seed trees (nurse trees) afford the young growth during its youth. The number and severity of the cuttings and hence the duration of the entire removal period, depends upon the rate of establishment and the need of light by the young growth.

G., Schirmschlagbetrieb (Gayer and Lorey), in part Femelschlagbetrieb (Lorey). F., régime de la futaie regulière.

In theory the series of cuttings is divided into four parts as follows:

Preparatory cuttings or fellings fit the stand for its reproduction (regeneration) by the removal of dead, dying, or defective trees and undesirable species, and prepares the ground for the seedbed and encourages seed production. A stand in which one or more preparatory cuttings have been made is in the preparatory stage. 
G., Vorbereitungschlag. F., coupe préparatoire.

Seed cutting or felling. A further opening of the stand, before seeding takes place, to secure the amount of light which the expected seedlings will require. A stand in which one or more seed cuttings have been made is in the seeding stage.

G., Besamungsschlag. F., coupe d'ensemencement.

Removal cuttings or fellings gradually remove the mature stand, which would otherwise retard the development of the young trees. A stand in which one or more removal cuttings have been made is in the removal stage.

G., Lichtschlag. F., coupe claire.

The final cutting or felling is the last of the removal cuttings, in which all of the old stand still remaining is cut. (G., Abtriebsschlag, Endhieb. F., coupe définitive.) In practice a two cut shelterwood method may be used, including the seed cutting and final cutting stages. The shelterwood method may be applied to a stand in narrow strips, from the leeward side, at such intervals that reproduction cuttings are generally going on in three strips at one time, one strip being in the removal stage, one in the seeding stage, and one in the preparatory stage. This manner of application is termed Shelterwood strip method.

Another modification of the shelterwood method of reproduction is that in which groups of valuable advance growth, if present, form the starting points for the cutting which radiates from these centers. Such an application is termed Shelterwood group method.

6. Coppice method. A method of renewing the forest in which reproduction is secured by sprouts.

Syn.: sprout method.

G., Niederwaldbetrieb. F., régime du taillis simple.

7. Coppice with standards. A method of reproduction in which seedling trees or selected sprouts (standards) are maintained above a coppice or sprout forest. See Composite forest.

G., Mittelwaldbetrieb. F., régime du taillis.

Reproduction period. The space of time required or normally decided upon for the renewal of a stand by natural regeneration.

Syn.: regeneration period; return period.

Reserve. 1. A tree or group of trees left uncut on an area for a period, usually a second rotation, after the stand is reproduced naturally or artificially. It may also refer to whole stands held back from utiliza- 
tion. A tree reserved primarily in order to seed the felling area is termed a seed tree. See Reproduction, Seed tree method. A tree held over from harvest to grow into or through a second rotation, usually to secure increased diameter development, may be termed a hold-over. A tree reserved in coppice cutting is termed a standard. See Reproduction, Coppice with standards.

2. A tract of forest set aside for forest management.

Syn.: national forest.

Restock. See Reforest.

Revision of working plan. The rewriting of a working plan at the end of, or during the working period. Such renewals may be made at fixed intervals of, say, ro years, or at irregular intervals, as is commonly the case where revised data or changes in prevailing market conditions, etc., necessitate modification of the original plan.

Ride. A term used in English literature for opened up division lines between compartments.

G., Schneisse, Gestell. F., laie.

Ripe. See Mature forest.

Root sucker. A sprout from a root.

Rotation. The predetermined time period during which it is intended to cut over a working group; the predetermined, approximate felling age of stands. Rotation refers to the forest as a whole and is expressed not by a definite year, but a period of Io to 20 years; felling age refers to a stand and a definite year.

Rotations are determined either by technical, economic, or financial considerations; silvicultural considerations exercising a limiting influence.

Technical rotations attempt to produce the maximum amount of material suitable for a certain purpose, such as railroad ties, mine timbers, saw logs of given size.

Economic rotations attempt to secure either the maximum average volume production, or the maximum average value production.

Financial rotations introduce considerations of cost and attempt to secure either the maximum forest rent or maximum soil rent $(q . v$.$) .$

Syn.: income rotation.

G., Umtrieb, Turnus. F., revolution.

Row planting. See Forest planting.

Sale value. See Value. 
Salvage felling. (New term.) Removal of trees killed or injured in a forest by fire, insects, fungi, or other harmful agencies, with the purpose of utilizing merchantable material and preventing the spread of insects and disease. See under Intermediate fellings.

G., Totalitätshieb. F., coupe accidentelle.

Sample plot. A sample plot is an accurately measured area used for purposes of experimentation or of mensuration. Sample plots may be either permanent or temporary.

Sample tree. See Mean sample tree.

Sapling. See Tree class.

Scale, $n$. The contents of a log or logs as determined by measurement with a scale stick.

Scale, $v$. To determine the contents of a log by measurement with a scale stick.

Scale rule. See Scale stick.

Scale stick. A stick usually graduated to inches, showing for logs of different diameters and lengths the corresponding contents in board feet or other unit according to a given log rule (see Log rule).

Screen. See Shade frame.

Scribe. A tool designed for carving symbols in wood or bark, commonly used to mark lines or corner posts.

Syn.: timber scribe, tree scribe.

Second growth. Forest growth which comes up naturally after cutting, fire, or other disturbing cause. In lumberman's parlance, the smaller trees left after lumbering or the available trees for a second logging. See Old growth.

Seedbed. 1. In natural reproduction the soil or forest floor on which seed falls.

2. In nursery practice, a subdivision of a nursery for the raising of seedlings.

G., saatbeet. F., couche de semis.

Seed board. See Forest planting.

Seed cutting or felling. See Reproduction (Shelterwood) method.

Seed drill. See Forest planting.

Seed forest. See High forest.

Seed horn. See Forest planting.

Seed spot. A prepared spot usually about a foot square in which tree seeds are to be planted. 
Seed spot method. See Direct seeding.

Seed tree. Any tree which bears seed; specifically, a tree which is to provide the seed for natural reproduction.

Syn.: mother tree; nurse tree.

G., Mutterbaum, Samenbaum. F., portegraine, semencier.

Seed tree method. See Reproduction, method of.

Seed year. A year in which a given species bears seed abundantly.

G., Samenjahr. F., année de semence.

Seeding. See Direct seeding.

Seeding stage. See Shelterwood method.

Seedling. 1. A tree grown from seed.

G., Kernwuchs. F., brin de semence.

2. In nursery practice, a tree which has not been transplanted in the nursery. See Planting stock.

3. In natural reproduction, a tree from seed which has not reached a height of 3 feet. See Tree class.

G., Sämling, Keimling. F., jeune brin.

Seedling forest. See High forest.

Seedling sprout. A sprout resulting from the cutting of a seedling or small sapling. This is differentiated from coppice sprout or shoot because of its subsequent behavior.

Selection forest. A forest through all parts of which many, or theoretically all age classes are represented.

Selection method. See Reproduction method.

Selection thinning. See Intermediate cuttings.

Self pruning. See Pruning and Clear.

Self-sown seed. Seed sown by any agency other than man.

Set free, $v$. See Intermediate (liberation) cuttings.

Severance felling or cutting. See under Intermediate cuttings or felling. Shade enduring. See Tolerant.

Shade frame. A frame for the partial shading of a seedbed. It consists of a cover of laths, brush, or cloth, arranged so that light can be admitted as desired and is frequently used in combination with a frame 'and cover provided with wire netting to keep out birds and rodents. Shaft. See Stem.

Shelterbelt. See Windbreak.

Shelter growth. An advanced growth used to protect shade-demanding species. A new term to designate nurse trees collectively. 
Shelterwood method. See Reproduction method.

Shoot. See Tree class.

Silvical. Pertaining to silvics.

Silvics. 1. A branch of ecology that treats of the life of trees in the forest; forest ecology.

2. The life history, requirements, and general characteristics of a forest tree from the point of view of silviculture.

Silvicultural characteristics. See Silvics (2).

Silviculture. The art of producing and tending a forest; the application of the knowledge of silvics in the treatment of a forest.

G., Waldbau, Holzzucht. F., Sylviculture.

Single tree method. (Obs.) See Reproduction (Selection) method.

Site. An area, considered as to its physical factors with reference to forest producing power; the combination of climatic and soil conditions of an area. See Site class.

Syn.: locality, physical type.

G., Standort. F., station.

Site class. A designation of the relative productive capacity or quality of different sites with reference to the species employed; the volume or the height produced at a given age being used as standard for classification. In Europe five classes, in the United States often only three classes are differentiated, designated by Roman numerals, quality I representing the most productive site class.

Syn.: quality of site.

G., Bonität. F., qualité du sol.

Slit method. See Forest planting.

Slope. The gradient of the land surface. In forest description, the following terms are used to define the slope, each of which has its equivalent in percentages of the horizontal distance and in degrees:

$$
\begin{array}{ll}
\text { Level } & =0-5 \%=0-3^{\circ} \\
\text { Gentle } & =5-15 \%=3-8^{\circ} \\
\text { Moderate } & =15-30 \%=8-16^{\circ} \\
\text { Steep } & =30-50 \%=16-26^{\circ} \\
\text { Very steep } & =50-100 \%=26-45^{\circ} \\
\text { Precipitous } & =\text { over } 100 \%=\text { over } 45^{\circ}
\end{array}
$$

Snowbreak. The breaking of limbs of trees by snow.

G., Schneebruch. F., bris de neige. 
Social. Said of species apt to form pure stands.

Syn.: gregarious.

Soil. In forest description, the origin, composition, depth and moisture of the forest soil are considered under soil. Its depth, to subsoil, rock or groundwater, is defined by the following terms, each of which has its equivalent in inches:

$$
\begin{aligned}
& \text { Very shallow }=\text { less than } 6 \text { inches. } \\
& \text { Shallow }=6 \text { to } \mathrm{I} 2 \text { inches. } \\
& \text { Moderate }=12 \text { to } 24 \text { inches. } \\
& \text { Deep }=24 \text { to } 36 \text { inches. } \\
& \text { Very deep = over } 36 \text { inches. }
\end{aligned}
$$

The moisture of the soil is defined by the following terms:

Wet. When water drips from a piece held in the hand without pressing.

Moist. When water drips from a piece pressed in the hand.

Fresh. When no water drips from a piece pressed in the hand, though it is unmistakably present.

Dry. When there is little or no trace of water.

Very dry. When the soil is parched. Such soils are usually caked and very hard, sand being an exception.

Soil rent. See Rent.

Soil rent value. Value based on soil rent.

Sour humus. See Humus.

Sowing. See Direct seeding.

Space number. The average distance between the trees in a stand divided by their average diameter; used to estimate volume of stand.

G., Abstandszahl.

Sprout. A tree which has grown from a stump or root. See Tree class.

Syn.: shoot, root sucker.

G., Stockausschlag. F., rejet de souche.

Sprout forest. See Coppice.

Sprout method. See Reproduction methods.

Stagheaded. A term applied to a tree dead at the top as a result of injury, disease, or deficient moisture and nutriment.

Stand. A general descriptive term referring to an aggregation of trees, standing on a limited area, of more or less uniformity of composition and condition, or of age. 
G., Bestand. F., peuplement.

In mensuration, the amount of material on a given area: usually expressed in terms of Stand per acre.

Syn.: growing stock.

Stand quality. See Quality of stand.

Stand table. A tabular enumeration showing separately for each diameter class and species, the number of trees on a given unit of area, usually an average acre. The corresponding volume may or may not be given. If given, the table may be called Stock table (q. v.).

Standard. 1. See Tree class (in reference to size classification).

2. A seedling or selected healthy sprout in a coppice forest left uncut to grow for more than one rotation. See Reserve.

Status records. An administrative term for records showing the ownership of lands. Complete status records will show in detail the chain of title for each parcel of land and also for all servitudes and easements attached to the land. In addition, they usually show the location and extent of all qualified or temporary alienations, such as unpatented mineral claims, leased areas, or lands otherwise specifically under permit or affected by outstanding contracts, as for the sale of timber, etc. Status records usually consist of sets of maps, often called "tract books " and of written or tabulated records supplemental to the map records.

Stem. The trunk of a tree. The stem may extend to the top of the tree, as in some conifers, or it may be lost in the ramification of the crown, as in most broadleaf trees. In tree description, the stem is described as long or short, straight or crooked, cylindrical or tapering, smooth or knotty, clear or rough, etc. The synonym bole may be suitably reserved when speaking from the standpoint of utilization, using stem or shaft from the standpoint of mensuration, stem or trunk for description merely.

Syn.: trunk, bole, shaft.

Stem analysis. The measurement of stated cross sections of a tree to determine its increment at different periods of its life. A stem analysis may be either partial or complete depending on whether the measurements include only a portion or all of the stem.

Stem class. See Tree class.

Stem density. See Stock density.

Stem form factor. See Form factor. 
Stock, $n$. 1. The stump of a coppice from which sprouts are expected.

2. A general term used to describe the character of the forest cover in composition or condition or supply of material (stumpage).

In organization, growing stock, the volume of material present, as basis of management; in finance, the value or capital represented in the stumpage of a stand or forest. See Normal stock. Undesirably used as synonym for Stand.

Stock density. Expressed by reference to number of trees or total basal area per acre, three grades being recognized: dense, medium, open.

G., Bestandesdichte. F., consistance.

Stock map. A map giving by symbols and numbers the composition of a stand or forest.

Stock table. See Stand table. A table enumerating the volume of a stand by tree classes.

Stock-taking. See Forest survey.

Stool shoot. A sprout from a stump.

Stoutwood. See Assortment.

Stratify. In nursery and planting practice, to preserve tree seeds by spreading them in layers alternating with layers of earth or sand.

Strip method. See Reproduction, clearcutting method and shelterwood method.

Strip selection method. See Reproduction (Selection) method.

Strip seeding method. See Direct seeding.

Strip survey. A partial survey; more precisely a process of estimating timber by measuring it on strips laid out over the area to be surveyed according to a systematic scheme (see Forest survey) and applying the measurements to the whole area in proportion.

Stub. That portion of the trunk left standing when a tree is accidentally broken off.

Stump. That portion of the trunk below the cut made in felling a tree. G., Stock. F., souche.

Stump analysis. A partial stem analysis in which the only section used is the surface of the stump. See Stem analysis.

Stump height. The average distance between the juncture of the stem and roots (root collar) and the surface of a stump.

Stumpage. 1. Amount of saleable material in a stand.

Syn.: stock. 
2. Stumpage value, the value of timber as it stands - "on the stump." May include all wood or only certain classes.

3. Price paid for standing timber.

Subcompartment. See Subdivision.

Subdivision. A larger or smaller part of a forest property segregated with a view to making units for purposes of administration, protection, organization, management.

District. Generically, any administrative unit; specifically, an aggregate of administrative units or forests for control and inspection purposes.

Forest. An administrative unit, as National forest, State forest, Municipal forest.

Ranger district or Range. Part of a forest, an executive unit under care of a ranger.

Patrol district or Beat. An executive unit for protective purposes, under a guard or patrol.

Compartment. An organization unit or small subdivision for purposes of orientation, administrative, and silvicultural operations.

G., Abteilung, Jagen (Prussia).

Lot. A small subdivision of a compartment, differing in composition, age, or character, requiring different treatment from the main body of the compartment; impermanent if due to accidental, permanent if due to site conditions.

Syn.: subcompartment.

G., Unterabteilung, Abteilung (Prussia).

Block. A major division of the working plan unit, intermediate in size between the working plan unit and a compartment. A block is usually based on topography and comprises a main logging unit or group of logging units. A single block may contain many thousand acres.

Working plan unit. A forest area managed under one working plan. It may or may not coincide with the administrative unit.

G., Wirtschaftsganzes.

Working group. An organization or working plan unit, comprising an aggregate of compartments or stands to be managed under the same silvicultural system and rotation.

Syn.: working block; working circle; working figure; working section; management class. 
G., Betriebsklasse. F., Serie d'exploitation.

Sublot. See Subdivision.

Suppressed, $a$. Having growth seriously retarded by shade, dying or so far injured that recovery is not probable. See also Crown class.

G., unterdrückt. F., dominé.

Sustained annual yield. See Sustained yield.

Sustained periodic yield. See Sustained yield.

Sustained yield. The yield or cut of timber from a forest which is managed in such a way as to permit the removal of an approximately equal volume of timber annually or periodically, equal to the increment.

Taper. The gradual diminution of diameter in the stem of a tree from base to top.

Taper table. A tabular statement of average diameter measurements of stems at specified heights above ground, recorded for trees of varying d. b. h. and height classes. Used for determining volumes and dimensions of products.

Thicket. A stand of saplings. See Development class.

G., Dickicht. F., fourre.

Thin, $v$. To make a thinning.

Thinning. See Intermediate cuttings.

Timber forest. See High forest.

Timberland. See under Forest.

Timber form factor. See Merchantable form factor.

Timber scribe. See Scribe.

Timberwood. See Assortment.

Tolerance. The capacity of a tree to endure shade.

Tolerant. Capable of enduring more or less heavy shade.

Syn.: shade-bearing, shade-enduring.

G., Schattenertragend. F., à tempérament délicat.

Transition period. The time used in bringing an unorganized forest into sustained yield management.

G., Uebergangszeitraum. F., période de transition.

Transplant, ข. To transfer seedlings from the seedbed and set them in the ground in another part of the forest nursery.

G., verpflanzen, verschulen. F., transplanter.

Transplant, $n$. A seedling which has been transplanted one or more times in the nursery. See Planting stock.

G., Schulpflanze. F., plant repiqué, plant rigolée. 
Transplant board. An implement used in setting seedlings in transplant rows or beds. The principle of the tool is a device which holds the trees in place in a notched board so that a number may be planted at a time.

Trap tree. A tree felled or girdled for the purpose of collecting injurious insects.

Tree analysis. See Stem analysis.

Tree class. All trees of approximately the same size. The following tree classes are distinguished:

Seedling. A tree, grown from seed, not yet 3 feet high.

Shoot. A sprout, not yet 3 feet high.

Small sapling. A tree from 3 to io feet high.

Large sapling. A tree to feet or over in height and less than 4 inches d. b. h.

Small pole. A tree from 4 to 8 inches d. b. h.

Large pole. A tree from 8 to 12 inches d. b. h.

Standard. A tree from I to 2 feet d. b. h.

Veteran. A tree over 2 feet d, b. h.

See also Development class.

Tree compass. An instrument for measuring diameter, consisting of a pair of dividers and a scale bar.

Tree form factor. See Form factor.

Tree scribe. See Scribe.

Tree tape. See Diameter tape.

Trench planting. See Forest planting.

Trench sowing. See Direct seeding.

Trunk. See Stem.

Turnus. See Rotation.

Two-storied forest. A stand in which two height or age classes of considerable difference, usually, are developed or are intended to be maintained, as upper story or overwood and lower story or underwood. The term is not applicable to forest under reproduction, in which the appearance of two stories is the temporary result of an incomplete process, but to those forests of which the two stories of growth are a permanent feature.

G., Zweihiebig. F., à double étage.

Underbrush. All large woody plants, which grow in a forest, but do not make trees. . 
Under-cut. In forest management the cutting of a quantity of timber less than the annual growth of the forest or the predetermined annual cut. See also Lumber manufacturing terms.

Undergrowth. A term used to include underbrush, seedlings, shoots, and small saplings.

Underplant. To set out young trees or sow seeds under an existing stand. Under-stock. A growing stock less than the normal growing stock.

Underwood. See Composite forest.

Uneven-aged. Applied to a stand or forest in which considerable differences in age of trees occur, differences varying with the average age of stand or forest. See Even-aged; Selection forest.

G., ungleichalteriger Bestand. F., peuplement melé.

Unit of regulation. See Subdivision, Working unit.

Used length. The total length of stem usable in commercial operations. Used volume. The volume of that portion of the tree usable in commercial operations.

Utilization value. See Value.

Valuation survey. The survey of an average area (valuation area) selected for detailed measurement and valuation. Often objectionably used for mensuration areas when no valuation is involved but only material is measured.

Value. The following values may be differentiated.

Investment value. The purchase price or the actual expenditures or investments that have been made in acquiring or creating the property with interest, less incomes actually derived from it, with interest.

G., Anlagekapitalwert.

Cost value. An investment value based on production. This may be differentiated into Subjective cost value if based on actual expenditures, and Objective cost value if based on estimated cost of replacement of the property (as in damage suits).

G., Kostenwert.

Sale or Exchange value. The market price based on statistics of actual sales; a special kind of sale value is the forced sale or wrecking value that can be obtained by exploitation of saleable parts (see Stumpage value).

G., Verkaufswert. F., valeur vénale.

Stock or Stumpage value. Based on sale value of material ready for immediate utilization. 
Syn.: utilization value.

G., Nutzungswert.

Expectancy value. The present worth of all estimated or expected future net earnings (discounted value); the capitalized net income value.

G., Erwartungswert. F., valeur d'attente.

Rent or Yicld value. A value, determined by capitalizing, with a demanded rate of interest, the yearly or intermittent net return possible to be derived from a managed property. Sec Forest rent and Soil rent.

G., Bodenrentierungswert; Waldrentierungswert.

Value increment. See Increment.

Veteran. See Tree class.

Virgin forest. Applies to mature or overmature forest grown entirely uninfluenced by human activity.

Syn.: old growth.

G., Urwald. F., forêt vierge.

Volume table. A tabular statement showing, for a given species, the average contents of trees of different sizes. The usual volume table is based on diameter and height. Volume tables may be made for any desired unit of volume.

Volunteer growth. See Advance growth.

Water sprout. An epicormic branch arising from a dormant or adventitious bud.

Weed tree. A tree of a species which has little or no value.

Weeding. See Intermediate cuttings, cleanings.

Windbreak. Any object which serves as an obstacle to surface winds; in forestry trees serve such a purpose. Tree windbreaks are classified according to their general arrangement.

1. Rows and hedge rows; 2. belts or shelterbelts of three or more rows; 3. groves, or in the most extensive case, forests. They may be of natural or artificial origin.

Windfall. 1. A tree thrown by wind.

2. An area on which the trees have been thrown by wind.

Syn.: windbreak, blow-down.

G., Windbruch. F., volis.

Wind-firm. Able to withstand heavy wind.

G., sturmfest, windfest. F., resistant au vent. 
Wind mantle. A screen of trees, commonly used to designate the dense border of a woodlot or forest which prevents penetration of wind into the interior.

G., Waldmantel.

Wolf tree. A tree occupying more space than its silvicultural value warrants, curtailing better neighbors. A term usually applied to broadcrowned, short-stemmed reserves.

Woodland. See Forest.

Woodlot. See Forest.

Working block. See Subdivision.

Working capital. See Capital.

Working circle. See Subdivision.

Working figure. See Subdivision.

Working period. The period of years during which the working plan is intended to apply.

Working plan. The plan or plans under which a given forest property is to be continuously managed. Annual or Periodic plans may be based on the general working plan and may refer to any specified class of work, as the annual cutting or felling, planting, protection, grazing, or administration and improvement plan. Such annual plans may be either mere schedules or may contain more or less detail, explanations, estimates of cost and results, as seems desirable.

Working plan control. The records of the progress of the work on the forest as outlined by the working plan. In European practice these records are kept by maps and books. The entries are made periodically or at the time of completing each of the various projects. This control operates as a check on the execution of the working plan.

Working section. See Subdivision.

Working unit. See Subdivision.

Yield. The timber or wood volume that is (actually) or can be (normally) produced by a stand of a given composition at a given age under given site conditions and treatment - the actual or normal product of the stand. See Normal. In finance, may be expressed as money yield.

The term $Y$ icld involves the idea of futurity, hence for a statement of actual material on hand the term Stock is preferable. For the expression Regulation of yield, the expression Regulation of cut or of felling budget is preferred.

Yield table. A tabular statement of periodic yields attainable at differ- 
ent ages (usually in ro-year periods) per unit of area (usually per acre).

Normal yield tables are constructed separately for given species on different sites (and sometimes different growth regions) under different treatment, and are used as standards with which to compare actual yields. The statements of a normal yield table are derived as an average from the best producing areas. If a normal forest were not only an idea, but actually attainable, the normal yield table would represent its productivity and stock.

Empirical yield table is a statement of the actual volumes of given stands. They are of local value only. Since there is no "experience" involved, the term Local yield table would be preferable.

In finance, volumes may be translated into values and referred to as money yield table, income table, or financial yicld table.

G., Wald- or Forstertrag; Materialertrag; Geldertrag. F., rendement. 



\section{INDEX}

Abnormal needle shedding, 279

Accretion cutting, I63, I 71

Administration, cost of, ro

Advance growth, 64, 71, 146

Adventitious buds, III

Esthetic effects, 5, 4I, 56, 78, 80, 103, ro8, 123,137

slash in relation to, 219

Age classes, 84, 9r, ro7, r 28, r 34

Agriculture, 2

All-aged, 84

Animals, protection against, 293

beaver, 293

birds, 294

deer, 293

mice, 294

porcupines, 293

rabbits, 294

squirrels, 294

Appendix, 299

Artificial reproduction, $33,36,40,55$,

$$
63,102, \text { Ir6, I32 }
$$

advantages of, $\mathrm{r} 9$

compared with natural, 18 to 22

definition of, 19

opportunities for applying, 22

Ash, white, $\mathrm{I}_{38}$

Ashe, W. W., 95

Aspen, 293

Assimilation, 60

Assistance cutting, $\mathrm{r}_{42}$

Avalanches, protection against, 296

Baden, 136

Balsam, eastern, 80

Bark-scorching, 279
Barnes, W. C., 289

Basal area, 161, 172

Basket willow, 125

Beaver, protection against, 293

Birch, D. C., 8

Birds, protection against, 294

Black Hills, 80

Blister rust, white pine, 277,278

Border cuttings, 70

Borggreve, 177

Borggreve's method of thinning, 162 , I 77,188

Broadcast burning, 29, 223, 229, 230, 231, 233

Brush, disposal of, 25, 29, 49, 116

Burning, broadcast, 29, 223, 229, 230 , 231, 233

Caccia, A. M. F., 95

Cambium, temperature to kill, 244

Causes of fires, 260

Chestnut, Ir 3,275

Chestnut blight, 275, 277, 278, 280

Chir pine, 228

Cleanings, 30, $142,144,159,192,208$

Clearcutting, 14, 15, 23, 25, 57, 77, 79, 107, 108, 117

advantages, 40

application of, 4I, 297

definition, 25

details of method, 25

disadvantages, 40

in alternate strips, 32

in one operation, 32

in patches, 37

in progressive strips, 35 
Clearcutting, in strips, 32

in two or more operations, 32, 35, 38,56

marking for, 207

modifications of the method, 32

slash disposal for, 224, 229

the whole stand, 32 , 100

with artificial reproduction, 25

with natural reproduction, 25,26 , 56

Clearings, location, 3I, 34

size, 3I, 4I

width, 30

Climbing vines, 147

Co-dominant trees, $47,63,64,134$, $146,156,162,163,172,175$, I 77

Compartment method, 59

Compound coppice, I27, $\mathbf{1}_{3} 6$

three kinds, 133

Conky trees, 48

Control of cuttings, 204 through inspection, 204, 2I3

through marking, 205

Conversion into high forest of coppice and coppice with standards, 139

Coppice forest methods, $\mathbf{I}_{5}$

Coppice method, III, I27, I36, I37, $\mathrm{r}_{3} 8$

advantages, I 21

application of, $\mathbf{I} 23$

conversion into high forest, $\mathbf{I} 39$

definition, III

details of, III

disadvantages, 122

marking, 207

modification of, II 7

slash disposal for, $23 \mathrm{I}$

Coppice with standards, advantages, I36

application of , 138,297
Coppice, conversion into high forest. I39

definition of, 127

details of, 127

disadvantages, 137

marking, 207

method, 127

modification of, $\mathrm{I}_{3} 6$

slash disposal for, $23 \mathrm{I}$

Costs, due to making the investment

a permanent one, ro

of administration, Io

of logging, 8, 9, 79

of lopping, 226

of marking, 207

of protection, 9

of pruning, 202, 203

of reproduction, 9

of silviculture, 7

of slash disposal, 233

Cottonwood, 49, 58, I 54

Cox, Wm. T., 234

Crown classes, basis for selecting trees in thinning, 160,161

classification into, 154

differentiation into, $\mathbf{I} 59$

relative position of trees of the different, 155

standard, 155

Crown fire, 250, 257

Cuttings, accretion, I63, I $7 \mathbf{I}$

assistance, $\mathrm{I}_{42}$

cleaning, 30, 142, 144, 159, 208

clearcutting, 25, 229

damage, 194

disengagement, $\mathbf{1 4 2}$

improvement, 142, I43, I44, 192, 208

interlucation, $163,17 \mathrm{I}$

intermediate, 6, I02, I4I, 153, I92, 208, 210, 23I

liberation, I42, I43, I44, I49, I59, 208, 232 
Cuttings, methods of controlling, 204 partial, 59 preparatory, $60,63,68,76,80$ primary, 71,74 pruning, $\mathrm{I} 43, \mathrm{I} 98,208$

relcase, 142 removal, $60,64,68$ reproduction, $6, \mathrm{I} 39, \mathrm{I} 72, \mathrm{I} 78, \mathrm{I} 95$, 207, 210, 229

salvage, I42, I43, I44, I94, 208 secondary, 7 I seed, $60,68,7 \mathrm{I}, 76,80$, II 7 selection, 83,107 severance, $143,195,208,261$ shelterwood, 60 thinning, I42, I44, 208 weeding, $\mathbf{I}^{2} 2$

Cutting cycle, 77, 81, 87, 91, 100 Cutting series, $36,69,70$

Damage cutting, 194

Deep rooted species, 57

Deer, protection against, 293

Density of stocking, 3

Diameter growth, I05, I57, I7I

Diameter limit, 92

Diœcious, 49

Disengagement cutting, $\mathrm{I}_{42}$

Dispersal of seed, $27,28,29,52$

Disposal of slash, $25,29,49$, II6, 210 , 215

Dominant trees, $47,52,63,64,146$, I55, I62, I63, I72, 175, I77, 183,192

Dormant buds, III

Douglas fir, 42, 47, 55

Eastern balsam, 8o

Entomology, 6

Epicormic branches, 135,176

Erosion, 4I, 56, 77, 103, 216, 249, 285, 289

Eucalypts, I 25
Evvenaged, $25,33,45,59,83,98,104$, I05, III, 143

Existence, struggle for, $153,158,178$, I94

Farm woodlot, 103

Felt, E. P., 268

Fernow, B. E., I, 177

Final crop trees, 175,177

Fir, Douglas, 42, 47, 55

white, 274

Fire, annual loss, $24 \mathrm{I}$

causes of, 260

character of, 250

classification of injuries caused by, 243

crown, 250, 257

effect of slash upon, 232, 26I

effects of, 24I

factors influencing spread and severity of, 254

ground, 250, 256

hazard in selection forest, 103

importance in forest protection, 239

in relation to fungi, 235

in relation to grazing, 287

injury as compared with fungi, 275 injury as compared with insects, 263 insurance, 55

lines, 198

methods of protection, 259

patrol, 234

Peshtigo, 250

protection, 6, 24I

regions of most severe, 253

resistance of tree species to, $2+4$

seed trees, 54

silvicultural treatment, effect of, in protecting against, 260 slash in relation to, 217 surface, 250 use of, to secure reproduction, 29 Fisher, W. R., 239 
Floods, 250, 296, 297

Forage, 284, 290

injury to, by fire, 249

Forest, Cœur d'Alene National, 209

form of, I2, 25, 45, 59, 83, III, I27, I 78

Minnesota National, 57

protection, 237

State, of France, I 24

Forest Terminology, I, 299

Forest Service, 'U. S., 54, 96, 208, 209, 254, 268

Forests, production in unmanaged, 3 unmanaged, I 2, I4I

virgin, $16,83,107$

Form of forest, I 2, 25, 45, 59, 83, I03, III, I 27, I 78

France, $\mathbf{1} 39$

State forests of, I 24

French method of thinning, 162, 172, I 77, I 82, I 88

Frost, I 23, I 24, I39, 279

Fumes, injury by acid, 279

Fungi, 48, I28, I42, I59, I95, I99, 2 I I, 274

action in rotting slash, 277

climate favorable to, 275

importance in forest protection, 239

injury as compared with fire, 275

injury as compared with insects, 275

injury caused by, 275

methods of control and prevention, 277

root destroying, 277

silvicultural measures as protection against, 277

slash in relation to, 216, 219, 235, 278

wood destroying, 276, 277

Furst, H., 264

German method of thinning, 162 , 188
Germination, favorable conditions for, of seed, $17,28,29,60$

Gipsy moth, 265, 268, 270

Girdling, 30, I5I, I52

Goats, 284, 286

Grades of thinning, $\mathrm{I} 62$

Graves, H. S., 8, 96, I I 7, I 34, 2 I0

Grazing, 40, 56, 78, 104

benefits versus injuries from, 287

effects of, 285

on reproduction, 286

on soil, 285

on trees past reproduction stage, 287

upon the control and prevention of fires, 287

exclude, to prevent avalanches and shifting sands, 297,298

importance in forest protection, 238 , 239

kinds of, animals, 284

methods of control and prevention, 288

protection against domestic animals, 284

protection by close regulation of, 289

protection by exclusion of animals, 289

regional importance of, in forests, 284

returns from, 287

Greeley, W. B., I 24

Ground fire, 250, 256

Group method, 37

Group seed tree method, 50,53

selection method, 96

shelterwood method, 66, 70, 72, 75

Groups, clearcutting in, 37

Growing stock, unmerchantable, 2I I

Growth, current, 96

diameter, I05, I57, I 7 I 
Growth, effect of fire upon, 248

favorable conditions for, of seedlings, $17,40,49$

height, 106, 157, 200 mean annual, 90,91

rapid, 122,136

\section{Hail, 279}

Hardwoods, 80

Hartig, R., 274

Height growth, 106, 157, 200

Hemlock, 105, 106

Hess, R., 237, 239

High forest, I 21, 136, 139

methods, 15

Hirst, E. C., 234

Hogs, 284, 286

Hopkins, A. D., 263, 267

Hopping, R., 234, 266

Improvement cutting, $142,143,144$

India, 228

$$
\text { 192, } 208
$$

Inferior species, 3, 42

Injury by fire, 243

to forage, 249

to human life, 250

to stream flow and industry, 249

to the productive power of the forest, 248

to the soil, 247

to trees containing merchantable material, 244

to young growth, 246

Insects, 41, 142, 159, 195, r99, 2 II

and fires, 265

causes of attacks, 265

character of injury by, 263

classification of, 264

damage caused by, 263

injury as compared with fungi, 275

methods of control and prevention,
Insects, most dangerous classes of, 265 protection against, 263

protection of natural enemies of injurious, 267

silvicultural measures as protection against, 270

slash in relation to, 216, 219, 235, 268

Interlucation cutting, 163,171

Intermediate cuttings, 6, 102, 141, $153,192,208,210$

application in evenaged versus unevenaged stands, 143

assistance cuttings, 142

classification of, 142

cleaning, 142,144

damage cutting, 194

definition, 14 I

disengagement cutting, 142

improvement cutting, $142,144,192$, 232

liberation cutting, $142,144,159,232$ pruning, 143 release cutting, $\mathbf{I}_{42}$

salvage cutting, $142,144,194,232$

severance cutting, $143,232,26 \mathrm{I}$

slash disposal for, $23 \mathrm{I}$

thinning, 142, 144, 232

weeding, 142

Intermediate trees, $134,156,162,163$, $172,175,177,183,192$

Irregular strip method, 37

Keene, N. H., 80

Knapp, F. B., 202

Koch, Elers, 234

Landslides, 4I, 56, 77, 102, 216, 296, 297

Larch, western, 55

Liberation cutting, $142,143,149,159$, 208,232

Light burning, 227 
Loblolly pine, $5^{8}$

Lodgepole pine, 27, 42, 108, 234

Logging, 8, 9, 79, 95, 98, 104, 204, $22 \mathrm{I}$ control of waste and destruction in, 2 I I

Longleaf pine, 229, 286

Lopping of slash, 225, 230

Marking, 205, 207

Marking rules, 208

Mason, D. T., 234

Mattoon, W. R., II4

Mean annual growth, 90 , 9 I

Method, artificial reproduction, I8, 25 border cutting, 70 brush disposal, 25, 29, 49, II6

clearcutting, 25 to 43,207

coppice, III to I 26

coppice forest, $\mathrm{I} 5,207$

coppice with standards, 127 to 140 , 207

group, 37, 72, 75, 96

high forest, 15

natural reproduction, 18,26

of controlling cuttings, 204

of controlling grazing, 288

of controlling insects, 267

of controlling tree diseases, 277

of fire protection, 259

of slash disposal, 220 to 229

polewood coppice, II 7, 207

reproduction, 5 , II to $24, I_{42}$

seed tree, $15,34,44$ to 58,207

selection, $\mathrm{I}_{4}, \mathrm{I}_{5}, 56,57,72,77,83$ to

IIO, 137,207

shelterwood, I4, I5, 34, 56, 59 to 82 , I08, 139, 207

sprout, III

thinning, $I 60$ to 185

uniform, 66

Mice, protection against, 294

Minnesota National Forest, 57

Minnesota State Forestry Board, 234
Mitchell, J. A., 220

Munger, T. T., 296

Natural pruning, $176, \mathbf{7} 78$

Natural reproduction, $15,17,19,36$, $45,56,58,59,64,80,84$, Iо3 advantages of, 2I, 77 compared with artificial, I8 to 22 effect of fire upon, 248 factors influencing, $17,18,28,29,97$

Nehasane Park, 246

Nisbet, J., I 72

Norway pine, 57,264

Norway spruce, 4I

Oak, 80, I34, I69, 286

red, 199

scrub, 147,256

white, 138

Oppressed trees, I56, I62

Ordinary method of thinning, 162,177 , I82, 183

Oregon State Board of Forestry, 242

Overtopped trees, I34, I56, I72, I75, I $76,178,183,192$

Partial cuttings, 59

Patch method, 37

Patches, clearcutting in, 37

Pathology, 6

Patrol, 234

Pearson, G. A., 48

Peshtigo fire, 250

Peters, J. G., 260

Piling and burning, 29, 221, 229, 232

Piling of slash, 220, 230, 234

Pine, 169

chir, 228

loblolly, 58

lodgepole, 27, 42, 108, 234

longleaf, 229, 286

Norway, 57,264

scrub, 42 
Pine, shortleaf, $58,154,286$

slash, 58

southern, 42

western white, 2 10, 274, 275

western white, type, 55,209

western yellow, $48,80,8 \mathrm{I}$

white, $9,57,80,145,149,154,163$,

I 77, 199, 202, 246, 277, 278, 288

white, weevil, 269

Plummer, F. G., 24I, 254

Polewood coppice method, Ir6, II7, 139, 207

Pollard head, II 9

Pollarding, I I9, 297

Poplar, yellow, 95

Populus deltoides, 49

Porcupines, protection against, 293

Practice, of silviculture, I, 2 silvicultural, 2, I 2

Preparatory cuttings, $60,63,68,76,80$

Primary cutting, 7I, 74

Progressive strip method, 39

Protection, 5, 6, 4I, I07, I 23, I37, 237 against animals, other than insects and domestic animals, 293

against avalanches, 296

domestic animals, grazing, 284

floods, 296, 297

fungi, 274

insects, 263

landslides, 296, 297

shifting sands, 296, 298

sun and wind, 30

tree diseases, 274

cost of, 9

fire, $6,239,24 \mathrm{I}$

necessity of, 4

to the site, IO2, II 7

Pruning, $\mathrm{I}_{3} 6, \mathrm{I}_{3} 8, \mathrm{I}_{43}, \mathrm{I} 98$

cost of, 202

Knapp's system, 202

natural, $176,178,198$

Purpose of silviculture, 5
Rabbits, protection against, 294

Rankin, W. H., 274

Red oak, 199

Red spruce, 80, 184

Release cutting, $\mathbf{1} 42$

Removal cuttings, $60,64,68$

Reproduction, cost of, 9

cuttings, $6,139,172,178,195,210$, 229

method, 5, II

methods, classification of, $\mathrm{I}_{4}$

methods, field identification of, 12

origin, 18

period, $6,13,70,144,178$

slash in relation to, 217

sprout, II 9

standard, methods, II, I5, I6, I42

Reserve seed tree method, 52

Ribes, 9, 278

Rodents, 28, 49

Root collar, III

Root-rot, 279

Root suckers, II I

Rotation, $13,59,77,89,91,100,107$, I I 5, I $21,124,132,134$

affected by pruning, 199

lengthened by thinnings, $\mathrm{I} 82$

shortened by thinnings, 156,158 ,

I 75

shortened to control fungi, 278

Salvage cutting, $142,143,144,194$, 208

Sampson, A. W., 285

Scattered seed trees, 53, 57

Scattered seed tree method, 45

Schlich, W., I69, 237, 239

Schwappach, I38, 169

Scrub oak, 147,256

Scrub pine, 42

Second growth, $8 \mathbf{I}$

Secondary cutting, 7 I

Secrest, E., 288 
Sectional area, I6I, I72

Seed, dissemination, 27, 29, 48, 51, 64

loss from rodents, 28,49

production, 48

source of, 27

stored in the duff, $27,42,224$

stored on the trees, $27,4^{2}$

supply, $17,45,57$

Seed cutting, 6o, 63, 68

Seed groups, 5 I

Seed tree method, $15,34,44,59,77$

advantages, 55

application of, 57,79

definition, 44

details of, 45

disadvantages, 55,56

marking for, 207

modifications of, 50

slash disposal for, 230

Seed trees, 44, 47, 48, 57

Seedbed, 6r, 63

Seedling sprouts, 132

Selection, I4, I5, 56, 57, 72, 77, 137

advantages, I02

application of, 106, 297, 298

definition, 83

details of, 84

disadvantages, IO2, 104

extensive versus intensive application, 98

increment under, I04

marking for, 207

modifications of, 96

protection against frost and snow, 279

quality of timber produced, IO4 requires protection from grazing, 289

single tree, 87

slash disposal for, 230

strip, 98

thinning, 177

Severance cutting, r43, r95, 208, 26r
Shallow rooted species, 40,46

Sheep, 284, 286, 289

Shelterwood, $14,15,34,56,57,59$, 108, I39

advantages, 77

application of, 79, 228

definition, 59

details of, 59

disadvantages, 77,78

extensively applied, 72,80

groups, 72,75

intensive application of, 72,78

marking for, 207

modifications of, 66

number of cuttings, 60

protection against frost, 279

slash disposal for, 230

Shifting sands, 296, 298

Shortleaf pine, 58, I54, 286

Silvics, I, 2, I5, I 8

Silvicultural practice, 2, I 2, I98

Silvicultural system, II

Silviculture, compared with agriculture, 2

cost of, 7

field of, 5

intensive, 2, I4I, 203

practice of, $I, 2$

purpose of, 5

relation to silvics, I

Simple coppice, III, I27, 136, I37, 138

Single tree selection, 87

Site, preparation of, $2,6,57,63$, II 6 range of, 16

Slash, application of methods of disposal, 229

broadcast burning of, 223, 229

burning as logging proceeds, 223

coniferous, 216

cost of, 233

definition, 215

disposal affects insect control, 268 
Slash, disposal of, $25,29,49,116,210$, 215

disposal of, protects against fire, $26 \mathrm{I}$ disposal of, to control fungi, 278 hardwood, 216

light burning, 227

lopping of, 225, 230

methods of disposal, 220

piling and burning of, 221, 229, 232, 234

piling of, 220,230

pulling the tops, 226

rotted by fungi, 277

selecting the method of disposal, 232

silvicultural effects of, 215

Slash pine, 58

Snow, damage by, 279

Snowslides, 4I, 56, 77, 102

Society of American Foresters, I, 154

Soil, effect of grazing upon, 285

injury by fires, 247

injury by light burning, 227

slash in relation to, 216,232

treatment of, 26, 30, 50, 57, 63, II 6

Southern pines, 42

Spacing, 20, 199

Special methods of thinning, 183

Sprout method, III

Sprout reproduction, II9

Sprouting ability, II3, II5

Spruce, Norway, 4I

red, 80,184

Squirrels, protection against, 294

Stagheadedness, 279, 280

Standard crown classes, 155

Standard reproduction methods, II, $15,16,142$

Standards, I27, I 32, I 34, I38

Stands, evenaged, 25, 45, 98, 104, 143 , I 78

life history of evenaged, 159

location of, $3 \mathrm{I}$

minimum size of, $\mathrm{r} 3$
Stands, natural development of, 153 protection of, 6

treatment of, during period of regeneration, 5 , II

treatment of, during that period of rotation not included in period of regeneration, 6,26

two-storied, 45

unevenaged, 83, 91, 105, 143, 178, 213

State Forests of Connecticut, 259

State Forests of France, I 24

Strips, clearcutting in alternate, 32 irregular, 37

progressive, 32, 35

selection, 98

shelterwood, $66,68,69$

Struggle for existence, $153,158,178$, I94

Stumps, low, II 4

Sunscald, injury from, 196

Suppressed trees, 156, 162, 172, 175, I 77

Surface fires, 250

Sustained annual yield, 90

Switzerland, ro6

System, silvicultural, II

Terminology, forest, $\mathrm{r}, 299$

Thinning, I34, I42, I43, I44, I53, 192 advantages of, 156 amount removed in, $163,175,182$ application of, 185 assists in securing reproduction, 34 Borggreve's method of, 162, 177 , 188

French method of, $162,172,188$

German method of, 162,188

grades of, $\mathrm{I}_{2}$

in plantations, 189

increases yield, 157

interval between, 186

keeps the stand healthy, 159 
Thinning, lengthen rotation by use of, 182

makes stand more resistant, 158 marking for, 208

methods of making, I6o

ordinary method of, I62, I76

quality improved by, 157,182

shorten rotation by use of, 156, I 75

special methods of, 183

time to start, $159, I 76,183$

to protect against insects, 270

to protect against tree diseases,

277

yield from, I63, I70

Top lopping, 225, 230

Torch for burning slash, 222

Toumey, J. W., I9

Trametes pini, 47

Tree diseases, classification of, 276

methods of control and prevention, 277

other than those produced by fungi, 279

protection against, 274

Tubeuf, K. F., 276

Tuliptree, 138

Two-storied form, 45, 54

Underbrush, disposal of, 26, 29, 49, II6

Understory, 54, I 72

Unevenaged, 83, 91, 103, I05, 108 I 43,213

Uniform method, 66

U. S. Forest Service, 54, 96, 208, 209, 254, 268

Vegetation, undesirable, 29, I 72

Virgin forests, 16,83, I07

Virgin timber, method of cutting, 42 , $76,81,100$
Wagner, 70

Wagner's border cutting, 70

Waste in logging, control of, 2 I I

Weeding, I42

Weeds, removal of, 49

Weir, J. R., 276

Western larch, 55

white pine, 210, 274, 275

white pine type, 55,209

yellow pine, $48,80,8 \mathrm{I}$

Weyl, L. H., 285

White ash, 138

fir, 274

oak, 138

pine, $9,57,80, I_{45}, I_{49}, I_{54}, I_{3}$, I 77, I99, 202, 246, 288

blister rust, 277,278

weevil, 269

Willow, basket, I 25

Wimmenauer, 169

Wind, danger of uprooting or breaking by, $35,46,57,78,92,137$, I88

direction in relation to location of cuttings, 28,280

effect on fires, 258

fungi, as cause of losses from, 277

necessity of clearcutting to avoid loss from, 40

protection against, 68, 103, I 58, 196

value of groups in resisting, $5 \mathbf{I}$

Wind River Experiment Station, 47

Woodward, K., 288

Wolf trees, I42, $\mathbf{I}_{5} \mathrm{O}$

Woolsey, T. S., Jr., 205

Yellow poplar, 95

Yield, sustained annual, 90

Zon, R., I I 3

Zoölogy, 6 


\section{BOOKS \\ ON}

FORESTRY

PUBLISHED BY

JOHN WILEY \& SONS, INC.

NEW YORK 


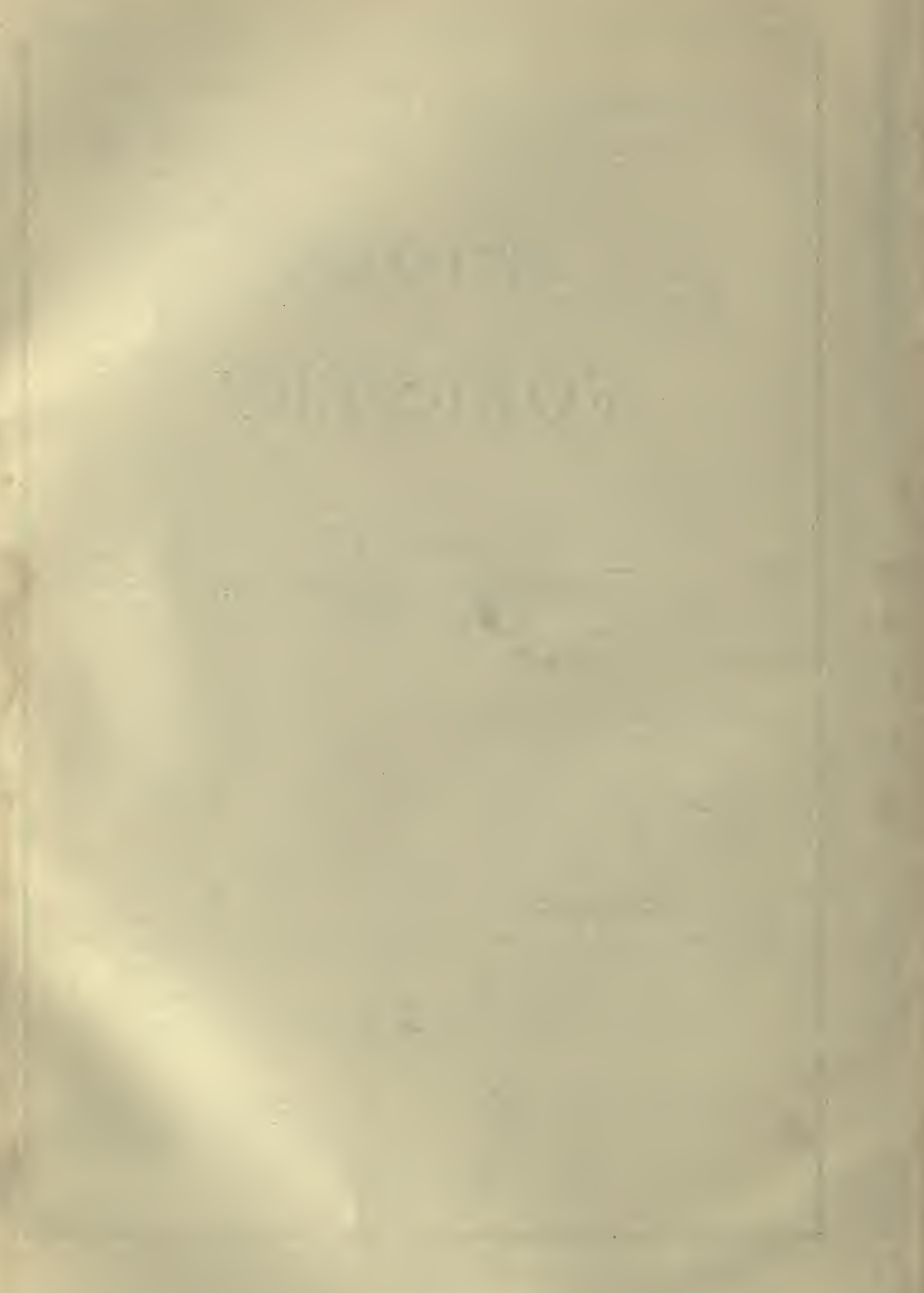




\section{Books on Forestry}

Forest Physiography-Physiography of the United States and Principles of Soils in Relation to Forestry.

By Isainh Bowman, Ph.D., Director American Geographical Society. xii +759 pages. 6 by 9.292 figures and 6 plates, including a New Geologic Map of North America, in colors. Cloth.............net, $\$ 5.00$ A book on physiography for students of forestry, and also a work which historians and economists will find of value.

\section{Elements of Forestry.}

By Frederick Franklin Moon, B.A., M.F., Professor of Forest Engineering, and Nelson Courtlandt Brown, B.A., M.F., Professor of Forest Utilization, The New York State College of Forestry, Syracuse University. xvii +392 pages. $51 / 4$ by 8.65 figures. Cloth......net, $\$ 3.50$ A textbook of broad scope, containing general information on all phases of the subject.

Forest Products; Their Manufacture and Use.

By Nelson Courtlandt Brown, B.A., M.F., Professor of Forest Utilization, The New York State College of Forestry, Syracuse University. xix +450 pages. 6 by 9.120 figures. Cloth............\$4.00

A book for lumbermen, manufacturers, users and importers of forest products, foresters, and students in professional schools of forestry.

The American Lumber Industry.

By Nelson Courtlandt Brown. xiv +275 pages. 6 by 9. 36 figures. Cloth ....................................... $\$ 3.00$

Embracing the principal features of the resources, production, distribution and utilization of lumber in the United States.

Logging-The Principles and General Methods of Operation in the United States.

By Ralph Clement Bryant, F.E., M.A., Manufacturers' Association Professor of Lumbering, Yale University. Second Edition, Thoroughly Revised and Reset. xiii +556 pages. 6 by 9.165 figures. Cloth. net, \$4.50) Discusses at length the chief facilities and methods for the movement of the timber from the stump to the manufacturing plant.

\section{Lumber: Its Manufacture and Distribution.}

By Ralph Clement Bryant. xxi +539 pages. 6 by 9. 155 figures.

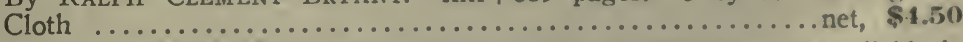
The only textbook on lumber manufacture and distribution now available in any language.

\section{Forest Valuation.}

By Herman Haupt Chapman, M.F., Harriman Professor of Forest Management, Yale University Forest School. xvi +310 pages. 6 by 9.

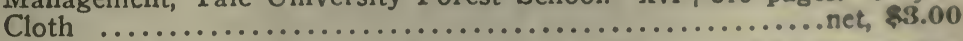
Treats the subject in a manner that may be readily grasped by the average reader, without previous preparation or study. 


\section{Forest Mensuration.}

By Herman Haupt Chapman, M.F. xvii +553 pages. 6 by 9.88 figures. Cloth ................................. $\$ 5.00$

A thorough discussion of the measurement of the volume of felled timber, in the forms of logs or other products, of the measurement of the volume of standing timber, and of the growth of trees, stands of timber and forests.

\section{Farm Forestry.}

By John Arden Ferguson, A.M., M.F., Professor of Forestry at The Pennsylvania State College. viii +241 pages. $5 x / 4$ by 8 . Illustrated.

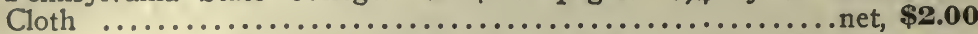

This book brings together in available form ideas and principles relating to the care and management of the farm woodlot and the utilization of the products of the woodlot.

\section{The Principles of Handling Woodlands.}

By Henry Solon Graves, M.A., Dean of the School of Forestry, Yale

University. xxit 325 pages. $5 x / 4$ by 8.63 figures. Cloth......net, $\$ \mathbf{2 . 5 0}$ Takes up the cutting of mature stands of timber and their replacement by new growth; cuttings in immature stands, and forest protection with reference to forest fires.

\section{Principles of American Forestry.}

By Samuel B. Green, Late Professor of Horticulture and Forestry, University of Minnesota. xiii +334 pages. 5 by $71 / 4$. 73 figures. Cloth, $\$ 2.00$

A book for the general reader who wishes to secure a general idea of the subject of forestry in North America.

\section{Manual of Forestry for the Northeastern United States.}

Being Volume I of "Forestry in New England", Revised.

By Ralph Chipman Hawley, M.F., Professor of Forestry, Yale University, and AUSTIN Foster HAWES, M.F., formerly State Forester of

- Connecticut and of Vermont. xii +281 pages. 6 by 9. 65 figures. Cloth ........................................net, \$3.50

Furnishes the woodland owner with a brief survey of the whole field of forestry.

\section{The Practice of Silviculture.}

With Particular Reference to Its Application in the United States. By Ralpi Chipman HaWley. xi+352 pages. $5 \mathrm{x} / 4$ by 8.82 figures. Cloth ........................................... \$4.00

A new textbook, presenting the subject from the standpoint of the teacher and covering a field heretofore unfilled.

The Development of Forest Law in America.

By J. P Kinney, A.B., LL.B., M.F., Chief Supervisor of Forests, United States Indian Service. xxxix +254 pages. 6 by 9 . Cloth.....net, $\$ 2.50$ A logical presentation of the chronological development of legislation in this field. 
The Essentials of American Timber Law.

By J. P Kinney, A.B., LL.B., M.F. xxix +279 pages. 6 by 9. Cloth, net, $\$ 3.00$

Gives the existing law regarding trees and their products as property. A book for both foresters and lawyers.

Both books ordered at one time.....................net $\$ 5.00$

\section{Studies of Trees.}

By J. J. Levison, M.F., formerly Lecturer on Ornamental and Shade Trees, Yale University Forest School. $x+253$ pages. $51 / 4$ by $7 x / 2$. 155 half-tone figures. Cloth............................ $\$ 2.00$

Takes up in a brief and not too technical way the most important facts concerning the identification, structure and uses of our more common trees, considering their habits, enemies and care.

(Also issued in loose-leaf form. Complete set of 20 pamphlets, 8 by $10 \frac{1}{2}$, $\$ 1.00$ net. Cloth binder, sold separately, 50 cents net.)

\section{Forest Management.}

By A. B. Recknagel, B.A., M.F., Professor of Forest Management and Utilization, and JoHn Bentley, JR., B.S., M.F., Assistant Professor of Forest Engineering, Cornell University. xiii +267 pages. 6 by 9.26 figures. Cloth ................................. $\$ 2.50$

Treats the subjects, forest mensuration, forest organization, forest finance, and forest administration in such a manner as to be readily understood and used by the layman timber owner and manager.

\section{The Theory and Practice of Working Plans (Forest Organization).}

By A. B. Recknager, B.A., M.F. Second Edition, Thoroughly Revised. xiv +265 pages. 6 by 9 . Illustrated. Cloth .............net, \$2.50

A book of value to the practicing forester, as well as to the student. The best of European methods are presented, adapted to the needs of American forestry.

\section{Identification of the Economic Woods of the United States.}

Including a Discussion of the Structural and Physical Properties of Wood. Second Edition, Revised and Enlarged.

By Samuel J. Record, M.A., M.F., Professor of Forest Products, Yale University. ix +157 pages. 6 by 9.15 figures and 6 full-page half-tone plates. Cloth ..................................... \$2.50

An efficient aid in the study and identification of wood. The new edition brings the work right up to date in every respect.

\section{The Mechanical Properties of Wood.}

Including a Discussion of the Factors Affecting the Mechanical Properties, and Methods of Timber Testing.

By Samuel J. Record, M.A., M.F. xi+165 pages. 6 by 9.51 figures. Cloth ....................................... \$2.50

All unnecessary technical language and descriptions have been avoided, making the subject-matter readily available to everyone interested in wood. 


\section{Range and Pasture Management.}

By Arthur W. Sampson, Associate Professor of Range Management, University of California. xix +421 pages. 6 by 9.130 figures, 1 plate showing stock-poisoning plants in natural colors. Cloth......net, $\$ 4.00$ Provides systematic instruction for those who desire a practical working knowledge of the subject, as well as for those who wish to follow technical grazing work as a profession and fit themselves for such positions as those offered by the United States Forest Service.

\section{Livestock Husbandry on Range and Pasture.}

By Arthur W. Sampson. (In Preparation.)

Devoted to a discussion of the management of range and pasture livestock.

\section{Native American Forage Plants.}

By Arthur W. Sampson. (In Preparation.)

Treats in detail all important native forage grasses and broad-leaved plants; pasture values, natural history, growth requirements and life processes of vegetation as related to forage production; and pastural botany.

\section{Shade-Trees in Towns and Cities.}

By William Solotaroff, B.S., Late Secretary and Superintendent of the Shade-Tree Commission of East Orange, N. J. xviii +287 pages. 6 by 9 . 46 full-page plates and 35 figures in the text. Cloth........net, \$3.50 Takes up the questions of the selection, planting and care of trees as applied to the art of street decoration; their diseases and remedies; their municipal control and supervision.

\section{Field Book for Street-Tree Mapping.}

By William Solotaroff, B.S. 160 pages. $41 / 2$ by $73 / 4$. Each, $\$ 1.25$

net. One dozen .................................... $\$ 12.00$

Blank field books for enumerating street-trees when taking a tree census.

\section{Handbook for Rangers and Woodsmen.}

By JAY L. B. TAYLOR, formerly Forest Ranger, United States Forest Service. ix +420 pages. $41 / 4$ by $63 / 4$. 236 figures. Flexible "Fabrikoid" binding ........................................ $\$ 3.00$

A guide for inexperienced men in woods work, and for others whose work or recreation takes them into rough and unsettled regions.

\section{Seeding and Planting in the Practice of Forestry.}

By James W. Toumey, M.S., M.A., Morris K. Jesup Professor of Silviculture, Yale University. xxxvi +455 pages. 6 by 9.140 figures. Cloth ............................................. \$4.00

A manual for the guidance of forestry students, foresters, nurserymen, forest owners, and farmers.

\section{Handbook of Field and Office Problems in Forest Mensuration.}

By Hugo Wrnkenwerder, Dean, College of Forestry, University of Washington, and Elias T. CLARK, Associate Professor of Forestry, University of Washington. ix +133 pages. 5 by $71 / 2$. Flexible binding ............................................... $\$ 20$

A series of carefully selected type exercises prepared as an aid to the laboratory instruction in forest mensuration, which may be used as practical illustrations to supplement recitation and textbook work. 


\section{The Valuation of American Timberlands.}

By K. W. Woodward, Professor of Forestry, New Hampshire State College. vii +253 pages. 6 by 9. 13 figures. Cloth...........net, $\$ 3.00$

This book supplies valuable information needed by the investor, timber cruiser and student of forestry. It gives for the continental United States and its outlying territories, Hawaii and the Canal Zone excepted, the principal facts regarding the timber resources.

French Forests and Forestry-Tunisia, Algeria, Corsica. With a Translation of the Algerian Code of 1903.

By Theodore S. Woolsey, JR., M.F., Executive Member of the Interallied War Timber Committee, 1917-1919, Paris, France; formerly Lecturer, Yale Forest School. xv +238 pages. 6 by 9. Illustrated. Cloth.

net, $\$ 3.00$

The results of a study of the more important phases of forest practice in Corsica, Algeria, and Tunisia, setting forth the essentials of method which may be applied directly in the United States.

\section{Studies in French Forestry.}

By Theodore S. Woolsey, Jr. Two chapters by William B. Greeley, formerly Chief of the Forestry Section, Engineers, A.E.F., Tours, France, and now Chief Forester, U. S. Forest Service. vii +550 pages. 6 by 9. Profusely illustrated .............................. $\$$ net.

This general book on French forestry is of interest to students, practicing foresters, lumbermen, estate owners, and all members of the 10th and 20th Engineers (Forestry) A. E. F.

\section{Forest Protection.}

By David T. Mason, Forest Engineer. (In Preparationi.)

Shows how the facts and principles developed by entomologists, pathologists, and others may be applied in a businesslike way to the protection of forests. 



\section{工触}

\section{Wiley Special Subject Catalogues}

For convenience a list of the Wiley Special Subject Catalogues, envelope size, has been printed. These are arranged in groups - each catalogue having a key symbol. (See special Subject List Below). To obtain any of these catalogues, send a postal using the key symbols of the Catalogues desired.

1-Agriculture. Animal Husbandry. Dairying. Industrlal Canning and Preserving.

2-Architecture. Building. Concrete and Masonry.

3-Business Administration and Management. Law.

Industrial Processes: Canning and Preserving; Oil and Gas Production; Paint; Printing; Sugar Manufacture; Textile.

\section{CHEMISTRY}

4a General; Analytical, Qualitative and Quantitative; Inorganic; Organic.

4b Electro- and Physical; Food and Water; Industrial; Medical and Pharmaceutical; Sugar.

\section{CIVIL ENGINEERING}

5a Unclassified and Structural Engineering.

5b Materials and Mechanics of Construction, including; Cement and Concrete; Excavation and Earthwork; Foundations; Masonry.

5c Railroads; Surveying.

5d Dams; Hydraulic Engineering; Pumping and Hydraulics; Irrigation Engineering; River and Harbor Engineering; Water Supply. 


\section{CIVIL ENGINEERING-Continued}

5e Highways; Municipal Engineering; Sanitary Engineering; Water Supply. Forestry. Horticulture, Botany and Landscape Gardening.

6-Design. Decoration. Drawing: General; Descriptive Geometry; Kinematics; Mechanical.

\section{ELECTRICAL ENGINEERING-PHYSICS}

7-General and Unclassified; Batteries; Central Station Practice; Distribution and Transmission; Dynamo-Electro Machinery; Electro-Chemistry and Metallurgy; Measuring Instruments and Miscellaneous Apparatus.

8-Astronomy. Meteorology. Explosives. Marine and Naval Engineering. Military. Miscellaneous Books.

\section{MATHEMATICS}

9-General; Algebra; Analytic and Plane Geometry; Calculus; Trigonometry; Vector Analysis.

\section{MECHANICAL ENGINEERING}

10a General and Unclassified; Foundry Practice; Shop Practice.

10b Gas Power and Internal Combustion Engines; Heating and Ventilation; Refrigeration.

10c Machine Design and Mechanism; Power Transmission; Steam Power and Power Plants; Thermodynamics and Heat Power.

\section{1-Mechanics.}

12-Medicine. Pharmacy. Medical and Pharmaceutical Chemistry. Sanitary Science and Engineering. Bacteriology and Biology.

\section{MINING ENGINEERING}

13-General; Assaying; Excavation, Earthwork, Tunneling, Etc.; Explosives; Geology; Metallurgy; Mineralogy; Prospecting; Ventilation.

14-Food and Water. Sanitation. Landscape Gardening. Design and Decoration. Housing, House Painting. 


SD

391

H3
Hawley, Ralph Chipman

The practice of silviculture

\title{
[164554]
}

\author{
LIBRARY \\ FACULTY OF FORESTRY \\ UNIVERSITY OF TORONTO
}




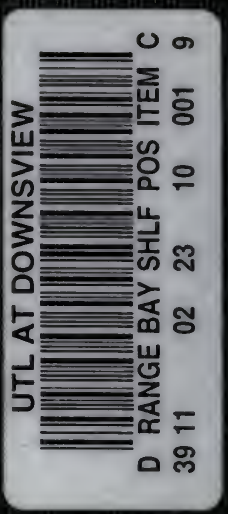

